\title{
Consequences of prenatal growth retardation on arterial properties
}

Citation for published version (APA):

Ruijtenbeek, K. (2002). Consequences of prenatal growth retardation on arterial properties. [Doctoral Thesis, Maastricht University]. Universiteit Maastricht. https://doi.org/10.26481/dis.20021115kr

Document status and date:

Published: 01/01/2002

DOI:

10.26481/dis.20021115kr

Document Version:

Publisher's PDF, also known as Version of record

\section{Please check the document version of this publication:}

- A submitted manuscript is the version of the article upon submission and before peer-review. There can be important differences between the submitted version and the official published version of record.

People interested in the research are advised to contact the author for the final version of the publication, or visit the DOI to the publisher's website.

- The final author version and the galley proof are versions of the publication after peer review.

- The final published version features the final layout of the paper including the volume, issue and page numbers.

Link to publication

\footnotetext{
General rights rights.

- You may freely distribute the URL identifying the publication in the public portal. please follow below link for the End User Agreement:

www.umlib.nl/taverne-license

Take down policy

If you believe that this document breaches copyright please contact us at:

repository@maastrichtuniversity.nl

providing details and we will investigate your claim.
}

Copyright and moral rights for the publications made accessible in the public portal are retained by the authors and/or other copyright owners and it is a condition of accessing publications that users recognise and abide by the legal requirements associated with these

- Users may download and print one copy of any publication from the public portal for the purpose of private study or research.

- You may not further distribute the material or use it for any profit-making activity or commercial gain

If the publication is distributed under the terms of Article $25 \mathrm{fa}$ of the Dutch Copyright Act, indicated by the "Taverne" license above, 
CONSEQUENCES OF PRENATAL GROWTH RETARDATION ON ARTERIAL PROPERTIES 
Printed by Unigraphics, Maastricht Lay-out: Vink, Fazzi, Ruijtenbeek Cover: Aartsen \& Ruijtenbeek ISBN: 90-568-144-4 


\title{
CONSEQUENCES OF PRENATAL GROWTH RETARDATION ON ARTERIAL PROPERTIES
}

\author{
PROEFSCHRIFT \\ ter verkrijging van de graad van doctor \\ aan de Universiteit Maastricht, \\ op gezag van de Rector Magnificus, Prof. dr. A.C. Nieuwenhuijzen Kruseman, \\ volgens het besluit van het College van Decanen, \\ in het openbaar te verdedigen \\ op vrijdag 15 november 2002 om 14.00 uur
}

door

Karin Ruijtenbeek

geboren op 25 juli 1974 te Oss 


\section{Promotores:}

prof.dr. C.E. Blanco

prof.dr. J.G.R. De Mey

Beoordelingscommissie:

prof.dr. R.A.M.G. Donckerwolcke (voorzitter)

mw.prof.dr. A.C. Gittenberger-de Groot (Universiteit Leiden)

prof.dr. H.A.J. Struijker Boudier

prof.dr. R. Vlietinck

dr. F.J. Walther (Universiteit Leiden)

Publication of this thesis was financially supported by "Stichting Vrienden van het AZM". 


\section{CONTENTS}

Chapter 1 General introduction 7

1.1. Fetal origins of cardiovascular disease 9

1.2. Intrauterine growth 11

1.3. Development of the vascular system $\quad 13$

1.4. Cardiovascular disease: vascular changes 19

1.5. Mechanisms behind the "fetal origins of cardiovascular disease" hypothesis 22

1.6. The chicken as an experimental model $\quad 25$

1.7. Aim and outline of this thesis 28

Chapter 2 Contractile and relaxing reactivity in carotid and femoral arteries of 43 chicken embryos

Chapter 3 Direct effects of acute hypoxia on the reactivity of peripheral arteries of the chicken embryo

Chapter 4 Chronic hypoxia stimulates periarterial nerve development in chicken embryo

Chapter 5 Effects of protein malnutrition on arterial structure and arterial sympathetic innervation of the chicken embryo

Chapter 6 Chronic moderate hypoxia and protein malnutrition both induce growth retardation, but have distinct effects on arterial endotheliumdependent reactivity in the chicken embryo

Chapter 7 Chronic moderate hypoxia during in ovo development alters arterial properties in chickens

Chapter 8 General discussion

Summary

Samenvatting

Curriculum Vitae

List of publications

Dankwoord 


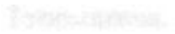

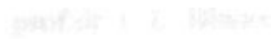

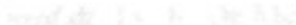

a

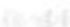

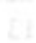

(4)

$\sqrt{2}$

34

西

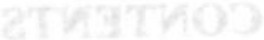

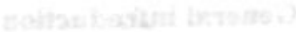

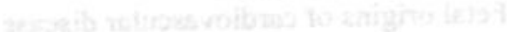

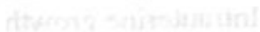

(1)

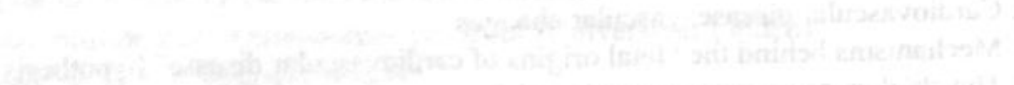

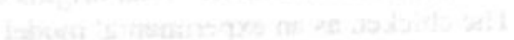

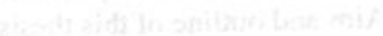

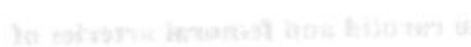

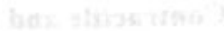

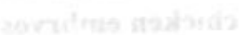

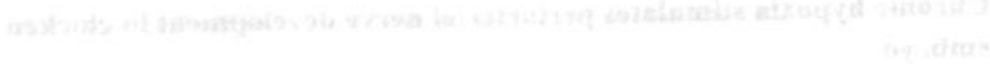

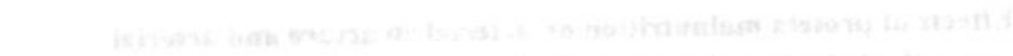

(1)

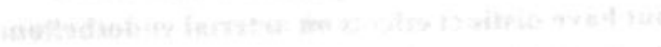




\section{CHAPTER 1}

\section{GENERAL INTRODUCTION}




\section{General introduction}

Epidemiological studies have found an association between low birth weight and cardiovascular disease in adult life. These studies have put forward the "fetal origins of cardiovascular disease" hypothesis, which proposes that fetal adaptations to adverse intrauterine conditions resulting in altered fetal growth lead to the development of disorders in adult life, including cardiovascular disease (10).

To achieve normal fetal growth, the fetal supply line (maternal-feto-placental unit), that guarantees the availability of nutrients and oxygen, has to be intact (110). Placental insufficiency is a major cause of intrauterine growth retardation and is characterized by a combination of malnutrition and chronic hypoxia $(143,252,260,265)$.

Permanent alterations of the properties of the developing arterial system by these conditions may explain the link between intrauterine growth retardation and cardiovascular disease in adult life. Since arterial sympathetic hyperinnervation and endothelial dysfunction are prominent features of hypertension and other cardiovascular diseases $(301,136)$, prenatal alterations at the level of sympathetic innervation and the endothelium could be the basis of the development of these diseases. 


\subsection{Fetal origins of cardiovascular disease}

\subsubsection{Origins of a hypothesis}

One of the first studies to suggest that adverse conditions in early life affect health in the adult was performed by Kermack and co-workers in the 1930's and includes data going back to as early as 1751 (141). The authors conclude that their data on relative adult mortality for various years of birth "behave as if expectation of life was determined by conditions, which existed during the child's earlier years" and that maternal health during and around the time of pregnancy may important in this respect.

In 1977, Forsdahl performed a geographical study in Nonvay and demonstrated that in areas in which infant mortality was high, mortality from atherosclerotic disease in people aged between 40 and 69 years from the same generation was increased. This made him suggest that poor living conditions, which are known to increase infant death rates, make babies that survive more vulnerable to disease in later stages of life (83).

Barker and colleagues performed similar studies in the United Kingdom and demonstrated that ischemic heart disease mortality rates were correlated with neonatal as well as post-neonatal mortality (14). When, additionally, they showed an association between maternal mortality from 1911 to 1914 and death rates from stroke of people that were born around that time (15), they hypothesized that cardiovascular diseases in the adult originate in intrauterine life. In follow-up studies with large cohorts Barker's research group strengthened their hypothesis by showing an association between low birth weight and death rates from ischemic heart disease (18, fig. 1). Moreover, they confirmed the inverse relationship between weight at birth and blood pressure later in life $(16,11)$, that had previously been observed in smaller cohorts $(92,310)$. As this relationship was not due to shortened gestation, Barker et al. attributed it to reduced fetal growth, which would be the result of adverse intrauterine conditions (16). The hypothesis put forward by Barker is now widely known as the "fetal origins of adult disease" hypothesis, which proposes that non-infectious disorders in adult life, including cardiovascular disease, are initiated by fetal adaptations during (adverse) intrauterine conditions (10).

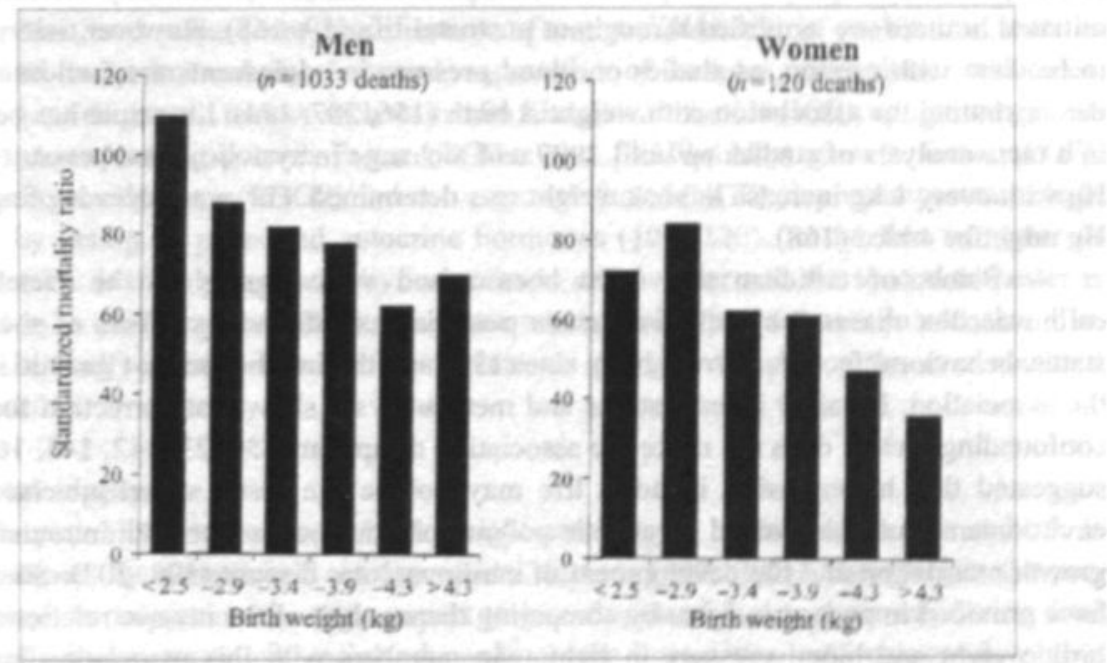

Fig. 1. Association between birth weight and death rates from ischemic heart disease in males and females (Hertfordshire study, Barker et al., 1989 (ref 18)). 


\subsubsection{Birth weight and cardiovascular disease}

During the past decade the "fetal origins" hypothesis has been the subject of many epidemiological studies. These have provided data that associate reduced size at birth and in early infancy with increased risks for coronary heart disease and stroke in adult life $(17,76,283$, $249,127,190)$. In addition, the relationship between early growth and insulin resistance has received much attention. Non-Insulin Dependent Diabetes Mellitus (NIDDM) and alterations in glucose and insulin metabolism have been related to low birth weight as independent risk factors $(50,295,176)$. An association between size at birth and the insulin resistance syndrome, which is closely related to coronary heart disease, also seems to be present $(75,13)$. There is some evidence that important risk factors for cardiovascular disease, namely raised plasma lipid concentrations, are inversely related with birth weight as well $(\mathbf{7 5}, \mathbf{8 2})$.

The large number of studies that have investigated the above mentioned diseases and risk factors and their association with size at birth have been extensively reviewed $(100,221$, $35,10)$. However, the relationship between birth weight or perinatal growth and blood pressure/hypertension has probably been studied most frequently and most thoroughly.

\subsubsection{Birth weight and blood pressure}

The first studies to suggest that low birth weight is associated with elevated blood pressure at later stages in life were based on birth weight data that heen registered a very long time ago and were mainly restricted to the UK. The association was subsequently confirmed in populations all over the world (Europe (169), USA (50, 49), Asia (42, 22), Africa (172)). Large cross sectional studies with more accurately defined data on perinatal anthropometry and birth characteristics together with longitudinal and even prospective studies have specified the relationship between birth weight and blood pressure.

These investigations demonstrate that the relationship between low birth weight and subsequent increases in blood pressure may particularly involve babies that are small for gestational age $(169,69)$. In addition to low birth weight, thinness, shortness, body shape at birth and placental weight have been reported to correlate with blood pressure $(17,158,289$, 279). The negative association between birth weight and blood pressure is also found in children (172, 157, 158), but may be less pronounced than in adults (207). This may indicate that effects initiated in utero are amplified throughout postnatal life $(59,168)$. However, interpretation has to be done with caution, as studies on blood pressure in adolescents are far less consistent in demonstrating the association with weight at birth $(156,207,194)$. Literature has been reviewed in a meta-analysis of studies up until 1999 and a change in systolic blood pressure of $-1.7 \mathrm{~mm}$ $\mathrm{Hg}$ with every $1 \mathrm{~kg}$ increase in birth weight was determined. For every decade of age $-0.35 \mathrm{~mm}$ $\mathrm{Hg}$ might be added (168).

Points of criticism that have been raised with regards to the "fetal origins of cardiovascular disease" hypothesis include potentially confounding effects of socio-economic status, behavioral factors, current body size (135) and the involvement of genetic influences in the association. Detailed investigations and meta-analyses show that correction for all sorts of confounding factors does not make the association disappear $(159,237,42,146,168)$. It is also suggested that hypertension in adult life may not be the result of an adverse intrauterine environment, but is explained by genetic polymorphisms that induce both intrauterine/neonatal growth retardation and the development of cardiovascular disease $(198,203)$. Studies in twins have provided important insights by comparing the strength of the inverse relationship between birth weight and blood pressure in light twin members with this association in heavy twin members. This is done in dizygotic twins, that have different genes, and in monozygotic twins, that are genetically identical. In these monozygotic twins the relationship would therefore not be 
affected by differences in genetic background. Although they are not conclusive, twin studies suggest that at least part of the association is due to effects of the intrauterine environment rather than genetic influences $(179,237,66,43)$.

Many issues, such as the role of postnatal or catch-up growth $(106,179,289)$ and gender differences $(279,69,42)$ in the association between low birth weight and hypertension in later life, remain to be clarified and are currently under investigation. However, the enormous amount of epidemiological data (for reviews see: 100, 221, 168) clearly suggests that conditions during intrauterine life not only affect prenatal growth, but may also induce changes that increase blood pressure and the risk for hypertension and related cardiovascular disorders at later stages in life.

\subsection{Intrauterine growth}

In the human fetus the first 4 weeks of intrauterine development comprise the formation of the germ layers. In the subsequent "embryonic" period of 4 weeks, specific organ systems and tissues develop from the ectodemal, mesodermal and endodermal cell layers. From the third month until term substantial growth of the body, organs and tissues takes place and this phase is called the fetal period (258).

Fetal growth can be characterized in terms of a range of anthropometric measures that are mainly determined just after birth. These include birth weight, length, head width or circumference, femur length, abdominal circumference and indices of body proportion/shape, such as ponderal index (weight/length ${ }^{3}$ ) and birth weight to length ratio. They reflect growth of different systems; e.g. length is an outcome of growth of the skeleton whereas birth weight mainly reflects skeletal muscle growth and fat deposition (252). By means of ultrasound some of these parameters can be measured before birth. Length of the fetus substantially increases from the third to the fifth month of gestation, while body weight doubles in the last trimester (317).

On a cellular basis, growth of the embryo and fetus involves cell replication, hypertrophy, differentiation, migration to specific anatomical sites and programmed cell death under the influence of control mechanisms. Early tissue interactions and responses are regulated by the deposition and subsequent modification of extracellular matrix molecules, such as fibronectin and tenascin, and by temporal expression of cellular recognition molecules. Furthermore, peptide growth factors such as insulin like growth factors (IGF), epidermal growth factor (EGF), transforming growth factor (TGF- $\alpha$ and $\beta$ ), fibroblast growth factor (FGF), platelet-derived growth factor (PDGF) and nerve growth factor (NGF) play an important role in fetal growth by acting as para- and autocrine hormones $(109,120)$. In the first trimester of pregnancy, growth is mainly mediated by increases in cell number and the second trimester is characterized by a stable rate of cellular divisions accompanied by increases in cell size. The rate of mitosis finally decreases in the third trimester and growth takes place as a result of hypertrophy (201).

\subsubsection{The fetal supply line}

While part of the variation in birth weight can not yet be explained, size at birth is mainly determined by genetic and environmental factors (109, 201). Though genetic predisposition plays an important role with respect to growth potential, actual growth during fetal life, particularly in late gestation, mainly depends on the intrauterine environment involving maternal, placental and fetal factors $(38,100)$. 


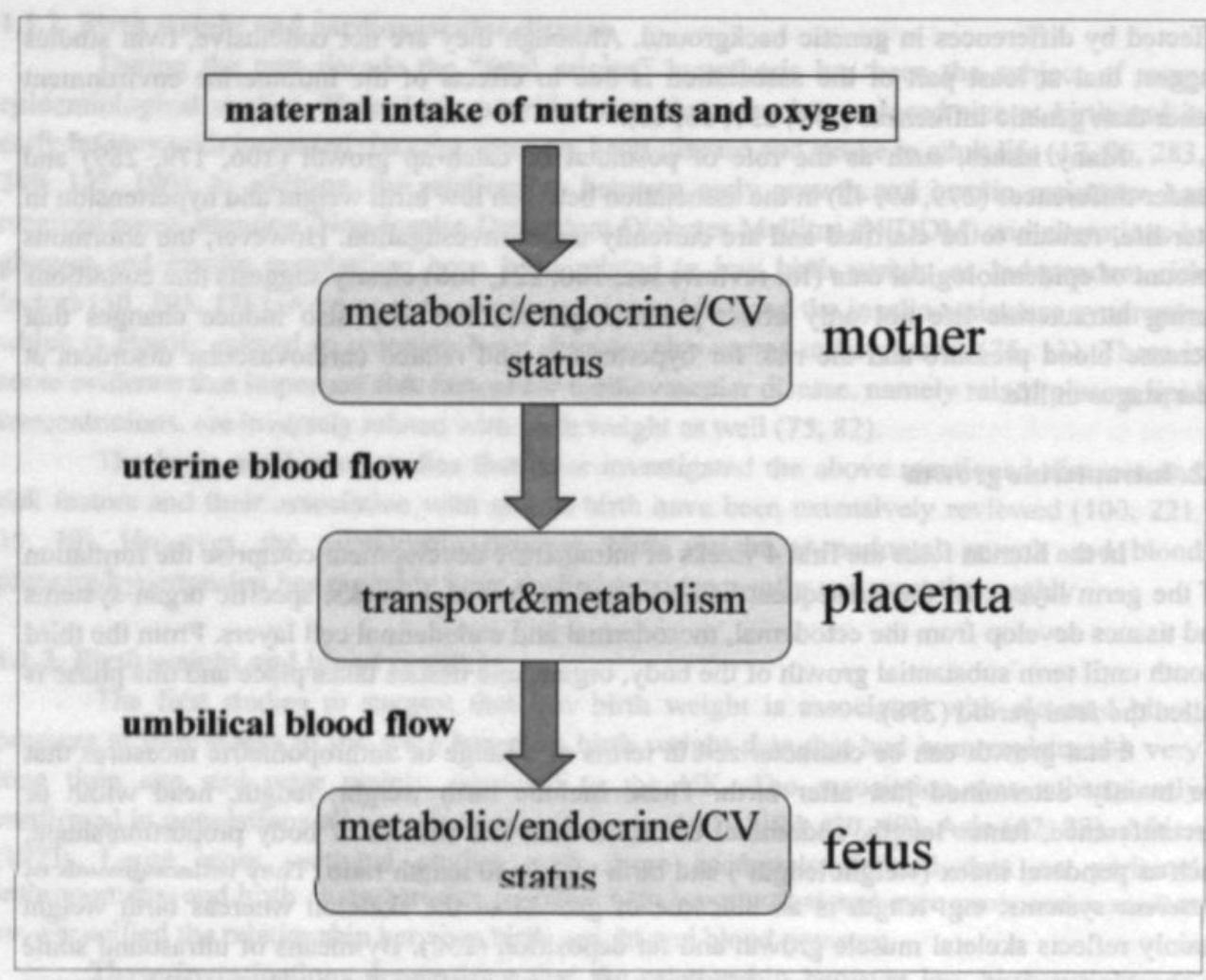

Fig. 2. Fetal supply line, $\mathrm{CV}=$ cardiovascular.

The fetus develops at the end of the so-called "fetal supply line" $(110$, fig. 2) which links all aspects that determine ultimate growth. The first part of this line includes maternal nutrition. Substrates, most importantly glucose and amino acids, and oxygen have to be available to provide fuel to the fetus for energy production and building materials for tissue growth. During pregnancy the cardiovascular, metabolic and endocrine status of the maternal body is altered in such a way that fetal caloric requirements can be met and that optimal functioning of the maternal-feto-placental unit is assured (30). Nutrients and oxygen are transported via the uterine circulation to the placenta and are delivered to the fetus by the umbilical vein. In the placenta the substrates essential for fetal growth are transported via diffusion (oxygen, carbondioxide), facilitated diffusion (glucose, lactate) and active transport (amino acids) (20). The placenta may therefore influence fetal growth by its own high metabolic demands, vascular capacity and, in addition, by the production of substrates and hormones, such as placental Growth Hormone (GH) (202).

\subsubsection{Endocrine control}

The endocrine status of the mother and placental hormones modulate fetal growth by affecting the supply of substrates, but important peptide hormones do not cross the placenta. There is substantial evidence that fetal Insulin Like Growth Factors (IGFs) have a major influence on tissue accretion and therefore on fetal growth. The two IGF subtypes, I and II, are expressed in all fetal tissues (201) and act, in addition to their auto-/paracrine actions, as circulating hormones. In humans, birth weight correlates with fetal plasma levels of IGFs (220). 
Mice that do not express IGF I, II and their receptors show reduced embryonic and fetal growth $(177,8)$. Administration of IGF I to fetal lambs reduces fetal protein breakdown and enhances fetal substrate uptake (112). IGF levels in the fetus are regulated by nutrient availability and by IGF Binding Proteins (IGFBPs).

Other hormones that are involved in fetal growth include insulin (220) and thyroid hormones, which may increase IGF levels and fetal $\mathrm{O}_{2}$ uptake $(85,84)$. Glucocorticoids may be more important in tissue maturation than in tissue accretion and are particularly influential at the end of gestation. At high concentrations glucocorticoids (86, 208) and catecholamines (19) reduce growth. Interactions between the growth hormones are common and their relative importance may vary with gestational age and differ for specific organ systems $(201,84)$.

\subsubsection{Intrauterine growth retardation (IUGR)}

An important indication of reduced fetal growth is low birth weight, which is commonly defined as a weight of $<2500 \mathrm{~g}$ at delivery for an infant bom at term $(\geq 37$ completed weeks of gestation) or as weight below the 10th percentile of the general population of neonates (244). However, in functional terms, a fetus is growth-restricted when it has not achieved its genetic potential of growth, which is difficult to determine by measuring just birth weight. Therefore the diagnosis of fetal growth restriction is made by means of various anthropometric parameters measured at birth (as mentioned in 1.2.). Furthermore, estimates of the metabolic and endocrine status obtained by cord blood sampling give additional information.

Growth is reduced when the fetal supply line (fig. 2) is at any point interrupted or interfered with, resulting in decreased availability of substrates and oxygen essential for fetal growth. Though the effect of a reduction in maternal food intake in humans is thought to have only small effects on birth weight $(255,193,110)$, growth retardation is observed in animals of which the mother's diet was restricted $(313,123,152)$. However, while maternal nutrition. behavior and disease may affect fetal growth, a more common cause of intrauterine growth retardation is placental insufficiency $(143,252,260,265)$. When placental function is impaired, the capacity to transport nutrients and oxygen will be limited and fetal metabolism affected. In experimental animal models of IUGR, fetal arterial oxygen and glucose levels are decreased and lactate concentrations are elevated $(251,223)$. Similarly, in human growth-retarded fetuses hypoxemia, hypoglycemia and hyperlacticemia have been demonstrated $(278,228,309)$.

In addition to the metabolic changes, the fetal endocrine status is altered when growth is restricted. Anabolic hormones, such as IGFs (165), insulin and thyroxin are generally decreased (252) and inhibitory and catabolic factors, like cortisol $(170,264)$ and catecholamines are increased. Increased levels of catecholamines are thought to be responsible for part of the circulatory adaptations observed in experimental and human growth restriction $(5,273,138)$. The associated redistribution of the cardiac output resulting in relative sparing of brain, adrenal and heart weight at the expense of the liver and "less vital" organs, has been proposed to cause asymmetric or disproportionate IUGR.

\subsection{Development of the vascular system}

\subsubsection{The making of an artery}

The cardiovascular system is the first organ system to develop in the embryo. Undifferentiated endothelial precursor cells (angioblast) differentiate to endothelial cells that proliferate and cluster. Through interconnection of long extending endothelial processes a primary vascular plexus is formed. This process of "vasculogenesis" is accompanied by 
"angiogenesis", which concerns the expansion and remodeling of the primitive plexus into a complex network through outgrowth of the pre-existing vessels $(37,53)$.

As vascologenesis and angiogenesis require a large range of actions of the endothelial cells (differentiation, proliferation, migration, adherence etc.), it follows that these occur under the influence of many regulators. Studies in knockout mice, but also in animal models that allow easier access to the embryonic vessels (zebrafish, chicken), have identified many paracrine factors, genes and transcription factors, that are involved $(37,53,218)$. Among these, Vascular Endothelial Growth Factor (VEGF) plays a pivotal role in both vasculo- and angiogenesis (250, 37. 53). Other growth factors that influence both or one of these processes are transforming growth factor (TGF- $\beta$ ), angiopoietins (Ang1 and Ang2), integrins and ephrins (37, 53, 2). In addition to regulation by growth factors, metabolic and hemodynamic modulation takes place. Particularly angiogenesis is stimulated by hypoxia (1) and, whereas the initial vascular plexus is formed in the absence of flow, blood flow is also a modulator of angiogenetic processes (149).

Once the initial endothelial tube is formed, cells (originating from the mesoderm or neural crest) are recruited from the surrounding mesenchyme or more distant tissues and eventually differentiate into vascular smooth muscle cells. This process of "vascular myogenesis" is again controlled by growth factors, such as Platelet-Derived Growth Factor (PDGF), basic Fibroblast Growth Factor (bFGF), angiopoietin 1, TGF- $\beta$ and VEGF, that regulate the interactions between the endothelial cells and the mural cells $(37,174,218)$. Differentiation of the vascular smooth muscle cells concerns the acquisition of synthetic, secretory and contractile properties. Together with the extracellular matrix (e.g. collagens and elastin, which are secreted by the vascular smooth muscle cells) and cytoskeletal proteins (desmin, vimentin), the contractile proteins (actin, myosin) provide stabilization and primary hemodynamic control $(37,284)$. Vascular smooth muscle cell phenotype may depend on cell origin (24), the future function of the vessel $(197,284)$ and local hemodynamic forces, namely pressure and flow $(150,126)$. It may continue changing in postnatal life (284).

Signals involved in smooth muscle cell recruitment and growth during vascular myogenesis are also presumed to play a role in "arteriogenesis". This phase is characterized by sprouting or by migration of vascular smooth muscle cells alongside preexisting vessels to cover them with a layered muscular coat $(37,284)$. The structure of concentric and helical layers of smooth muscle cells ("tunica media") is given strength and flexibility by the presence of collagen and elastin. The number of layers in the tunica media depends on arterial size and type. Thickness increases during intrauterine and postnatal development $(284,215,7,151)$.

The outermost tissue compartment of blood vessels is the "tunica adventitia", which contains fibroblasts, elastin and collagen fibers and also sensory and autonomic nerve fibers. Particularly the sympathetic nerve endings play a very important role in the control of vascular tone.

Cells of the peripheral nervous system originate from the neural crest cells. These cells migrate and aggregate into spinal (sensory) or autonomic ganglia (sympathetic and parasympathetic). Bone morphogenetic proteins and sonic hedgehog released by tissues along the migration pathway (dorsal aorta, the notochord and neural tube), are proposed to stimulate the differentiation towards the (nor)adrenergic phenotype $(70,88,71)$. The presence of enzymes involved in the synthesis of catecholamines (tyrosine hydroxylase, dopamine $\beta$-hydroxylase), neurotransmitter (norepinephrine) storage vesicles, neurotransmitter transporter systems and the ability to take up norepinephrine from the extracellular medium characterize this cell type (70). Circulating norepinephrine has also been proposed to promote sympathoadrenal differentiation of neural crest cells via interaction with the early functioning uptake system $(319,272)$. The sympathoadrenal progenitors subsequently differentiate into specialized cell types, with the 
sympathetic neurons of the pre- and paravertebral ganglia on the one hand and the chromaffin cells of the adrenal gland on the other representing the largest cell populations. Though this is under debate, glucocorticoids have been proposed to mediate differentiation to the chromaffin cell type $(262,6,304)$. Growth factors, such as FGF, seem to give rise to the immature neuroblast (6). Differentiation of this neuroblast concerns an increase of cell volume and the outgrowth of neurites (axon or dendrite).

To make contact with the target organ, the young neuron depends on the growth cone of the growing neurite with its extending processes. While initial outgrowth of neurites appears to be under genetic influence, fine-tuning and ultimate destination are determined by environmental factors (245). Nerve growth factor (NGF) was one of the first target-derived neurotrophic factors to be discovered (171). In explanted sympathetic ganglia administration of NGF stimulates neurite outgrowth and increases survival of neurons $(243,108,88)$. This dependence of neuronal survival on NGF has been confirmed by in vivo experiments in NGF knock out mice $(275,108,88)$. NGF released by the vascular smooth muscle cells during development, stimulates and maintains postganglionic vascular sympathetic innervation ( 280 , 46). In addition to NGF, recent studies have implicated the involvement of many other targetderived neurotrophic factors, such as neurotrophin-3 (NT-3), glia cell line-derived neurotrophic factor (GNDF) and endothelin $(88,87,144,52)$, that promote sympathetic neuronal survival. Neurons are initially overproduced (88), but active regulation by genes preventing (e.g. bcl-2) or promoting apoptosis (e.g. bax) $(248,206,88)$ determines ultimate innervation density.

\subsubsection{Vascular tone and reactivity}

All three components of the vascular wall are involved in the maintenance and control of arterial tone (fig. 3). Factors released by the endothelium or peri-arterial nerves induce contraction or relaxation of the vascular smooth muscle cells. Circulating hormones and mechanical stimuli may affect smooth muscle cell contractility directly or by stimulating the endothelium or peri-arterial nerves to secrete vasoconstrictors or dilators.

Contraction of the vascular smooth muscle cell takes place when (by the action of mechanical stimuli or of vasoactive compounds that bind to their receptors) intracellular calcium increases and in turn mediates the interaction of actin and myosin filaments. The concentration of intracellular calcium depends on entry across the cell membrane and on sequestration within the cell. Ion channels are involved in the regulation of these processes and vasoactive substances may also directly activate or inactivate these channels. The cascade that leads to the formation of the actine-myosin complex can also be activated without the rise in intracellular calcium; by altering the calcium sensitivity of the contractile machinery (277).

Two potent vasoconstrictors are endothelin-1 and angiotensin II. Both can be produced by the endothelium involving converting enzymes that are localized within or at the surface of the endothelial cells $(125,257)$. Another endothelial source of vasoconstrictors is the cyclooxygenase pathway, which catalyzes the synthesis of tromboxanes and prostaglandins (204).

Many of the substances that induce endothelium-mediated relaxation (57) induce the release of endothelium-derived NO (e.g. acetylcholine, bradykinin, ATP). When these dilator substances bind to their receptors on the endothelium, NO synthase is activated by the resulting increase in intracellular calcium. NO synthase mediates the conversion of $\mathrm{L}$-arginine into $\mathrm{L}$-citruline and NO and after diffusion to the vascular smooth muscle cell, NO stimulates the production of the second messenger cGMP. cGMP in turn interferes with the myosin-actin coupling leading to relaxation (205). The cyclo-oxygenase pathway generates, in addition to vasoconstrictors, substances such as prostacyclin, which mediate vasodilatation via cAMP (204). Endotheliumderived hyperpolarizing factor (EDHF), of which the exact nature remains to be determined, 
exerts its relaxing effects by reducing the membrane potential of the smooth muscle cell which leads to a decrease in intracellular calcium. EDHF has been demonstrated to be partly responsible for relaxing actions of e.g. acetylcholine and bradykinin (78).

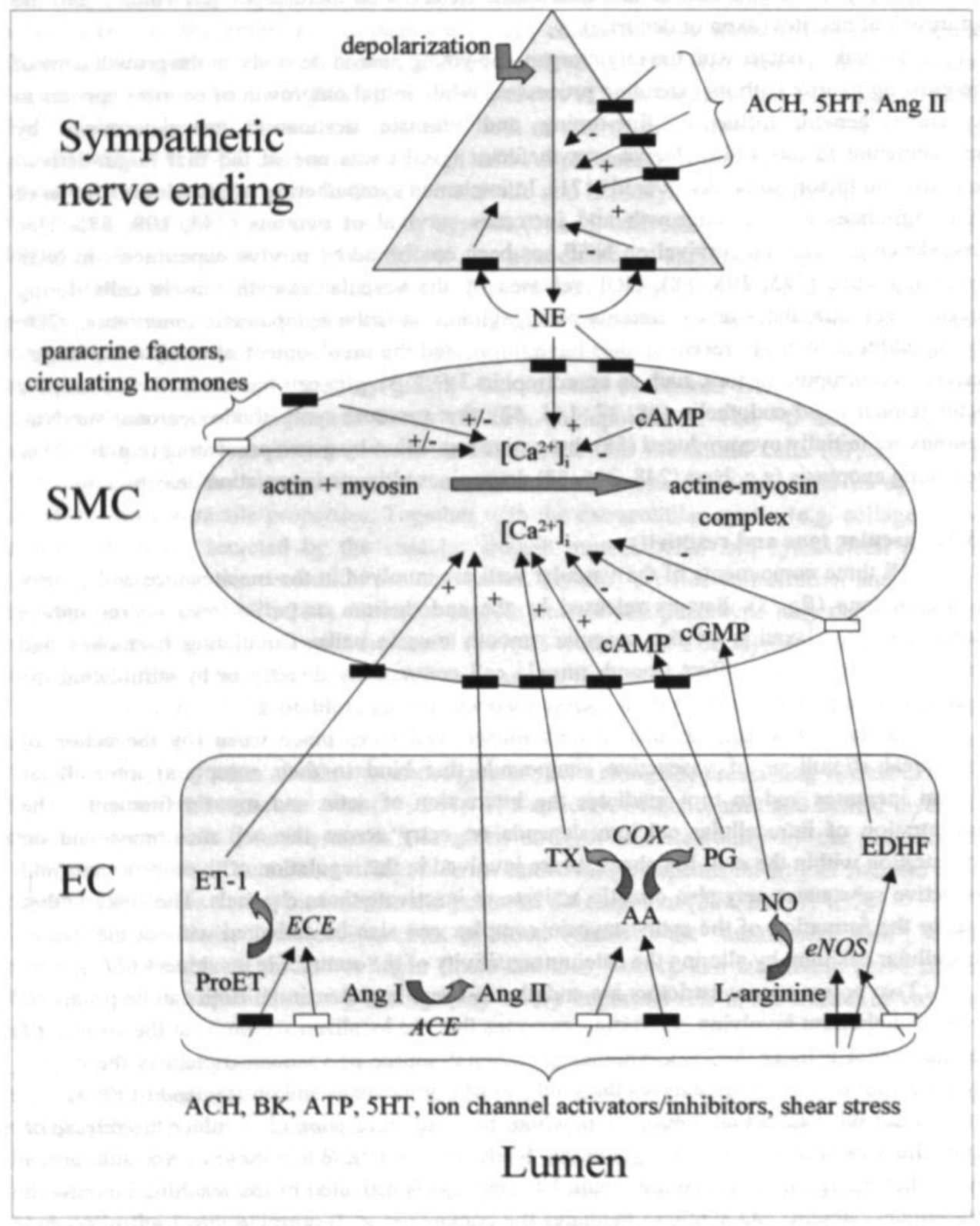

Fig. 3. Schematic presentation of smooth muscle cell (SMC), endothelial cell (EC) and peri-arterial sympathetic nerve ending and their involvement in the regulation of vascular tone. 


\section{Legends to fig. 3:}

Vasoactive substances like acetylcholine ( $\mathrm{ACH})$, bradykinin (BK), adenosine triphosphate (ATP), serotonin $(5 \mathrm{HT})$, ion channel activators/inhibitors and mechanical stimuli such as shear stress induce (directly or via interaction with receptors or ion channels) the production and release of endothelium derived relaxing and contractile factors (ET=endothelin. Ang=angiotensin, $\mathrm{AA}=$ arachidonic acid, PG-prostaglandins, $\mathrm{TX}=$ tromboxanes, $\mathrm{NO}$-nitric oxide, EDHF=endothelium derived hyperpolarizing factor, ECE=endothelin converting enzyme, ACE=angiotensin converting enzyme, eNOS-endothelial nitric oxide synthase, $\mathrm{COX}=$ cyclo-oxygenase). These factors modulate the intracellular calcium concentration via different pathways (among which cAMP and cGMP dependent routes), which results in either the formation or degradation of the actin-myosin complex. Vasoactive substances can also induce contraction or relaxation without concomitant changes in intracellular calcium.

Depolarization of arterial sympathetic nerve endings leads to the release of norepinephrine (NE) from the nerve fiber terminal. NE can interact with receptors on the vascular smooth muscle cell inducing contraction ( $\alpha$-adrenergic) or relaxation ( $\beta$-adrenergic). Ang II, ACH and $5 \mathrm{HT}$ can modulate the release of NE. NE can inhibit its own release and the sympathetic nerve ending is also able to take NE back up again.

Circulating hormones and paracrine factors can also stimulate the vascular smooth muscle cells without interference of the endothelium or sympathetic nerve endings.

=-receptor $\square$ =ionchannel

An acute rise in blood flow is associated with frictional forces on the endothelium, so called shear stress. Though the exact shear sensing elements on the endothelium are not identified yet, the endothelium-derived relaxing factors mentioned above are involved in the flow-induced vasodilatation $(293,25,185,300)$.

The extent to which vascular smooth muscle cell contractility is influenced by the postganglionic sympathetic nerve fibers surrounding arteries may depend largely on the sympathetic innervation density, which varies between vascular beds (73, 282, 281). Norepinephrine is the dominant neurotransmitter released by the peri-arterial nerve endings. While it can bind to $\beta$-receptors, which leads to vasodilatation, in most arteries the main effect of norepinephrine is contraction mediated by $\alpha_{1}$-receptors (and to a lesser extent $\alpha_{2}$-receptors) on the vascular smooth muscle cells (281). The amount of the norepinephrine released by the sympathetic nerves into the synaptic cleft can be modulated by substances, such as angiotensin II, serotonin and acetylcholine, that have receptors on the neuron $(54,55)$. Norepinephrine can bind to neuronal $\alpha_{2}$-receptors to inhibit its own release $(148,34)$. Once released, the amount of norepinephrine available for contraction is modulated by the reuptake of norepinephrine by the nerve fibers $(34,54)$.

\subsubsection{Vascular tone and reactivity during development}

Vascular smooth muscle cells can be phenotypically characterized as synthetic, intermediate or contractile cells. The contractile phenotype is predominant in adult blood vessels and represents the more mature differentiation status $(222,126)$. Markers for contractile proteins are present at early stages in development. In the chicken embryo, smooth muscle $\alpha$ actin is already expressed at embryonic day 2.5 (of 21-days incubation time). This marker and other contractile and cytoskeleton proteins (myosin heavy chain isoforms, vimentin, desmin) are present before (chicken) embryonic day 6/7 and at least from week 7/8 of gestation in human blood vessels $(296,222)$. The content of contractile proteins in smooth muscle cells increases during development and seems to correlate with increasing contractility (222). Indeed, in chicken embryo aorta, contraction in response to high calcium increases with developmental age (219). Studies in fetal lamb and chicken embryos also demonstrate augmentations of responses 
to norepinephrine throughout development $(285,256)$. While there are clear indications that expression of ion channels and receptors is developmentally regulated $(270,222,59,229,263$, $28,94)$, it is largely unknown when first expression and activity occur. The same holds true for intracellular signals that mediate contraction and relaxation $(3,311,269)$.

Because the endothelium is present in vessels as soon as they are assembled (see 1.3.1.), the endothelium-derived vasoactive substances (see 1.3.2.) may play a role in the control of vascular resistance early in gestation. Studies in 3-6 days old zebrafish larvae have demonstrated the presence of NO synthase in vascular endothelial cells, vasodilatation in response to exogenous application of $\mathrm{NO}$ and vasoconstriction when NO synthase was inhibited (89). The importance of NO and other endothelium-derived vasodilators (such as prostaglandins) in systemic and pulmonary vascular control in the last trimester and the perinatal period has been reported $(247,266,269,113,268)$. Endothelin-1 may play a particularly important role in the pulmonary vasculature. Endothelin-1 protein, mRNA and converting enzyme are observed in the fetal lung (29) and in vitro effects on pulmonary arterial reactivity have been demonstrated (59). However, low plasma levels and the lack of effect of ET-1 receptor blockade on pulmonary vascular resistance make the role of ET-1 in the regulation of vascular tone controversial (312).

The influence of the endothelium on vascular tone is apparent before the sympathetic innervation of the vessels becomes important. Vascular adrenergic responses to catecholamines are observed early in gestation $(94,285)$ and enzymes involved in catecholamine production in the neurons are present prior to midgestation (71). However, ultimate innervation of the vasculature and modulation of vascular tone by the release of sympathetic neurotransmitter is established at the end of gestation (e.g. chicken, lamb) or even postnatally (e.g. rats) $(285,181$, 71). While knowledge about sympathetic innervation of various organs is limited, the sympathetic nervous system of the human fetus is assumed to be less developed than the lamb's and more mature than the sympathetic system of the fetal rat (147).

Useful information on cardiovascular sympathetic innervation is provided by studies (mostly in sheep) evaluating in vivo fetal responses to acute hypoxemia. An acute decrease in arterial $\mathrm{pO}_{2}$ leads to increased peripheral vascular resistance whereas the blood flow to vital organs such as brains, adrenal glands and heart is maintained or even increased. Only at later stages of development, sympathetic stimulation of the adrenal and peri-arterial nerves induces the release of catecholamines leading to $\alpha$-adrenergic peripheral vasoconstriction (chemoreflex) $(99,97)$. At earlier stages hypoxia directly triggers the premature adrenal medulla to secrete catecholamines during hypoxemia (274).

Various vasoactive hormones, in addition to catecholamines, may be important in the maintenance of fetal peripheral hypoxemic constriction. Components of the renin angiotensin system are expressed as early as 35 days of gestation (263) and angiotensin II plasma levels are increased during acute hypoxia in the late gestation fetus (105). However, the RAS system only seems to play a role in hypoxemic peripheral vasoconstriction after removal of neuronal input (105) and its role in fetal vascular control during normoxic conditions is not clear either (105, 129). In contrast, vasopressin may be involved in increasing peripheral resistance during hypoxemia $(95,98)$, as blockade of the vasopressinergic $V_{1}$-receptor partly reverses fetal hypertension and cardiac output redistribution in these conditions (230). The contribution of vasopressine to vascular resistance may depend on the species (98) and gestational age of the fetus (242).

Effects of mechanical stimuli (pressure (28) and flow (160)), on vascular reactivity have been observed in isolated fetal arteries and also play a role at earlier stages of development when they may be essential for vascular (structural) development (150) (see 1.3.1.). The exact 
contribution of auto-, para- and endocrine vasoactive substances and mechanical stimuli to the control of vascular tone, in particular the dependence of these influences on developmental stage, is to a large extent unknown. Clearly, the magnitude of effects of vasoactive stimuli during development may differ considerably from those observed after birth $(33,149,291)$.

\subsection{Cardiovascular disease: vascular changes}

\subsubsection{Arterial sympathetic hyperinnervation and endothelial dysfunction in cardiovascular disease}

With the improvement of living conditions and medical care in welfare countries, the prevalence of infectious diseases and poor nutrition drastically reduced and cardiovascular disease became the most common cause of mortality and morbidity in Western countries (292. 246). While a large range of vascular properties can be modified in cardiovascular disease, this introduction will focus on two important features, namely changes in sympathetic innervation and endothelial function.

Decreased endothelial function is reflected by an impairment of endothelium-dependent relaxing responses. This can be the result of a decrease in the secretion of endothelium-derived vasodilators and/or an elevated production of vasoconstrictors by the endothelium. While the decrease in endothelial function with age is a physiological process (56), pronounced endothelial dysfunction is commonly observed in pathological conditions, such as hypertension, atherosclerosis, heart failure, stroke and diabetes (301).

Elevated plasma levels of low-density lipoproteins (LDLs) and cholesterol are major risk factors for atherosclerosis and coronary heart disease. Atherosclerosis, hypercholesterolemia and exposure to LDLs are associated with impaired endotheliumdependent relaxation and reduced expression of endothelial enzymes, such as NO-synthase, in animal models and humans $(184,204,34)$. Responses to endothelium-independent vasodilators are hardly changed. NO and other endothelium-derived relaxing factors (e.g. prostacyclin) do not only play a role in the control of vascular smooth muscle tone, but are also secreted into the vessel lumen to inhibit cell (platelets and leukocytes) adhesion and platelet aggregation. Together with the increased production of vasoconstrictor substances $(184,301)$, the reduced protective effects of these vasodilators will therefore stimulate the formation of an atherosclerotic plaque (204). The decrease in endothelium-dependent vasodilator capacity can be detected before the development of intima thickening and vascular lesions and may therefore be an early pathogenic effect $(301,166)$.

The observation that endothelium-dependent relaxation is smaller in arteries of strokeprone hypertensive rats (SHRSP) than in hypertensive rats without a predisposition to stroke (SHR) suggests that endothelial dysfunction also plays a role in this cardiovascular disorder (305). Similarly, features of altered endothelial function have also been demonstrated in insulin resistance and Diabetes Mellitus. These changes may be secondary to other underlying cardiovascular pathologies, but independent effects of altered insulin metabolism on endothelial function have also been described $(192,47,34)$. Furthermore, independent of the cause (e.g. hypertension, coronary heart disease, diabetes mellitus), impaired endothelial function. indicated by reduced acetylcholine-induced vasodilatation and increased plasma endothelin levels, is observed in heart failure (299).

The sympathetic nervous system plays a very important role in the control of blood flow by its actions on heart rate, cardiac contractility and vascular resistance. Pathological conditions as occurring in cardiovascular disease are often accompanied by sympathetic hyperactivity. Clinically, important signs of enhanced sympathetic drive are increases in heart rate, changes in 
heart rate variability, increases in total peripheral vascular resistance and elevated plasma levels of norepinephrine. In large epidemiological studies, such as the Framingham Heart Study, coronary heart disease and heart failure have been associated with tachycardia (93). Smaller studies demonstrate that decreases in myocardial performance and function are accompanied by a compensatory increase in sympathetic drive to maintain arterial blood pressure, which in turn may aggravate the pathological condition (136). The changes in blood flow pulsations, that are a consequence of the sympathetically mediated increase in heart rate, have been suggested to be a mechanical stimulus for the development of atherosclerosis $(136,186)$. High plasma levels of norepinephrine, tachycardia and changes in heart rate variability are also observed in insulin resistance/diabetes $(80,136)$. Whether the hyperactivity of the sympathetic nervous system plays a causal role in the development of these diseases, remains to be established.

\subsubsection{Hypertension}

High blood pressure is one of the main risk factors for the diseases described above (139). Even small increases in blood pressure may lead to a significant increase of the risk. While hypertension can be the consequence of underlying pathology (secondary hypertension), in many cases the cause of hypertension is unknown (primary or essential hypertension) and multiple factors may be involved in the development. In terms of hemodynamics, elevated arterial blood pressure, normal cardiac output and increased peripheral vascular resistance characterize hypertension. According to Poseuille's law, peripheral vascular resistance is determined by the viscosity of the blood, vessel length and diameter $(R=8 \mathrm{~L} \eta / \pi \mathrm{r} 4, \mathrm{~L}=$ vessel length, $\eta=$ viscosity, $r=$ radius). Both functional and structural changes in arterial diameter control are observed in conditions of hypertension.

Functional alterations include increased vasoconstriction and decreased vasodilatation, whereas the vessel wall is structurally thickened as a result of hypertrophy or hyperplasia (81, 145). Other signs of structural alterations in hypertension are changes in sensitivity to circulating hormones and modified receptor densities (54), decreases in extracellular matrix components (collagen) (128) and altered network geometry (e.g. rarefaction) (239). While a large variety of arterial components is affected in hypertension, endothelial dysfunction and sympathetic hyperinnervation play an important role in the pathology of hypertension. Fig. 4 schematically depicts the changes that occur during hypertension in small arteries.

\subsubsection{Endothelial dysfunction and hypertension}

In human subjects with essential hypertension reduced vasodilatation in response to acetylcholine in the forearm is observed $(286,226)$. Similarly, in animal models of hypertension $(63,56)$ reduced responses to this and other endothelium-dependent vasodilators have been demonstrated $(238,77,315,142,301,184)$. In many of these studies relaxation induced by compounds acting directly on the vascular smooth muscle cells were normal $(238,77)$. In addition, relaxation in response to flow, which is endothelium-dependent $(236,26)$, is reduced in spontaneously hypertensive rats (SHR, 238).

It has been reported that the impaired vasodilatation and increases in constriction in hypertensive animals and patients is due to the increased release of vasoconstrictors, such as cyclo-oxygenase products, from the endothelium $(318,286,301,131$, fig. 4$)$. These in turn may directly or via interference with $\mathrm{NO}$ availability $(131,301)$ decrease vasodilatation. In addition, reduced formation or release of NO may also play a prominent role in endothelial dysfunction. By using inhibitors of NO-synthase, studies in humans demonstrated that both basal and stimulated release of NO are reduced in hypertensive patients $(226,36)$. However, the involvement of the L-arginine-NO pathway in impaired endothelium-dependent relaxation is 
not observed in all forms of hypertension and all vascular beds studied (315, 241, 184, 301). Reduced release of other endothelium-derived relaxing factors, such as hyperpolarizing components, has also been described $(315,90$, fig. 4$)$.

Endothelial function decreases with the increase in blood pressure (184) and endothelial relaxation can be normalized by treatment with anti-hypertensive agents (183). This may suggest that impaired endothelial function is not causally involved in the development of hypertension (184, 301). However, the intact endothelium and NO inhibit proliferation of vascular smooth muscle cells under physiological conditions and this protective effect has been shown to be decreased in hypertensive rats $(261,294)$. Therefore, endothelial dysfunction may play a role in the maintenance of elevated peripheral vascular resistance and may promote the development of cardiovascular complications, such as atherosclerosis.

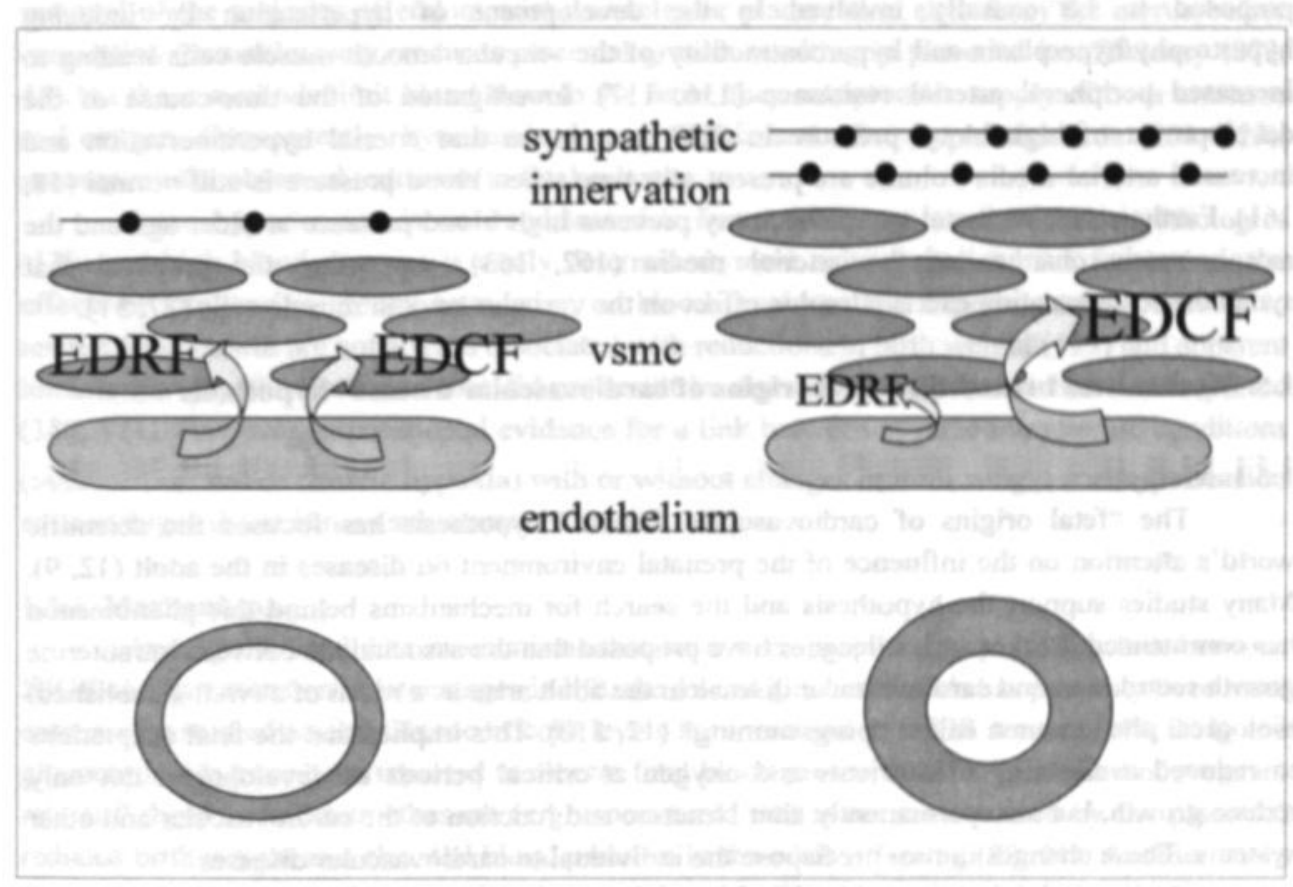

Fig. 4. Small artery under normotensive (left) and hypertensive (right) conditions.

Nerve density is increased and the arterial media, containing vascular smooth muscle cells (vsmc), is thicker. The release of contractile factors from the endothelium (ECDF) is augmented, whereas the production of endothelium derived relaxing factors (EDRF) is decreased. Increased vsme contraction and media thickening lead to narrowing of the arterial lumen.

\subsubsection{Sympathetic hyperinnervation and hypertension}

There is now substantial evidence that hypertension in humans is associated with increased sympathetic activity. This has been demonstrated by indirect measures; plasma levels of the main neurotransmitter of the sympathetic system, norepinephrine (NE) and resting heart rate are increased in hypertensive patients $(72,54,186,136)$. More precise techniques, such as clinical microneurography and biochemical assessment of norepinephrine "spillover" from the neuro-effector junctions, have revealed increased firing rates of nerves innervating skin and skeletal muscle and augmented secretion of norepinephrine by the sympathetic nerves of several organs (72, 54, 186). Changes in sensitivity and density of pre- and postsynaptic receptors 
involved in sympathetic responses explaining altered cardiac function as well as increased peripheral vasoconstriction have also been demonstrated in human hypertension $(54,136)$.

Studies in spontaneously hypertensive rats have provided additional insights in the changes in arterial sympathetic function and structure that play a role in hypertension. Though plasma levels of NE and NE content of the heart are not altered in SHR $(40,64)$, increases in arterial NE content have been observed $(40,118,64)$ and arteries are more densely innervated by sympathetic nerves (39) (fig. 4). Functionally, these changes are reflected by increased responses to sympathetic stimulation of the nerve endings and larger neuronal reuptake of norepinephrine in isolated arteries of the hypertensive rats $(58,39)$. Nerve growth factor expression parallels the altered arterial sympathetic innervation in $\operatorname{SHR}(\mathbf{7 3}, \mathbf{7 4})$.

Largely based on the studies in SHR, arterial sympathetic hyperinnervation has been proposed to be causally involved in the development of hypertension by inducing hypertrophy/hyperplasia and hypercontractility of the vascular smooth muscle cells leading to increased peripheral arterial resistance $(116,117)$. Investigation of the time-course of the development of high blood pressure in SHR has shown that arterial hyperinnervation and increased arterial media volume are present at a time when blood pressure is still normal (58, 161). Furthermore, neonatal sympathectomy prevents high blood pressure at older age and the morphometric changes of the arterial media (162, 163), supporting the proposal that sympathetic innervation exerts a trophic effect on the vascular smooth muscle cells $(27,51)$.

\subsection{Mechanisms behind the "fetal origins of cardiovascular disease" hypothesis}

\subsubsection{Methods}

The "fetal origins of cardiovascular disease" hypothesis has focused the scientific world's attention on the influence of the prenatal environment on diseases in the adult $(12,9)$. Many studies support the hypothesis and the search for mechanisms behind this phenomenon has commenced. Barker and colleagues have proposed that the associations between intrauterine growth retardation and cardiovascular disease in the adult arise as a result of a (well-established) biological phenomenon called "programming" $(12,110)$. This implies that the fetal adaptations to reduced availability of nutrients and oxygen at critical periods of development not only reduce growth, but also permanently alter structure and function of the cardiovascular and other systems. These changes in turn predispose the individual to cardiovascular diseases.

Studies in humans examine risk factors for and mediators of cardiovascular disease in subjects in relation to birth weight or other anthropometric measures $(189,41,102,232,233$, 122). These factors can be evaluated in people that may have been exposed to intrauterine conditions that compromise growth. For instance, data obtained from the "Dutch famine" imply that reduced maternal intake of nutrients during pregnancy may not only reduce birth weight of babies, but may also predispose them to chronic heart disease (254). In these retrospective studies other risk factors for cardiovascular disease have been evaluated (255). Similarly, studies in subjects that were exposed to high altitude chronic hypoxia during prenatal development, which is associated with intrauterine growth retardation $(133,195,96)$, may provide useful information.

However, the acquisition of more specific and detailed data with regards to the mechanism involved in the fetal programming of cardiovascular disease requires animal studies. While animals that were small or appropriate for gestational age due to natural selection have been studied (21), more often intrauterine growth retardation is experimentally induced.

Maternal malnutrition is a frequently used method to induce growth-compromising conditions. Many studies in rats $(152,313)$ have shown that restriction of the total caloric intake 
or protein malnutrition result in offspring with reduced birth weight. Furthermore, reduced IGF levels and hypoglycemia in the fetus indicate that this intervention reduces the availability of nutrients for fetal growth (111). Reduced IGF levels and growth retardation are also demonstrated in fetuses of which the mother is exposed to chronic hypoxia during pregnancy (288, 130). Chronic hypoxia of the mother is established by placing the animal in a hypoxic chamber or by keeping it at high altitude for a prolonged period of time. Both methods result in decreased fetal arterial $\mathrm{pO}_{2}$ and increased fetal hemoglobin concentrations $(130,178)$.

Several experimental approaches have been developed to mimic the conditions that may occur during placental insufficiency. Reductions in uterine blood flow can be induced by vascular occlusion or ligation $(224,132)$. The procedure of umbilico-placental embolization uses the repetitive infusion of microspheres to restrict placental function $(180,214)$. Surgical removal of the majority of endometrial caruncles or placentation sites from the uterus before conception (carunclectomy) reduces placental growth resulting in placental insufficiency (273. 45). As these methods limit blood flow to the fetus, they compromise supply of both nutrients and oxygen. Consequently, hypoxemia, hypoglycemia and often hyperlacticemia $(251,223)$, accompany the observed reduction in fetal growth.

Since hypertension is an important risk factor for many cardiovascular pathologies (139) and high blood pressure is easily determined, most animal studies have focused on the effects of intrauterine growth retardation on blood pressure. The experimental procedures to restrict fetal growth are not always associated with reductions in birth weight (123) and apparent intrauterine growth retardation that did not result in elevated blood pressure has been reported $(180,124)$. However, experimental evidence for a link between adverse intrauterine conditions (malnutrition and/or chronic hypoxia) with or without changes in birth weight and hypertension at later stages in life is now substantial $(123,103,153)$.

\subsubsection{Mechanisms}

Among the candidate mechanisms that have been proposed to provide a link between IUGR and hypertension at later stages in life, the role of glucocorticoids has probably been most extensively studied so far. Glucocorticoid levels are increased in IUGR fetuses $(170,264)$ and glucocorticoids have been reported to elevate fetal blood pressure (287). Treatment of pregnant rats and sheep with dexamethasone (a glucocorticoid that is not metabolized by the placenta) reduced birth weight and elevated blood pressure in the adult offspring (23, 61). Another study in rats has shown that hypertension in 6-weeks old offspring induced by maternal protein malnutrition disappeared after adrenalectomy and could be restored by cortisone replacement (91).

Under physiological conditions, maternal glucocorticoids are converted to inactive metabolites by $11 \beta$-hydroxysteroid dehydrogenase type 2 (11- $\beta$ HSD) in the placenta. Activity of this enzyme seems to be positively correlated with birth weight in rats (23) and reduced expression of this placental enzyme resulting in fetal overexposure to maternal glucocorticoids has been demonstrated after maternal undemutrition (170). Maternal administration of an inhibitor of 11- $\beta$ HSD results in hypertensive adult offspring (175). While these studies indicate that glucocorticoids are involved in the programming of hypertension, it has been suggested that these effects are not direct effects, but are mediated by factors associated with the reduction in prenatal growth the glucocorticoids induce $(208,264)$.

Excessive fetal exposure to glucocorticoids has been proposed to alter the hypothalamic-pituitary-adrenal (HPA) axis $(231,67)$. This axis, which regulates the release of adrenal hormones, such as adrenocorticotropic hormone $(\mathrm{ACTH})$ and glucocorticoids, plays an important role in cardiovascular control and maturation of organ systems. While low birth 
weight has been associated with increased plasma cortisol in adult men (233), human evidence for HPA axis programming in association with IUGR is limited. Increased adrenal responsiveness and pituitary expression of $\mathrm{ACTH}$ precursor has been observed after repeated umbilical cord occlusion in ovine fetuses (104), but maternal nutrient restriction has resulted in activation of the fetal HPA-axis (rat (170)) and depressed function (sheep (115)). The lack of evidence for HPA resetting in adult sheep after prenatal exposure to dexamethasone (62), also demonstrates that the role of the HPA axis in fetal programming of hypertension requires further investigation.

Activation of the renin-angiotensin system (RAS) has also been suggested in the fetal programming of hypertension. Inhibition of angiotensin converting enzyme may reduce high blood pressure induced by exposure to prenatal malnutrition in rats (154). However, reductions in plasma and kidney renin levels have also been determined in newborns in these conditions $(302,314)$. While research is ongoing to elucidate the exact role of RAS in the development of hypertension, its importance for renal development is well established (182). Intrauterine growth retardation is associated with hypertension and reduced kidney size in rats (155), and leads to a permanent deficit in nephron numbers and a consequent impairment of renal function $(155,199,21)$. The involvement of RAS in these effects has been postulated $(182,60)$.

Hypertension is characterized by vascular changes, such as increased contractility and media thickness $(81,145$, see 1.4.2.), which are proposed to play a causal role. Therefore, in addition to alterations in endocrine control systems and factors associated with renal development and function, consequences of IUGR for vascular structure and function are implicated to play a role in the fetal programming of cardiovascular disease.

Elastin provides (large) arteries with elasticity. Decreased arterial compliance, a measure for elasticity, is associated with hypertension (259). Increased arterial stiffness of the carotid artery and of the aorta has been related to size at birth in children and adults, respectively $(187,189)$. Studies in knockout mice have shown that elastin is also important in the regulation of proliferation and organization of vascular smooth muscle cells. Mice that lack elastin exhibit smaller and thicker arteries than wild type animals (173). These experimental data, together with the fact that elastin is a protein of remarkable longevity, have led to the suggestion that changes in arterial elastin may participate in the development of high blood pressure associated with intrauterine growth retardation (191).

Other studies have concentrated on the potential association of intrauterine growth retardation with altered vascular vasodilator and -constrictor function. Maternal food restriction in rats has been reported to result in decreased contractile responses to $\alpha$-adrenergic stimulation in 20-days old offspring, but these differences had disappeared at 100 days after birth. By that time enhanced contraction induced by a tromboxane analog, increased sensitivity to high potassium solution and decreased relaxation in response to exogenous NO were observed (225). While no apparent changes in endothelium-dependent relaxation were observed in this study (225), more severe maternal undernutrition reduced relaxation in response to acetylcholine and bradykinin in 100-120 days old rat offspring (124). An association between endothelial function and intrauterine growth restriction is also suggested by studies in human subjects. Children with a history of low birth weight showed impaired responses to acetylcholine in arteries of the skin (187). A positive correlation between birth weight and flow-mediated relaxation of the brachial artery was observed in children (164). Flow-related dilatation was also reduced in young adults that were small at birth (102).

In addition to changes in vascular structure or function, altered organization of the microcirculatory network may also play a role in the development of hypertension (239). Empirical evidence on vascular density with respect to fetal growth retardation is largely 
lacking. However, reduced microvascular density of the retina has been demonstrated in lowbirth weight men (41).

The sympathoadrenal system plays a pivotal role in the regulation of fetal cardiovascular control and catecholamines are increased in growth retarded fetuses (309, 273 . 132). The importance of this system in the fetal programming of hypertension (and insulin resistance) is emphasized by the observation that low birth weight is associated with high pulse pressure, an indirect index of sympathetic nervous activity (232). Increased norepinephrine release by stimulated sympathetic neurons has been suggested in growth retarded sheep fetuses (273). Changes in sympathoadrenal function may persist into postnatal life, since uterine artery ligation enhanced basal synthesis and release of adrenal catecholamines and cardiac sympathetic neuronal activity in newborn rats (267). Older rats that suffered from IUGR as a consequence of the same experimental procedure exhibited augmented norepinephrine spillover to plasma (132).

\subsubsection{Limitations}

Intrauterine growth retardation is a complex phenomenon and a consequence of multiple causes, among which fetal hypoxia and malnutrition are most prominent. Animal experimental studies (as mentioned in 1.5.2.) have put forward many candidate systems and mediators that may be involved in the fetal programming of hypertension and other cardiovascular diseases. However, in these studies fetal growth retardation is induced by procedures that do not only affect the intrauterine environment, but may also induce maternal endocrine, cardiovascular and metabolic adaptations. This, and the fact that many of the techniques comprise a combination of malnutrition and hypoxia, may complicate the detailed study of mechanisms that are potentially involved. An animal model, in which multiple factors can be investigated separately without direct maternal influences, would overcome these difficulties.

\subsection{The chicken as an experimental model}

\subsubsection{The chicken embryo as a model in cardiovascular development}

The attractiveness of the chicken embryo, with its short incubation period of 21 days, as an experimental model of cardiovascular development has long been recognized. Studies in the chicken embryo have given important insights in the origins of vascular cells (germ layers) and their commitment towards a certain fate within the cardiovascular system. Groups of cells in the developing chicken embryo can be substituted by marked quail cells. These so-called quailchicken chimeras are frequently used to study the behavior of vascular cells with regards to migration and differentiation during early stages of vascular development $(235,306)$. In angiogenesis research, investigations in the chicken embryo are also of great merit. Studies of the developing vasculature of the chorioallantoic membrane and its response to exposure to exogenous stimuli (such as hypoxia or applied compounds) have identified many angiogenic factors $(1,167,65)$. In addition, vascular development and the influence of growth factors and hormones can be histologically studied by making sections of the whole embryo or individual arteries $(140,24)$.

The chicken embryo as an experimental model is also extensively used to investigate neuronal development. The sympathoadrenal lineage is studied with respect to commitment of cells to the neuronal cell type or chromaffin cell type $(303,71,271,88)$. Studies investigating neuronal outgrowth and differentiation in isolated sympathetic ganglia have demonstrated the important role of growth factors, such as NGF $(108,101,243,88)$. 
While the above mentioned applications of the chicken embryo model emphasize its value for developmental research of the (cardio)vascular system, most of these studies are confined to early stages of development and do not examine control of vascular reactivity. However, a substantial number of studies have now demonstrated that the chicken embryo is also a suitable experimental model to investigate hemodynamic aspects during development.

The circulation of the chicken embryo is comparable to that of the mammalian fetus with the chorioallantoic membrane being equivalent to the placenta and the chorioallantoic artery and vein resembling the umbilical circulation in mammalians $(200,253)$. Time-dependent changes in blood pressure, heart rate, chorioallantoic blood flow, cardiac output and cardiac output distribution can be measured from early stages of development onwards $(44,307,32$, $216,298,290,212)$. In the chicken embryo, vascular resistance is initially high and decreases as the circulation expands. Cardiac output and blood pressure gradually increase (44). Early in development, hemodynamic regulation is controlled primarily by mechanical factors (307). At later stages neurohumoral control becomes increasingly important.

Parasympathetic and sympathetic control of the heart is functional from day 15 and 16 onwards, respectively $(227,119)$. Effects of ganglion blockade on mean arterial pressure are not observed at early stages of development $(48,211)$. Therefore, control of vascular tone by the sympathetic nerve endings is assumed to play a role only at the very end of the incubation period. Prior to functional sympathetic regulation, circulating factors are important in the regulation of vascular reactivity. Chromaffin cells of the adrenal gland start secreting catecholamines around day 10 (308). Plasma levels of adrenaline increase with developmental age, while this may not be the case for norepinephrine (209). However, the increase in norepinephrine observed during short episodes of hypoxia becomes more pronounced at later stages of development $(209,68)$. Studies examining the effect of acute hypoxia in the chicken embryo, have also demonstrated that increases in mean arterial pressure and cardiac output redistribution (as a result of peripheral vasoconstriction) in response to this insult, are mediated by $\alpha$-adrenergic receptors $(48,210,256)$. Adrenergic constrictor capacity in the chicken embryo also increases with developmental age $(210,256)$. The hemodynamic consequences of acute hypoxia observed in the chicken embryo suggest high similarity with mammalian species (297, 210). Much less is known about the involvement of other circulating vasoactive substances and the role of the endothelium in vascular reactivity in the chicken embryo. Arterial dilator responses to acetylcholine are observed in 13 and 17 days old chicken embryos (256).

The large comparability of vascular responses to acute hypoxia of the chicken embryo with those in mammalian species $(297,210)$ and the high conservation of factors involved in blood vessel development (218) indicate that this non-mammalian experimental model is of great value to research of the prenatal (cardio)vascular system.

\subsubsection{The chicken and cardiovascular pathology}

Although the knowledge of the cardiovascular system is more limited in birds than in mammalian species, important information on cardiovascular parameters in chickens is available. The mechanisms involved in the control of blood pressure and flow (autoregulation, humoral factors, neural control) (276) and responses to vasoactive substances $(234,4,114)$ are largely the same as in mammalians. However, blood pressure of chickens is relatively high (mean arterial pressure ranging from 130 to 220 in adult chickens) and hypertension is observed $(217,137,276)$. It has been suggested that this high blood pressure, together with the high plasma catecholamine levels observed in chickens, indicates high sympathetic and/or adrenomedullary activity (137). In addition to hypertension, chickens can spontaneously develop arterial plaques, which largely resemble those observed in mammalian atherosclerosis 
$(107,240)$. Furthermore, some chicken strains (e.g. broilers) are prone to ascites and pulmonary hypertension (188). While differences between strains and between males and females exist $(188,137)$, chickens may be thus sensitive to the development of cardiovascular pathologies.

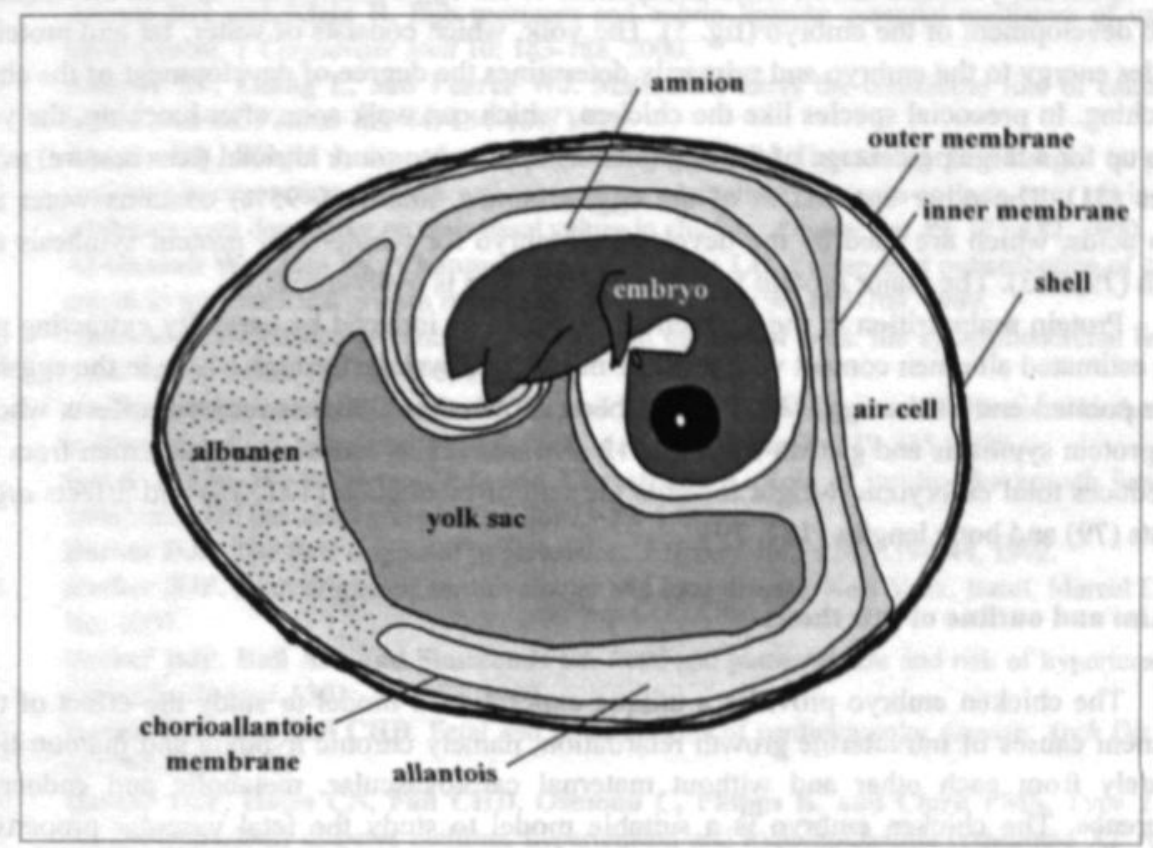

Fig. 5. Schematic representation of a chicken egg with embryo.

\subsubsection{Interventions: chronic hypoxia and malnutrition}

The attractiveness of the chicken embryo as a experimental model to study vascular structure and function during development and the fact that chickens are prone to hypertension and other cardiovascular pathology, may make the chicken a useful model to study the relationship between adverse conditions during development and cardiovascular disease at later stages in life. This is the case if methods can be applied to induce conditions that may interfere with fetal growth (e.g. chronic hypoxia and malnutrition).

The freshly laid egg contains everything the chicken embryo needs for its growth and development (fig. 5), except for oxygen and heat. Development of the embryo in the freshly laid egg will not commence if temperature is kept low $\left(<25{ }^{\circ} \mathrm{C}\right)$. Once incubation is started, temperature is kept around $38^{\circ} \mathrm{C}$ by the hen or artificially (in an incubator). Oxygen from the surrounding air and $\mathrm{CO}_{2}$ and water from the egg can be exchanged through small pores in the eggshell. The outer and inner shell membranes lie directly adjacent to each other except at the end of the egg where they form the air cell. Until it penetrates the aircell with its beak (internal pipping) and pulmonary respiration starts, the embryo is depend on oxygen diffusion through shell and shell membranes into the capillaries of the chorioallantoic membrane. The chorioallantoic vein transports the oxygenated blood to the embryo $(134,253)$.

Hypoxia of the chicken embryo is easily induced by covering part of the egg, which limits $\mathrm{O}_{2}$ diffusion through the shell (196) or by incubating the eggs in a low oxygen environment (316). Both methods, when prolonged, result in retarded growth as reflected by reduced total body weight on day 18 of the 21 days incubation period $(196,316)$. While the severity of growth retardation and the consequences of chronic hypoxia for growth of individual 
organs may depend on the level and duration of oxygen deprivation, relative sparing of the brain has been demonstrated (196). These methods of inducing chronic hypoxia in the chicken embryo do not concomitantly disturb the embryo's access to food.

Both the yolk and the albumen component of the egg contain nutrients that are required for the development of the embryo (fig. 5). The yolk, which consists of water, fat and proteins, provides energy to the embryo and primarily determines the degree of development of the chick at hatching. In precocial species like the chicken, which can walk soon after hatching, the yolk makes up for a large percentage of the egg mass as opposed to more altricial (less mature) avian species (31). The other component of the egg, albumen, mainly $(\approx 95 \%)$ contains water and amino acids, which are used by the developing embryo for whole-body protein synthesis and growth $(79,213)$. The major protein found in the albumen is ovalbumen.

Protein malnutrition in the chicken embryo can be induced by carefully extracting part of the estimated albumen content with a sterile needle and syringe through a hole in the eggshell (at the pointed end of the egg) (121). It has been shown that albumen removal affects wholebody protein synthesis and growth from day 12 onwards (213). Extraction of albumen from the egg reduces total embryonic weight towards the end of incubation $(121,79)$ and affects organ weights (79) and bone lengths $(121,79)$.

\subsection{Aim and outline of this thesis}

The chicken embryo provides a unique experimental model to study the effect of two prominent causes of intrauterine growth retardation, namely chronic hypoxia and malnutrition, separately from each other and without maternal cardiovascular, metabolic and endocrine interference. The chicken embryo is a suitable model to study the fetal vascular properties. Furthermore, vascular characteristics can also be investigated in older chickens, which may be prone to develop cardiovascular pathology.

The present thesis aims to determine the effects of prenatal exposure to chronic hypoxia and malnutrition on arterial function and structure by using the chicken as an experimental model. Since arterial sympathetic hyperinnervation and endothelial dysfunction are important features of hypertension and other cardiovascular diseases, the studies presented in this thesis focus on these arterial components.

In order to evaluate arterial structure and function, reactivity studies (using the wire myograph technique) and histological studies were performed in isolated femoral arteries". Prior to starting intervention studies the feasibility of the intended methods had to be evaluated, as isolated chicken embryo arteries have not been investigated in this way before (chapter 2). In addition, the effects of acute hypoxia on arterial reactivity in the chicken embryo were evaluated (chapter 3).

Effects of exposure to chronic hypoxia and protein malnutrition during development on sympathetic innervation of arteries at the end of the incubation period were determined (chapter 4 and 5, respectively). The effects of these interventions on arterial endothelial function at the same stage of development are presented in chapter 6 . The consequences of exposure to chronic hypoxia during in ovo development for vascular function and structure and for hemodynamic parameters were also examined in 3 and 14 weeks old chickens (chapter 7). The results of these studies are discussed in chapter 8.

\footnotetext{
"In strict anatomical terms this artery is named "a. ischiadica" in the chicken. Location and size are comparable to the mammalian femoral artery.
} 
1. Adair TH, Gay WJ, and Montani JP. Growth regulation of the vascular system: evidence for a metabolic hypothesis. Am J Physiol 259: R393-R404, 1990.

2. Adams RH and Klein R. Eph receptors and ephrin ligands: essential mediators of vascular development. T Candiovase Med 10: 183-188, 2000.

3. Akopov SE, Zhang L, and Pearce WJ. Maturation alters the contractile role of calcium in basilar arteries. Pediatr Res 44: 154-160, 1998.

4. Aksulu HE, Bingol I, Karatas F, Sagmanligil H, and Unstundag B. Changes in plasma angiotensin-converting enzyme activity and noradrenaline responses to long-term nitric oxide inhibition vary depending on their basal values in chicken. Physiol Res 49: 175-182, 2000.

5. Al-Ghazali W, Chita SK, Chapman MG, and Allan L.D. Evidence of redistribution of cardiac output in asymmetrical growth retardation. Br JObst Gyn 96: 697-704, 1989.

6. Anderson DJ. Molecular control of cell fate in the neural crest: the sympathoadrenal lineage. Anmu Rev Neurosci 16: 129-158, 1993.

7. Arciniegas E, Servin M, Arguello C, and Mota M. Development of the aorta in the chick embryo: structural and ultrastructural study. Atherosclerosis 76: 219-235, 1989.

8. Baker J, Liu JP, Robertson EJ, and Efstratiadis A. Role of insulin-like growth factors in embryonic and postnatal growth. Cell 75: 73-82, 1993.

9. Barker DJP. The fetal origins of hypertension. J Hypertension 10: S39-S44, 1992.

10. Barker DJP. Fetal origins of cardiovascular and lung disease. New York, Basel. Marcel Dekker Inc. 2001.

11. Barker DJP, Bull AR, and Simmonds SJ. Fetal and placental size and risk of hypertension in adult life. Br Med J 301: 259-262, 1990.

12. Barker DJP and Fall CHD. Fetal and infant origins of cardiovascular disease. Arch Dis Child 68: 797-799, 1993.

13. Barker DJP, Hales CN, Fall CHD, Osmond C, Phipps K, and Clark PMS. Type 2 (noninsulin-dependent) diabetes mellitus, hypertension and hyperlipidaemia (syndrome X): relation to reduced fetal growth. Diabetologia 36: 62-67, 1993.

14. Barker DJP and Osmond C. Infant mortality, childhood nutrition, and ischaemic heart disease in England and Wales. Lancet 1(8493): 1077-1081, 1986.

15. Barker DJP and Osmond C. Death rates from stroke in England and Wales predicted from past maternal mortality. Br Med J 295: 83-86, 1987.

16. Barker DJP, Osmond C, Golding J, Kuh D, and Wadsworth MEJ. Growth in utero, blood pressure in childhood and adult life, and mortality from cardiovascular disease. $\mathrm{Br}$ Med J 298: 564-567, 1989.

17. Barker DJP, Osmond C, Simmonds SJ, and Wield GA. The relation of small head circumference and thinness at birth to death from cardiovascular disease in adult life. $\mathrm{Br}$ Med J 306: 422-426, 1993.

18. Barker DJP, Winter PD, Osmond C, Margetts B, and Simmonds S.J. Weight in infancy and death from ischaemic heart disease. Lancet 2: 577-580, 1989.

19. Basset JM and Hanson C. Catecholamines inhibit growth in fetal sheep in the absence of hypoxaemia. Am J Physiol 43: R1536-R1545, 1998.

20. Bauer MK, Harding JE, Bassett NS, Breier BH, Oliver MH, Gallaher BH, Evans PC, Woodall SM, and Gluckman PD. Fetal growth and placental function. Mol Cell Endocrinol 140: 115-120, 1998.

21. Bauer R, Walter B, and Zwiener $\mathbf{U}$. Effect of severe normocapnic hypoxia on renal function in growth restricted newbom piglets. Am J Physiol 279: R1010-R1016, 2000.

22. Bavdekar A, Yajnik CS, Fall CHD, Bapat S, Pandit AN, Deshpande V, Bhave S, Kellingray SD, and Joglekar C. Insulin resistance syndrome in 8-year-old Indian children. Small at birth, big at 8 years, or both? Diabetes 48: 2422-2429, 1999.

23. Benediktsson R, Lindsay RS, Noble J, Seckd JR, and Edwards CRW. Glucocorticoid exposure in utero: new model for adult hypertension. Lancet 341: 339-341, 1993.

24. Bergwerff M, DeRuiter MC, Poelmann RE, and Gittenberger-de Groot AC. Onset of elastogenesis and downregulation of smooth muscle actin as distinguishing phenomena in artery differentiation in the chick embryo. Anat Embryol 194: 545-557, 1996. 
25. Bevan JA. Flow regulation of vascular tone. Its sensitivity to changes in sodium and calcium. Hypertension 22: 273-281, 1993.

26. Bevan JA. Shear stress, the endothelium and the balance between flow-induced contraction and dilation in animals and man. Int J Microcirc Clin Exp 17: 248-256, 1997.

27. Bevan RD. Influence of adrenergic innervation on vascular growth and mature characteristics. Am Rev Respir Dis 140: 1478-1482, 1989.

28. Bevan RD, Vijayakumaran E, Gentry A, Wellman T, and Bevan JA. Intrinsic tone of cerebral artery segments of human infants between 23 weeks of gestation and term. Pediatr Res 43: 20-27, 1998.

29. Black SM, Bekker JM, Johengen MJ, Parry AJ, Soifer SJ, and Fineman JR. Altered regulation of the ET-1 cascade in lambs with increased pulmonary blood flow and pulmonary hypertension. Pediatr Res 47: 97-106, 2000.

30. Bocking AD. Maternal adaptation to pregnancy. Eds.: Harding $R$ and Bocking AD. in: Fetal growth and development. University Press. Cambridge. 2001. pp. 224-240.

31. Boersma PD. Why some birds take so long to hatch. Am Nat 120: 733-750, 1982.

32. Broekhuizen M, Mast F, Struijk PC, van der Bie W, Mulder PGH, Gittenberger-de Groot AC, and Wadimiroff JW. Hemodynamic parameters of stage 20 to 35 chick embryo. Pediatr Res 34: 44-46, 1993.

33. Buchholz J, Edwards-Teunissen K, and Duckles SP. Impact of development and chronic hypoxia on NE release from adrenergic nerves in sheep arteries. Am J Physiol 276: R799-808, 1999.

34. Burnstock $\mathbf{G}$ and Ralevic $\mathbf{V}$. New insights into the local regulation of blood flow by perivascular nerves and endothelium. Br J Plast Surg 47: 527-543, 1994.

35. Byrne CD and Phillips DI. Fetal origins of adult disease: epidemiology and mechanisms. J Clin Pathol 53: 822-828, 2000.

36. Calver A, Collier J, Moncada S, and Vallance P. Effect of local intra-arterial Ng-monomethyl$\mathrm{L}$-arginine in patients with hypertension: the nitric oxide dilator mechanism appears abnormal. $J$ Hypertension 10: 1025-1031, 1992.

37. Carmeliet P. Mechanisms of angiogenesis and arteriogenesis. Nature Med 3: 389-395, 2000.

38. Carr-Hill R, Hall MH, and Meredith A. Is birth weight determined genetically? Br Med J 295: 687-689, 1987.

39. Cassis LA, Stitzel RE, and Head RJ. Hypernoradrenergic innervation of the caudal artery of the spontaneously hypertensive rat: an influence upon neuroeffector mechanisms. J Pharmacol Exp Therap 234: 792-803, 1985.

40. Cassis LA, Stitzel RE, and Head RJ. Influence of cold-induced increases in sympathetic nerve activity on norepinephrine content in the vasculature of the spontaneously hypertensive rat. Blood Vessels 25: 82-88, 1988.

41. Chapman N, Mohamudally A, Cerutti A, Stanton A, Sayer A, Cooper C, Barker D, Rauf A, Evans J, Wormald R, Sever P, Hughes A, and Thom S. Retinal vascular network architecture in low-birth-weight men. J Hypertension 15: 1449-1453, 1997.

42. Cheung YB, Low L, Osmond C, Barker D, and Karlberg J. Fetal growth and early postnatal growth are related to blood pressure in adults. Hypertension 36: 795-800, 2000.

43. Christensen $\mathbf{K}$, Stovring $\mathbf{H}$, and MeGue $\mathbf{M}$. Do genetic factors contribute to the association between birth weight and blood pressure? J Epidemiol Community Health 55: 583-587, 2001.

44. Clark EB and Hu N. Developmental hemodynamic changes in the chick embryo form stage 18 to 27. Circ Res 1982: 810-815, 1982.

45. Coulter CL, McMillen IC, Robinson JS, and Owens JA. Placental restriction alters adrenal medullary development in the midgestation sheep fetus. Pediatr Res 44: 656-662, 1998.

46. Creedon D and Tuttle JB. Nerve growth factor synthesis in vascular smooth muscle. Hypertension 18: 730-741, 1991.

47. Crijns FRL, Struijker Boudier HAJ, and Wolffenbuttel BHR. Arteriolar reactivity in conscious diabetic rats. Influence of aminoguanidine treatment. Diabetes 47: 918-923, 1998.

48. Crossley $\mathbf{D}$ and Altimiras J. Ontogeny of cholinergic and adrenergic cardiovascular regulation in the domestic chicken. Am J Physiol 279: R1091-R1098, 2000.

49. Curhan GC, Chertow GM, Willett WC, Spiegelman D, Colditz GA, Manson JE, Speizer FE, and Stampfer M. Birth weight and adult hypertension and obesity in women. Circulation 94: 1310-1315, 1996. 
50. Curhan GC, Willet WC, Rimm EB, Spiegelman D, Ascherio AL, and Stampfer MJ. Birth weight and adult hypertension, Diabetes Mellitus, and obesity in US men. Cinculation 94: 3246$3250,1996$.

51. Daemen MJAP and De Mey JGR. Regional heterogeneity of arterial structural changes. Hypertension 25: 464-473, 1995.

52. Damon DH. NGF-independent survival of postganglionic sympathetic neurons in neuronalvascular smooth muscle cocultures. Am J Physiol 280: H1722-H1728, 2001.

53. Daniel TO and Abrahamson D. Endothelial signal integration in vascular assembly. Amn Rev Physiol 62: 649-671, 2000.

54. De Champlain J. Pre- and postsynaptic adrenergic dysfunctions in hypertension. J Hypertension 8: S77-S85, 1990.

55. De Mey JGR, Burnstock G, and Vanhoutte PM. Modulation of the evoked release of noradrenaline in canine saphenous vein via presynaptic receptors for adenosine but not ATP. Eur J Pharmacol 55: 401-405, 1979.

56. De Mey JGR and Gray SD. Endothelium-dependent reactivity in resistance vessels. Prog Appl Microcire 8: 181-187, 1985.

57. De Mey JGR and Vanhoutte PM. Role of the intima in cholinergic and purinergic relaxation of isolated canine femoral arteries. J Physiol 316: 347-355, 1981.

58. Dickhout JG and Head R. Structural and functional analysis of small arteries from young spontaneously hypertensive rats. Hypertension 29: 781-789. 1997.

59. Decherty CC, Kalmar-Nagy J, Engelen M, Koenen SV, Nijland M, Kuc RE, Davenport AP, and Nathanielsz PW. Effect of in vivo fetal influsion of dexamethasone at $0.75 \mathrm{GA}$ on fetal ovine resistance artery responses to ET-1. Am J Physiol 281: R261-R268, 2001.

60. Dodic M, Baird R, Hantris V, Koukoulas I, Moritz K, Peers A, and Wintour EM. Organs/systems potentially involved in one model of programmed hypertension in sheep. Clin Exp Pharmacol Physiol 28: 952-956, 2001.

61. Dodic M, May CN, Wintour EM, and Coghlan JP. An early prenatal exposure to excess glucocorticoid leads to hypertensive offspring in sheep. Clin Sci 94: 149-155, 1998.

62. Dodic M, Peers A, Moritz K, Hantzis V, and Wintour EM. No evidence for HPA resetting in adult sheep with high blood pressure due to short prenatal exposure to dexamethasone. Am J Physiol 282: R343-R350, 2002.

63. Doggrell SA and Brown L. Rat models of hypertension, cardiac hypertrophy and failure. Cardiovase Res 39: 89-105, 1998.

64. Donohue SJ, Stitzel RE, and Head RJ. Time course of changes in the norepinephrine content of tissues from spontaneously hypertensive and Wistar Kyoto rats. J Pharmacol Exp Therap 245: 24-31, 1988.

65. Dusseau JW and Hutchins PM. Microvascular responses to chronic hypoxia by the chick chorioallantoic membrane: a morphometric analysis. Microvase Res 37: 138-147. 1989.

66. Dwyer T, Blizard L, Morley R, and Ponsonby A. Within pair association between birth weight and blood pressure at age 8 in twins from a cohort study. $\mathrm{Br}$ Med J 319: 1325-1329. 1999.

67. Edwards LJ, Coulter CL, Symonds ME, and MeMillen IC. Prenatal undernutrition, glucocorticoids and the programming of adult hypertension. Clin Exp Pharmacol Physiol 28: 938-941, 2001.

68. Epple A, Gill TS, and Nibbio B. The avian allantois: a depot of stress-released catecholamines. Gen Comp Endocrinol 85: 462-476, 1992.

69. Eriksson J, Forsen T, Tuomilehto J, Osmond C, and Barker D. Fetal and childhood growh and hypertension in adult life. Hypertension 36: 790-794, 2000.

70. Ernsberger U. Evidence for an evolutionary conserved role of bone morphogenetic protein growth factors and Phox 2 transcription factors during noradrenergic differentation of sympathetic neurons. Eur J Biochem 267: 6976-6981, 2000.

71. Ernsberger $\mathbf{U}$ and Rohrer $\mathbf{H}$. The development of the noradrenergic transmitter phenotype in postganglionic sympathetic neurons. Neurochem Res 21: 823-829, 1996.

72. Esler M, Lambert G, and Jennings G. Increased regional sympathetic nervous activity in human hypertension: causes and consequences. J Hypertension 8: S53-S57, 1990. 
73. Falckh PH, Harkin LA, and Head RJ. Nerve growth factor mRNA content parallels altered sympathetic innervation in the spontaneously hypertensive rat. Clin Exp Pharmacol Physiol 19 (8): 541-545, 1992.

74. Falckh PH, Harkin LA, and Head R.J. Resistance vessel gene expression of nerve growth factor is elevated in young spontaneously hypertensive rats. J Hypertension 10: 913-918, 1992.

75. Fall CHD, Osmond C, Barker DJP, Clark PMS, Hales CN, Stirling Y, and Meade TW. Fetal and infant growth and cardiovascular risk factors in women. Br Med J310: 428-432, 1995.

76. Fall CHD, Vijayakumar M, Barker DJP, Osmond C, and Duggleby S. Weight in infancy and prevalence of coronary heart disease in adult life. Br Med J 310: 17-20, 1995.

77. Falloon BJ, Bund SJ, Tulip JR, and Heagerty AM. In vitro perfusion studies of resistance artery function in genetic hypertension. Hypertension 22: 486-495, 1993.

78. Feletou $\mathbf{M}$ and Vanhoutte PM. Endothelium-derived hyperpolarizing factor. Clin Exp Pharmacol Physiol 23: 1082-1090, 1996.

79. Finkler MS, Van Orman JB, and Sotherland PR. Experimental manipulation of egg quality in chickens: influence of albumen and yolk on the size and body composition of near-term embryos in a precocial bird. J Comp Physiol 168: 17-24, 1998.

80. Flanagan DE, Vaile JC, Petley GW, Moore VM, Godsland IF, Cockington RA, Robinson JS, and Philips DI. The autonomic control of heart rate and insulin resistance in young adults. $J$ Clin Endocrin Metab 84: 1263-1267, 1999.

81. Folkow B. Structure and function of the arteries in hypertension. Am Heart J 114: 938-948, 1987.

82. Forrester TE, Wilks RJ, Bennett FI, Simeon D, Osmond C, Allen M, Chung AP, and Scott P. Fetal growth and cardiovascular risk factors in Jamaican schoolchildren. Br Med J 312: 156$160,1996$.

83. Forsdahl A. Are poor living conditions in childhood and adolescence an important risk factor for arteriosclerotic heart disease? Br J Prev Soc Med 31: 91-95, 1977.

84. Fowden AL and Forhead AJ. The role of hormones in intrauterine development. Eds.: Barker DJP. in: Fetal origins of cardiovascular and lung disease. Marcel Dekker Inc. New York, Basel. 2001. pp. 199-228.

85. Fowden AL and Silver $\mathbf{M}$. The effects of thyroid hormones on oxygen and glucose metabolism in the sheep fetus during late gestation. $J$ Physiol 482: 203-213, 1995.

86. Fowden AL, Szemere J, Hughes P, and Gilmour RS. The effects of cortisol on the growth rate of the sheep fetus during late gestation. J Endocrinol 151: 97-105, 1996.

87. Francis N, Farinas I, Brennan C, Rivas-Plata K, Backus C, Reichardt L, and Landis S. NT3. like NGF, is required for survival of sympathetic neurons, but not their precursors. Devel Biol 210: 411-427, 1999.

88. Francis NJ and Landis SC. Cellular and molecular determinants of sympathetic neuron development. Anmu Rev Neurosci 22: 541-566, 1999.

89. Fritsche R, Schwerte T, and Pelster B. Nitric oxide and vascular reactivity in developing zebrafish. Am J Physiol 279: R2200-R2207, 2000.

90. Fujii K, Tominaga M, Ohmori S, Kobayashi K, Koga T, Takata Y, and Fujishima M. Decreased endothelium-dependent hyperpolarization to acetylcholine in smooth muscle of the mesenteric artery of spontaneously hypertensive rats. Circ Res 70: 660-669, 1992.

91. Gardner DS, Jackson AA, and Langley-Evans SC. Maintenance of maternal diet-induced hypertension in the rat is dependent on glucocorticoids. Hypertension 30: 1525-1530, 1997.

92. Gennser G, Rymark P, and Isberg PE. Low birth weight and risk of high blood pressure in adulthood. Br Med J 296: 1498-1499, 1988.

93. Gheorghiade $\mathbf{M}$ and Bonow RO. Chronic heart failure in the United States. A manifestation of coronary heart disease. Circulation 97: 282-289, 1998.

94. Girard H. Adrenergic sensitivity of circulation in the chick embryo. Am J Physiol 224: 461-469, 1973.

95. Giussani DA, MeGarrigle HHG, Spencer JAD, Moore PJ, Bennet L, and Hanson MA. Effect of carotid denervation on plasma vasopressin levels during acute hypoxia in the lategestation sheep fetus. J Physiol 477.1: 81-87, 1994.

96. Giussani DA, Philips PS, Anstee S, and Barker D.J. Effects of altitude versus economic status on birth weight and body shape at birth. Pediatr Res 49: 490-494, 2001. 
97. Giussani DA, Riquelme RA, Moraga FA, MeGarrigle HGH, Gaete CR, Sanhueza EM, Hanson MA, and Llanos A.J. Chemoreflex and endocrine components of the cardiovascular responses to acute hypoxaemia in the llama fetus. Am J Physiol 271: R73-R83, 1996.

98. Giussani DA, Riquelme RA, Sanhueza EM, Hanson MA, Blance CE, and Lanos A.J. Adrenergic and vasopressinergic contributions to the cardiovascular response to acute hypoxaemia in the llama fetus. J Physiol 515: 233-241, 1999.

99. Giussani DA, Spencer JAD, Moore PJ, Bennet L, and Hanson MA. Afferent and efferent components of the cardiovascular reflex responses to acute hypoxia in the term fetal sheep. $J$ Physiol 461: 431-449, 1993.

100. Godfrey KM and Barker DJP. Fetal nutrition and adult disease. Am J Clin Nutr 71: 1344S1352S, 2000.

101. Goldstein RS, Avivi C, and Geffen R. In vivo NGF treatment increases proliferation in the primary sympathetic ganglia of chick embryos. Devel Biol 181: 116-120, 1997.

102. Goodfellow J, Bellamy MF, Gorman ST, Brownlee M, Ramsey MW, Lewis MJ, Davies DP, and Henderson AH. Endothelial function is impaired in fit young adults of low birth weight. Candiovase Res 40: 600-606, 1998.

103. Green L.R. Programming of endocrine mechanisms of the cardiovascular control and growth. $J$ Soc Gynecol Invest 8: 57-68, 2001.

104. Green LR, Kawagoe Y, Fraser M, Challis JRG, and Richardson BS. Activation of the hypothalamic-pituitary-adrenal axis with repetitive umbilical cord occlusion. J Soc Gynecol Imvest 7: 224-232, 2000.

105. Green LR, MeGarrigle HHG, Bennet L, and Hanson MA. Angiotensin II and cardiovascular chemoreflex responses to acute hypoxia in late gestation fetal sheep. $J$ Physiol 507.3: 857-867, 1998.

106. Gunnell D, Smith GD, MeConnachie A, Greenwood R, Upton M, and Frankel S. Separating in-utero and postnatal influences on later disease. Lancet 354: 1526-1527, 1999.

107. Gupta PP and Grewal GS. Spontaneous aortic atherosclerosis in chicken. Indian J Med Res 71: 410-415, 1980.

108. Hallbook F, Backstrom A, Kullander K, Kylberg A, Williams R, and Ebendal T. Neurotrophins and their receptors in chicken neuronal development. Int J Dev Biol 39: 855-868, 1995.

109. Han VKM. Pathophysiology, cellular and molecular mechanisms of foetal growth retardation. Equine Vet J Suppl 14: 12-16, 1993.

110. Harding $\mathbf{J E}$. The nutritional basis of the fetal origins of adult disease. Int J Epidemiol 30: 15-23, 2001.

111. Harding JE and Gluckman PD. Growth, metabolic, and endocrine adaptations to fetal undernutrition. Eds.: Barker DJP. in: Fetal origins of cardiovascular and lung disease. Marcel Dekker, Inc. New York - Basel. 2001. pp. 181-197.

112. Harding JE, Liu L, Evans PC, and Gluckman PD. Insulin-like growth factor 1 alters fetoplacental protein and carbohydrate metabolism in fetal sheep. Endocrinology 124: 1509-1514, 1994.

113. Harris AP, Helou S, Gleason CA, Traystan RJ, and Koehler RC. Fetal and peripheral circulatory responses to hypoxia after nitric oxide synthase inhibition. Am J Physiol 281: R.381. R390, 2001.

114. Hasegawa $\mathbf{K}$ and Nishimura $\mathbf{H}$. Humoral factor mediates acetylcholine-induced endotheliumdependent relaxation of the chicken aorta. Gen Comp Endocrinol 84: 164-169, 1991.

115. Hawkins P, Steyn C, MeGarrigle HHG, Saito T, Ozaki T, Stratford L., Noakes DE, and Hanson MA. Effect of maternal nutrient restriction in early gestation on development of the hypothalamo-pituitary-adrenal axis in fetal sheep at 0.8-0.9 of gestation. $J$ Endocrinol 163: 553561, 1999.

116. Head R.J. Hypernoradrenergic innervation: its relationship to functional and hyperplastic changes in the vasculature of the spontaneously hypertensive rat. Blood Vessels 26: 1-20, 1989.

117. Head RJ. Hypernoradrenergic innervation and vascular smooth muscle hyperplastic change. Blood Vessels 28: 173-178, 1991.

118. Head RJ, Cassis LA, Barone S, Stitzel RE, and De la Lande IS. Neuronal deamination of the endogeneous and exogeneous noradrenaline in the mesenteric artery of the spontaneously hypertensive rat. J Pharm Pharmacol 36: 382-385, 1984. 
119. Higgins D and Pappano AJ. Development of transmitter secretory mechanisms by adrenergic neurons in the embryonic chick heart ventricle. Devel Biol 87: 148-162, 1981.

120. Hill DJ and Han VKM. The role of growth factors in tissue development. Eds.: Harding R and Bocking AD. in: Fetal Growth and development. University Press. Cambridge. 2001. pp. 279 283.

121. Hill WL. Importance of prenatal nutrition to the development of a precocial chick. Dev Psychobiol 26: 237-249, 1993.

122. Hinchliffe SA, Lynch MRJ, Sargent PH, Howard CV, and van Velzen D. The effect of intrauterine growth retardation on the development of renal nephrons. Br J Obst Gyn 99: 296$301,1992$.

123. Hoet JJ and Hanson MA. Intrauterine nutrition: its importance during critical periods for cardiovascular and endocrine development. J Physiol 514.3: 617-627, 1999.

124. Holemans K, Gerber R, Meurrens K, De Clerck F, Poston L, and Van Assche FA. Maternal food restriction in the second half of pregnancy affects vascular function but not blood pressure of rat female offspring. Br J Nutrition 81: 73-79, 1999.

125. Holtz $\mathbf{J}$ and Goetz RM. The endothelium and the renin-angiotensin system. Drug Res 44: 397 402, 1994.

126. Hungerford JE and Little CD. Developmental biology of the vascular smooth muscle cell: building a multilayered vessel wall. $J$ Vasc Res 36: 2-27, 1999.

127. Hypponen E, Leon DA, Kenward MG, and Lithell $\mathbf{H}$. Prenatal growth and the risk of occlusive and haemorrhagic stroke in Swedish men and women born 1915-29: historical cohort study. Br Med J 323: 1033-1034, 2001.

128. Intengan HD and Schiffrin EL. Vascular remodeling in hypertension. Roles of apoptosis, inflammation, and fibrosis. Hypertension 38: 581-587, 2001.

129. Iwamoto HS and Rudolph AM. Effects of endogenous angiotensin II on the fetal circulation. $J$ Develop Physiol 1: 283-293, 1979.

130. Jacobs R, Robinson JS, Owens JA, Falconer J, and Webster MED. The effect of prolonged hypobaric hypoxia on growth of fetal sheep. J Develop Physiol 10: 97-112, 1988.

131. Jameson M, Dai X, Luscher T, Skopec J, Diederich A, and Diederich D. Endotheliumderived contracting factors in resistance arteries of young spontaneously hypertensive rats before development of overt hypertension. Hypertension 21: 280-288, 1993.

132. Jansson $\mathbf{T}$ and Lambert $\mathbf{G W}$. Effect of intrauterine growth restriction on blood pressure, glucose tolerance and sympathetic nervous system activity in the rat at 3-4 months of age. $J$ Hypertension 17: 1239-1248, 1999.

133. Jensen GM and Moore LG. The effect of high altitude and other risk factors on birth weight: independent or interactive effects? Am J Public Health 87: 1003-1007, 1997.

134. Johnson AL. Reproduction in the female. Eds.: Whittow GC. in: Avian Physiology. Academic Press. San Diego. 2000. pp. 569-596.

135. Joseph KS and Kramer MS. Review of the evidence on fetal and early childhood antecendents of adult chronic disease. Epidemiol Rev 18: 158-174, 1996.

136. Julius $\mathbf{S}$ and Valentini $\mathbf{M}$. Consequences of the increased autonomic nervous drive in hypertension, heart failure and diabetes. Blood Pressure 7: 5-13, 1998.

137. Kamimura K, Nishimura H, and Bailey JR. Blockade of beta-adrenoceptor in control of blood pressure in fowl. Am J Physiol 269: R914-922, 1995.

138. Kamitomo M, Alonso JG, Okai T, Longo LD, and Gilbert RD. Effects of long-term, highaltitude hypoxemia on ovine fetal cardiac output and blood flow redistribution. Am J Obstet Gynecol 169: 701-707, 1993.

139. Kannel WB. Elevated systolic blood pressure as a cardiovascular risk factor. Am J Cardiol 85: 251-255, 2000.

140. Kempf H, Linares C, Corcol P, and Gase JM. Pharmacological inactivation of the endothelin type A receptor in the early chick embryo: a model of mispatteming of the brachial arch derivatives. Development 125: 4931-4941, 1998.

141. Kermack WO, MeKendrick AG, and MeKinlay PL. Death-rates in Great Britain and Sweden. Lancet 31 March: 698-703, 1934.

142. Kitazono T, Faraci FM, and Heistad DD. L-Arginine restores vasodilator responses of the basilar artery to acetylcholine during chronic hypertension. Hypertension 27: 893-896, 1996. 
143. Kliegman RM. Intrauterine growth retardation. Eds.: Fanaroff AA and Martin RU. in: Neonatalperinatal medicine. Diseases of the fetus and infant. Mosby-Yearbook inc. St. Louis, 1997. pp. 203-240.

144. Kobayashi M and Matsuoka L. Enhancement of sympathetic neuron survival by synergistic action of NT3 and GDNF. Neuroreport 11: 2541-2545, 2000.

145. Korner PJ and Angus JA. Structural determinants of vascular resistance properties in hypertension. Hemodynamic and model analysis. J Vase Res 29: 293-312, 1992.

146. Koupilova I, Leon DA, and Vagero D. Can confounding by sociodemographic and behavioural factors explain the association between size at birth and blood pressure at age 50 in Sweden? J Epidemiol Community Health 51: 14-18, 1997.

147. Lagercrantz H. Sympathoadrenal mechanisms during development. Eds.: Polin RA and Fox WW. in: Fetal and neonatal physiology. Saunders. Philadelphia. 1998. pp. 220-225.

148. Langer SZ. Presynaptic regulation of the release of catecholamines. Pharmacol Rev 32: 337 $362,1980$.

149. Langille BL. Remodeling of developing and mature arteries: endothelium, smooth muscle, and matrix. J Cardiovase Pharmacol 21: S11-S17, 1993.

150. Langille BL. Arterial remodeling: relation to hemodynamies. Can J Phosiol Pharmacol 74: 834. $841,1996$.

151. Langille BL, Brownlee RD, and Adamson SL. Perinatal aortic growth in lambs: relation to blood flow changes at birth. Am J Physiol 259: H1247-H1253, 1990.

152. Langley-Evans SC, Gardner DS, and Jackson AA. Association of disproportionate growth of fetal rats in late gestation with raised systolic blood pressure in later life. $J$ Reprod Fert 106: 307-312, 1996.

153. Langley-Evans SC, Gardner DS, and Welham SJM. Intrauterine programming of cardiovascular disease by matemal nutritional status. Nutrition 14:39-47, 1998.

154. Langley-Evans SC and Jackson AA. Captopril normalises systolic blood pressure in rats with hypertension induced by fetal exposure to maternal low protein diets. Comp Biochem Physiol 110: 223-228, 1995.

155. Langley-Evans SC, Welham S.JM, and Jackson AA. Fetal exposure to a maternal low protein diet impairs nephrogenesis and promotes hypertension in the rat. Life Sci 64: 965-974, 1999.

156. Laor A, Stevenson DK, Shemer J, Gale R, and Seidman DS. Size at birth, maternal nutritional status in pregnancy, and blood pressure at age 17: population based analysis. $\mathrm{Br}$ Med J 315: 449. 453, 1997.

157. Launer LJ, Hofman A, and Grobbee DE. Relation between birth weight and blood pressure: longitudinal study of infants and children. Br Med J 307: 1451-1454, 1993.

158. Law CM, Egger P, Dada O, Delgado H, Kylberg E, Lavin P, Tang GH, Von Hertzen H, Shiell AW, and Barker DJP. Body size at birth and blood pressure among children in developing countries. Int J Epidemiol 29: 52-59, 2000.

159. Law CM and Shiell AW. Is blood pressure inversely related to birth weight? The strength of evidence from a systematic review of the literature. J Hypertension 14: 935-941, 1996.

160. Learmont JG and Poston L. Nitric oxide is involved in flow-induced dilation of isolated human small fetoplacental arteries. Am J Obstet Gynecol 174: 583-588, 1996.

161. Lee RMKW. Vascular changes at the prehypertensive phase in the mesenteric arteries from SHR. Blood Vessels 22: 105-126, 1985.

162. Lee RMKW, Borkowski KR, Leenen FHH, Tsoporis J, and Coughlin MD. Interaction between sympathetic nervous system and adrenal medulla in the control of cardiovascular changes in hypertension. J Cardiovase Pharmacol 17: S114-\$116, 1991.

163. Lee RMKW, Triggle CR, Cheung DWT, and Coughlin MD. Structural and functional consequences of neonatal sympathectomy on the blood vessels of spontaneously hypertensive rats. Hypertension 10: 328-338, 1987.

164. Leeson CPM, Whincup PH, Cook DG, Donald AE, Papacesta O, Lucas FRCP, and Deanfield JE. Flow-mediated dilation in 9- to 11-year-old children. The influence of intrauterine and childhood factors. Circulation 96: 2233-2238, 1997.

165. Leger J, Oury F, Moel M, Baron S, Benali K, Blot P, and Czernichow P. Growth factors and intrauterine growth retardation. I serum growth hormone, insulin-like growth factor (IGF)-I, IGF-II, and IGF-binding protein 3 levels in normally grown and growth retarded human fetuses during the second half of gestation. Pediatr Res 40: 94-100, 1996. 
166. Leistikow EA. Is coronary artery disease initiated perinatally? Sem Thromb Hemost 24: 139143, 1998.

167. Le Noble FAC, Hekking JWM, Van Straaten HWM, Slaaf DW, and Struijker Boudier HAJ. Angiotensin II stimulates angiogenesis in the chorio-allantoic membrane of the chick embryo. Eur J Pharmacol 195: 305-306, 1991.

168. Leon DA and Koupilova I. Birth weight, blood pressure, and hypertension: epidemiological studies. Eds.: Barker DJP. in: Fetal origins of cardiovascular and lung disease. Marcel Dekker, Inc. New York. 2001. pp. 23-48.

169. Leon DA, Koupilova I, Lithell HO, Berglund L, Mohsen R, Vagero D, Lithell U, and MeKeigue PM. Failure to realise growth potential in utero and adult obesity in relation to blood pressure in 50 year old Swedish men. Br Med J 312: 401-406, 1996.

170. Lesage J, Blondeau B, Grino M, Breant B, and Dupouy JP. Maternal undernutrition during late gestation induces fetal overexposure to glucocorticoids and intrauterine growth retardation, and disturbs the hypothalamo-pituitary adrenal axis in the newborn rat. Endocrinology 142: 1692-1702, 2001.

171. Levi-Montalcini, R. The nerve growth factor 35 years later. Science 237: 1154-1162, 1987.

172. Levitt NS, Steyn K, De Wet T, Morrell C, Edwards R, Ellison GTH, and Cameron N. An inverse relation between blood pressure and birth weight among 5 year old children from Soweto, South Africa. J Epidemiol Community Health 53: 264-268, 1999.

173. Li DY, Brooke B, Davis EC, Mecham RP, Sorensen LK, Boak BB, Eichwald E, and Keating MT. Elastin is an essential determinant of arterial morphogenesis. Nature 393: 276-280, 1998.

174. Lindahl P, Hellström M, Kalén M, and Betsholtz C. Endothelial-perivascular cell signaling in vascular development: lessons from knockout mice. Curr Opin Lipidol 9: 407-411, 1998.

175. Lindsay RS, Lindsay RM, Edwards CRW, and Seckl JR. Inhibition of $11 \beta$-hydroxysteroid dehydrogenase in pregnant rats and the programming of blood pressure in the offspring. Hypertension 27: 1200-1204, 1996.

176. Lithell HO, MeKeigue PM, Berglund L, Mohsen R, Lithell U, and Leon DA. Relation of size at birth to non-insulin dependent diabetes and insulin concentrations in men aged 50-60 years. $\mathrm{Br}$ Med J 312: 406-410, 1996.

177. Liu JP, Baker J, Perkins AS, Robertson J, and Efstratiadis A. Mice carrying null mutations of the genes encoding insulin-like growth factor 1 (IGF-1) and type IGF receptor (IGF1r). Cell 75: 59-72, 1993.

178. Longo LD and Pearce WJ. High altitude, hypoxic-induced modulation of noradrenergicmediated responses in fetal and adult cerebral arteries. Comp Biochem Physiol 119A: 683-694, 1998.

179. Loos R.JF, Fagard R, Beunen G, Derom C, and Vlietinck R. Birth weight and blood pressure in young adults. A prospective twin study. Circulation 104: 1633-1638, 2001.

180. Louey S, Cock ML, Stevenson KM, and Harding R. Placental insufficiency and fetal growth restriction lead to postnatal hypotension and altered postnatal growth in sheep. Pediatr Res 48: 808-814, 2000.

181. Luff SE. Ultrastructure of sympathetic axons and their structural relationship with vascular smooth muscle. Anat Embryol 193: 515-531. 1996.

182. Lumbers ER, Yu Z, and Gibson K. The selfish brain and the Barker hypothesis. Clin Exp Pharmacol Physiol 28: 952-956, 2001.

183. Luscher TF. Imbalance of endothelium-derived relaxing and contracting factors. A new concept in hypertension? Am J Hypertension 3: 317-330, 1990.

184. Luscher TF. The endothelium as a target and mediator of cardiovascular disease. Eur J Clin Imvest 23: 670-685, 1993.

185. Malek AM and Izume S. Molecular aspects of signal transduction of shear stress in the endothelial cell. J Hypertension 12: 989-999. 1994.

186. Mancia G, Grassi G, Giannattasio C, and Seravalle G. Sympathetic activation in the pathogenesis of hypertension and progression of organ damage. Hypertension 34: 724-728. 1999.

187. Martin H, Hu J, Gennser G, and Norman M. Impaired endothelial function and increased carotid stiffness in 9-year-old children with low birth weight. Circulation 102: 2739-2744, 2000. 
188. Martinez-Lemus LA, Hester RK, Becker E, Jeffrey JS, and Odom TW. Pulmonary artery endothelium-dependent vasodilation is impaired in a chicken model of pulmonary hypertension. Am J Physiol 277: R190-R197, 1999.

189. Martyn CN, Barker DJP, Jespersen S, Greenwald S, Osmend C, and Berry C. Growth in utero, adult blood pressure, and arterial compliance. $\mathrm{Br}$ Heart J 73: 116-121, 1995.

190. Martyn CN, Barker DJP, and Osmond C. Mothers' pelvic size, fetal growth, and death from stroke and coronary heart disease. Lancet 348: 1264-1268, 1996.

191. Martyn CN and Greenwald SE. Impaired synthesis of elastin in walls of aorta and large conduit arteries during early development as an initiating event in pathogenesis of systemic hypertension. Lancet 350: 953-955, 1997.

192. Mather K, Anderson TJ, and Verma S. Insulin action in the vasculature: physiology and pathophysiology. J Vase Res 38: 415-422, 2001.

193. Mathews F, Yudkin P, and Neil A. Influence of matemal nutrition on outcome of pregnancy: prospective cohort study. $\mathrm{Br}$ Med J 319: 339-343, 1999.

194. Matthes JWA, Lewis PA, Davies DP, and Bethel JA. Relation between birth weight at term and systolic blood pressure in adolescence. Br Med J 308: 1074-1077, 1994.

195. MeCullough RE, Reeves $\mathbf{J T}$, and Liljegren RL. Fetal growth retardation and increased infant mortality at high altitude. Arch Emvinon Health 32: 36-39, 1977.

196. MeCutcheon IE, Metcalfe J, Metzenberg AB, and Ettinger T. Organ growth in hyperoxic and hypoxic chick embryos. Resp Physiol 50: 153-163, 1982.

197. Mecham RP, Stenmark KR, and Parks WC. Connective tissue production by vascular smooth muscle in development and disease. Chest 99: 43S-47S, 1991.

198. Melander O, Mattiasson I, Marsal K, Groop L, and Hulthen U. Heredity for hypertension influences intra-uterine growth and the relation between fetal growth and adult blood pressure. $J$ Hypertension 17: 1557-1561, 1999.

199. Merlet-Benichou C, Gilbert T, Muffat-Joly M, Lelievre-Pegorier M, and Leroy B. Intrauterine growth retardation leads to a permanent nephron deficit in the rat. Pediatr Nephrol 8: 175-180, 1994.

200. Metcalfe $\mathbf{J}$ and Stock MK. Current topic: oxygen exchange in the chorioallantoic membrane. avian homologue of the mammalian placenta. Placenta 14: 605-613, 1993.

201. Milner RDG and Gluckman PD. The regulation of growth. Eds.: Harding R and Bocking AD. in: Fetal growth and development. University Press. Cambridge. 2001. pp. 284-289.

202. Mirlesse V, Frankenne F, Alsat E, Poncelet M, Hennen G, and Evain-Brion D. Placental growh hormone levels in normal pregnancy and in pregnancies with intrauterine growh retardation. Pediatr Res 34: 439-442, 1993.

203. Mogren I, Hogberg U, Stegmayr B, Lindahl B, and Stenlund H. Fetal exposure, heredity and risk indicators for cardiovascular disease in a Swedish welfare cohort. Int J Epidemiol 30: 853862, 2001.

204. Mombouli JV and Vanhoutte PM. Endothelial dysfunction: from physiology to therapy. $J$ Mol Cell Cardiol 31: 61-74, 1999.

205. Moncada $\mathbf{S}$ and Higgs EA. Endogenous nitric oxide: physiology, pathology and clinical relevance. Eur J Clin Invest 21: 361-374, 1991.

206. Monk CS, Webb SJ, and Nelson CA. Prenatal neurobiological development: molecular mechanisms and anatomical change. Dev Neuropsychol 19: 211-236, 2001.

207. Moore VM, Cockington RA, Ryan P, and Robinson JS. The relationship between birth weight and blood pressure amplifies from childhood to adulthood. J Hypertension 17: 883-888, 1999.

208. Moss TJM, Sloboda DM, Gurrin LC, Harding R, Challis JRG, and Newnham JP. Programming effects in sheep of prenatal growh restriction and glucocorticoid exposure. Am J Physiol 281: R960-R970, 2001.

209. Mulder ALM, Van Golde JMCG, Van Goor AAC, Giussani DA, and Blanco CE. Developmental changes in plasma catecholamine concentrations during normoxia and acute hypoxia in the chick embryo. J Physiol 527.3: 593-599, 2000.

210. Mulder ALM, van Goor CA, Giussani DA, and Blance CE. $\alpha$-Adrenergic contribution to the cardiovascular response to acute hypoxia in the chick embryo. Am J Physiol 281: R2004-R2010. 2001 . 
211. Mulder ALM, Miedema A, de Mey JGR, Giussani DA, and Blanco CE. Sympathetic control of the cardiovascular response to acute hypoxemia in the chick embryo. Am J Physiol 282: R1156-R1163, 2002.

212. Mulder TLM, Van Golde JC, Prinzen FW, and Blanco CE. Cardiac output distribution in the chick embryo from stage 36 to 45 . Cardiovasc Res 34: 525-528, 1997.

213. Muramatsu T, Hiramoto K, Koshi N, Okumura J, Miyoshi S, and Mitsumoto T. Importance of albumen content in whole body protein synthesis of the chick embryo during incubation. $\mathrm{Br}$ Poultry Science 31: 101-106, 1990.

214. Murotsuki J, Bocking AD, and Gagnon R. Fetal heart rate patterns in growth-restricted sheep induced by chronic fetal placental embolization. Am JObstet Gynecol 176: 282-290, 1997.

215. Nakamura H. Electron microscopic study of the prenatal development of the thoracic aorta in rat. Am J Anat 181: 406-418, 1988.

216. Nakazawa M, Miyagawa S, Ohno T, Miura S, and Tkao A. Developmental hemodynamic changes in rat embryos at 11 to 15 days of gestation: normal data of blood pressure and the effect of caffeine compared to data from chick embryo. Pediatr Res 23: 200-205, 1988.

217. Nishimura H, Nakamura Y, Taylor AA, and Madey MA. Renin-angiotensin and adrenergic mechanisms in control of blood pressure in fowl. Hypertension 3: I41-I49, 1981.

218. Oettgen P. Transcriptional regulation of vascular development. Circ Res 89: 380-388, 2001.

219. Ogut $O$ and Brozovich FV. Determinants of the contractile properties in the embryonic chicken gizzard and aorta. Am J Physiol 279: C1722-C1732, 2000.

220. Ong K, Kratzsch J, Kiess W, Alspac Study Team, Costello M, Scott C, and Dunger D. Size at birth and cord blood levels of insulin, insulin-like growth factor I (IGF-I), IGF-II, IGF-binding protein-1 (IGFBP-1), IGFBP-3, and the soluble IGF-II/Mannose-6-phosphate receptor in term human infants. J Clin Endocrin Metab 85: 4266-4269, 2000.

221. Osmond $\mathbf{C}$ and Barker D.JP. Fetal, infant, and childhood growth are predictors of coronory heart disease, diabetes, and hypertension in adult men and women. Environ Health Perspect 108 suppl 3: 545-563, 2000.

222. Owens GK. Regulation of differentiation of vascular smooth muscle cells. Physiol Rev 75: 487517, 1995.

223. Owens JA, Falconer J, and Robinson JS. Effect of restriction of placental growth on fetal and utero-placental metabolism. J Develop Physiol 9: 225-238, 1987.

224. Oyama K, Padbury J, Chappell B, Martinez A, Stein H, and Humme J. Single umblical artery ligation-induced fetal growth retardation: effect on postnatal adaptation. Am J Physiol 263: E575-E583, 1992.

225. Ozaki T, Nishina H, Hanson MA, and Poston L. Dietary restriction in pregnant rats causes gender-related hypertension and vascular dysfunction in offspring. $J$ Physiol 530.1: 141-152, 2001.

226. Panza JA, Casino PR, Badar DM, and Quyyumi AA. Effect of increased availability of endothelium-derived nitric oxide precursor on endothelium-dependent vascular relaxation in normal subjects and in patients with essential hypertension. Circulation 87: 1475-1481, 1993.

227. Pappano AJ and Loeffelholz K. Ontogenesis of adrenergic and cholinergic neuroeffector transmission in chick embryo heart. J Pharmacol Exp Therap 191: 468-478, 1974.

228. Pardi G, Buscaglia M, Ferrazzi E, Bozzetti P, Marconi A, Cetin I, Battaglia FC, and Makowski EL. Cord sampling for the evaluation of oxygenation and acid-base balance in growth-retarded human fetuses. Am JObstet Gynecol 157: 1221-1228, 1987.

229. Pearce WJ, Duckles SP, and Buchhok J. Effects of maturation on adrenergic neurotransmission in ovine cerebral arteries. Am J Physiol 277: R931-R937, 1999.

230. Perez R, Espinoza M, Riquelme R, Parer J, and Llanos A.J. Arginine vasopressin mediates cardiovascular responses to hypoxemia in fetal sheep. Am J Physiol 256: R1011-R1018, 1989.

231. Phillips DIW. Fetal growth and programming of the hypothalamic-pituitary-adrenal axis. Clin Exp Pharmacol Physiol 28: 967-970, 2001.

232. Phillips DIW and Barker DJP. Association between low birth weight and high resting pulse in adult life: is the sympathetic nervous system involved in programming the insulin resistance syndrome? Diabet Med 14: 673-677, 1997.

233. Phillips DIW, Walker BR, Reynolds RM, Flanagan DEH, Wood PJ, Osmond C, Barker D.JP, and Whorwoed CB. Low birth weight predicts elevated plasma cortisol concentrations in adults from 3 populations. Hypertension 35: 1301-1306, 2000. 
234. Ploucha JM and Ringer $\mathbf{R}$. Vascular response of the chicken hindlimb to vasoactive agents, asphyxia, and exercise. Can J Physiol Pharmacol 59: 1228-1233, 1981.

235. Poelmann RE, Gittenberger-de Groot AC, Mentink MMT, Bokenkamp R, and Hogers B. Development of the cardiac coronary vascular endothelium, studied with anti-endothelial antibodies, in chicken-quail chimeras. Circ Res 73: 559-568, 1993.

236. Pohl U. Large arterioles in the control of blood flow: role of endothelium-dependent dilation. Acta Physiol Scand 168: 505-510, 2000.

237. Poulter NR, Chang CL, MacGregor AJ, Snieder H, and Spector TD. Association between birth weight and adult blood pressure in twins: historical cohort study. Br Med J 319: 1330-1333, 1999 .

238. Pourageaud $\mathbf{F}$ and Freslon $\mathrm{JL}$. Impaired endothelial relaxations induced by agonists and flow in spontaneously hypertensive rat compared to Wistar-Kyoto perfused coronary arteries. $J$ Vase Res 32: 190-199, 1995.

239. Prewitt RL, Chen IIH, and Dowell R. Development of microvascular rarefaction in the spontaneously hypertensive rat. Am J Physiol 243: H243-H251, 1982.

240. Qin Z-L and Nishimura $\mathbf{H}$. $\mathrm{Ca}^{2+}$ signaling in fowl aortic smooth muscle increases during maturation but is impaired in neointimal plaques. J Exp Biol 201: 1695-1705, 1998.

241. Radaelli A, Mircoli L, Mori I, Mancia G, and Ferrari AU. Nitric oxide-dependent vasodilation in young spontaneously hypertensive rats. Hypertension 32: 735-739, 1998.

242. Raff $\mathrm{H}$ and Wood CE. Effect of age and blood pressure on the heart rate, vasopressin, and renin response to hypoxia in fetal sheep. Am J Physiol 263: R880-R884, 1992.

243. Ramirez-Ordinez $\mathbf{R}$, Barreto-Estrada $\mathbf{J}$, and Garcia-Arraras $\mathbf{J E}$. Growth factors effects on the expression of morphological and biochemical properties of avian embryonic sympathetic cells. Emphasis on NGF. Developmental Brain Research 114: 27-36, 1999.

244. Rasmussen KM. The fetal origins hypothesis: challenge and opportunities for maternal and child nutrition. Anmu Rev Nutr 21: 73-95, 2001.

245. Rees $\mathbf{S}$ and Walker $\mathbf{D}$. Nervous and neuromuscular systems. Eds.: Harding $\mathbf{R}$ and Bocking $\mathbf{A D}$. in: Fetal growth and development. University Press. Cambridge. 2001. pp. 154-184.

246. Reitsma JB, Dalstra JAA, Bonsel GJ, van der Meulen JHP, Koster RW, Gunning-Schepers LJ, and Tijssen JGP. Cardiovascular disease in the Netherlands, 1975-1999: decline in mortality, but increasing numbers of patients with chronic conditions. Heart 82: 52-60, 1999.

247. Reller MD, Burson MA, Lohr JL, Morton M.J, and Thornburg KL. Nitric oxide is an important determinant of coronary flow at rest and during hypoxaemic stress in fetal lambs. $\mathrm{Am} \mathrm{J}$ Physiol 269: H2074-H2081, 1995.

248. Riccio A, Ahn S, Davenport CM, Blendy JA, and Ginty DD. Mediation by a CREB family transcription factor of NGF-dependent survival of sympathetic neurons. Science 286: 2358-2361. 1999.

249. Rich-Edwards JW, Stampfer MJ, Manson JE, Rosner B, Hankinson SE, Colditz GA, Hennekens CH, and Willet WC. Birth weight and risk of cardiovascular disease in a cohort of women followed up since 1976. Br Med J 315: 396-400, 1997.

250. Risau W. Development and differentiation of endothelium. Kidney Int 54: S3-S6, 1998.

251. Robinson JS, Kingston EJ, Jones CT, and Thornburn GD. Studies on experimental growth retardation in sheep. The effect of removal of endometrial caruncles on fetal size and metabolism. J Develop Physiol 1: 379-398, 1979.

252. Robinson JS and Owens JA. Pathophysiology of intrauterine growth failure. Eds: Gluckman PD and Heymann MA. in: Pediatrics \& perinatology, the scientific basis. Amold, Hodder Headline group. London. 1996. pp. 290-297.

253. Romanoff AL. The extraembryonic membranes. Eds.: Romanoff AL. in: The avian embryo: structural and functional development. The Macmillan Company. New York. 1960. pp. 1039. 1140.

254. Roseboom TJ, van der Meulen JHP, Osmond C, Barker DJP, Ravelli ACJ, SchroederTanka JM, van Montfrans GA, Michels RPJ, and Bleker OP. Coronary heart disease after prenatal exposure to the Dutch famine, 1944-45. Heart J84: 595-598, 2000.

255. Roseboem TJ, van der Meulen JHP, Ravelli ACJ, Osmond C, Barker DJP, and Bleker OP. Effects of prenatal exposure to the Dutch famine on adult disease in later life: an overview. Mol Cell Endocrinol 185: 93-98, 2001. 
256. Rouwet EV, De Mey JGR, Slaaf DW, Heineman E, Ramsay G, and Le Noble FAC. Development of vasomotor responses in fetal mesenteric arteries. Am J Physiol 279 (3): H1097H1105, 2000.

257. Rubanyi GM and Polokoff MA. Endothelins: molecular biology, biochemistry, pharmacology, physiology, and pathophysiology. Pharm Rev 46: 325-415, 1994.

258. Sadler TW. Langman's medical embryology. Baltimore. The Williams \& Wilkins Company. 1988.

259. Safar ME, Girerd $\mathbf{X}$, and Laurent $\mathbf{S}$. Structural changes of large conduit arteries in hypertension. J Hypertension 14: 545-555, 1996.

260. Salafia CM. Placental pathology of fetal growth restriction. Obstet Gynecol 40: 740-749, 1997.

261. Schiffers PMH, Fazzi GE, Janssen GMJ, Uitendaal MP, Struijker Boudier HAJ, and De Mey JGR. DNA synthesis in isolated arteries of normotensive and hypertensive rats: effects of the endothelium. J Hypertension 12: 245-250, 1994.

262. Schober A, Krieglstein K, and Unsicker K. Molecular cues for the development of adrenal chromaffin cells and their preganglionic innervation. Eur J Clin Imvest 30: 87-90, 2000.

263. Schutz S, Le Moullec J-M, Corvol P, and Gase JM. Early expression of the components of the renin-angiotensin-system in human development. Am J Pathol 149: 2067-2079, 1996.

264. Seckl JR, Cleasby M, and Nyirenda MJ. Glucocorticoids, 11 beta-hydroxysteroid dehydrogenase, and fetal programming. Kidney Int 57: 1412-1417, 2000.

265. Seeds JW. Impaired fetal growth: definition and clinical diagnosis. J Am Coll Obstet Gynecol 64: 303-310, 1984.

266. Shaul PW. Regulation of vasodilator synthesis during lung development. Early Hum Dev 54: 271-294. 1999.

267. Shaul PW, Cha CM, and Oh W. Neonatal sympathoadrenal response to acute hypoxia: impairment after experimental intrauterine growth retardation. Pediatr Res 25: 466-467, 1989.

268. Shaul PW, Farrar MA, and Magness RR. Prostacyclin synthesis and stimulation of cyclic AMP production in ovine fetal vasculature: heterogeneity in pulmonary and systemic arteries. Dev Pharmacol Ther 18: 89-99, 1992.

269. Shaul PW, Farrar MA, and Magness RR. Pulmonary endothelial nitric oxide production is developmentally regulated in the fetus and newborn. Am J Physiol 265: H1056-1063, 1993.

270. Shaul PW, Magness RR, Muntz KH, DeBeltz D, and Buja LM. $\alpha_{1}$-Adrenergic receptors in pulmonary and systemic vascular smooth muscle. Alterations with development and pregnancy. Circ Res 67: 1193-1200. 1990.

271. Shirley ML, Campbell JD, and Hall AK. Developing sympathetic neurons express a neuronal trait before a catecholaminergic synthetic enzyme in vivo. J Neuroscience Res 46: 42-48, 1996.

272. Sieber-Blum $\mathbf{M}$ and Ren $\mathbf{Z}$. Norepinephrine transporter expression and function in noradrenergic cell differentiation. Mol Cell Biochem 212: 61-70, 2000.

273. Simonetta G, Rourke AK, Owens JA, Robinson JS, and MeMillen IC. Impact of placental restriction on the development of the sympathoadrenal system. Pediatr Res 42: 805-811. 1997.

274. Slotkin TA and Seidler FJ. Adrenomedullary catecholamine release in the fetus and newbom: secretory mechanisms and their role in stress and survival. J Develop Physiol 10: 1-16, 1988.

275. Smeyne RJ, Klein R, Schnapp A, Long LK, Bryant S, Lewin A, Lira SA, and Barbacid M. Severe sensory and sympathetic neuropathies in mice carrying a disrupted Trk/NGF receptor gene. Nature 368: 246-249, 368 .

276. Smith FM, West NH, and Jones DR. The cardiovascular system. Eds.: Whittow GC. in: Sturkie's Avian Physiology. Academic press. San Diego. 2000. pp. 141-231.

277. Somlyo AP and Somlyo AV. Signal transduction and regulation in smooth muscle. Nature 372: 231-326. 1994.

278. Soothill PW. Prenatal asphyxia, hyperlacticaemia, hypoglycaemia, and erythroblastosis in growth retarded fetuses. Br Med J 294: 1051-1053, 1987.

279. Sorensen HT, Thulstrup AM, Norgard B, Engberg M, Madsen KM, Johnsen SP, Olsen J, and Lauritzen T. Fetal growth and blood pressure in a Danish population aged 31-51 years. Scand Candiovase J 34: 390-395, 2000.

280. Southwell BR, Chamley-Campbell JH, and Campbell GR. Trophic interactions between sympathetic nerves and vascular smooth muscle. J Auton Nerv Syst 13: 343-354, 1985. 
281. Stassen F, Maas R, Schiffers P, Janssen G, and De Mey J. A positive and reversible relationship between adrenergic nerves and $\alpha_{1 \mathrm{~A}}$ adrenoreceptors in rat arteries. $J$ Pharmacol Exp Therap 284: 399-405, 1998.

282. Stassen FRM, Raat NJH, Brouwers-Ceiler DL, Fazzi GE, Smits JFM, and De Mey JGR. Angiotensin II induces media hypertrophy and hyperreactivity in mesenteric but not epigastric small arteries of the rat. J Vase Res 34: 289-297, 1997.

283. Stein CE, Fall CHD, Kumaran K, Osmond C, Cox V, and Barker DJP. Fetal growth and coronary heart disease in South India. Lancet 348: 1269-1273, 1996.

284. Stenmark KR, Weiser MC, Buga GM, and Ignarro LJ. Vascular development and function. Eds.: Gluckman PD and Heysmann MA. in: Pediatrics and perinatology. Amold. New York. 1996. pp. 681-709.

285. Su C, Bevan JA, Assali NS, and Brinkman CR. Development of neuroeffector mechanisms in the carotid artery of the fetal lamb. Blood Vessels 14: 12-24. 1977.

286. Taddei S, Virdis A, Mattei $\mathbf{P}$, and Salvetti $\mathbf{A}$. Vasodilation to acetylcholine in primary and secondary forms of human hypertension. Hypertension 21: 929-933, 1993.

287. Tangalakis K, Lumbers ER, Moritz KM, Towsteless MK, and Wintour EM. Effect of cortisol on blood pressure and vascular reactivity in the ovine fetus. Exp Physiol 77: 709-717. 1992.

288. Tapanainen PJ, Bang P, Wilson K, Unterman TG, Vreman HJ, and Resenfeld RG. Maternal hypoxia as a model for intrauterine growh retardation: Effects on insulin-like growth factors and their binding proteins. Pediatr Res 36: 152-158, 1994.

289. Taylor SJC, Whincup PH, Cook DG, Papacosta O, and Walker M. Size at birth and blood pressure: cross sectional study in 8-11 year old children. Br Med J 314: 475-480, 1997.

290. Tazawa H. Direct measurement of allantoic blood flow in the chicken, gallus domesticus. Responses to alterations in ambient temperature and $\mathrm{pO}_{2}$. Comp Biochem Physiol 81A: 641-642. 1985.

291. Teng GQ, Williams J, Zhang L, Purdy R, and Pearce WJ. Effects of maturation, artery size and chronic hypoxia on $5 \mathrm{HT}$ receptor type in ovine cranial arteries. Am J Physiol 44: R742R753, 1998.

292. Thom TJ and Epstein FH. Heart disease, cancer, and stroke mortality trends and their interrelations. Circulation 90: 574-582, 1994.

293. Topper JN and Gimbrone Jr MA. Blood flow and vascular gene expression: fluid shear stress as a modulator of endothelial phenotype. Mol Med Today 5: 40-46, 1999.

294. Ueno H, Kanellakis P, Agrotis A, and Bobik A. Blood flow regulates the development of vascular hypertrophy, smooth muscle cell proliferation, and endothelial cell nitric oxide synthase in hypertension. Hypertension 36: 89-96, 2000.

295. Valdez R, Athens MA, Thompson GH, Bradshaw BS, and Stern MP. Birth weight and adult health outcomes in a biethnic population in the USA. Diabetologia 37: 624-631, 1994.

296. Van Der Loop FTL, Gabbiani G, Kohnen G, Ramaekers FCS, and Van Eys GJJM. Differentiation of smooth muscle cells in human blood vessels as defined by smoothelin, a novel marker for the contractile phenotype. Arterioscler Thromb Vasc Biol 17: 665-671, 1997.

297. Van Golde J, Mulder T, and Blanco CE. Changes in mean chorioallantoic artery blood flow and heart rate produced by hypoxia in the developing chick embryo. Pediatr Res 42: 293-298. 1997.

298. Van Golde J, Mulder T, van Straaten H, and Blanco CE. The chorioallantoic blood flow of the chick embryo from stage 34-43. Pediatr Res 40: 867-871, 1996.

299. Vanhoutte PM. Endothelium-dependent responses in congestive heart failure. $J$ Mol Cell Cardiol 28: 2233-2240, 1996.

300. Vanhoutte PM, Boulanger CM, and Mombouli JV. Endothelium-derived relaxing factors and converting enzyme inhibition. Am J Cardiol 76: 3e-12e, 1995.

301. Vanhoutte PM, Perrault LP, and Vilaine JP. Endothelial dysfunction and vascular disease. Eds.: Rubanyi GM and Dzau VJ. in: The endothelium in clinical practice. Source and target of novel strategies. Marcel Dekker.Inc. New York. Basel, Hong Kong. 1997. pp. 265-289.

302. Vehaskari VM, Aviles DH, and Manning J. Prenatal programming of adult hypertension in the rat. Kidney Int 59: 238-245, 2001.

303. Vogel KS and Weston JA. The sympathoadrenal lineage in avian embryos. L. Adrenal chromaffin cells lose neuronal traits during embryogenesis. Devel Biol 139: 1-12, 1990. 
304. Vogel KS and Weston JA. The sympathoadrenal lineage in avian embryos. II. Effects of glucocorticoids on cultured neural crest cells. Devel Biol 139: 13-23, 1990.

305. Volpe M, Laccarino G, Vecehione C, Rizzoni D, Russo R, Rubattu S, Condorelli G, Ganten U, Ganten D, Trimarco B, and Lindpaintner K. Association and cosegregation of stroke with impaired endothelium-dependent vasorelaxation in stroke prone, spontaneously hypertensive rats. J Clin Invest 98: 256-261, 1996.

306. Vrancken Peeters MPFM, Gittenberger-de Groot AC, Mentink MMT, and Poelmann RE. Smooth muscle cells and fibroblasts of the coronary arteries derive from epithelial-mesenchymal transformation of the epicardium. Anat Embryol 199: 367-378, 1999.

307. Wagman A.J, Hu N, and Clark EB. Effect of changes in circulating blood volume on cardiac output and arterial and ventricular blood pressure in the stage 18, 24 and 29 chick embryo. Circ Res 67: 187-192, 1990.

308. Wasserman, GF, Bernard, EA. Adrenaline content of the chick embryo adrenal gland during development. Acta Physiol Lat Am 20: 171-173, 1970.

309. Westgren M, Lingman G, and Persson B. Cordocentesis in IUGR fetuses. Obstet Gynecol 40: 755-763, 1997.

310. Whincup PH, Cook DG, and Shaper AG. Early influences on blood pressure: a study of children aged 5-7 years. Br Med J 299: 587-591, 1989.

311. White CR, Hao X, and Pearce WJ. Maturational differences in soluble guanylate cyclase activity in ovine carotid and cerebral arteries. Pediatr Res 47: 369-375, 2000.

312. Winters JW, Wong J, Van Dyke D, Johengen M, Heymann MA, and Fineman JR. Endothelin receptor blockade does not alter the increase in pulmonary blood flow due to oxygen ventilation in fetal lambs. Pediatr Res 40: 152-157, 1996.

313. Woodall SM, Johnston BM, Breier BH, and Gluckman PD. Chronic maternal undernutrition in the rat leads to delayed postnatal growth and elevated blood pressure of offspring. Pediatr Res 40: 438-443, 1996.

314. Woods LL, Ingelfinger JR, Nyengaard JR, and Rasch R. Maternal protein restriction suppresses the newborn renin-angiotensin sytem and programs adult hypertension in rats. Pediatr Res 49: 460-467, 2001.

315. Wu X, Makynen H, Kahonen M, Arvola P, and Porsi I. Mesenteric arterial function in vitro in three models of experimental hypertension. J Hypertension 14: 365-372, 1996.

316. Xu L and Mortola JP. Effects of hypoxia and hyperoxia on the lung of the chick embryo. Can J Physiol Pharmacol 67: 515-519, 1989.

317. Zelop CM. Prediction of fetal weight with use of three-dimensional ultrasonography. Obstet Gynecol 43: 321-325, 2000.

318. Zerrouk A, Auguet M, and Chabrier P. Augmented endothelium-dependent contraction to angiotensin II in the SHR aorta: Role of an inducible cyclooxygenase metabolite. J Cardiovasc Pharmacol 31: 525-533, 1998.

319. Zhang J-M and Sieber-Blum M. Characterization of the norepinephrine uptake system and the role of norepinephrine in the expression of the adrenergic phenotype by quail neural crest cells in clonal culture. Brain Res 570: 251-258, 1992. 


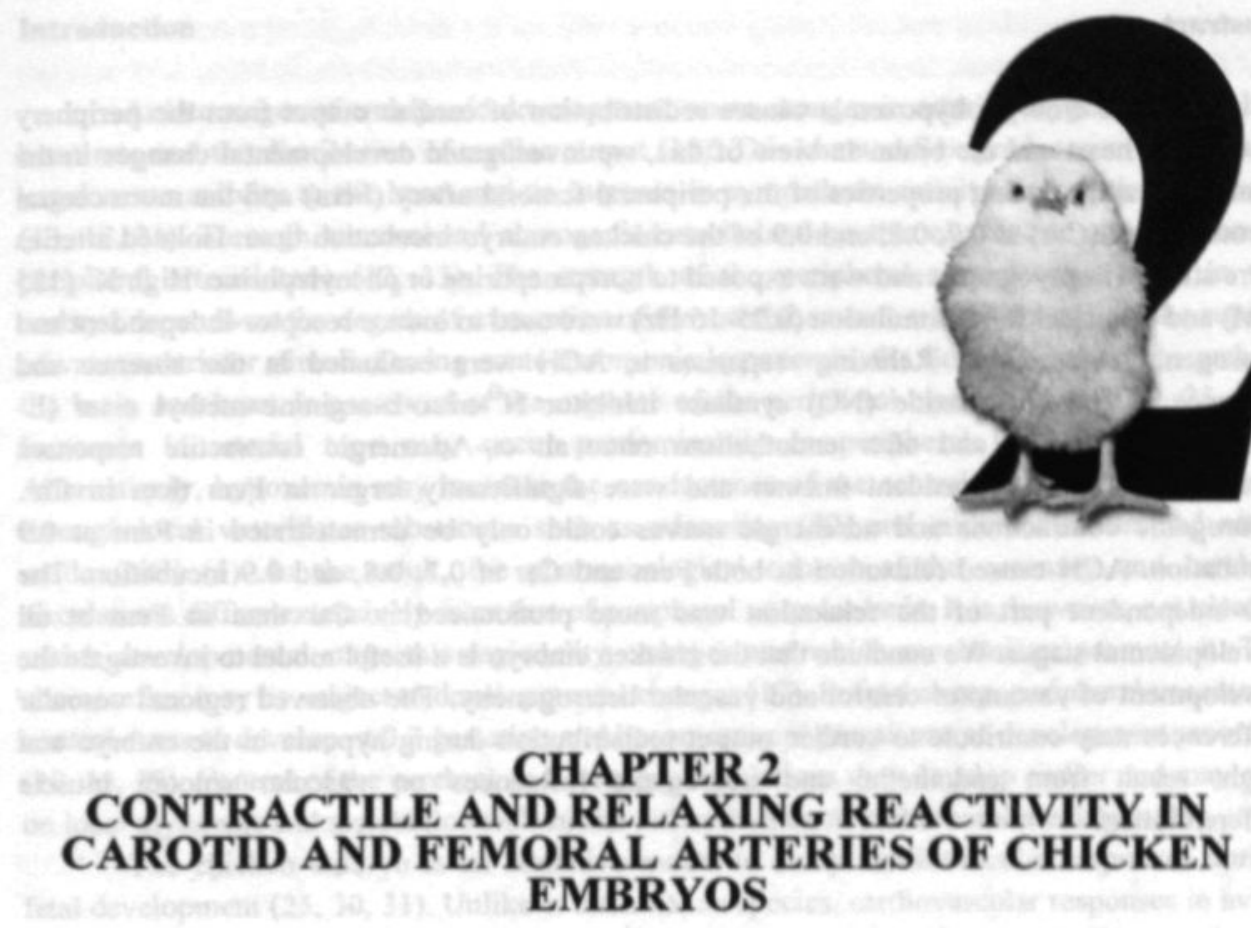

Ferdinand A. C. le Noble, Karin Ruijtenbeek, Susanne Gommers, Jo G. R. De Mey, Carlos E. Blanco

American Journal of Physiology 278: H1261-1268, 2000 


\begin{abstract}
In the embryo, hypoxemia causes redistribution of cardiac output from the periphery toward the heart and the brain. In view of this, we investigated developmental changes in the contractile and relaxing properties of the peripheral femoral artery (Fem) and the more central carotid artery (Car) at $\mathbf{0 . 7}, \mathbf{0 . 8}$, and 0.9 of the chicken embryo incubation time. Isolated arteries were studied in myographs and were exposed to norepinephrine or phenylephrine. High $\mathrm{K}^{+}(125$ $\mathrm{mM})$ and electrical field stimulation $(0.25-16 \mathrm{~Hz})$ were used to induce receptor-independent and neurogenic contractions. Relaxing responses to $\mathrm{ACH}$ were evaluated in the absence and presence of the nitric oxide (NO) synthase inhibitor $\mathrm{N}^{G}$-nitro-L-arginine methyl ester ( $\mathrm{L}$ NAME) and before and after endothelium removal. $\alpha_{1}$-Adrenergic contractile responses increased in a time-dependent manner and were significantly larger in Fem than in Car. Neurogenic contractions and adrenergic nerves could only be demonstrated in Fem at 0.9 incubation. $\mathrm{ACH}$ caused relaxation in both Fem and Car at $0.7,0.8$, and 0.9 incubation. The NO-independent part of the relaxation was more pronounced in Car than in Fem at all developmental stages. We conclude that the chicken embryo is a useful model to investigate the development of vasomotor control and vascular heterogeneity. The observed regional vascular differences may contribute to cardiac output redistribution during hypoxia in the embryo and might result from endothelial and neurogenic influences on vascular smooth muscle differentiation.
\end{abstract}




\section{Introduction}

At late stages of embryonic development, acute changes in arterial oxygen tension alter heart rate and the distribution of cardiac output (13). This chemoreflex produces an increase in vagal nerve activity to the heart and an increase in sympathetic activity toward the periphery $(13,18,21)$. Through humoral and neurogenic catecholamines this can lead to an elevation of peripheral arterial tone $(12,13)$. The strength of the peripheral arterial constriction in the embryo depends on the degree of maturation of the arterial smooth muscle as well as the supply of vasoconstrictor stimuli. During acute embryonic hypoxemia, the flow to vital organs such as the brain and heart is preserved at the expense of the peripheral circulation $(17,19,25,26)$. Increases in arterial tone may occur predominantly in peripheral tissues (12, 19, 26). Alternatively, hypoxemia may increase the conductance of the central vascular compartments through local vasodilator substances such as adenosine (22) and endothelium-derived nitric oxide (NO) (1). In the adult, the pharmacological control of the coronary and cerebral circulations differs extensively from that of peripheral vascular beds. It is, however, not clear at which developmental stage this regionality emerges and which mechanisms promote it. The chemoreflex may be subject to developmental changes (17). In fetal sheep, peripheral vasomotor control starts to develop at 0.7 gestation and becomes more prominent as development proceeds $(10,15,19)$. Control of the cerebral and coronary circulations may develop earlier and may rely on local myogenic and metabolic mechanisms rather than on neurohumoral mediators (15).

The chicken embryo is an attractive model to study cardiovascular responses during fetal development $(25,30,31)$. Unlike in mammalian species, cardiovascular responses in avian embryos are not influenced by maternal or placental vasoactive hormones. We previously demonstrated in 0.47 - to 0.9 -gestation chicken embryos that acute hypoxemia leads to bradycardia (30) and redistribution of cardiac output in favor of the heart and brain (26). We noted that, similar to results in fetal sheep, the fraction directed to the heart and brain increased with gestational age (26), indicating a maturation of vascular control mechanisms. This may be due to changes in the efficacy of the chemoreceptors and changes in the ability of peripheral arteries to regulate resistance, as well as developmental changes in sympathetic nervous and endothelium-dependent control of these peripheral arteries.

The goal of the present study was to describe development and regionality of arterial vasomotor control in the chicken embryo. A central artery, the carotid artery, and a peripheral artery, the femoral artery, were isolated from $0.7-, 0.8-$, and 0.9 -incubation chicken embryos (i.e., after 15, 17, and 19 days of the 21-day incubation period). Their responses to adrenergic stimuli, sympathetic nerve stimulation, and $\mathrm{ACH}$ were compared. The latter compound is generally considered to be an endothelium-dependent vasodilator $(5,7,8,10,14)$, but this has not yet been demonstrated in the chicken embryo. The choice of carotid and femoral arteries was justified by their anatomic location, their size, and by the relative ease with which these vessels could be isolated from even the smallest embryos investigated.

\section{Materials and methods}

\section{Vessel isolation}

Experimental procedures followed Dutch laws for animal experiments. Fertilized Lohman-selected White Leghorn eggs were incubated at $38^{\circ} \mathrm{C}$ and $60 \%$ relative air humidity and were rotated once every hour, until day 15,17 , or $19(0.7,0.8$, or 0.9 incubation time, respectively). The eggs were opened at their blunt side. The eggshell and the outer eggshell 
membrane were carefully removed using forceps to expose the inner eggshell membrane, which was then superfused with Krebs-Ringer bicarbonate (KRB) solution. An incision of $2 \mathrm{~cm}$ was then made in the chorioallantoic membrane. The egg was turned upside down, and the embryo was collected on a petri dish. The extraembryonic membranes were removed, and the embryo was transferred to a petri dish that had been coated with Sylgard (Dow Corning) and filled with KRB. The right carotid and right femoral artery were carefully dissected from the embryo.

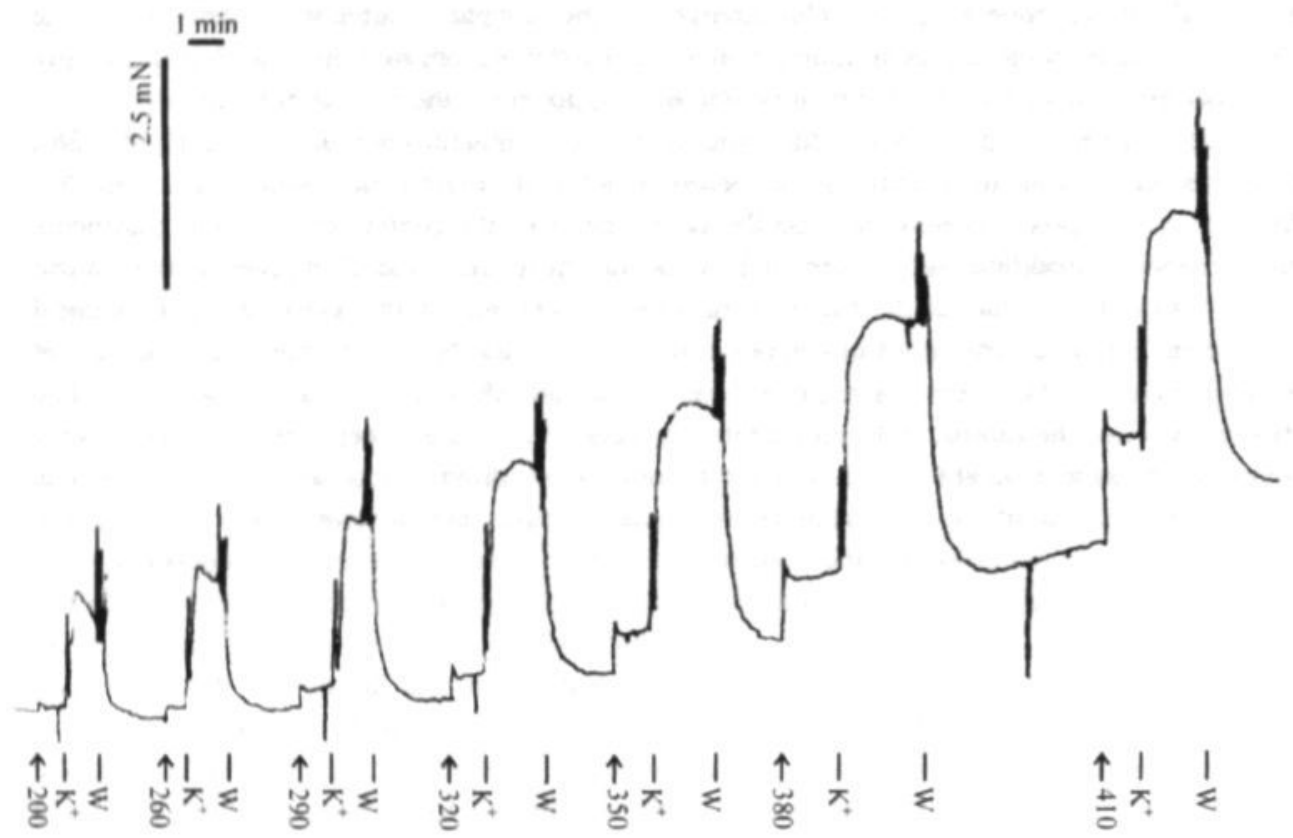

Fig. 1. Typical tracing of isometric force vs. time illustrating contractile responses in a carotid artery of 0.9-incubation chicken embryo as a function of imposed distension. Isolated arterial segment was mounted in organ chamber, and its lumen diameter was increased in steps of $30 \mu \mathrm{m}$ from 200 to $410 \mu \mathrm{m}$ (arrows). At each level of distension, vessel was intermittently stimulated by exposure to $125 \mathrm{mM} \mathrm{K}^{+}$ [between $\mathrm{K}^{+}$and $\mathrm{w}$ (wash)]. Note that maximal contractile response $\left(\mathrm{E}_{\max }\right)$ was obtained at a diameter of $380 \mu \mathrm{m}$.

\section{Recording of arterial reactivity}

The isolated arteries were mounted as ring segments (length 1.7 to $2.0 \mathrm{~mm}$ ) between an isometric force transducer (Kistler Morce DSC 6, Seattle, WA) and a displacement device in a myograph (model 610M, J.P. Trading. Aarhus, Denmark) using two stainless steel wires (diameter $40 \mu \mathrm{m}$ ). Force was divided by twice the vessel segment length to calculate wall tension. During mounting and experimentation, the myograph organ bath $(5 \mathrm{ml}$ vol) was filled with $\mathrm{KRB}$ maintained at $37^{\circ} \mathrm{C}$ and aerated with $95 \% \mathrm{O}_{2}-5 \% \mathrm{CO}_{2}$. Each artery was stretched to its individual optimal lumen diameter, i.e., the diameter at which it developed the strongest contractile response to $125 \mathrm{mM} \mathrm{K}-\mathrm{KRB}$ (K-KRB), using a diameter-tension protocol as previously described for mammalian small arteries (Ref.29; fig. 1).

Reactivity and sensitivity to agonists were examined by constructing concentrationresponse curves $(0.001$ to $10 \mu \mathrm{mol} / \mathrm{l})$. Between experiments the arterial preparations were allowed to recover for at least $15 \mathrm{~min}$. Contractile agonists were evaluated under basal conditions; relaxing agonists were evaluated during contraction induced by $35 \mathrm{mM} \mathrm{K}$. The effects of $\mathrm{ACH}$ were evaluated in the absence and in the presence of $0.1 \mathrm{mmol} / \mathrm{N} \mathrm{N}^{6}$-nitro- $\mathrm{L}$ - 
arginine methyl ester (L-NAME). The NO synthase inhibitor was added during contractions induced by $35 \mathrm{mM} \mathrm{K}^{*}$, and the effects of $\mathrm{ACH}$ were evaluated 30 min later.

In a series of experiments restricted to femoral arteries of 0.9-incubation chicken embryos, the effects of $\mathrm{ACH}$ were also evaluated before and after the removal of the endothelium. For this purpose we used two procedures: sliding of human hair $(10 \mathrm{~cm})$ through the lumen of the vessel (27), and perfusing the lumen during $90 \mathrm{~s}$ with $0.1 \%$ Triton X-100 in KRB with 40-mmHg perfusion pressure (8). Using scanning electron microscopy, we observed that both procedures resulted in complete denudation of the luminal endothelial cells.

Organ chamber experiments were terminated by fixing the vessels in phosphatebuffered ( $\mathrm{pH} \mathrm{7.4)}$ formaldehyde $(4 \%)$ during $30 \mathrm{~min}$ at $37^{\circ} \mathrm{C}$.

\section{Morphometry}

Fixed vessels were transferred to $70 \%$ ethanol and embedded in paraffin. To determine medial cross-sectional area, we performed immunohistochemistry on thin cross sections $(4 \mu \mathrm{m})$ with antibodies against smooth muscle $\alpha$-actin (Sigma Chemical, St. Louis, MO). Endogenous peroxidase was blocked by $0.1 \% \mathrm{H}_{2} \mathrm{O}_{2}$ in methanol for 20 min at room temperature, and the sections were incubated for 45 min with primary antibody $(1: 4,000)$. Horseradish peroxidaseconjugated rabbit anti-mouse antibodies (Daka; dilution 1:200) and diaminobenzioline- $\mathrm{H}_{2} \mathrm{O}_{2}$ substrate were subsequently used to visualize the immunoreactivity. The area occupied by smooth muscle $\alpha$-actin was determined using a Zeiss Axioscope (Zeiss, Germany), a standard CCD camera (Stemmer, Germany), and commercially available software (JAVA 1.21, Jandel Scientific, Corte Madera, CA).

We used an actin-based method rather than the more classical Lawson staining of elastine (29), because continuous internal and external elastic laminae could not be observed in the arterial preparations before 0.9 incubation.

\section{Staining of perivascular sympathetic nerves}

To demonstrate the presence of l-norepinephrine(NE)-containing nerves, we stained whole mount vessel preparations with glyoxylic acid $(24,29)$. Vessel segments were opened longitudinally and were incubated for $30 \mathrm{~min}$ at $20^{\circ} \mathrm{C}$ in $2 \%$ glyoxylic acid in $10 \%$ sucrose containing phosphate buffer (pH 7.2). Subsequently, the vessel segments were transferred to a mounting glass, air-dried for $30 \mathrm{~min}$, stretched at $100^{\circ} \mathrm{C}$ for $4 \mathrm{~min}$, and enclosed with Entellan and a coverslip. The presence of glyoxylic acid-induced fluorescence, representing catecholamine-containing nerves, was visualized using fluorescent microscopy (microscope Nikon Diaphot, BA 470-DM 455 filter; Nikon FE2 camera). Photographs of the vessel segments were taken through the microscope (objective Fluo x10, Nikon) using Kodak 320 ASA film.

\section{Solutions and drugs}

The composition of KRB solution (in mmol/1) was as follows: $118.5 \mathrm{NaCl}, 4.7 \mathrm{KCl}, 1.2$ $\mathrm{MgSO}_{4} \cdot 7 \mathrm{H}_{2} \mathrm{O}, 1.2 \mathrm{KH}_{2} \mathrm{PO}_{4}, 25.0 \mathrm{NaHCO}_{3}, 2.5 \mathrm{CaCl}_{2}$, and 5.5 glucose. In K-KRB (125 mmol/ $\mathrm{K}^{+}$) all $\mathrm{NaCl}$ was replaced by an equimolar amount of $\mathrm{KCl} . \mathrm{K}^{+}$-containing solution $(35 \mathrm{mmol} / \mathrm{l})$ was prepared by mixing appropriate volumes of K-KRB and KRB. Phosphate-buffered solution consisted of $0.1 \mathrm{~mol} / / \mathrm{NaH}_{2} \mathrm{PO}_{4} \cdot \mathrm{H}_{2} \mathrm{O}$ and $0.1 \mathrm{~mol} / 1 \mathrm{Na}_{2} \mathrm{HPO}_{4} \cdot 2 \mathrm{H}_{2} \mathrm{O}$. ACH, glyoxylic acid, LNAME, l-NE, l-phenylephrine (PE), and prazosin were all obtained from Sigma Chemical. BHT-933 (azepexol) was a generous gift from Boehringer. For all agents $1,000 \mathrm{x}$ concentrated stock solutions were prepared in double-distilled water. 


\section{Data analysis}

Concentration-response curves were analyzed in terms of sensitivity and maximal response by fitting the individual experimental data with a nonlinear sigmoid regression curve (GraphPad Software, San Diego, CA). Maximal contractile responses $\left(\mathrm{E}_{\max }\right)$ were expressed in terms of active wall tension (force divided by twice the segment length; $\mathrm{N} / \mathrm{m}$ ); sensitivities are shown as $\mathrm{pD}_{2}$, where $\mathrm{pD}_{2}=-\log _{10} \mathrm{EC}_{30}\left(\mathrm{EC}_{50}\right.$ represents the concentration at which $50 \%$ of the maximal responses were observed). Changes and differences in $\mathrm{E}_{\max }$ and $\mathrm{pD}_{2}$ with time and between types of vessels were evaluated by ANOVA with Bonferroni's correction for multiple comparisons. $\mathrm{P}<0.05$ was accepted to represent statistical significance. Data are shown as means \pm SEM.

\section{Results}

Femoral and carotid arteries obtained from 0.7- to 0.9-incubation chicken embryos responded to depolarizing high- $\mathrm{K}^{+}$solution with a contraction (fig.1). In both types of vessels, the diameter at which maximal responses were obtained $\left(D_{o p t}\right)$ and the amplitude of the maximal response $\left(\mathrm{K}_{\max }\right)$ increased significantly with increasing incubation (figs. 2 and 3 ). In femoral arteries, $D_{\text {opt }}$ averaged $357 \pm 8,409 \pm 13$, and $449 \pm 15 \mu \mathrm{m}$ and $K_{\max }$ averaged $0.26 \pm 0.03,0.73$ \pm 0.15 , and $1.78 \pm 0.14 \mathrm{~N} / \mathrm{m}$ at $0.7,0.8$, and 0.9 incubation, respectively $(\mathrm{n}=10-18)$. In carotid arteries, $\mathrm{D}_{\text {opt }}$ averaged $368 \pm 8,406 \pm 8$, and $468 \pm 15 \mu \mathrm{m}$; and $\mathrm{K}_{\max }$ averaged $0.19 \pm 0.02,0.21 \pm$ 0.04 , and $1.01 \pm 0.15 \mathrm{~N} / \mathrm{m}$ at $0.7,0.8$, and 0.9 incubation, respectively $(\mathrm{n}=8-13)$. Despite comparable diameters (fig. 2), contractile responses to $\mathrm{K}^{+}$were significantly larger in femoral than in carotid arteries at 0.8 and 0.9 incubation (fig. 3 ).

Part of the reason for these results seems to be the significantly larger medial mass in femoral than in carotid arteries (fig. 2), but statistically significant differences between both vessels persist when contractility was normalized to medial thickness. Active wall stress averaged $69 \pm 7$ and $41 \pm 5 \mathrm{~N} / \mathrm{m}^{2}$ at 0.8 incubation and $142 \pm 11$ and $85 \pm 9 \mathrm{~N} / \mathrm{m}^{2}$ at 0.9 incubation in femoral and carotid arteries, respectively.

In femoral and carotid arteries at $\mathbf{0 . 7}, 0.8$, and 0.9 incubation, high concentrations of relaxing agonists, such as $\mathrm{ACH}(10 \mu \mathrm{mol} / \mathrm{l})$, adenosine $(1 \mathrm{mmol} / \mathrm{l})$, and papaverine $(1 \mathrm{mmol} / \mathrm{l})$ failed to affect basal tension, indicating the absence of spontaneous tone under the experimental conditions.

In all femoral arteries from 0.7 incubation onwards, and in all carotid arteries at 0.9 incubation, $\mathrm{NE}$ and the selective $\alpha_{1}$-adrenergic agonist $\mathrm{PE}$ induced concentration-dependent tonic contractile responses (figs. 3 and 4). At 0.7 and 0.8 incubation, only $30-40 \%$ of the carotid arteries investigated responded to the agonists; maximal responses were close to the detection limit of $0.01 \mathrm{~N} / \mathrm{m}$. At all time points, $\mathrm{E}_{\max }$ to the adrenergic stimuli were significantly larger in femoral than in carotid arteries (fig. 3). At 0.9 incubation, the sensitivity $\left(\mathrm{pD}_{2}\right)$ for NE was significantly smaller in femoral $(6.03 \pm 0.8)$ than in carotid arteries $(6.53 \pm 0.11)$, whereas the sensitivity for PE was comparable in femoral $(5.58 \pm 0.09)$ and carotid arteries $(5.27 \pm 0.17)$. Both femoral and carotid arteries failed to contract in response to BHT-933, a selective $\alpha_{2}-$ adrenergic agonist (data not shown), indicating a lack of functional $\alpha_{2}$-adrenergic receptors on arterial smooth muscle at the developmental stages investigated. 
A

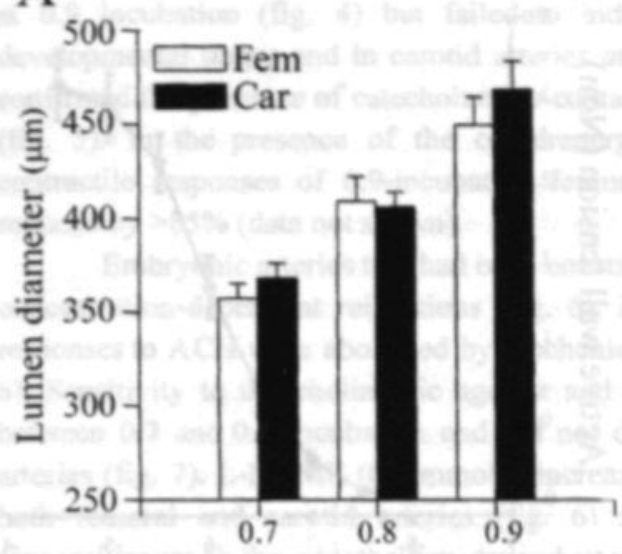

incubation
B

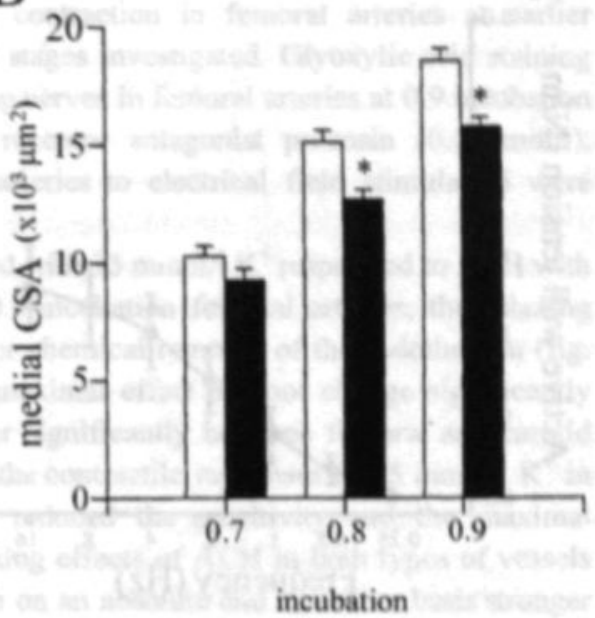

Fig. 2. Lumen diameter and medial cross-sectional area (CSA) of chicken embryonic arteries as a function of gestational age. A: diameter at which $\mathrm{E}_{\max }$ to $125 \mathrm{mM} \mathrm{K} \mathrm{K}^{+}$could be obtained is shown for isolated femoral arteries (Fem) and carotid arteries (Car). B: medial CSA was determined on anti-smooth muscle $\alpha$-actin-stained cross sections. Values are means \pm SEM (number of arteries: $n=8-18$ ). *Differences between both types of arteries were statistically significant $(\mathrm{P}<0.05)$.

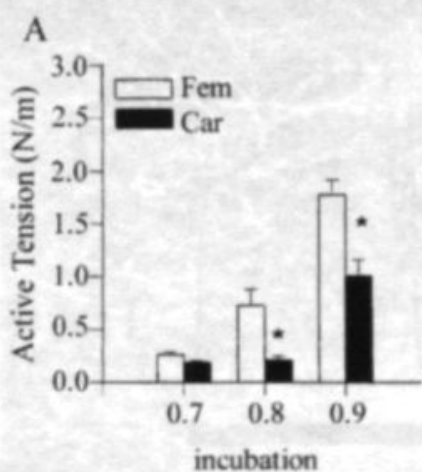

B

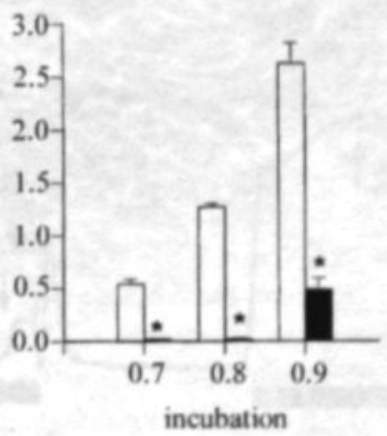

C

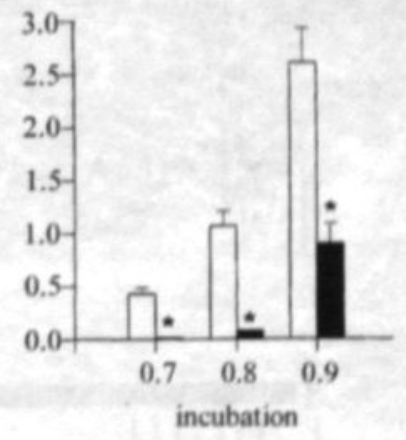

Fig. 3. Contractile reactivity of chicken embryonic arteries as function of incubation. $\mathrm{E}_{\max }$ to $125 \mathrm{mM} \mathrm{K}$ (A), norepinephrine (NE, B), and phenylephrine (C) are shown for isolated Fem and Car. Values are means \pm SEM $(\mathrm{n}=8-18)$. "Difference from Fem is statistically significant $(\mathrm{P}<0.05)$. Data analysis was restricted to arterial segments that exhibited $\mathrm{K}^{*}$-induced contractions exceeding the detection limit $(0.1$ $\mathrm{N} / \mathrm{m})$. 
A

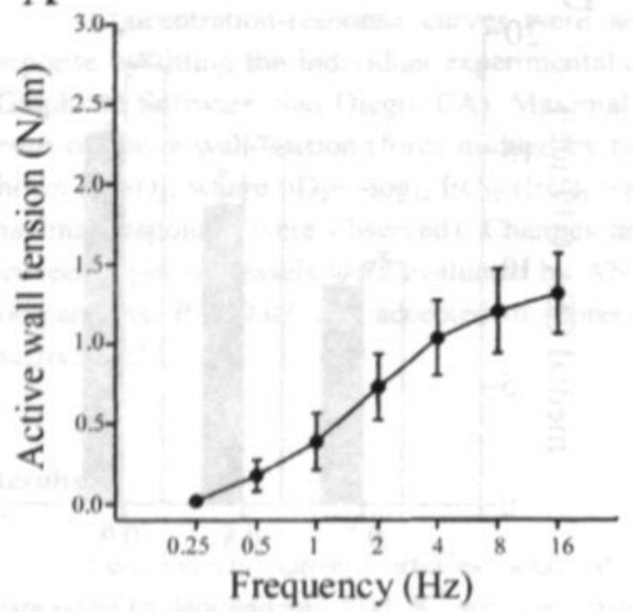

B

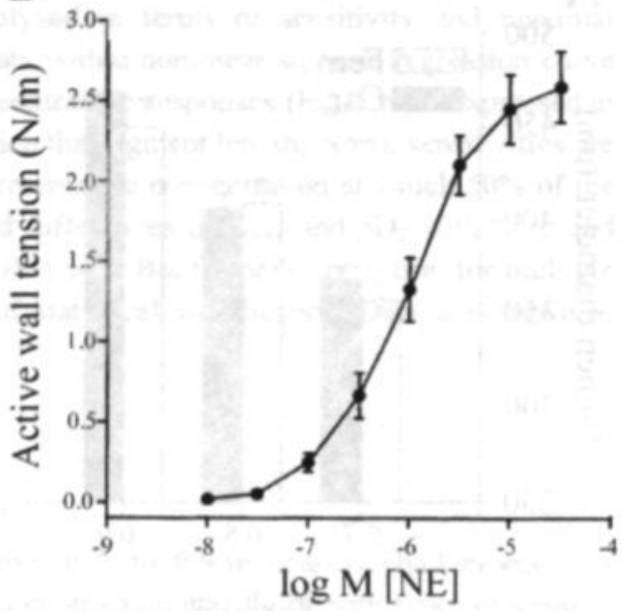

Fig. 4. Contractile responses of 0.9-incubation chicken embryonic Fem to electrical field stimulation of perivascular nerves $(A)$ and exogenously supplied NE $(B)$. Values are means $\pm \operatorname{SEM}(n=10)$.

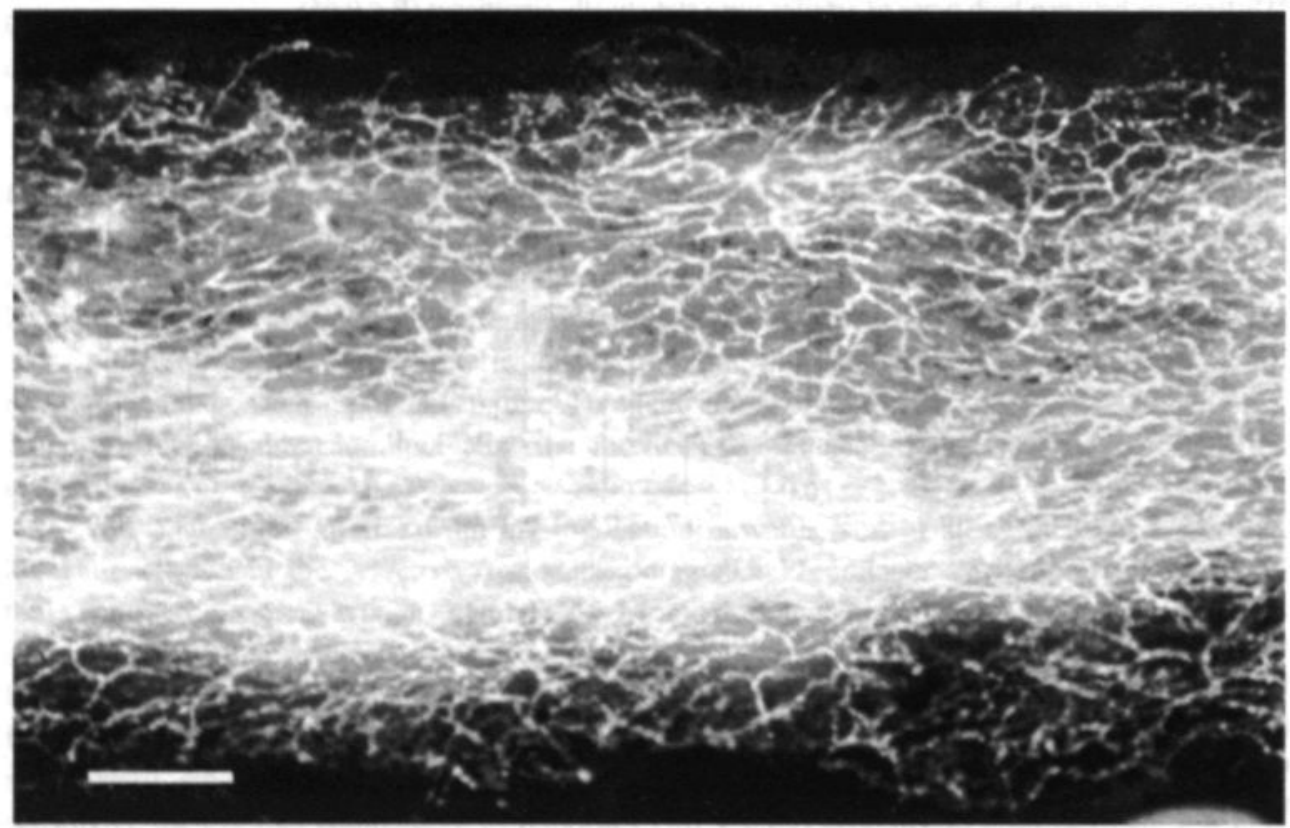

Fig. 5. Glyoxylic acid-induced fluorescence in a whole mount preparation of 0.9 -incubation chicken embryonic Fem highlighting the presence of NE-containing perivascular nerves. Calibration bar: $280 \mu \mathrm{m}$. 
Electrical field stimulation caused frequency-dependent contractions in femoral arteries at 0.9 incubation (fig. 4) but failed to induce contraction in femoral arteries at earlier developmental stages and in carotid arteries at all stages investigated. Glyoxylic acid staining confirmed the presence of catecholamine-containing nerves in femoral arteries at 0.9 incubation (fig. 5). In the presence of the $\alpha_{1}$-adrenergic receptor antagonist prazosin $(0.1 \mu \mathrm{mol} / \mathrm{)})$, contractile responses of 0.9 -incubation femoral arteries to electrical field stimulation were reduced by $>85 \%$ (data not shown).

Embryonic arteries that had been constricted with $35 \mathrm{mmol} / \mathrm{K} \mathrm{K}^{+}$responded to $\mathrm{ACH}$ with concentration-dependent relaxations (fig. 6). In 0.9-incubation femoral arteries, the relaxing responses to $\mathrm{ACH}$ were abolished by mechanical or chemical removal of the endothelium (fig. 6). Sensitivity to the cholinergic agonist and its maximal effect did not change significantly between 0.7 and 0.9 incubation and did not differ significantly between femoral and carotid arteries (fig. 7). L-NAME ( $0.1 \mathrm{mmol} /$ ) increased the contractile responses to $35 \mathrm{mmol} / \mathrm{K}^{+}$in both femoral and carotid arteries (fig. 6) and reduced the sensitivity and the maximal responsiveness to the endothelium-dependent relaxing effects of $\mathrm{ACH}$ in both types of vessels (fig. 7). Although $\mathrm{K}^{+}$-induced contraction was both on an absolute and a relative basis stronger in femoral than in carotid arteries, the L-NAME-resistant component of the relaxing effects of $\mathrm{ACH}$ was significantly more pronounced in carotid than in femoral arteries at 0.7 and at 0.9 incubation (fig. 7). It is noteworthy that the contractile effect of L-NAME in embryonic arteries was not significantly altered by endothelium removal (fig. 6).

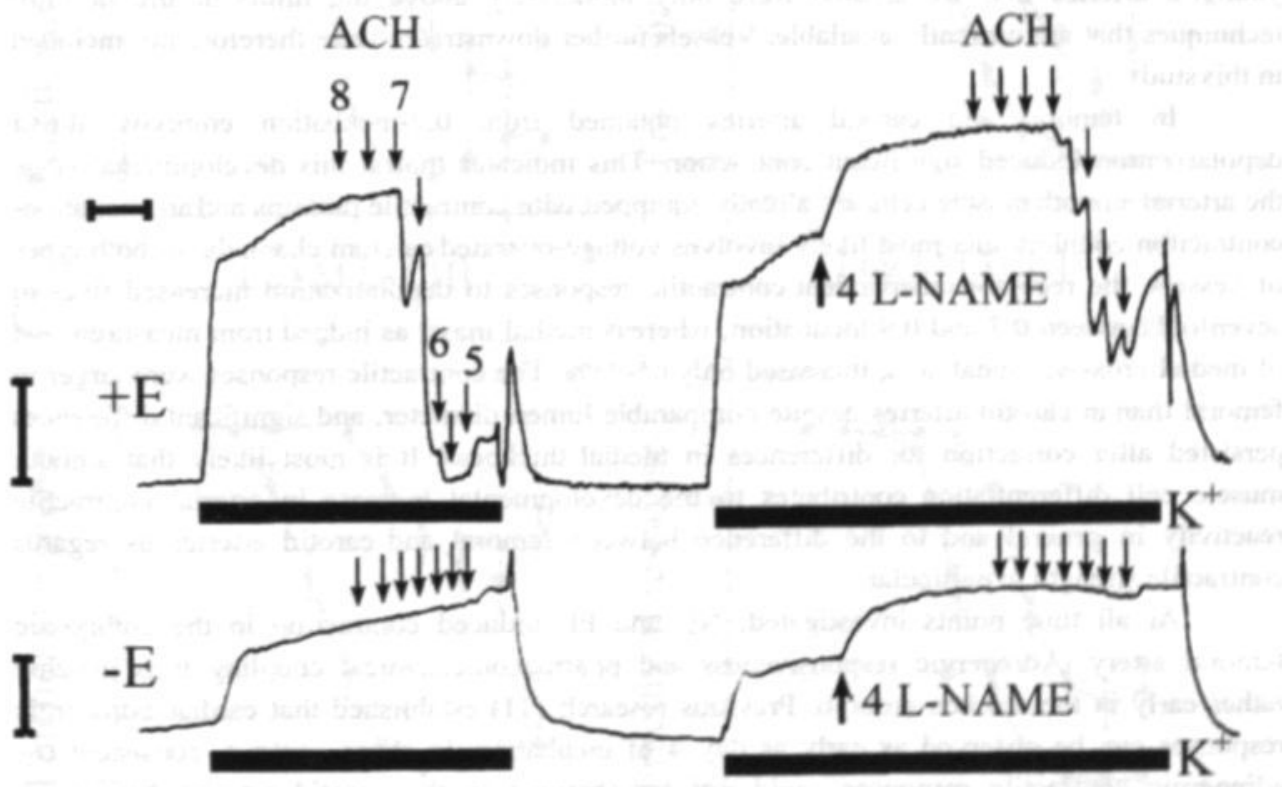

Fig. 6. Typical tracings of isometric tension vs. time illustrating effects of $35 \mathrm{mM} \mathrm{K}, \mathrm{ACH}$, and $\mathrm{N}^{\circ}$ nitro-L-arginine methyl ester (L-NAME) in intact [+endothelium (+E); top] and denuded [-endothelium ( E); bottom] segments of 0.9 -incubation chicken embryonic Fem. Removal of endothelium was obtained by perfusion with $0.1 \%$ Triton $\mathrm{X}-100$. Concentrations of pharmacological agents are shown as log $\mathrm{M}$. Horizontal bar: $5 \mathrm{~min}$; vertical bars: $1 \mathrm{~N} / \mathrm{m}$. 


\section{Discussion}

Between 0.7 and 0.9 incubation, the contractile reactivity to $\alpha_{1}$-adrenergic and receptorindependent stimulation increased in the femoral and carotid arteries of chicken embryos. Late developmental increases in contractile reactivity, in neurogenic vasoconstrictor responses, and in the responsiveness to endothelium-derived NO were more pronounced in the peripheral femoral artery than in the central carotid artery. Such regional heterogeneity may contribute to the redistribution of cardiac output during hypoxemia in the embryo and may find its origin in neurogenic and endothelial influences on the functional differentiation of arterial smooth muscle.

Previous studies of cardiovascular responses in chicken embryos revealed similarities to those in fetal sheep $(17,26)$. Most notably, acute hypoxemia results not only in bradycardia but also in a redistribution of cardiac output from the peripheral circulation to the heart and brain in both species. Catecholamines participate in this embryonic chemoreflex in both systems $(12,15$, $17,18,20,21,25,26,30)$. In the present study we analyzed isolated arteries of the chicken embryo.

The use of in vitro approaches, which are well established for adult arteries (e.g. 7, 8, 29), allow quantification of responses and sensitivities of individual blood vessels to various vasoactive agents and allow us to quantify neurogenic and endothelium-dependent responses in the absence of modulatory circulating hormones. We compared femoral and carotid arteries as model systems for a peripheral and a central vascular bed. The size and reactivity of the youngest arteries that we studied were only moderately above the limits of the in vitro techniques that are currently available. Vessels further downstream were therefore not included in this study.

In femoral and carotid arteries obtained from 0.7 -incubation embryos, direct depolarization induced significant contraction. This indicates that at this developmental stage the arterial smooth muscle cells are already equipped with contractile proteins and an excitationcontraction coupling that most likely involves voltage-operated calcium channels. In both types of vessels, the receptor-independent contractile responses to depolarization increased five- to sevenfold between 0.7 and 0.9 incubation, whereas medial mass, as judged from measurements of medial cross-sectional area, increased only $65-75 \%$. The contractile responses were larger in femoral than in carotid arteries despite comparable lumen diameter, and significant differences persisted after correction for differences in medial thickness. It is most likely that smooth muscle cell differentiation contributes to the developmental increase in arterial contractile reactivity in general and to the difference between femoral and carotid arteries as regards contractile strength in particular.

At all time points investigated, $\mathrm{NE}$ and $\mathrm{PE}$ induced contraction in the embryonic femoral artery. Adrenergic responsiveness and pharmacomechanical coupling thus develop rather early in the chicken embryo. Previous research (11) established that cardiac adrenergic responses can be observed as early as day 4 of incubation. In sharp contrast, consistent $\alpha_{1^{-}}$ adrenergic contractile responses could not be obtained in the carotid arteries before 0.9 incubation. With the use of $0.3 \mathrm{nM}\left[{ }^{3} \mathrm{H}\right]$ prazosin and previously described ligand-binding techniques in intact arterial segments (28), we observed that the density of $\alpha_{1}$-adrenergic receptors was comparable in 0.9 -incubation femoral arteries $(10.8 \pm 1.3 \mathrm{fmol} / \mathrm{mg}$ total protein, $\mathrm{n}$ $=8$ ) and carotid arteries $(11.1 \pm 1.8 \mathrm{fmol} / \mathrm{mg}$ total protein, $\mathrm{n}=4)$. Consequently, aspects beyond the receptors, most likely involving the coupling of these sarcolemmal structures to the contractile apparatus, account for the regional difference. Little is known about the mechanisms that control $\alpha_{1}$-adrenergic mechanisms in general and during development in particular. 

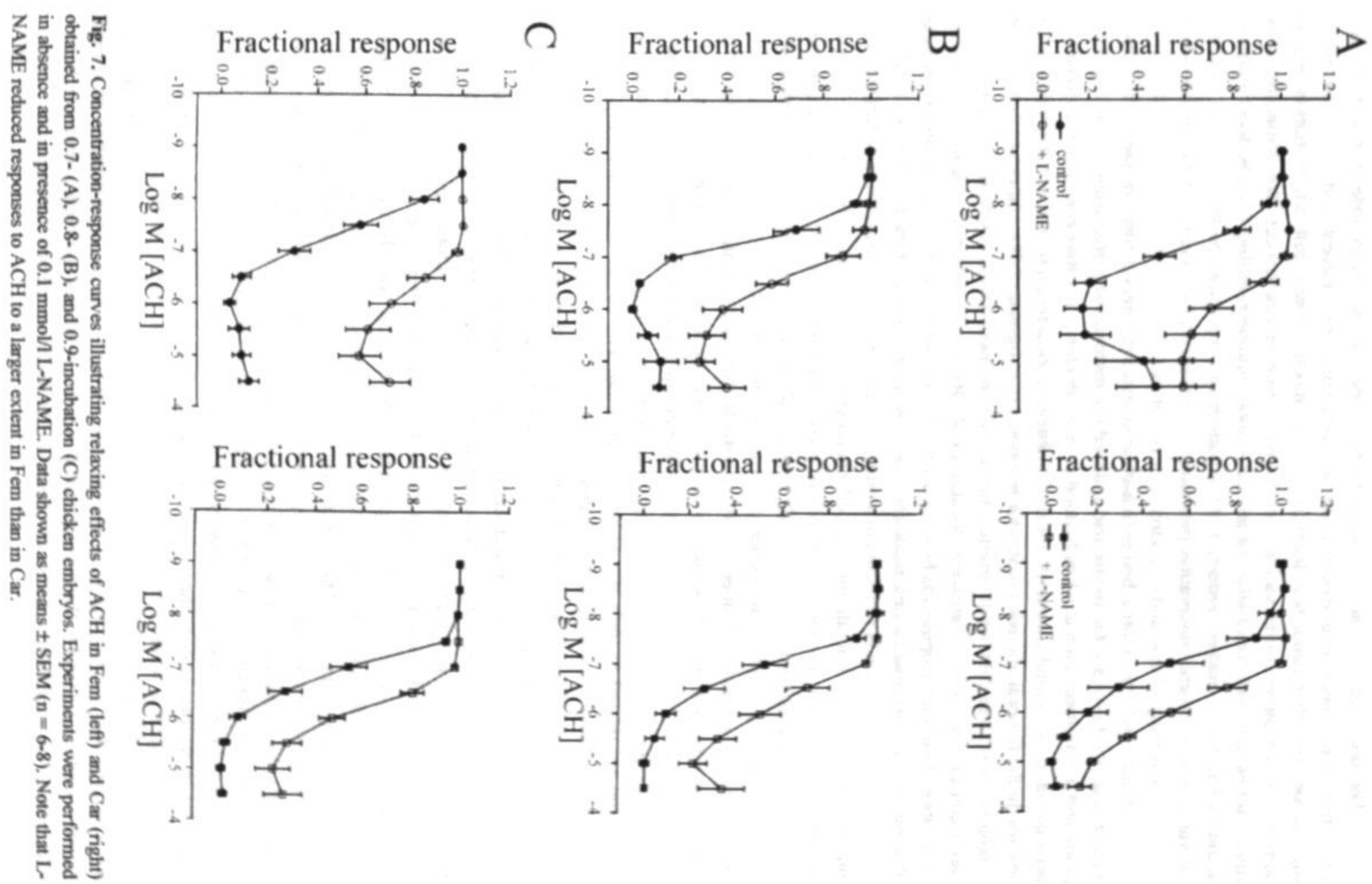
The observed difference between the two types of arteries excludes a major role for circulating factors such as glucocorticoids and catecholamines. Recent findings of our group suggest, on the other hand, that local aspects of smooth muscle cell differentiation and of perivascular sympathetic innervation play a pivotal role in this respect. We demonstrated in adult arteries that dedifferentiation of arterial smooth muscle resulting from balloon injury is accompanied by a marked reduction of $\alpha_{1}$-adrenergic receptor density (3) and that the perivascular sympathetic innervation promotes the presence of $\alpha_{1 \mathrm{~A}}$-adrenergic receptors while reducing the density of $\alpha_{1 B^{-}}$and $\alpha_{1 D^{-a d r e n e r g i c ~ r e c e p t o r s ~(28) . ~}}$.

In this study we approached perivascular sympathetic nerves histochemically and from a functional point of view. Glyoxylic acid-induced fluorescence of perivascular nerve fibers was prominent in late-incubation chicken femoral arteries. Prazosin-sensitive contractile responses to perivascular nerve stimulation were obtained in late-gestation femoral arteries but not in carotid arteries. In the femoral arteries, constrictor responses to exogenous NE could be obtained before neurogenic responses. In adult arteries, the density of perivascular sympathetic innervation varies considerably between anatomic locations (28). Regionally selective vascular sympathetic innervation during development is brought about by timely secretion by vascular smooth muscle of a mixture of nerve-attracting mediators such as nerve growth factor and nerve-repelling substances. This secretion is restricted to a rather limited period of time and may be limited to an intermediate vascular smooth muscle cell phenotype $(9,16)$. It may furthermore be more prominent in vascular smooth muscle cells of mesodermal origin than in those that are derived from the neural crest and which primarily populate the blood vessels in the cranial region. In addition to altering the pharmacological properties of the innervated blood vessel (e.g., see 29), the perivascular sympathetic innervation can initially stimulate growth and proliferation of the smooth muscle cells and subsequently promote the development and maintenance of a contractile phenotype (for review, see Ref. 6). We thus propose that the stronger contractility of femoral arteries during late development and their larger responsiveness to $\alpha_{1}$-adrenergic stimulation are related to their sympathetic innervation. The causal interrelationship between these aspects clearly remains to be established.

Another vessel wall component that plays important roles in the morphogenesis and development of the vascular system and in the control of vasomotor tone is the endothelium. Endothelial cells give rise to the earliest vascular channels and later attract mesenchymal cells to the vessel wall (4). Subsequently, endothelium-derived mediators promote the differentiation of these vessel wall cells into contractile smooth muscle cells (4). Endothelium-derived NO that stimulates cGMP production and protein kinase $\mathrm{G}$ activity has been proposed to participate in this differentiating action $(2,23)$. We approached this mediator with the use of $\mathrm{ACH}$, an agent that induces endothelium-dependent relaxation in adult arteries of various species $(5,7,8,10)$, including chicken aorta (14). Our experiments with mechanical and chemical endothelium removal demonstrate the endothelium dependency of cholinergic vasodilatation in the chicken embryo. Partial blockade of these relaxations by the NOS inhibitor L-NAME indicates an involvement of endothelium-derived NO. Relaxing effects of endothelium-derived NO could be demonstrated from the earliest developmental stages investigated and were at all stages more prominent in femoral arteries than in carotid arteries. Our current findings do not allow us to attribute the regional difference to a larger endothelial release of $\mathrm{NO}$ or to a more elaborated guanylate cyclase-protein kinase $\mathrm{G}$ system in femoral than in carotid arteries. Yet, the findings are consistent with a contribution of endothelium-derived NO to the differentiation of arterial smooth muscle $(2,23)$ and to the developmental increase in arterial contractile reactivity. Future pharmacological intervention studies are, however, needed to strengthen this proposal. 
It is noteworthy that in chicken embryonic arteries, as in some adult mammalian systems (5) and in the aorta of mature chickens (14), the endothelium-dependent relaxing responses to ACH could only partly be blocked by L-NAME. A role for an endothelium-derived hyperpolarizing factor (5) seems unlikely because the relaxing effects of ACH were studied during contraction induced by depolarizing high- $\mathrm{K}^{+}$solution. The exact nature of the L-NAMEresistant component of endothelium-dependent relaxation remains to be established in chicken embryonic arteries. This also applies for the observed endothelium-independency of the LNAME-induced contraction.

In summary, we observed differences between carotid and femoral arteries of chicken embryos as regards the developmental increase in contractile strength, $\alpha_{1}$-adrenergic vasoconstriction, perivascular sympathetic innervation, and endothelium-dependent vasodilatation involving NO. From approximately "mid-incubation", the cardiovascular system of the chicken embryo can respond to hypoxemia with a redistribution of cardiac output from peripheral vascular beds to the heart and brain $(25,26)$. As development progressed, this chemoreflex became more prominent. Based on our observations, the development of arterial contractile reactivity, i.e. its pharmacological control and regional heterogeneity, may participate herein and seems to involve neurogenic and endothelial influences on arterial smooth muscle cell differentiation.

\section{Acknowledgments}

We gratefully acknowledge the assistance of Gregorio Fazzi, Rein van Gool, Ger Janssen, and Lilian Kessels in the morphometry, scanning electron microscopy, radioligand binding, and histofluorescence aspects of this study. 


\section{References}

1. Bel F Van, Sola A, Roman C, and Rudolph AM. Role of nitric oxide in the regulation of the cerebral circulation in the lamb during normoxemia and hypoxemia. Biol Neonate 68: 200-210, 1995.

2. Boerth NJ, Dey NB, Cornwell TL, and Lincoln TM. Cyclic GMP-dependent protein kinase regulates vascular smooth muscle cell phenotype. J Vasc Res 34: 245-259, 1997.

3. Bruijns RHJ, van Kleef EM, Smits JFM, De Mey JGR, and Daemen MJAP. Effects of chemical sympathectomy on angiotensin II induced neointima growth in the balloon-injured rat carotid artery. J Vasc Res 35: 124-133, 1998.

4. Carmeliet $\mathbf{P}$, and Collen D. Genetic analysis of blood vessel format. Role of endothelial versus smooth muscle cells. Trends Cardiovasc Med 7: 271-281, 1997.

5. Cohen RA, and Vanhoutte PM. Endothelium-dependent hyperpolarization. Circulation 92: 3337-3349, 1995.

6. Daemen MJAP, and De Mey JGR. Regional heterogeneity of arterial structural changes. Hypertension 25: 464-473, 1995.

7. De Mey JG, and Vanhoutte PM. Heterogenous behavior of the canine arterial and venous wall. Importance of the endothelium. Circ Res 5: 439-447, 1982.

8. De Mey JGR, and Gray D. Endothelium-dependent reactivity in resistance vessels. Prog Appl Microcirc 8: 181-187, 1985.

9. Falckh PH, Harkin LA, and Head R.J. Resistance vessel gene expression of nerve growth factor is elevated in young spontaneously hypertensive rats. J Hypertension 10: 913-918, 1992.

10. Furchgott RF, and Vanhoutte PM. Endothelium-derived relaxing and contracting factors. FASEB J 3: 2007-2018, 1989.

11. Girard H. Adrenergic sensitivity of circulation in the chick embryo. Am J Physiol 224: 461-469, 1973.

12. Giussani DA, Spencer JA, Moore PJ, Bennet L, and Hanson MA. Afferent and efferent components of the cardiovascular reflex responses to acute hypoxia in term fetal sheep. J Physiol 461: 431-449, 1993.

13. Hanson MA. The importance of baro- and chemoreflexes in the control of the fetal cardiovascular system. J Dev Physiol 10: 491-511, 1988.

14. Hasegawa $\mathbf{K}$, and Nishimura $\mathbf{H}$. Humoral factor mediates acetylcholine-induced endotheliumdependent relaxation of chicken aorta. Gen Comp Endocrinol 84: 164-169, 1991.

15. Iwamoto HS, Kaufman T, Keil LC, and Rudolph AM. Responses to acute hypoxemia in fetal sheep at 0.6-07 gestation. Am J Physiol Heart Circ Physiol 256: H613-H620, 1989.

16. Jeffreson S, Rush R, Zettler C, Frewin DB, and Head RJ. The influence of the reninangiotensin system on abnormal expression of nerve growth factor in the spontaneously hypertensive rat. Clin Exp Pharmacol Physiol 22: 478-480, 1995.

17. Jensen A, and Berger R. Regional distribution of cardiac output. In: Fetus and Neonate: Physiology and Clinical Applications, edited by Hanson MA, Spencer JAD, and Rodeck CH. Cambridge, UK: Cambridge University Press, 1993, vol. 1, p. 23-74.

18. Jensen A, and Lang $\mathbf{U}$. Foetal and circulatory responses to arrest in uterine blood flow in sheep: effects of chemical sympathectomy. J Dev Physiol 17: 75-86, 1992.

19. Jensen A, Roman C, and Rudolph AM. Effects of reducing uterine blood flow on fetal blood flow distribution and oxygen delivery. J Dev Physiol 15: 309-323, 1991.

20. Jones CT, and Robinson RO. Plasma catecholamines in foetal and adult sheep. J Physiol 248: 15-33, 1975.

21. Jones CT, Roebuck MM, Walker DW, and Johnston BM. The role of the adrenal medulla and peripheral sympathic nerves in the physiological responses of the fetal sheep to hypoxia. $J$ Dev Physiol 10: 17-36, 1988.

22. Kurth CD, and Wagerle LC. Cerebrovascular reactivity to adenosine analogues on 0.6-0.7 gestation and near term fetal sheep. Am J Physiol Heart Circ Physiol 262: H1338-H1342, 1992. 
23. Lincoln TM, Dey NB, Boerth NJ, Cornwell TL, and Soff GA. Nitric oxide cyclic GMP pathway regulates vascular smooth muscle cell phenotypic modulation: implications in vascular diseases. Acta Physiol Scand 164: 507-515, 1998.

24. Lindvall O, Bjorkland A, Nobin A, and Stenevi $\mathbf{U}$. The adrenergic innervation of the rat thalamus as revealed by the glyoxylic acid fluorescence method. $J$ Comp Neurol 154: 317-347. 1974.

25. Mulder ALM, Van Golde JC, Prinzen FW, and Blance CE. Cardiac output distribution in the chick embryo stage 36 to 45. Cardiovase Res 34: 525-528, 1997.

26. Mulder ALM, Van Golde JC, Prinzen FW, and Blance CE. Cardiac output distribution in response to hypoxia in the chick embryo in the second half of the incubation time. J Plosiol 505: 281-287, 1998.

27. Osol G, Cipolla M, and Knutson S. A new method for mechanically denuding the endothelium of small $(50-150 \mu \mathrm{m})$ arteries with a human hair. Blood Vessels 26: 320-324, 1989.

28. Stassen FR, Maas R, Schiffers P, Janssen G, and De Mey JG. A positive and reversible relationship between adrenergic nerves and $\alpha-1 \mathrm{~A}$ adrenoreceptors in rat arteries. J Pharmacol Exp Ther 284: 399-405, 1998.

29. Stassen FR, Raat NJ, Brouwers-Ceiler DL, Fazi GE, Smits JF, and De Mey JG. Angiotensin-II induces media hypertrophy and hyperreactivity in mesenteric but not epigastric small arteries of the rat. J Vase Res 34: 289-297, 1997.

30. Van Golde J, Mulder T, and Blance CE. Changes in mean chorioallantoic artery blood flow and heart rate produced by hypoxia in the developing chick embryo. Pediatr Res 42: 293-298, 1997.

31. Van Golde J, Mulder T, Van Straaten HWM, and Blance CE. The chorioallantoic artery blood flow of the chick embryo from stage 34 to 43 . Pediatr Res 40: 867-871, 1996. 


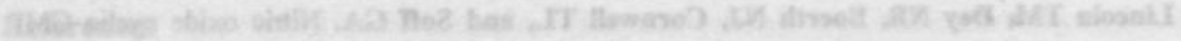

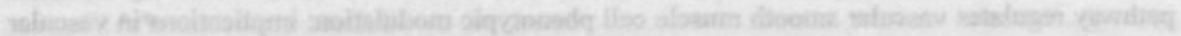

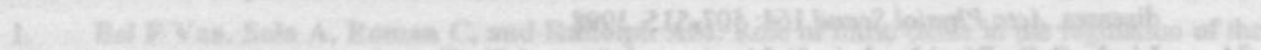

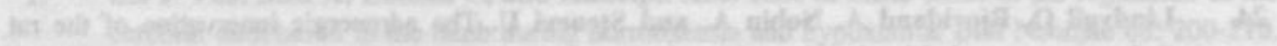

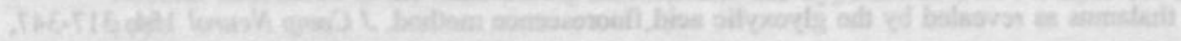

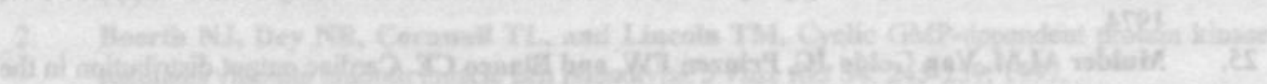

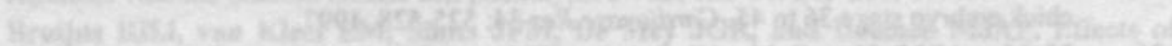

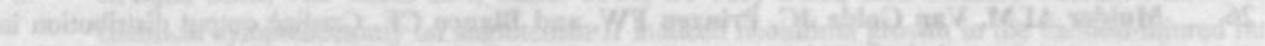

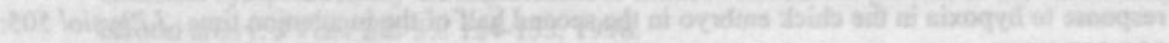

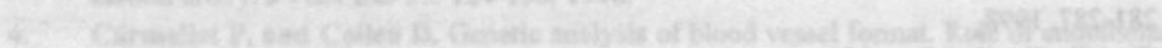

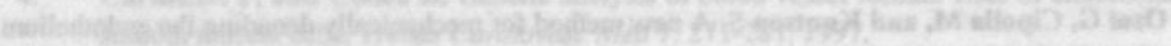

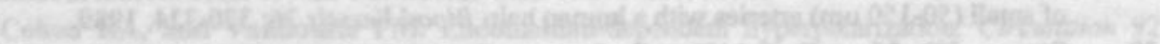

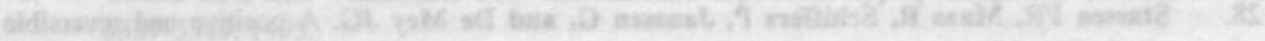

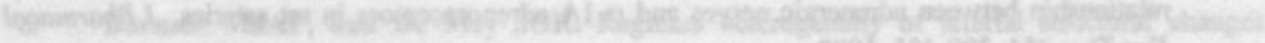

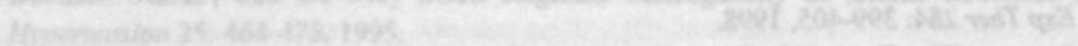

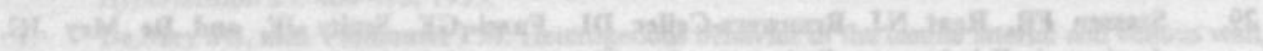

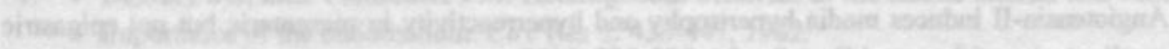

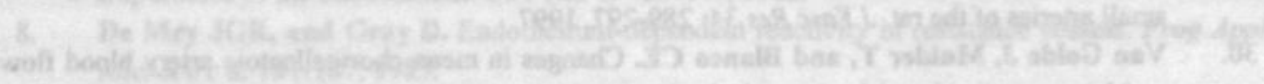

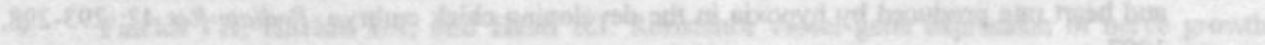

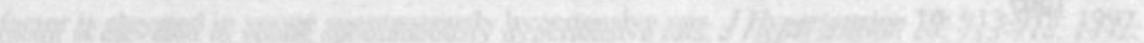

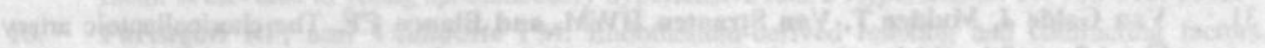

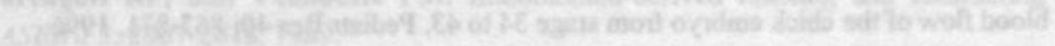

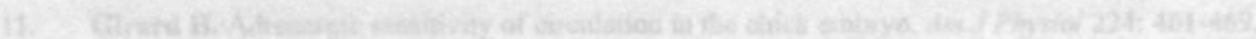
wash

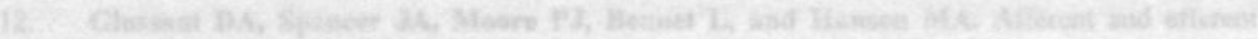

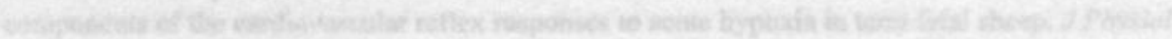

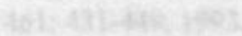

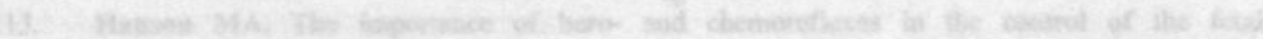

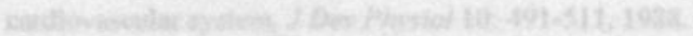

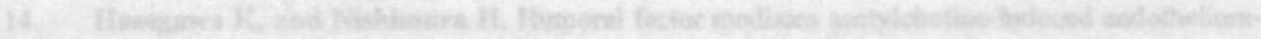

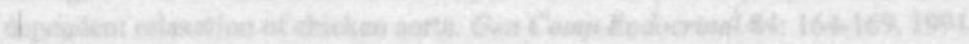

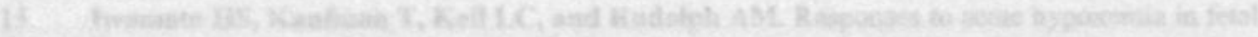

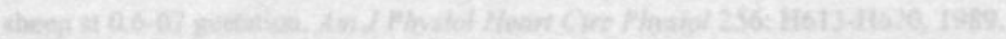

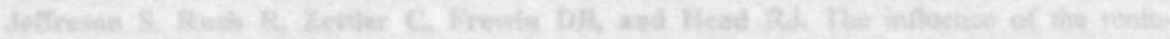

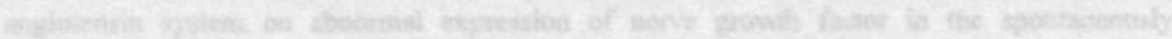

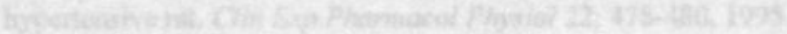

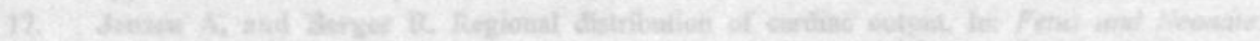

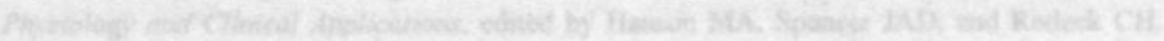

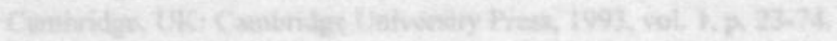

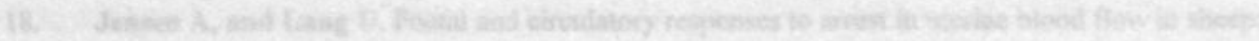

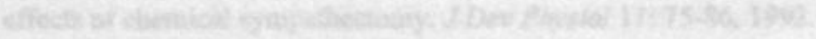

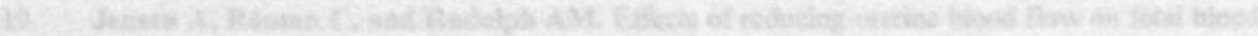

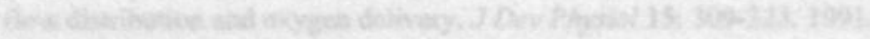

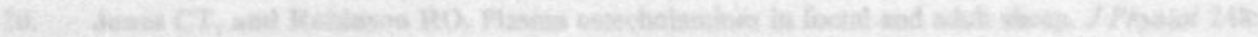

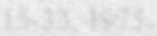

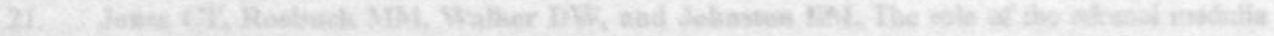

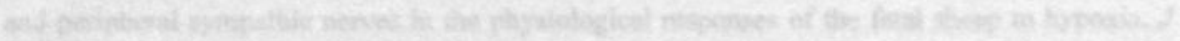

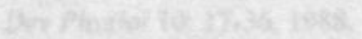

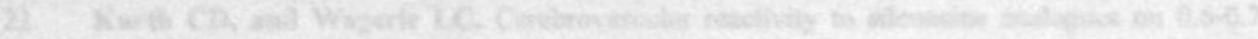

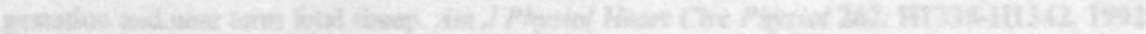




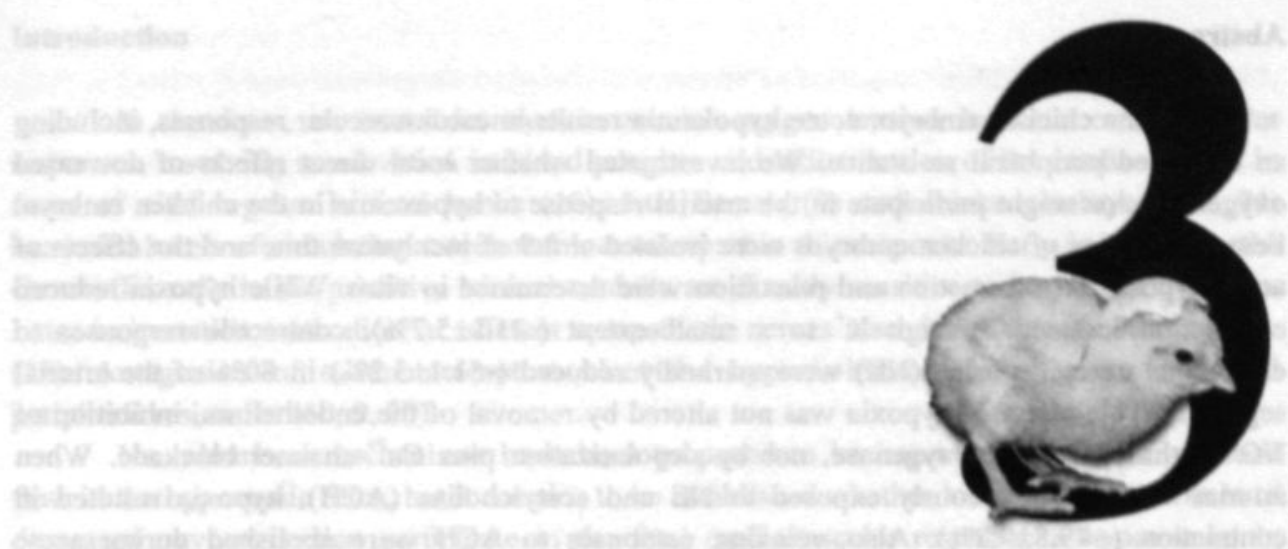

\section{CHAPTER 3}

\section{DIRECT EFFECTS OF ACUTE HYPOXIA ON THE REACTIVITY OF PERIPHERAL ARTERIES OF THE CHICKEN EMBRYO}

Karin Ruijtenbeek, Lilian C. G. A. Kessels, Eduardo Villamor, Carlos E. Blanco, Jo G. R. De Mey

American Journal of Physiology 283: R331-338, 2002 
60 | Chapter 3

\begin{abstract}
In the chicken embryo, acute hypoxemia results in cardiovascular responses, including an increased peripheral resistance. We investigated whether local direct effects of decreased oxygen tension might participate in the arterial response to hypoxemia in the chicken embryo. Femoral arteries of chicken embryos were isolated at 0.9 of incubation time and the effects of acute hypoxia on contraction and relaxation were determined in vitro. While hypoxia reduced contraction induced by high $\mathrm{K}^{+}$to a small extent $(-21.8 \pm 5.7 \%)$, contractile responses to exogenous norepinephrine (NE) were markedly reduced $(-51.1 \pm 3.2 \%)$ in $80 \%$ of the arterial segments. This effect of hypoxia was not altered by removal of the endothelium, inhibition of NO synthase or cyclo-oxygenase, nor by depolarization plus $\mathrm{Ca}^{2+}$-channel blockade. When arteries were simultaneously exposed to $\mathrm{NE}$ and acetylcholine $(\mathrm{ACH})$, hypoxia resulted in contraction $(+49.8 \pm 9.3 \%)$. Also, relaxing responses to $\mathrm{ACH}$ were abolished during acute hypoxia, while the vessels became more sensitive to the relaxing effect of the NO-donor, sodium nitroprusside $\left(\mathrm{pD}_{2}: 5.81 \pm 0.21\right.$ vs. $5.31 \pm 0.27$ ). Thus, in chicken embryo femoral arteries, acute hypoxia blunts agonist-induced contraction of the smooth muscle and inhibits stimulated EDRF release. The consequences of this for in vivo fetal hemodynamics during acute hypoxemia depend on the balance between vasomotor influences of circulating catecholamines and those of the endothelium.
\end{abstract}




\section{Introduction}

In the fetus, an acute decrease in arterial oxygen tension leads to cardiovascular responses, involving an elevation in blood pressure and redistribution of the cardiac output in favor of vital organs. In fetal lambs (10), fetal llama's (9) and chicken embryos $(25,24)$ increased levels of circulating catecholamines take part in this response. Early in gestation, the chromaffin cells in the primitive adrenal medulla are directly sensitive to low oxygen tension. Later in gestation, activation of efferent sympathetic nerves also contributes to the response (38). Antagonists of $\alpha$-adrenoreceptors blunt the hypoxia-induced increase in fetal total peripheral resistance $(10,9,25)$.

Neurohumoral mechanisms have been proposed to be important regulators of blood flow in the hypoxemic fetus, but it remains to be established whether local and direct effects of decreased oxygen tension participate in the fetal cardiovascular response to hypoxemia. In previous studies we have shown that chronic exposure to hypoxia affects both sympathetic innervation (34 (chapter 4)) and endothelium-dependent relaxation (abstract 33 (chapter 6)) of femoral arteries of the chicken embryo, but acute effects of hypoxia in isolated systemic arteries were not studied. Moreover, acute effects of low oxygen tension have been studied in fetal pulmonary $(35,42)$ and cerebral and carotid arteries $(8,3,43)$, but few studies have addressed this in isolated systemic peripheral arteries of fetuses.

In adult animals, a broad variety of local responses to acute hypoxia have been observed in systemic arteries. Contraction, relaxation and even biphasic responses have been described (47). Reduction of relaxation and augmentation of contractile responses during hypoxia/anoxia have been mainly attributed to an inhibition of EDRF/NO release (26, 44). Vasorelaxation in response to a decrease in oxygen tension has been shown to involve NO $(17,12)$, prostaglandins $(22,12)$, potassium channels $(19,41)$, calcium channels $(15)$ and/or adenosine $(41)$. The role of the endothelium in relaxing responses to hypoxia is a subject of discussion. The different types of responses seem to depend not only on the vascular bed and the species studied, but also on the degree of hypoxia (15) and on the developmental stage of the animal studied (27).

In the present study we investigated the acute effect of low oxygen tension on isolated femoral arteries of the chicken embryo near the end of incubation. In previous studies, we showed that at this time point in the chicken embryo neurohumoral mechanisms are important in in vivo responses to acute hypoxia (23) and that vasoconstrictor and vasodilator responses are detectable using the wire myograph technique (18 (chapter 2)). Therefore, we studied the effect of acute hypoxia in the presence of mediators that play a role in the sympathetic nervous system and in the regulation of vascular tone during fetal hemodynamic responses to hypoxemia.

\section{Methods}

Fertilized eggs of White Leghom chickens ('t Anker, Ochten, NL) were incubated at 38 ${ }^{\circ} \mathrm{C}$ and $21 \% \mathrm{O}_{2}$ with a relative air humidity of $60 \%$ and were rotated hourly. After 19 days of the 21 days incubation time the eggs were opened. The embryos were taken out and immediately killed by decapitation. Ring segments of the femoral artery ( $2 \mathrm{~mm}$ long) were isolated and mounted in a myograph organ bath (model 610M, J.P.Trading. Aarhus, Denmark) for recording of isometric force development. The organ bath was filled with Krebs-Ringer bicarbonate solution (KRB), which was maintained at $37{ }^{\circ} \mathrm{C}$ and aerated with $95 \% \mathrm{O}_{2}$ and $5 \%$ $\mathrm{CO}_{2}$. The experiments complied with the Dutch law for animal experimentation. 


\section{Study protocol}

After an equilibration period of 30 minutes, the vessel segments were stretched to their optimal diameter, i.e. the diameter at which the largest contraction in response to a high potassium solution $\left(63 \mathrm{mmol} \mathrm{L}^{-1} \mathrm{~K}^{+}\right)$was observed $(494 \pm 4 \mu \mathrm{m})$. Then, either no stimulus was given or contraction was induced by a single concentration of NE or potassium. An acute decrease in oxygen tension was induced after 10 minutes (when contraction was stable) by switching the gas mixture (aerating the organ bath) from $95 \% \mathrm{O}_{2} / 5 \% \mathrm{CO}_{2}$ to $95 \% \mathrm{~N}_{2} / 5 \% \mathrm{CO}_{2}$ as has been described by others studying fetal preparations $(8,3,43)$. The $\mathrm{pO}_{2}$ in the organ chambers was measured with an $\mathrm{ISO}_{2}$ dissolved oxygen meter and oxygen electrode (World Precision Instruments, Berlin, Germany) and reduced rapidly $\left(\mathrm{pO}_{2}\right.$ became less than $25 \mathrm{~mm} \mathrm{Hg}$ after 4 minutes and was $16.7 \pm 2.7 \mathrm{~mm} \mathrm{Hg}$ after 8 minutes).

Different concentrations of $\mathrm{NE}\left(1 \mu \mathrm{mol} \mathrm{L} \mathrm{L}^{-1}\right.$ and $5 \mu \mathrm{mol} \mathrm{\textrm {L } ^ { - 1 } )}$ were used to induce receptor-mediated contraction. Depolarization-induced contraction was obtained by raising the $\mathrm{K}^{+}$concentration of the $\mathrm{KRB}\left(63,94\right.$ and $\left.125 \mathrm{mmol} \mathrm{L}^{-1}\right)$ in exchange for $\mathrm{Na}^{+}$. Arterial responses to a decrease in oxygen tension were also studied during electrical field stimulation, which was previously shown to activate peri-arterial sympathetic nerves of the chicken embryo femoral artery (18 (chapter 2)). Because neurogenic contractile responses to nerve stimulation were not stable the above mentioned protocol had to be adjusted. Transient responses to $4 \mathrm{~Hz} \mathrm{(} 2 \mathrm{msec}, 85$ $\mathrm{mA}$ ) field stimulation were studied during hypoxia (after 10 minutes) and under control conditions.

To evaluate the role of changes in membrane potential and of L-type $\mathrm{Ca}^{2+}$ channels the following protocol was used. Vessels were exposed to $75 \mathrm{mmol} \mathrm{L}^{-1} \mathrm{~K}^{+}$in the presence of nifedipine $\left(1 \mu \mathrm{mol} \mathrm{L}^{-1}\right)$, a blocker of voltage-operated calcium channels, and were then stimulated with $1 \mu \mathrm{mol} \mathrm{L^{-1 }} \mathrm{NE}$. Hypoxia was induced and maintained for 10 minutes. In addition, experiments were performed with Bay-K8644, which stimulates L-type $\mathrm{Ca}^{2+}$-channels. As $300 \mathrm{nmol} \mathrm{L}^{-1}$ Bay-K8644 did not change basal tone, it was added during contraction with 25 $\mathrm{mM} \mathrm{K} \mathrm{K}^{+}$or $1 \mu \mathrm{mol} \mathrm{L}{ }^{-1} \mathrm{NE}$. When contraction was stable a 10 minutes period of hypoxia was induced.

The response to low oxygen tension was also studied in vessel segments with and without endothelium. The endothelium was removed by rubbing the inside of the mounted vessel with a human hair or by perfusing the vessel segment for $90 \mathrm{sec}$. with $0.1 \%$ Triton X100 (perfusion pressure $=40 \mathrm{~mm} \mathrm{Hg}$ ) prior to mounting.

The response to acetylcholine $\left(1 \mu \mathrm{mol} \mathrm{L} \mathrm{L}^{-1}\right)$ during contraction with high $\mathrm{K}^{+}$was used to check whether the vessel was successfully denuded. For a number of vessels this was also checked histologically by means of scanning electron microscopy. The effect of hypoxia in denuded and intact vessels was studied in unstimulated vessel segments and during NE-induced contraction.

The response to hypoxia in vessel segments contracted with $1 \mu \mathrm{mol} \mathrm{L}{ }^{-1} \mathrm{NE}$ was also studied in the presence of the NO-synthase blocker L-NAME $\left(100 \mu \mathrm{mol} \mathrm{L}^{-1}\right)$ and in the presence of the cyclo-oxygenase inhibitor indomethacin $\left(3 \mu \mathrm{mol} \mathrm{L^{-1 }}\right)$.

Relaxing responses to acetylcholine $\left(10 \mathrm{nmol} \mathrm{L}^{-1}-10 \mu \mathrm{mol} \mathrm{L^{-1 }}\right.$, half $\log$ steps) and

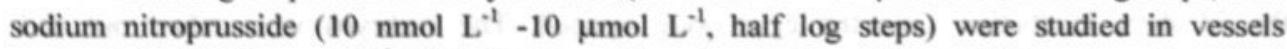
contracted with $63 \mathrm{mmol} \mathrm{\textrm {L } ^ { - 1 }} \mathrm{K}^{+}$during hypoxic and control conditions. Furthermore, the effect of acute hypoxia was also studied in vessels in which relaxation was induced by acetylcholine $\left(300 \mathrm{nmol} \mathrm{L}^{-1}\right)$ during contraction stimulated by $\mathrm{NE}\left(1 \mu \mathrm{mol} \mathrm{L} \mathrm{L}^{-1}\right)$.

The effect of reoxygenation is not discussed in this paper. Responses to hypoxia were reversible and reproducible within one experiment, which enabled the use of different stimuli within one vessel segment. 


\section{Drugs and solutions}

Krebs-Ringer bicarbonate buffer (KRB) contained (in mmol L-1): $\mathrm{NaCl}, 118.5 ; \mathrm{MgSO}_{4}$ $-7 \mathrm{H}_{2} \mathrm{O}, 1.2 ; \mathrm{KH}_{2} \mathrm{PO}_{4}, 1.2 ; \mathrm{NaHCO}_{3}, 25.0 ; \mathrm{CaCl}_{2}, 2.5$; glucose, 5.5. Solutions containing different concentrations of $\mathrm{K}^{*}$ were prepared by replacing part of the $\mathrm{NaCl}$ by an equimolar amount of $\mathrm{KCl}$. Arterenol bitartrate (norepinephrine), indomethacin and $\mathrm{N \omega}$-nitro-L-arginine methyl ester (L-NAME) were obtained from Sigma Chemical Co (St. Louis, MO), nifedipine from Bayer (Leverkusen, Germany), acetylcholine chloride from Janssen Chimica (Beersen, Belgium) and sodium nitroprusside from Acros (Geel, Belgium). Bay-K8644 was kindly supplied by Dr. Kazda (Bayer, FRG). Indomethacin and nifedipine were dissolved in $100 \%$ ethanol, Bay-K8644 in dimethyl sulfoxide (DMSO), and all other agents in distilled water.

\section{Data analysis}

Active wall tension (AWT) was calculated by dividing force by two times the length of the vessel segment $(\mathrm{N} / \mathrm{m})$. Responses to acute hypoxia were expressed as percentage change of AWT. Whenever possible, two vessel segments were taken from one artery of the same chicken embryo (femoral artery segment of $4 \mathrm{~mm}$ cut in two) to study the effect of acute hypoxia under the different circumstances. In this case paired t-test or the non-parametric variant (Wilcoxon signed rank test) were used for statistical analysis. Otherwise, data were analyzed with t-test for two groups or the non-parametric variant (Mann Whitney U-test), when normality test failed (Sigma Stat 2.0, Jandel Scientific). Data are presented as mean \pm SEM of $n$ embryos and $P<0.05$ was considered statistically significant.

\section{Results}

\section{Hypoxia-induced increase in arterial tone}

In unstimulated vessels, acute hypoxia induced a small transient increase in tone $\left(3.8 \pm 0.9 \%(n=18)\right.$ of the contraction induced by $\left.63 \mathrm{mmol} \mathrm{L}^{-1} \mathrm{~K}^{+}\right)$. Endothelial removal seemed to increase this contraction $\left(+8.9 \pm 2.5\right.$ vs. $2.1 \pm 1.0 \%$ of $\mathrm{K}^{+}$-induced contraction $\mathrm{n}=6$, Wilcoxon signed rank test, $\mathrm{P}=0.03)$, but blockade of NO-synthase did not induce changes $(+6.3 \pm 2.9 \%$ vs. $+4.2 \pm 2.0 \%$ of $\mathrm{K}^{+}$-induced contraction, Wilcoxon signed rank test, $\left.\mathrm{n}=6, \mathrm{P}=0.44\right)$. When an acute decrease in oxygen tension was induced during contraction stimulated by $1 \mu \mathrm{mol} \mathrm{L^{-1 }}$ norepinephrine (NE), no effect was observed in 12 out of 59 vessel segments. In 28 artery segments hypoxia induced a transient increase in tension $(+12.7 \pm 2.4 \%$ increase of NE induced contraction, fig. 2), which was not modified by the presence of L-NAME $(+7.3 \pm 1.8 \%$ vs. $+8.9 \pm 2.6 \%$, $n=7$, paired $t-t e s t, P=0.52)$, nor by denudation $(+17.6 \pm 4.5 \%$ vs. $+8.6 \pm 1.8 \%, n=7$, paired $t$-test. $\mathrm{P}=0.06$ ).

\section{Hypoxia-induced decrease of contraction in stimulated arteries}

NE-induced contraction. In $80 \%$ of the studied vessel segments, hypoxia ultimately induced a decrease in the contraction induced by $1 \mu \mathrm{mol} \mathrm{L}^{-1} \mathrm{NE}(-51.1 \pm 3.2 \%, \mathrm{n}=47$ ) (fig.1). Using $5 \% \mathrm{O}_{2}$ instead of $95 \% \mathrm{O}_{2}$ to aerate the organ bath did not modify $\mathrm{NE}-\left(1 \mu \mathrm{mol} \mathrm{L} \mathrm{L}^{-1}\right)$ induced contraction ( $1.92 \pm 0.15$ vs. $2.16 \pm 0.24 \mathrm{~N} / \mathrm{m}, \mathrm{n}=5$, Wilcoxon signed rank test, $\mathrm{P}=0.25$ ). Hypoxia $\left(0 \% \mathrm{O}_{2}\right)$ had similar effects on NE-induced contraction in artery segments that were equilibrated in $95 \% \mathrm{O}_{2}$ and in $5 \% \mathrm{O}_{2}(-42.0 \pm 7.3 \%$ vs. $-51.0 \pm 11.2 \%, \mathrm{n}=5$, Wilcoxon signed rank test, $\mathrm{P}=0.63)$. 


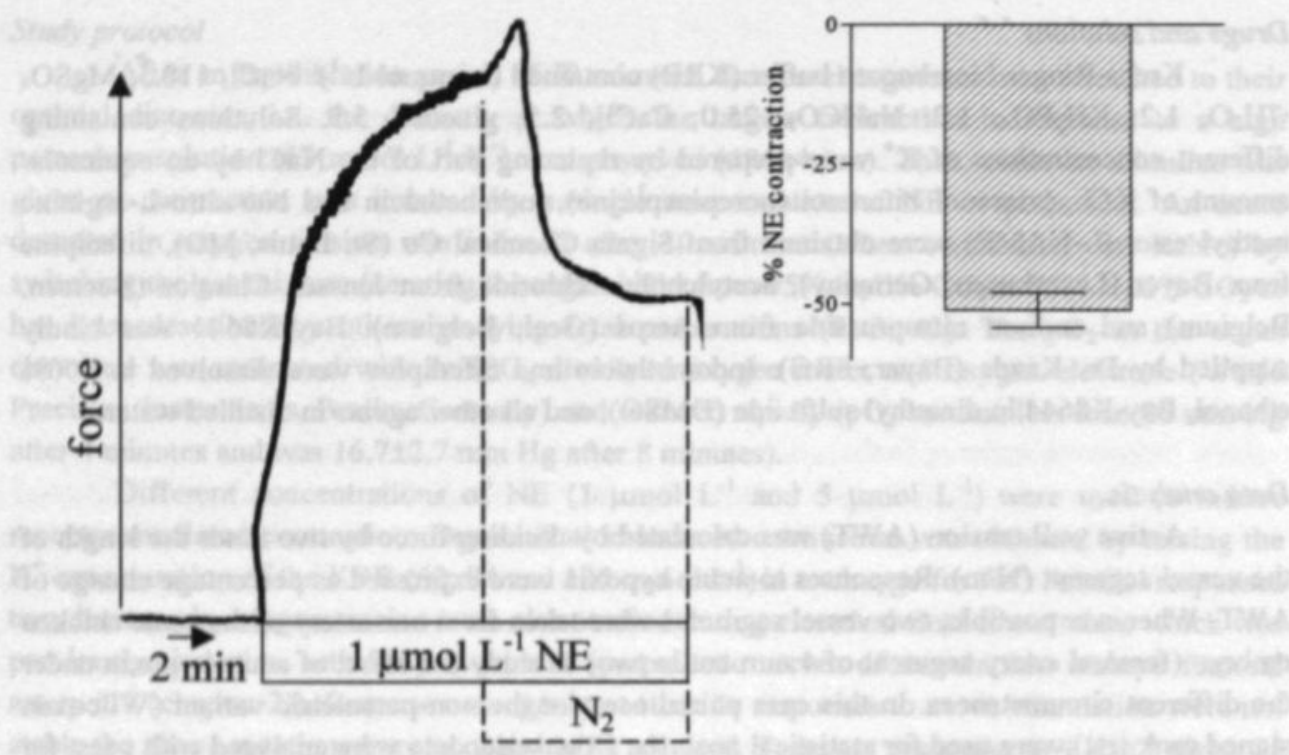

Fig. 1. Typical tracing of isometric force as a function of time illustrating the effect of hypoxia $\left(\mathrm{N}_{2}\right)$ on the contraction induced by $1 \mu \mathrm{mol} \mathrm{L^{-1 }}$ norepinephrine (NE). Bar graph shows mean \pm SEM of 47 artery segments.

The decrease in contraction during biphasic responses to hypoxia was not different from hypoxic relaxation that was not preceded by hypoxic contraction $(-47.6 \pm 3.0 \%$ vs. $-56.2 \pm 6.5 \%$, $\mathrm{n}=19-28$, Mann Whitney $\mathrm{U}$-test, $\mathrm{P}=0.14)$. Initial $\mathrm{NE}$ induced contraction did not differ either $(1.77 \pm 0.12$ vs. $1.98 \pm 0.09 \mathrm{~N} / \mathrm{m}, \mathrm{n}=19-28$, $\mathrm{t}$-test, $\mathrm{P}=0.16$ ).

Under control conditions, contraction induced by $5 \mu \mathrm{mol} \mathrm{L}^{-1} \mathrm{NE}(2.08 \pm 0.18 \mathrm{~N} / \mathrm{m})$ was comparable to that induced by $1 \mu \mathrm{mol} \mathrm{L} \mathrm{L}^{-1} \mathrm{NE}(2.06 \pm 0.19 \mathrm{~N} / \mathrm{m}, \mathrm{t}-\mathrm{test}, \mathrm{n}=5-7)$. The hypoxiainduced decreases in contraction did not differ between vessel segments stimulated by $5 \mu \mathrm{mol}$ $\mathrm{L}^{-1} \mathrm{NE}(-44.3 \pm 3.9 \%)$ or $1 \mu \mathrm{mol} \mathrm{L}^{-1} \mathrm{NE}(\mathrm{n}=5-8, \mathrm{t}$-test, $\mathrm{P}=0.43)$.

Neurogenic sympathetic contraction induced by $4 \mathrm{~Hz}$ electrical field stimulation was reduced by half during hypoxia $(0.69 \pm 0.10 \mathrm{~N} / \mathrm{m}$ vs. $1.45 \pm 0.24 \mathrm{~N} / \mathrm{m}$ during normoxia, $\mathrm{n}=6$, Wilcoxon signed rank test, $\mathrm{P}=0.03$ ).

Contraction induced by depolarization. Under control conditions, contractile responses to high $\mathrm{K}^{+}\left(63 \mathrm{mmol} \mathrm{L}^{-1}: 1.57 \pm 0.22 \mathrm{~N} / \mathrm{m}, 94 \mathrm{mmol} \mathrm{L}^{-1}: 1.54 \pm 0.23 \mathrm{~N} / \mathrm{m}\right.$ and $125 \mathrm{mmol} \mathrm{L} \mathrm{L}^{-1}$ : $1.79 \pm 0.16 \mathrm{~N} / \mathrm{m}$ ) did not significantly differ from those to $1 \mu \mathrm{mol} \mathrm{L^{-1 }} \mathrm{NE}$ (Wilcoxon signed rank test and paired t-test, $\mathrm{n}=6, \mathrm{P}=0.44, \mathrm{P}=0.48$ and $\mathrm{P}=0.95$ respectively). The decrease of contraction in response to hypoxia $(-21.8 \pm 5.7 \%,-19.0 \pm 4.5 \%$ and $-11.7 \pm 13.2 \%$, respectively, fig. 2) was significantly smaller during contraction stimulated by depolarization than during $\alpha$ adrenergic contraction (Mann-Whitney U-test, $n=5-8, P<0.01$ for all concentrations $K^{+}$).

Blockade of voltage-operated calcium channels ( $\mathrm{Cav}$ ) by nifedipine markedly reduced contractile responses to $75 \mathrm{mmol} / \mathrm{L}^{-1} \mathrm{~K}^{+}$(remaining contraction: $20 \pm 3.1 \%$ of initial contraction). Contraction to NE was decreased by $40 \%$ in the continuous presence of $75 \mathrm{mmol} \mathrm{L}^{-1} \mathrm{~K}^{+}$and 1 $\mu$ mol $\mathrm{L}^{-1}$ nifedipine $(0.98 \pm 0.23$ vs. $1.71 \pm 0.32 \mathrm{mN} / \mathrm{mm}$, paired $\mathrm{t}$-test, $\mathrm{n}=5, \mathrm{P}=0.02)$. Fig. 3 illustrates that the amplitude of the hypoxic relaxation was not reduced under these circumstances $(-81.0 \pm 11.9 \%$ vs, $-51.5 \pm 6.6 \%$, paired $t-t e s t, n=5, P=0.28)$. 
Bay-K8644 (300 nmol L-1), which activates L-type $\mathrm{Ca}^{2+}$ channels, did not change active wall tension in unstimulated artery segments. However, contractile responses to $25 \mathrm{mmol} \mathrm{L}^{-1} \mathrm{~K}^{+}$ were increased by $50 \%(1.61 \pm 0.16 \mathrm{~N} / \mathrm{m}$ vs. $1.07 \pm 0.10 \mathrm{~N} / \mathrm{m}$, paired t-test, $\mathrm{n}=7, \mathrm{P}<0.01)$. Responses to $1 \mu \mathrm{mol} \mathrm{L}{ }^{-1} \mathrm{NE}$ were slightly altered in the presence of Bay-K8644 $(2.05 \pm 0.14 \mathrm{~N} / \mathrm{m}$ vs. $1.85 \pm 0.14 \mathrm{~N} / \mathrm{m}$, paired $\mathrm{t}$-test, $\mathrm{n}=8, \mathrm{P}<0.01$ ). Induction of hypoxia reduced contraction in

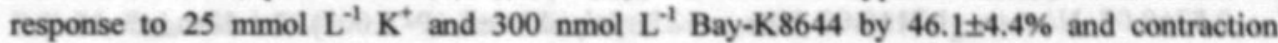
stimulated with $1 \mu \mathrm{mol} \mathrm{L}{ }^{-1} \mathrm{NE}$ and $300 \mathrm{nmol} \mathrm{L}^{-1}$ Bay-K8644 by $61.7 \pm 9.3 \%$.

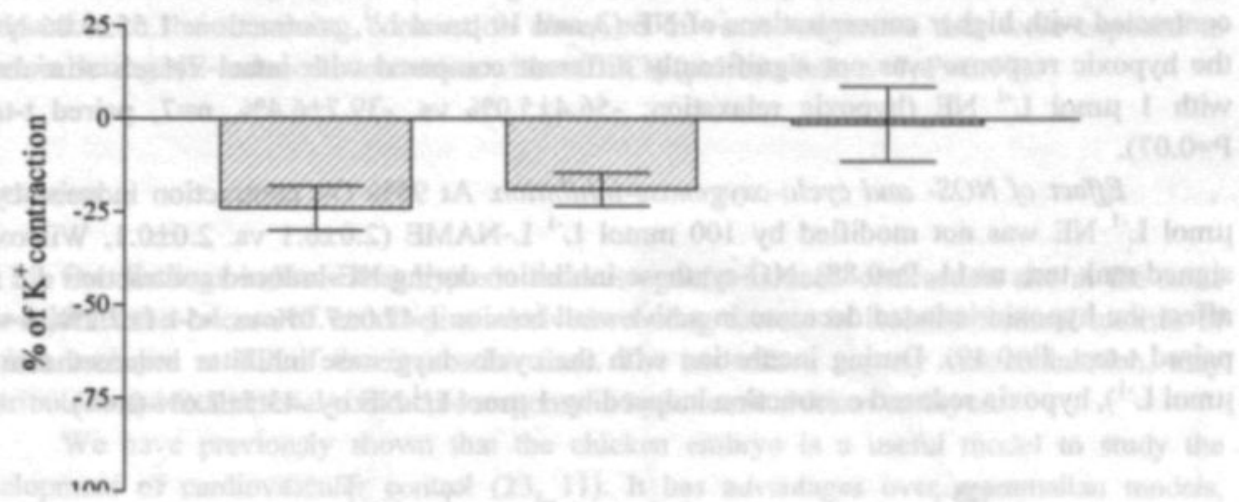

Fig. 2. Ultimate effect of hypoxia on contractile responses to potassium $\left(\mathrm{K}^{+}: 63 \mathrm{mmol} \mathrm{L}{ }^{-1}\right.$ (left), $94 \mathrm{mmol}$ $\mathrm{L}^{-1}$ (middle), and 125 mmol $\mathrm{L}^{-1}$ (right)). Data are expressed as percentage change of contraction and shown as mean \pm SEM ( $\mathrm{n}=5-7$ ). Responses to hypoxia are significantly different from those observed in arteries contracted with $1 \mu \mathrm{mol} \mathrm{L} \mathrm{L}^{-1}$ norepinephrine.

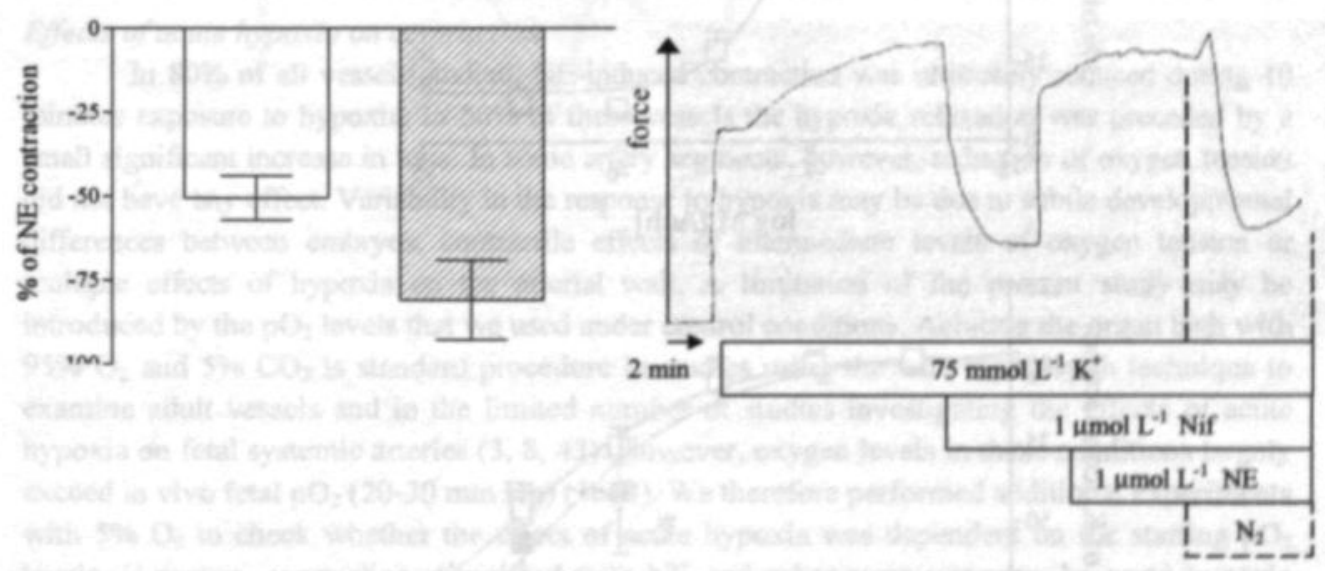

Fig. 3. Effect of hypoxia on contraction induced by $1 \mu \mathrm{mol} \mathrm{L} \mathrm{L}^{-1}$ norepinephrine in absence (open bars) and presence of $1 \mu \mathrm{mol} \mathrm{L} \mathrm{L}^{-1}$ nifedipine and $75 \mathrm{mmol} \mathrm{L}^{-1} \mathrm{~K}^{+}$(filled bars); the decrease of contraction induced by hypoxia is presented as the percentage change in NE-induced active wall tension, mean \pm SEM $(n=5)$. The hypoxia-induced decrease in contraction was not attenuated in the presence of nifedipine and $\mathrm{K}^{*}$. The accompanying tracing shows the effect of hypoxia $\left(\mathrm{N}_{2}\right)$ on isometric force as a function of time during high $\mathrm{K}^{+}$, nifedipine (Nif) and norepinephrine (NE). 
Effect of endothelium removal. Endothelium removal abolished relaxing responses to ACH $\left(1 \mu \mathrm{mol} \mathrm{L}{ }^{-1}:-4.5 \pm 1.3 \%\right.$ vs. $\left.-74.2+2.1 \%, n=25\right)$. Mechanical and chemical removal of endothelium resulted in significant and comparable decreases of contractile responses to NE (1 $\mu \mathrm{mol} \mathrm{L}{ }^{-1}: 1.06 \pm 0.08 \mathrm{~N} / \mathrm{m}$ vs. $1.91 \pm 0.13 \mathrm{~N} / \mathrm{m}, \mathrm{n}=20$, paired $\mathrm{t}$-test, $\left.\mathrm{P}<0.001\right)$ and $\mathrm{K}^{+}\left(125 \mathrm{mmol} \mathrm{L}^{-}\right.$ 1 : $0.87 \pm 0.07 \mathrm{~N} / \mathrm{m}$ vs. $1.71 \pm 0.09 \mathrm{~N} / \mathrm{m}, \mathrm{n}=25$, paired t-test, $\mathrm{P}<0.001$ ). In denuded arteries contracted with $1 \mu \mathrm{mol} \mathrm{L}{ }^{-1} \mathrm{NE}$ the hypoxic change in contraction tended to be less pronounced $(-16.5 \pm 10.1 \%$ vs. $-43.3 \pm 3.8 \%$, paired $t$-test, $n=8, P=0.08)$. However, in denuded vessels contracted with higher concentrations of $\mathrm{NE}$ ( 3 and $10 \mu \mathrm{mol} \mathrm{L}{ }^{-1}$, contraction: $1.55 \pm 0.06 \mathrm{~N} / \mathrm{m}$ ) the hypoxic response was not significantly different compared with intact vessels stimulated with $1 \mu \mathrm{mol} \mathrm{L}^{-1} \mathrm{NE}$ (hypoxic relaxation: $-56.4 \pm 5.0 \%$ vs. $-39.7 \pm 6.4 \%, \mathrm{n}=7$, paired $\mathrm{t}$-test, $\mathrm{P}=0.07)$.

Effect of NOS- and cyclo-oxygenase-inhibition. At $95 \% \mathrm{O}_{2}$, contraction induced by 1 $\mu \mathrm{mol} \mathrm{L}^{-1} \mathrm{NE}$ was not modified by $100 \mathrm{mmol} \mathrm{L}^{-1} \mathrm{~L}-\mathrm{NAME}(2.0 \pm 0.1$ vs. $2.0 \pm 0.1$, Wilcoxon signed rank test, $\mathrm{n}=11, \mathrm{P}=0.88$ ). NO-synthase inhibition during $\mathrm{NE}$-induced contraction did not affect the hypoxia-induced decrease in active wall tension $(-47.0 \pm 7.0 \%$ vs. $-54.1 \pm 7.2 \%, n=11$, paired $t$-test, $\mathrm{P}=0.49$ ). During incubation with the cyclo-oxygenase inhibitor indomethacin ( 3 $\left.\mu \mathrm{mol} \mathrm{L} \mathrm{L}^{-1}\right)$, hypoxia reduced contraction induced by $1 \mu \mathrm{mol} \mathrm{L}^{-1} \mathrm{NE}$ by $-43.5 \pm 7.6 \%(\mathrm{n}=4)$.

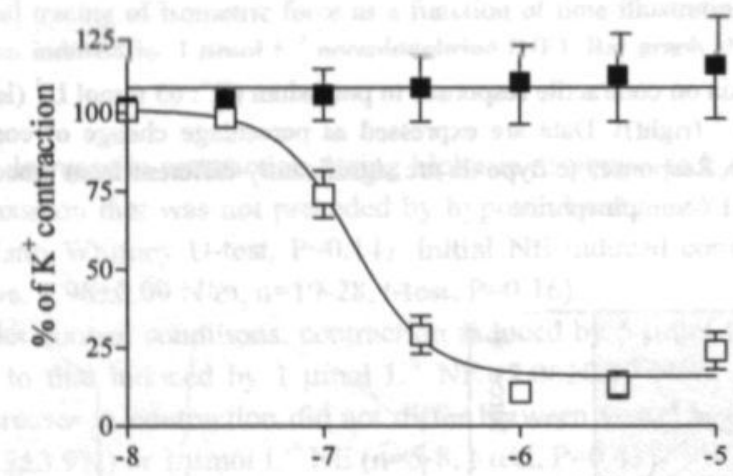

$\log \mathrm{M}$ [Ach]

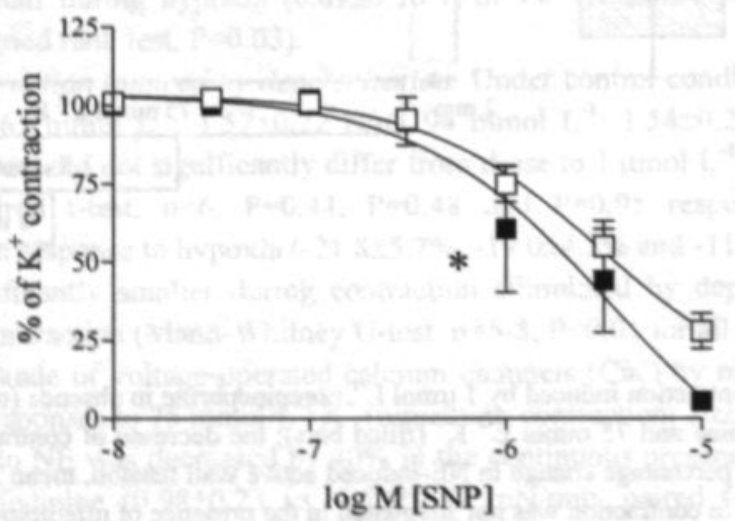

Fig. 4. Effect of hypoxia on relaxation induced by acetylcholine (ACH) (top) and sodium nitroprusside (SNP)(bottom) during normoxia (open symbols) and hypoxia (filled symbols). Hypoxia completely abolished $\mathrm{ACH}$-induced relaxation $(\mathrm{n}=6)$ and significantly increased sensitivity to $\mathrm{SNP}(\mathrm{n}=6)$, * $\mathrm{P}<0.05$. 


\section{Effect of hypoxia on $\mathrm{ACH}$-induced relaxation}

Under control conditions, acetylcholine induced dose-dependent relaxation ( $\mathrm{n}=6$, $\mathrm{pD}_{2}=6.82 \pm 0.09, \mathrm{E}_{\max }=85.3 \pm 2.8 \%$, fig. 4). This relaxation was completely abolished by hypoxia (fig. 4). However, low oxygen tension did not reduce relaxation induced by the NO-donor SNP; sensitivity was even increased during hypoxia $\left(\mathrm{pD}_{2}: 5.81 \pm 0.21\right.$ vs. $5.31 \pm 0.27$, paired t-test, $\mathrm{n}=6$, $\mathrm{P}=0.04, \mathrm{E}_{\max }:-95.1 \pm 2.4 \%$ vs. $-91.7 \pm 3.8 \%$, paired $\mathrm{t}-\mathrm{test}, \mathrm{n}=6, \mathrm{P}=0.47$, fig. 4 ).

Hypoxia reversed relaxing responses to $300 \mathrm{nmol} \mathrm{L}^{-1} \mathrm{M} \mathrm{ACH}$ during $\mathrm{NE}-\left(1 \mu \mathrm{mol} \mathrm{L}{ }^{-1}\right)$ induced contraction (fig.5). The resulting contraction ( $49.80 \pm 9.27 \%$ of NE contraction) was comparable to the remaining contraction observed in vessel segments that were exposed to hypoxia during NE-induced contraction without $\mathrm{ACH}$ (paired t-test, $\mathrm{n}=7, \mathrm{P}=0.77$ ).

\section{Discussion}

Our findings indicate that hypoxia reduces agonist-induced contraction and at the same time inhibits the release of endothelium-derived relaxing factors in isolated femoral arteries of chicken embryos at 0.9 of the incubation time. The net effect, namely vasocontraction, may contribute to the total arterial contractile response in hypoxemic chicken embryos.

We have previously shown that the chicken embryo is a useful model to study the development of cardiovascular control $(23,11)$. It has advantages over mammalian models, including the possibility to evaluate effects of isolated environmental factors, such as hypoxia and malnutrition. We described effects of hypoxia on cardiac output distribution, circulating catecholamines (acute) and on the development of cardiovascular sympathetic nerves in the chicken embryo (chronic) $(25,24,34$ (chapter 4$)$ ). The present study was undertaken to investigate whether low oxygen tension directly influences peripheral arterial reactivity.

\section{Effects of acute hypoxia on contraction}

In $80 \%$ of all vessels studied, NE-induced contraction was ultimately reduced during 10 minutes exposure to hypoxia. In $50 \%$ of these vessels the hypoxic relaxation was preceded by a small significant increase in tone. In some artery segments, however, reduction of oxygen tension did not have any effect. Variability in the response to hypoxia may be due to subtle developmental differences between embryos, contractile effects of intermediate levels of oxygen tension or multiple effects of hypoxia on the arterial wall. A limitation of the present study may be introduced by the $\mathrm{pO}_{2}$ levels that we used under control conditions. Aerating the organ bath with $95 \% \mathrm{O}_{2}$ and $5 \% \mathrm{CO}_{2}$ is standard procedure in studies using the wire myograpgh technique to examine adult vessels and in the limited number of studies investigating the effects of acute hypoxia on fetal systemic arteries $(3,8,43)$. However, oxygen levels in these conditions largely exceed in vivo fetal $\mathrm{pO}_{2}(20-30 \mathrm{~mm} \mathrm{Hg})(16,4)$. We therefore performed additional experiments with $5 \% \mathrm{O}_{2}$ to check whether the effect of acute hypoxia was dependent on the starting $\mathrm{pO}_{2}$ levels. However, contraction stimulated with NE and subsequent responses to acute hypoxia were comparable using $95 \% \mathrm{O}_{2}$ or $5 \% \mathrm{O}_{2}$ as control conditions.

In the majority of arteries stimulated with NE, induction of acute hypoxia ultimately resulted in a partial decrease in tone. A reduction in tone in response to hypoxia may be the result of energy limitation, hypoxia-induced release of vasodilators, or interruption of pharmacomechanical coupling. 

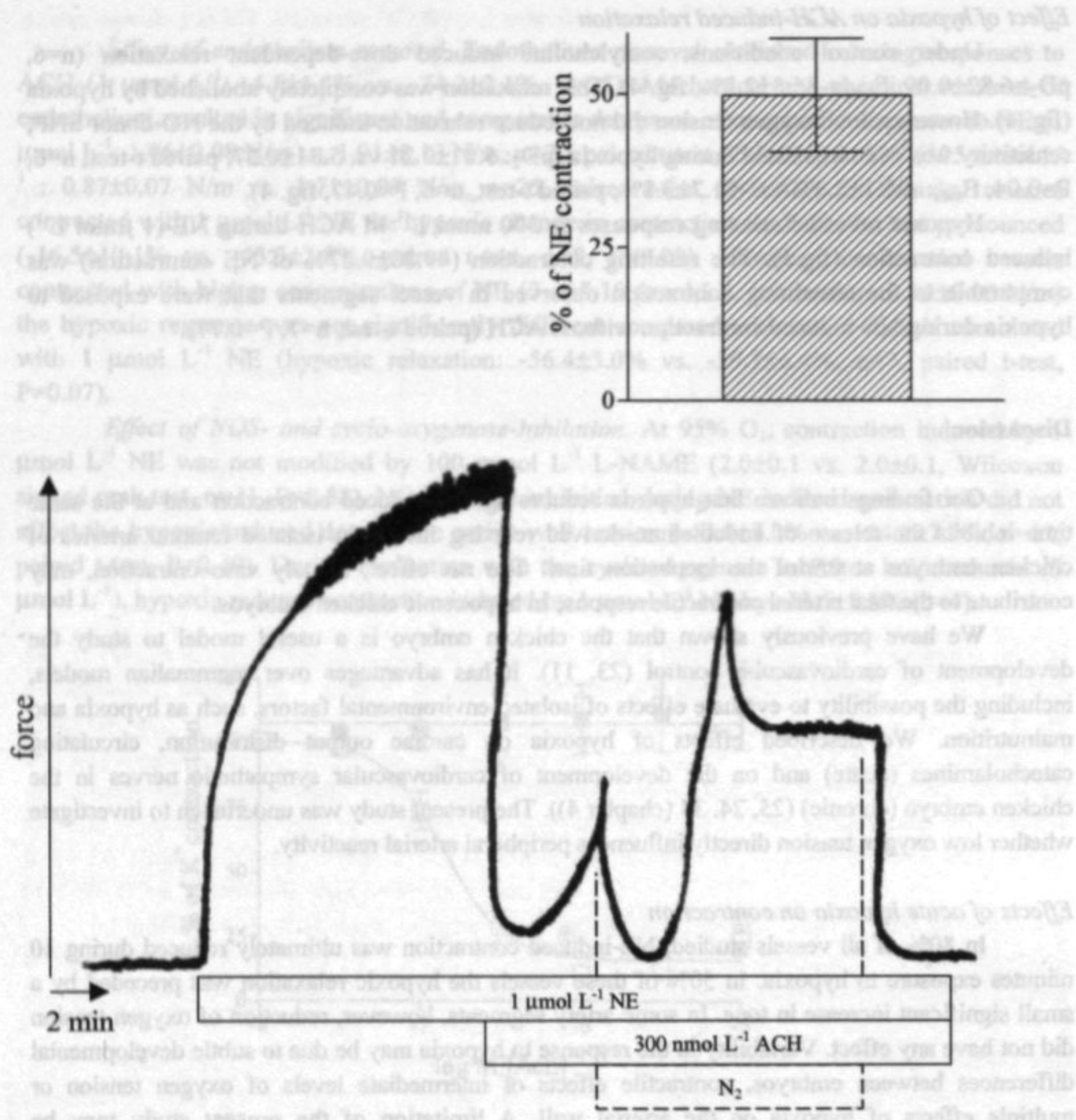

Fig. 5. Typical tracing of isometric force as a function of time illustrating the effect of hypoxia $\left(\mathrm{N}_{2}\right)$ during both contraction induced with norepinephrine (NE) and relaxation induced with acetylcholine (ACH). Bar graph shows mean \pm SEM of 7 artery segments.

Hypoxia did not attenuate contractile responses to high $\mathrm{K}^{+}$to a large extent. Thus, femoral arteries of chicken embryos, like adult arteries of mammalian species (7), can derive energy from anaerobic glycolysis in hypoxic/anoxic conditions. Energy limitations may therefore not be responsible for the reduction of the contractile response to NE by low oxygen tension.

Many studies in adult species show that hypoxia stimulates the release of endothelium derived relaxing factors, such as NO $(17,12)$, prostaglandins $(22,12)$, and EDHF (19). Removal of the endothelium did not abolish the hypoxic response in the femoral artery of the chicken embryo. It should be mentioned that endothelium removal decreased contractions to $\mathrm{NE}$ and $\mathrm{K}^{+}$up to $50 \%$. This could indicate that the denudation procedure damaged the vascular smooth muscle cells. However, inhibition of NO-synthase and cyclo-oxygenase did not blunt the effects of hypoxia. 
Combined depolarization and $\mathrm{Ca}^{2+}$-channel blockade also failed to inhibit the hypoxia-induced decrease in contraction in artery segments contracted with NE. Thus, the reduction of contractile force during acute hypoxia does not seem to be caused by the release of EDRFs like NO. prostaglandins and hyperpolarizing factors. This is in agreement with studies that demonstrate that the role of the endothelium in hypoxic relaxation only becomes evident in mature carotid and cerebral ovine arteries (48). Persistence of hypoxia-induced decrease of contraction in the presence of Bay-K8644 demonstrates that inactivation of voltage-operated $\mathrm{Ca}^{2+}$-channel is not involved in the response either.

In previous experiments we have shown that NE-induced contraction can be blocked by the $\alpha_{1}$-adrenergic antagonist prazosin and that agonists of $\alpha_{r}$ and $\beta$-adrenergic receptors have no significant effects in chicken embryo femoral arteries (18 (chapter 2), 34 (chapter 4)). In the present study we show that, though nifedipine severely reduced contraction induced by high $\mathrm{K}^{+}$, almost $60 \%$ of NE-induced contraction persisted during depolarization and $\mathrm{Ca}$-channel blockade. This indicates that in the chicken embryo, $\alpha_{1}$-adrenergic receptors stimulate contraction at least partly by pharmaco-mechanical coupling as has been documented for mammalian arteries (39). This coupling seems to be more sensitive to low oxygen tension than electro-mechanical coupling induced by high $\mathrm{K}^{+}$. In adult mammalian arteries $\alpha_{1}$-adrenergic contraction involves phospholipase $\mathrm{C}$, protein kinase $\mathrm{C}$, calcium release from intracellular stores and an increase in calcium-sensitivity of the contractile apparatus (see review: 32 ). The relative importance of these processes in arteries of chicken embryos is currently unknown, but may be of interest to study since acute hypoxia has been shown to modulate the $\left[\mathrm{Ca}^{2}\right]$-force relationship $(40,37,5)$ in adult mammalian arteries and may interfere with the ability of $\mathrm{IP}_{3}$ to induce contraction in fetal arteries (2) and possibly with calcium handling in arteries of neonates (48). Studies in sheep suggest that fetal cerebral arteries display increased calcium sensitivity compared with those of the adult (20). The role of calcium sensitization in contraction induced by depolarization with high $\mathrm{K}^{+}$is proposed to be smaller than in agonist-induced contraction $(29,39,45)$. This could explain why hypoxia in arteries of the chicken embryo appears to interfere with pharmaco-mechanical coupling in response to NE rather than electro-mechanical coupling stimulated by high $\mathrm{K}^{+}$. The effect of acute hypoxia on calcium sensitivity in these arteries would therefore be an interesting topic for future research.

\section{Effects of acute hypoxia on relaxation}

While $\alpha$-adrenergic contraction was partially reduced, acetylcholine-induced relaxation of chicken embryo femoral arteries was completely abolished by acute hypoxia. We and others have previously shown that responses to $\mathrm{ACH}$ in chicken arteries are endothelium-dependent $(14,46)$ and, in the femoral artery, are mediated by the release of endothelium-derived NO, EDHF and a factor of which the nature remains to be established (18 (chapter 2)). Hypoxia abolished ACHinduced relaxation in arteries contracted with $\mathrm{K}^{+}$. Blockade of $\mathrm{ACH}$-induced relaxation during hypoxia was not due to reduced responsiveness of the vascular smooth muscle cells to NO, as maximal relaxation to the exogenous NO-donor SNP was unchanged and sensitivity was even increased. Reduced $\mathrm{ACH}$-induced relaxation during exposure to low oxygen tension has been described in arteries of adult animals $(44,6)$ and it has been proposed that oxygen is rate limiting in the regulation of endothelial NOS. Similar mechanisms seem to play a role in fetal pulmonary (36) and carotid (43) arteries. As ACH-stimulated cGMP levels in fetal pulmonary arteries decrease when $\mathrm{pO}_{2}$ in the tissue bath is lowered (36) and fetal arteries may be more sensitive to cGMP than adult arteries (28), it is interesting to note that ODQ, a blocker of guanylate cyclase, completely blocks relaxation in response to ACH in the femoral artery of the chicken embryo (data not shown). However, in view of the complexity of endothelium-dependent relaxations in the chicken embryo 
femoral artery, the exact nature of the EDRFs and/or signaling pathways influenced by hypoxia remains unclear for now.

\section{Relevance for in vivo hemodynamics during acute hypoxemia}

We show that in isolated femoral arteries contracted with $1 \mu \mathrm{M} \mathrm{NE}$ and those in which peri-arterial sympathetic nerve endings were stimulated to release NE, contraction is partly counteracted by acute hypoxia. This may seem at variance with in vivo findings. However, fig. 5 illustrates that our in vitro findings might be relevant for the hemodynamics in prenatal life in vivo. In the mammalian fetus an acute decrease in oxygen results in cardiovascular responses involving an elevation in blood pressure and redistribution of the cardiac output mediated by increased levels of circulating catecholamines $(9,10)$, which are released from the adrenals and later in gestation from the sympathetic nerves (38). During acute hypoxia norepinephrine levels rise from $0.1 \mu \mathrm{M}$ up to $0.8 \mu \mathrm{M}$ in the chicken embryo (24). $\alpha_{1}$-Adrenergic stimulation in response to acute hypoxia resulting in peripheral vasoconstriction has directly and indirectly been shown in the intact chicken embryo $(31,25)$. In the intact embryo, the arterial system may not only be exposed to vasoconstrictors such as NE, but also to a tonic endothelial dilator influence. Vasodilator substances including endothelium-derived NO can be released under the influence of shear stress offered by flow in adult systems $(21,1)$ and it has also been shown to play a role in the fetal circulation $(30,13)$. In the experiment shown in fig. 5 we tried to mimic conditions that play a role during in vivo hypoxemia, namely $\alpha$-adrenergic stimulation and NO-release. During simultaneous agonist-induced stimulation of the smooth muscle with $\mathrm{NE}$ and of the endothelium with $\mathrm{ACH}$, we found that hypoxia resulted in contraction. Provided that the effects of low oxygen tension on agonist-induced endothelium dependent relaxation and those mediated by shear stress involve the same mechanism, this local contraction might contribute to the hemodynamic response to hypoxemia.

It is interesting to note that the effects of acute hypoxia on isolated arteries of the chicken embryo do not seem to be very different from those observed in arteries of adult animals. However, since in vivo fetal $\mathrm{pO}_{2}$ is low, a small reduction in oxygen levels may directly influence vascular tone. Furthermore, as mentioned, certain signal transduction pathways that are potential targets during acute hypoxia may be relatively more important in fetal arteries than in adult arteries (20, 28, 2).

In conclusion, hypoxia was found to partially counteract $\alpha_{1}$-adrenergic contraction and to inhibit endothelium-dependent relaxation in femoral arteries of the chicken embryo. The net result of these local direct effects may contribute to the peripheral arterial response to acute hypoxemia in the chicken embryo.

\section{Acknowledgments}

This work was supported by a grant from "Vrienden van het AZM". The authors like to thank R. van Gool for technical assistance in scanning electron microscopy. 


\section{References}

1. Adeagbo ASO, Tabrizchi R, and Triggle CR. The effect of perfusion rate and n-nitro-Larginine methyl ester on cirazoline- and $\mathrm{KCl}$-induced responses in the perfused mesenteric arterial bed of rats. Br J Pharmacol 111: 13-20, 1994.

2. Angeles DM, Williams J, Purdy RE, Zhang L, and Pearce WJ. Effects of maturation and acute hypoxia on receptor-IP3 coupling in ovine common carotid arteries. Am J Physiol 280: R410-417, 2001.

3. Angeles DM, Williams J, Zhang L, and Pearce WJ. Acute hypoxia modulates 5-HT receptor density and agonist affinity in fetal and adult ovine carotid arteries. Am J Physiol 279: H502H510, 2000.

4. Bennet L, Rossenrode S, Gunning MI, Gluckman PD, and Gunn AJ. The cardiovascular and cerebrovascular responses of the immature fetal sheep to acute umbilical cord occlusion. $J$ Physiol 517.1: 247-257, 1999.

5. Coburn RF, Moreland S, Moreland RS, and Baron CB. Rate-limiting energy-dependent steps controlling oxidative metabolism-contraction coupling in rabbit aorta. $J$ Physiol 448: 473-492. 1992.

6. De Mey JG and Vanhoutte PM. Interaction between $\mathrm{Na}^{+}, \mathrm{K}^{+}$exchanges and the direet inhibitory effect of acteylcholine on canine femoral arteries. Circ Res 46: 826-836, 1980.

7. De Mey JG and Vanhoutte PM. Anoxia and endothelium-dependent reactivity of the canine femoral artery. J Physiol 335: 65-74, 1983.

8. Gilbert RD, Pearce WJ, Ashwal S, and Longo LD. Effects of hypoxia on contractility of isolated fetal lamb cerebral arteries. J Develop Physiol 13: 199-203, 1990.

9. Giussani DA, Riquelme RA, Sanhueza EM, Hanson MA, Blanco CE, and Llanos A.J. Adrenergic and vasopressinergic contributions to the cardiovascular response to acute hypoxaemia in the llama fetus. J Physiol 515: 233-241, 1999.

10. Giussani DA, Spencer JAD, Moore PJ, Bennet L, and Hanson M. Afferent and efferent components of the cardiovascular reflex responses to acute hypoxia in the term fetal sheep. $J$ Physiol 1993: 431-449, 1993.

11. Van Golde J, Mulder T, and Blanco CE. Changes in mean chorioallantoic artery blood flow and heart rate produced by hypoxia in the developing chick embryo. Pediatr Res 42: 293-298. 1997.

12. Graser $\mathbf{T}$ and Rubanyi GM. Different mechanisms of hypoxic relaxation in canine coronary arteries and rat abdominal aortas. J Cardiovasc Pharmacol 20 (suppl. 12): S117-S119, 1992.

13. Harris AP, Helou S, Gleason CA, Traystan RJ, and Koehler RC. Fetal and peripheral circulatory responses to hypoxia after nitric oxide synthase inhibition. Am J Physiol 281: R381R390, 2001.

14. Hasegawa K, Nishimura $\mathbf{H}$, and Khosla $\mathbf{M}$. Angiotensin II-induced endothelium-dependent relaxation of fowl aorta. Am J Physiol 264: R903-R911, 1993.

15. Herrera GM and Walker BR. Involvement of L-type calcium channels in hypoxic relaxation of vascular smooth muscle. J Vase Res 35: 265-273, 1998.

16. Iwamoto HS. Cardiovascular effects of acute fetal hypoxia and asphyxia. Eds.: Hanson MA, Spencer JAD, and Rodeck CH. in: Fetus and neonate. Physiology and clinical applications: 1. Circulation. Cambridge University Press. Cambridge, 1993. pp. 197-214.

17. Jimenez AH, Tanner MA, Caldwell WM, and Myers PR. Effects of oxygen tension on flowinduced vasodilation in porcine coronary resistance arterioles. Microvase Res 51: 365-377, 1996.

18. Le Noble FAC, Ruijtenbeek K, Gemmers S, De Mey JGR, and Blanco CE. Contractile and relaxing reactivity in carotid and femoral arteries of chicken embryos. Am J Physiol 278: H1261H1268, 2000.

19. Liu Q and Flavahan NA. Hypoxic dilatation of porcine small coronary arteries: role of endothelium and $\mathrm{K}_{\mathrm{ATr}}$-channels. Br J Pharmacol 120: 728-734, 1997. 
20. Long W, Zhao $\mathbf{Y}, \mathbf{Z h a n g} \mathrm{L}$, and Longo LD. Role of $\mathrm{Ca}^{2+}$ channels in NE-induced increase in $\left[\mathrm{Ca}^{2+}\right]$ and tension in fetal and adult cerebral arteries. Am J Physiol 277: R286-294, 1999.

21. Martin W, Furehgott RF, Villani GM, and Jothianandan D. Depression of contractile responses in rat aorta by spontaneously released endothelium-derived relaxing factor. $J$ Pharmacol Exp Therap 237: 529-538, 1986.

22. Messina EJ, Sun D, Koller A, Wolin MS, and Kaley G. Role of endothelium-derived prostaglandins in hypoxia-elicited arteriolar dilation in rat skeletal muscle. Circ Res 71: 790-796, 1992.

23. Mulder ALM, Van Golde JC, Prinzen FW, and Blanco CE. Cardiac output distribution in response to hypoxia in the chick embryo in the second half of the incubation time. JPhysiol 508 (part1): 281-287, 1998.

24. Mulder ALM, Van Golde JMCG, Van Goor AAC, Giussani DA, and Blanco CE. Developmental changes in plasma catecholamine concentrations during normoxia and acute hypoxia in the chick embryo. J Physiol 527.3: 593-599, 2000.

25. Mulder ALM, van Goor CA, Giussani DA, and Blanco CE. $\alpha$-Adrenergic contribution to the cardiovascular response to acute hypoxia in the chick embryo. Am J Physiol 281: R2004-R2010, 2001.

26. Muramatsu M, Iwama Y, Shimizu K, Asano H, Toki Y, Miyazaki Y, Okumura K, Hashimoto $\mathbf{H}$, and Ito $\mathbf{T}$. Hypoxia-elicited contraction of aorta and coronary artery via removal of endothelium-derived nitric oxide. Am J Physiol 63: H1339-H1347, 1992.

27. Nankervis CA and Miller CE. Developmental differences in response of mesenteric artery to acute hypoxia in vitro. Am J Physiol 274: G694-G699, 1998.

28. Nauli SM, Zhang L, and Pearce WJ. Maturation depresses cGMP-mediated decreases in $\left[\mathrm{Ca}^{2+}\right]_{1}$ and $\mathrm{Ca}^{2+}$ sensitivity in ovine cranial arteries. Am J Physiol 280: H1019-1028, 2001.

29. Raat NJH, Wetzels GEC, and De Mey JGR. Calcium-contraction relationship in rat mesenteric arterial smooth muscle. Effects of exogenous and neurogenic noradrenaline. Pflügers Arch 436: 262-269, 1998.

30. Reller MD, Burson MA, Lohr JL, Morton MJ, and Thornburg KL. Nitric oxide is an important determinant of coronary flow at rest and during hypoxaemic stress in fetal lambs. Am J Physiol 269: H2074-H2081, 1995.

31. Rouwet EV, De Mey JGR, Slaaf DW, Heineman E, Ramsay G, and Le Noble FAC. Development of vasomotor responses in fetal mesenteric arteries. Am J Physiol 279 (3): H1097H1105, 2000.

32. Ruffolo RR, Nichols AJ, Stadel JM, and Hieble JP. Structure and function of alphaadrenoceptors. Pharmacol Rev 43: 475-505, 1991.

33. Ruijtenbeek K, Blanco C, and De Mey J. Fetal programming of cardiovascular disease. Findings in the chicken embryo. Abstract in: $J$ Vasc Res 38: 1, 2001.

34. Ruijtenbeek K, Le Noble FAC, Janssen GMJ, Kessel CGA, Fazzi GE, Blanco CE, and De Mey JGR. Chronic hypoxia stimulates periarterial sympathetic nerve development in chicken embryo. Circulation 102: 2892-2897, 2000.

35. Shaul P, Farrar MA, and Magness RR. Pulmonary endothelial nitric oxide production is developmentally regulated in the fetus and newborn. Am J Physiol 265: H1056-1063, 1993.

36. Shaul PW, Wells LB, and Horning KM. Acute and prolonged hypoxia attenuate endothelial nitric oxide production in rat pulmonary arteries by different mechanisms. $J$ Cardiovasc Pharmacol 22: 819-827, 1993.

37. Shimizu S, Bowman PS, Thorne G, and Paul RJ. Effects of hypoxia on isometric force, intracellular $\mathrm{Ca}^{2+}, \mathrm{pH}$ and energetics in porcine coronary artery. Circ Res 86: 862-870, 2000.

38. Slotkin TA and Seidler FJ. Adrenomedullary catecholamine release in the fetus and newborn: secretory mechanisms and their role in stress and survival. J Develop Physiol 10: 1-16, 1988.

39. Somlyo AP and Somlye AV. Signal transduction and regulation in smooth muscle. Nature 372: 231-326, 1994. 
40. Taggart MJ and Wray S. Hypoxia and smooth muscle function: key regulatory events during metabolic stress. J Physiol 509: 315-325, 1998.

41. Taguchi H, Heistad DD, Kitazono T, and Faraci FM. ATP-sensitive K channels mediate dilatation of cerebral arterioles during hypoxia. Circ Res 74: 1005-1008, 1994.

42. Theis JWG, Liu Y, and Coceani F. ATP-gated potassium channel activity of pulmonary resistance vessels in the lamb. Can J Physiol Pharmacol 75: 1241-1248, 1997.

43. Thompson LP and Weiner CP. Effects of acute and chronic hypoxia on nitric oxide mediated relaxation of fetal guinea pig arteries. Am J Obstet Gynecol 181: 105-111, 1999.

44. Vallet B, Winn M, Asante NK, and Cain SM. Influence of oxygen on endothelium-derived relaxing factor/nitric oxide and $\mathrm{K}^{+}$-dependent regulation of vascular tone. $J$ Candiovase Pharmacol 24: 595-602, 1994.

45. Van Bavel E, Wesselman J, and Spaan J. Myogenic activation and calcium sensitivity of cannulated rat mesenteric small arteries. Circ Res 82: 210-220, 1998.

46. Villamer E, Ruijtenbeek K, Pulgar V, De Mey JGR, and Blance CE. Vascular reactivity in intrapulmonary arteries of chicken embryos during transition to ex vivo life. Am J Physiol 282: R917-R927, 2002.

47. Wadsworth RM. Vasoconstrictor and vasodilator effects of hypoxia. TIPS 15: 47-52, 1994.

48. Zurcher SD, Ong-Velose GL, Akopov SE, and Pearce WJ. Maturational modification of hypoxic relaxation in ovine carotid and cerebral arteries: role of endothelium. Biol Neonate 74: 222-232, 1998. 


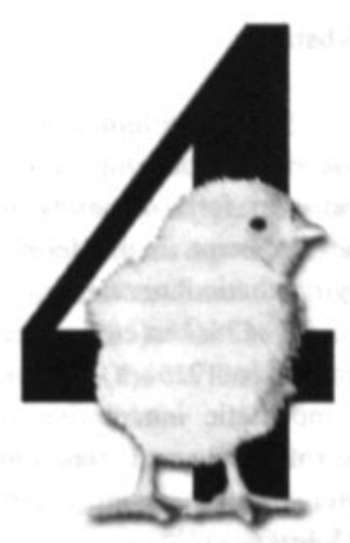

CHAPTER 4

CHRONIC HYPOXIA STIMULATES PERIARTERIAL SYMPATHETIC NERVE DEVELOPMENT IN CHICKEN EMBRYO

Karin Ruijtenbeek, Ferdinand A. C. le Noble, Ger M. J. Janssen, Lilian C. G. A. Kessels, Gregorio E. Fazzi, Carlos E. Blanco, Jo G. R. De Mey Circulation 102: 2892-2897, 2000 


\begin{abstract}
Epidemiological findings suggest an association between low-for-age birth weight and the risk to develop coronary heart diseases in adulthood. During pregnancy, an imbalance between fetal demands and supply may result in permanent alterations of neuroendocrine development in the fetus. We evaluated whether chronic prenatal hypoxia increases arterial sympathetic innervation.

Chicken embryos were maintained from 0.3 to 0.9 of the 21-day incubation period under normoxic $\left(21 \% \mathrm{O}_{2}\right)$ or hypoxic conditions $\left(15 \% \mathrm{O}_{2}\right)$. At 0.9 incubation, the degree of sympathetic innervation of the embryonic femoral artery was determined by biochemical, histological, and functional (in vitro contractile reactivity) techniques. Chronic hypoxia increased embryonic mortality (32\% versus $13 \%$ ), reduced body weight ( $21.9 \pm 0.4$ versus $25.4 \pm 0.6 \mathrm{~g}$ ), increased femoral artery norepinephrine (NE) content (78.4 \pm 9.4 versus $57.5 \pm 5.0$ $\mathrm{pg} / \mathrm{mm}$ vessel length), and increased the density of periarterial sympathetic nerve fibers (14.4 \pm 0.7 versus $12.5 \pm 0.6$ counts $\left./ 10^{4} \mu \mathrm{m}^{2}\right)$. Arteries from hypoxic embryos were less sensitive to $\mathrm{NE}\left(\mathrm{pD}_{2}, 5.99 \pm 0.04\right.$ versus $6.21 \pm 0.10$ ). In the presence of cocaine, however, differences in

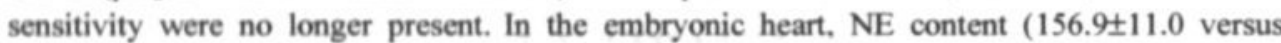
$108.1 \pm 14.7 \mathrm{pg} / \mathrm{mg}$ wet $\mathrm{w}$ ) was also increased after chronic hypoxia.

In the chicken embryo, chronic moderate hypoxia leads to sympathetic hyperinnervation of the arterial system. In humans, an analogous mechanism may increase the risk for cardiovascular disease in adult life.
\end{abstract}




\section{Introduction}

There is now substantial evidence that small size at birth is linked with a higher prevalence of cardiovascular and metabolic diseases in adult life (3, 2). The mechanisms are unknown, but evidence from animal studies and preliminary evidence in humans suggest that an imbalance between fetal demands and supply leads to an adaptive series of stress responses that appear to permanently alter neuroendocrine development (17). Effects of maternal malnutrition on the fetal adrenocortical system have been addressed to some extent (25). We sought to determine whether prenatal hypoxemia interferes with the development of the cardiovascular sympathetic innervation.

In fetal mammals, acute hypoxia induces a redistribution of cardiac output from the periphery to vital organs such as adrenals, brain, and heart $(13,12)$ Direct hypoxia-induced release of adrenal catecholamines (CA) participates in this acute fetal cardiovascular response. Prolonged periods of hypoxia may stimulate the expression of tyrosine hydroxylase (TH), the rate-limiting step in CA synthesis (18), as has also been shown in adult animals (31). This enzyme is essential for fetal development as knock-out mice die in utero at mid-gestation from cardiovascular failure (44). We hypothesize that chronic fetal hypoxia, besides stimulating adrenal CA release and synthesis, also promotes the growth and development of CA-producing autonomic nerves in the immediate vicinity of their cardiovascular effector tissues.

Findings in spontaneously hypertensive rats (SHR) indicate that once established, sympathetic hyperinnervation of the cardiovascular system persists throughout life and leads, after a substantial delay, to the functional, structural, and hemodynamic characteristics of hypertension such as increased peripheral resistance, cardiovascular hypertrophy, and high blood pressure $(26,15,7)$. In humans, high blood pressure involves the cardiovascular sympathetic nervous system and is a well-known risk factor for coronary heart disease (10). which was found to be associated with small for age birth weight (3,2).

In avian embryos, unlike in mammalian species, direct effects of chronic hypoxia can be analyzed in the absence of restricted nutrient supply and matemal or placental hormones. In the chicken embryo, a widely used developmental biological model, the cardiovascular effects of acute hypoxia mimic those seen in a broad variety of mammalian fetuses $(41,29)$, and isolated organ techniques can be used that aim at perivascular autonomic nerves ( 28 (chapter 2)).

In the present study, we tested the hypothesis that prenatal chronic hypoxia stimulates the development of sympathetic nerves in the peripheral arterial system. Chicken embryos were maintained from 0.3 to 0.9 incubation in $21 \%$ or $15 \% \mathrm{O}_{2}$, and the presence and function of sympathetic vasomotor nerves were evaluated in femoral arteries with the use of biochemical, histological, and pharmacological techniques.

\section{Materials and methods}

Experiments were performed in accordance with Dutch law for animal experimentation. Fertile Lohman-selected White Leghom eggs ('t Anker, Ochten, NL), incubated at $38^{\circ} \mathrm{C}$ and relative air humidity of $60 \%$, were transferred on embryonic day 6 to an incubator (Salvis Biocenter 2001) maintained at an oxygen level of $21 \%$ or $15 \% \mathrm{O}_{2}$. On embryonic day 19 of the 21-day incubation, $75 \mu \mathrm{L}$ of blood was obtained from a vessel of the chorioallantoic membrane to determine hematocrit values as an index of chronic hypoxemia. The embryo was removed from the egg. immediately decapitated, and weighed. Arteries and/or organs were isolated for 
determination of arterial reactivity, arterial structure, nerve density, norepinephrine (NE) content, and organ (wet) weights.

\section{Arterial reactivity}

Two-millimeter segments of the right femoral artery were mounted (steel wires, diameter $40 \mu \mathrm{m}$ ) in a myograph organ bath (model 610, Danish Myotechnology by J.P. Trading, Denmark) for isometric force measurement. Organ baths were filled with a Krebs-Ringer bicarbonate buffer, maintained at $37^{\circ} \mathrm{C}$, and aerated with $95 \% \mathrm{O}_{2}$ and $5 \% \mathrm{CO}_{2}$. The arterial segments were stretched until maximal contractile responses to $63 \mathrm{mmol} / \mathrm{L}$ potassium solution were achieved (optimal diameter). Concentration-response curves for $\mathrm{NE}\left(10^{-8}\right.$ to $10^{-5} \mathrm{~mol} / \mathrm{L}$, half $\log$ units) were constructed in the presence and absence of cocaine $(1 \mu \mathrm{mol} / \mathrm{L})$, a blocker of neuronal uptake of NE. Responses to nerve stimulation were tested with the use of electrical field stimulation (EFS, 0.25 to $32 \mathrm{~Hz}$ ), which was previously shown to activate periarterial nerves of the chicken embryo femoral artery and to result in adrenergic nervous contractile responses (28 (chapter 2)). Endothelium was shown to be intact, as acetylcholine induced almost complete relaxation in femoral arteries of hypoxic and normoxic embryos $(86.2+2.5 \%$ and $87.0 \pm 2.1 \%$ relaxation, respectively). Responses to acetylcholine have been shown by us to be completely endothelium dependent in chicken embryos (28 (chapter 2)).

At the end of the experiments, vessel segments were fixed in the organ chamber in phosphate-buffered formaldehyde $\left(4 \%, \mathrm{pH} 7.4,37^{\circ} \mathrm{C}, 30\right.$ minutes) for subsequent morphometric analysis.

\section{Morphometry}

Cross sections ( $4 \mu \mathrm{m}$ thick) of vessels were stained with Lawson solution, and media cross-sectional area, media thickness, radius, and wall/lumen ratio were determined as previously described (37). Video images were generated by a Zeiss Axioscope and standard CCD camera (Stemmer) and were analyzed with commercially available software (JAVA 1.21, Jandel Scientific).

\section{Staining of perivascular nerves}

Whole mount preparations of femoral artery segments were incubated, while in the organ bath, in $2 \%$ glyoxylic acid and $10 \%$ sucrose in phosphate buffer for 10 minutes at room temperature. After this, the segments were air-dried (90 seconds), stretched at $100^{\circ} \mathrm{C}$ for 4 minutes, and enclosed with entellan and a coverslip. Glyoxylic acid-induced fluorescence was visualized with fluorescent microscopy (microscope objective Fluo 10x, Nikon Diaphot, BA 470-DM 455 filter, Nikon FE2 camera). Nerve density was quantified by counting intersections of nerve fibers with a Merz grid (distance $50 \mu \mathrm{m}$, radius $35 \mu \mathrm{m}$ ) within a selected area of the image (42).

\section{NE and DNA content}

Right femoral artery, right carotid artery segments, and heart were solubilized in 0.5 $\mathrm{mol} / \mathrm{L}$ acetic acid $\left(15\right.$ minutes, $\left.100^{\circ} \mathrm{C}\right)$. NE content of the extract was measured by highperformance liquid chromatography and fluorescent detection (38), after which the tissues were solubilized in 1N KOH ( 24 hours, room temperature) and DNA content was determined (23). Unlike for NE, the levels of dopamine and epinephrine were below detection limits in the embryonic arteries and heart. NE levels were expressed relative to arterial segment length or cardiac wet weight. 


\section{Drugs and solutions}

Krebs-Ringer bicarbonate buffer contained (in mmol/L): $\mathrm{NaCl} 118.5, \mathrm{MgSO}_{4} \cdot 7 \mathrm{H}_{2} \mathrm{O}$ 1.2, $\mathrm{KH}_{2} \mathrm{PO}_{4} 1.2, \mathrm{NaHCO}_{3} 25.0, \mathrm{CaCl}_{2} 2.5$, and glucose 5.5. A $60 \mathrm{mmol} / \mathrm{L} \mathrm{K} \mathrm{K}^{+}$solution was prepared by replacing part of the $\mathrm{NaCl}$ by an equimolar amount of $\mathrm{KCl}$. Phosphate-buffered solution consisted of $0.1 \mathrm{~mol} / \mathrm{L} \mathrm{NaH}_{2} \mathrm{PO}_{4} \cdot \mathrm{H}_{2} \mathrm{O}$ and $0.1 \mathrm{~mol} / \mathrm{L} \mathrm{Na} \mathrm{HPO}_{4} \cdot 2 \mathrm{H}_{2} \mathrm{O}$. Arterenol bitartrate (norepinephrine) and cocaine hydrochloride were obtained from Sigma Chemical Co, isoproterenol hemisulfate hydrate from ICN Biomedicals Inc, Lawson solution from Boom b.v., and acetylcholine from Janssen Chimica. Agents were dissolved in distilled water.

\section{Data Analysis}

Sensitivity to $\mathrm{NE}$ (expressed as $\mathrm{pD}_{2}\left[-\log \mathrm{EC}_{50}\right]$ ) and nerve stimulation were determined for each artery by fitting individual concentration-response data to a nonlinear sigmoid regression curve and interpolation (Graphpad Prism version 2.01, Graphpad Software Inc). pD values of arteries of normoxic embryos were compared with those of hypoxic embryos. Maximal responses $\left(\mathrm{E}_{\max }\right)$ to $\mathrm{NE}$ and $\mathrm{EFS}$ for each artery were expressed in terms of active wall tension $(\mathrm{N} / \mathrm{m})$. The effect of cocaine was calculated as the difference between $\mathrm{pD}_{2}$ for $\mathrm{NE}$ in the presence and absence of cocaine $\left(\Delta \mathrm{pD}_{2}\right)$. Differences between findings in normoxic and hypoxic embryos were tested with Student's $t$ test or Mann-Whitney $U$ test when normality test (Kolmogorov-Smirov) failed. A value of $\mathrm{P}<0.05$ was considered statistically significant. Data are presented as mean \pm SEM.

\section{Results}

Exposure of chicken embryos to $15 \% \mathrm{O}_{2}$ from 0.3 to 0.9 incubation reduced embryonic survival ( $68 \%$ versus $87 \%$ ). In the surviving embryos, the hematocrit was significantly increased $(34.6 \pm 1.2 \%$ versus $30.0 \pm 1.8 \%)$ and body weight was significantly reduced $(21.9 \pm 0.4$ versus $25.4 \pm 0.6 \mathrm{~g}$ ). Unlike kidney, liver, and heart weight, relative brain weight was not reduced after chronic hypoxia. Instead, the relative brain weight and brain-to-liver ratio were significantly increased in chicken embryos chronically exposed to low oxygen tension (table 1).

Table 1. Effects of chronic hypoxia on general characteristics of chicken embryos.

\begin{tabular}{|c|c|c|c|c|c|}
\hline & normoxia & & hypoxia & & \\
\hline survival (\%) & 87 & $\mathrm{n}=39$ & 68 & $\bullet$ & $n=65$ \\
\hline body weight (g) & $25.40 \pm 0.56$ & $\mathrm{n}=29$ & $21.86 \pm 0.43$ & $3+$ & $\mathrm{n}=32$ \\
\hline $\mathrm{Ht}(\%)$ & $30.00 \pm 1.81$ & $n=10$ & $34.63 \pm 1.23$ & $3 \bullet$ & $\mathrm{n}=16$ \\
\hline heart (mg) & $200 \pm 5.5$ & $n=29$ & $149 \pm 3.0$ & $\uparrow$ & $n=39$ \\
\hline (\% bodyweight) & $0.79 \pm 0.02$ & & $0.69 \pm 0.01$ & + & \\
\hline kidney (mg) & $100.0 \pm 2.80$ & $n=29$ & $68.0 \pm 1.69$ & $\uparrow$ & $\mathbf{n}=39$ \\
\hline ( $\%$ body weight) & $0.39 \pm 0.01$ & & $0.31 \pm 0.01$ & $\dagger$ & \\
\hline liver (mg) & $596 \pm 14.9$ & $n=29$ & $472 \pm 8.4$ & $t$ & $\mathrm{n}=39$ \\
\hline ( $\%$ body weight) & $2.36 \pm 0.05$ & & $2.18 \pm 0.04$ & + & \\
\hline (mg) & $853 \pm 12.6$ & $n=29$ & $798 \pm 11.5$ & $\because$ & $\mathbf{n}=39$ \\
\hline ( $\%$ body weight) & $3.39 \pm 0.07$ & & $3.69 \pm 0.08$ & $\bullet$ & \\
\hline brain/liver ratio & $1.45 \pm 0.03$ & $n=29$ & $1.70 \pm 0.02$ & 4 & $n=20$ \\
\hline
\end{tabular}

$\mathrm{Ht}=$ hematocrit; means \pm SEM: * $\mathrm{P}<0.05 * \mathrm{P}<0.01, \uparrow \mathrm{P}<0.001$

A $36 \%$ increase in NE content was observed in femoral arteries of hypoxic chicken embryos (78.4 \pm 9.4 versus $57.5 \pm 5.0 \mathrm{pg} \mathrm{NE} / \mathrm{mm}$ vessel length), though the difference failed to reach significance $(\mathrm{P}=0.08)$. In the heart, chronic exposure to hypoxia resulted in a significant 
increase of $45 \%$ ( $156.9 \pm 11.0$ versus $108.1 \pm 14.7 \mathrm{pg} \mathrm{NE} / \mathrm{mg}$ wet weight), but NE content was not altered in carotid arteries (fig. 1). Chronic hypoxia did not modify DNA content of embryonic femoral arteries ( $0.379 \pm 0.02$ versus $0.350 \pm 0.03 \mu \mathrm{g} / \mathrm{mm}$ vessel length), carotid arteries $(0.334 \pm 0.02$ versus $0.314 \pm 0.03 \mu \mathrm{g} / \mathrm{mm}$ vessel length), and heart ( $3.11 \pm 0.07$ versus $3.07 \pm 0.12$ $\mu \mathrm{g} / \mathrm{mg}$ wet $\mathrm{wt})$. Neither were media cross-sectional area $\left(16.2 \pm 1.3\right.$ versus $\left.16.2 \pm 1.110^{3} \mu \mathrm{m}^{2}\right)$, lumen radius $(245 \pm 5$ versus $250 \pm 4 \mu \mathrm{m})$, or medial thickness $(10.3 \pm 0.7$ versus $10.2 \pm 0.7 \mu \mathrm{m})$ of the femoral artery changed by prolonged exposure to low oxygen tension.

In embryonic femoral arteries, chronic hypoxia not only increased NE content but also the density of catecholamine-containing perivascular nerves (fig. 2). Quantitative analysis of whole mounts, stained with glyoxylic acid, indicates that chronic hypoxia significantly increased sympathetic nerve density by $13 \%\left(14.4 \pm 0.7\right.$ versus $12.5 \pm 0.6$ counts $\left./ 10^{4} \mu \mathrm{m}^{2}\right)$.

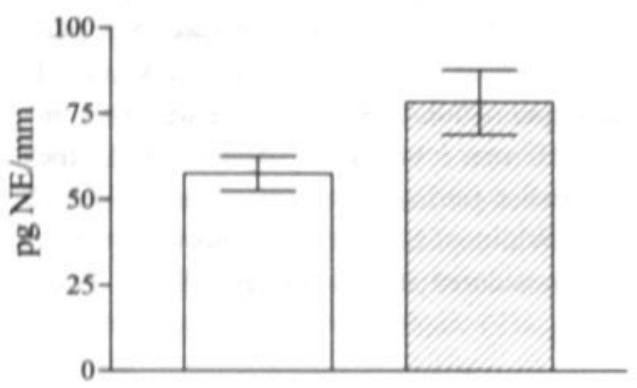

femoral artery

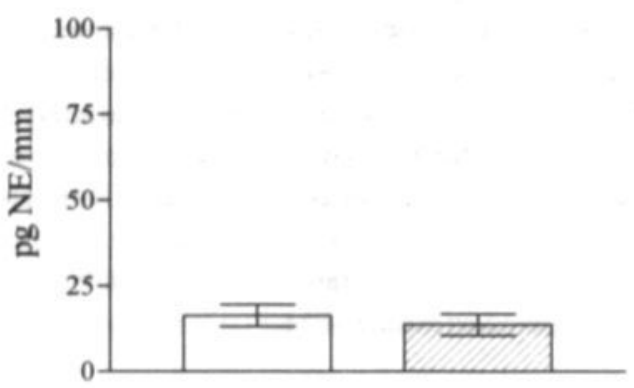

carotid artery

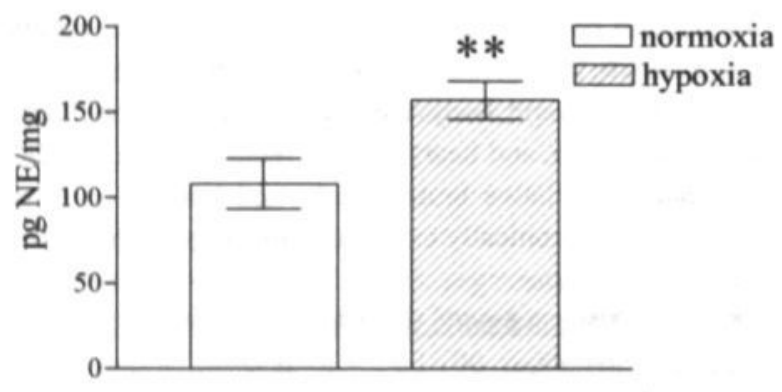

heart

Fig. 1. NE content in femoral artery, carotid artery, and heart of normoxic (open bars) and hypoxic (filled bars) chicken embryos. Values are mean $\pm \operatorname{SEM}(\mathrm{n}=17-21),{ }^{* *} \mathrm{P}<0.01$.

Table 2 summarizes contractile reactivity of femoral artery segments isolated from chicken embryos exposed to $15 \% \mathrm{O}_{2}$ and control embryos $\left(21 \% \mathrm{O}_{2}\right)$. The arterial preparations contracted in vitro in response to high potassium solution and to exogenous NE. Maximal responses to these vasoconstrictor stimuli were not significantly modified after chronic hypoxia. Sensitivity to NE was, however, significantly smaller in vessels from hypoxic embryos (table 2 and fig. 3). Cocaine, an inhibitor of the neuronal reuptake of NE, increased the sensitivity of the arterial preparations to exogenously supplied NE. In the presence of cocaine, the sensitivity to NE no longer differed between arteries of hypoxic and control embryos (table 2 and fig. 3 , suggesting that the sensitizing effect of cocaine was larger in femoral arteries of hypoxic embryos compared with controls $(\triangle \mathrm{pD} 2,0.54 \pm 0.06$ versus $0.37 \pm 0.06)$. The difference failed to 
reach statistical significance $(\mathrm{P}=0.06)$. The $\mathrm{B}$-adrenergic agonist isoproterenol $(3 \mu \mathrm{mol} / \mathrm{L})$ induced only marginal relaxation in $\mathrm{K}^{+}$-precontracted femoral arteries. This effect did not differ between hypoxic $(5.5 \pm 1.0 \%)$ and control $(9.8 \pm 2.7 \%)$ embryos.

Table 2. Effects of chronic hypoxia on in vitro femoral arterial reactivity of chicken embryos.

\begin{tabular}{lllll}
\hline & normoxia & & hypoxia \\
\hline $\mathrm{K}_{\max }(\mathrm{N} / \mathrm{m})$ & $1.66 \pm 0.12$ & $\mathrm{n}=15$ & $1.89 \pm 0.07$ & $\mathrm{n}=24$ \\
$\mathrm{pD}_{2} \mathrm{NE}$ & $6.21 \pm 0.10$ & $\mathrm{n}=15$ & $5.99 \pm 0.04 *$ & $\mathrm{n}=24$ \\
$\mathrm{NE} \mathrm{E}_{\max }(\mathrm{N} / \mathrm{m})$ & $2.10 \pm 0.16$ & $\mathrm{n}=15$ & $2.27 \pm 0.09$ & $\mathrm{n}=24$ \\
$\mathrm{pD}_{2} \mathrm{NE}$ i.p.o. cocaine & $6.58 \pm 0.10$ & $\mathrm{n}=15$ & $6.54 \pm 0.08$ & $\mathrm{n}=24$ \\
$\Delta \mathrm{pD}_{2}$ (cocaine-effect) & $0.37 \pm 0.06$ & $\mathrm{n}=15$ & $0.54 \pm 0.06$ & $\mathrm{n}=24$ \\
$\mathrm{EFS}(50 \% \max$.) $(\mathrm{Hz})$ & $1.94 \pm 0.58$ & $\mathrm{n}=10$ & $4.44 \pm 0.85^{*}$ & $\mathrm{n}=17$ \\
EFS $\mathrm{E}_{\max }(\mathrm{N} / \mathrm{m})$ & $1.21 \pm 0.09$ & $\mathrm{n}=10$ & $1.45 \pm 0.10$ & $\mathrm{n}=17$ \\
EFS E & $0.59 \pm 0.04$ & $\mathrm{n}=10$ & $0.62 \pm 0.03$ & $\mathrm{n}=17$ \\
\hline
\end{tabular}

$\mathrm{K}_{\max }=$ contractile response to $60 \mathrm{mM} \mathrm{K}^{+} ; \mathrm{NE} \mathrm{E}_{\max }=$ maximal response to norepinephrine;

$\mathrm{EFS}=$ electrical field stimulation; EFS $\mathrm{E}_{\max }=$ maximal response to electrical field stimulation; Means \pm SEM. * $\mathrm{P}<0.05$.

Maximal responses to EFS did not significantly differ between arteries of hypoxic embryos and control $(1.45 \pm 0.10$ versus $1.21 \pm 0.09 \mathrm{~N} / \mathrm{m})$. The frequency required to induce $50 \%$ of the maximal response to nerve stimulation was significantly higher in arteries of hypoxic embryos compared with controls $(4.44 \pm 0.85$ versus $1.94 \pm 0.58 \mathrm{~Hz})$. This indicates that although $\mathrm{NE}$ content and nerve density in femoral arteries of hypoxic chicken embryos were increased, sensitivity to the constrictor effect of periarterial nerve stimulation was decreased. This is in line with the observed reduction of the arterial sensitivity to exogenously applied NE.

\section{Discussion}

The present study shows that in chicken embryos, chronic moderate hypoxia increases arterial sympathetic innervation. Exposure of chicken embryos to $15 \%$ instead of $21 \% \mathrm{O}_{2}$ increased embryonic mortality, suggesting an imbalance between embryonic oxygen demand and availability. In the surviving embryos, the hematocrit was significantly increased even at 0.9 incubation, indicating that moderate embryonic hypoxemia was chronically maintained. The observed reduction of total body weight after chronic hypoxia is in agreement with studies of babies born at high altitude (1) and with experimental animal studies (19, 20), which have pointed out the growth inhibiting effects of prolonged hypoxemia. The hypoxia-induced embryonic growth retardation was accompanied by an increase in relative brain weight and brain/liver ratio, suggesting disproportionate growth. The sparing effect on a vital organ such as the brain may be in line with the acute hypoxia-induced redistribution of cardiac output that we previously observed in the chicken embryo (41, 29). 


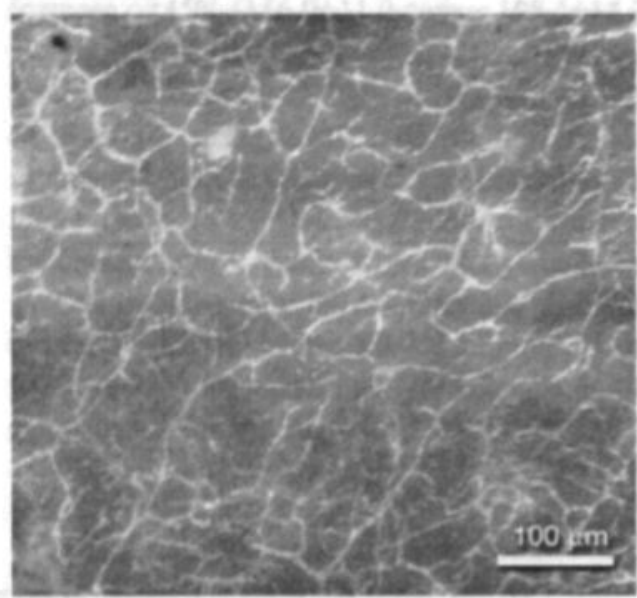

normoxia

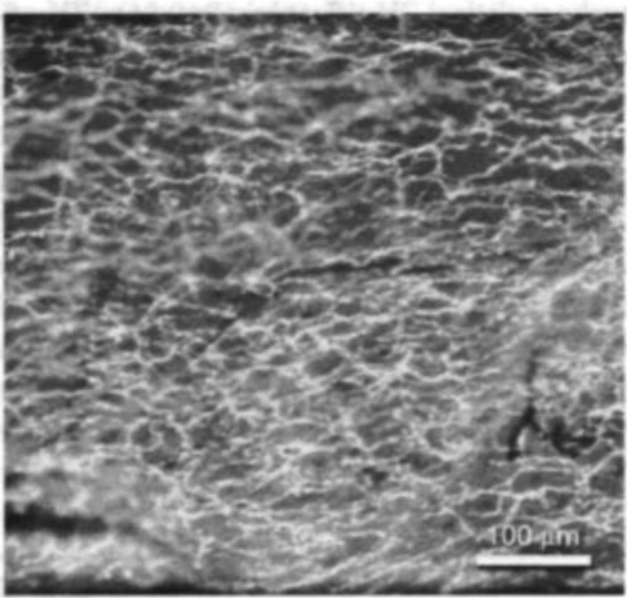

hypoxia

Fig. 2. Typical examples of perivascular sympathetic nerves stained with glyoxylic acid in femoral artery of chicken embryo exposed to normoxia (left) and hypoxia (right).
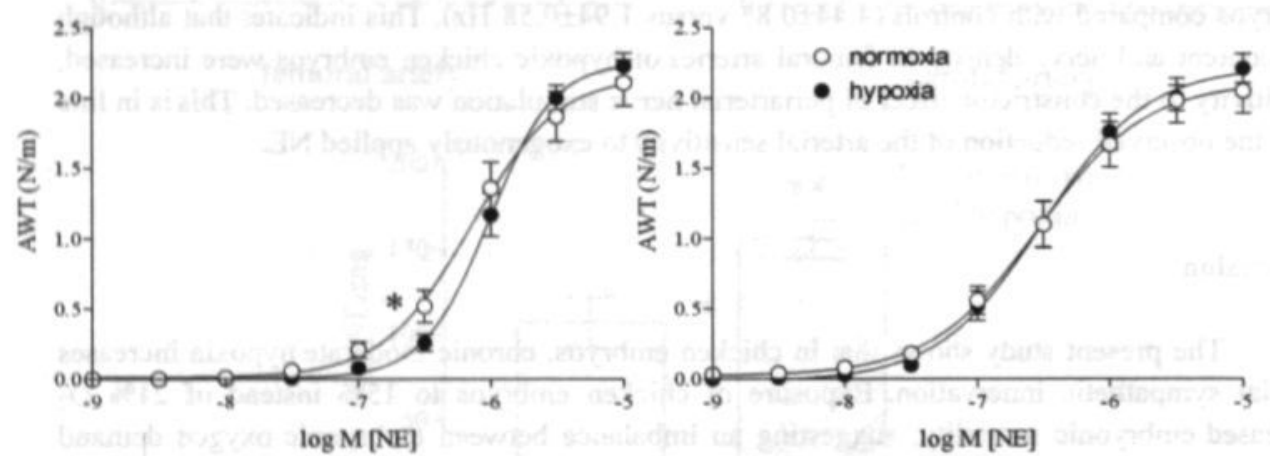

Fig. 3. Contractile responses (AWT, active wall tension) to exogenous NE in isolated femoral artery segments of normoxic and hypoxic chicken embryos. Before (left) and after (right) cocaine. Values are mean $\pm \mathrm{SEM}, * \mathrm{P}<0.05$ (for entire concentration-response curve).

The findings in chicken embryo femoral artery indicate that chronic hypoxia increased periarterial sympathetic innervation. After exposure to $15 \% \mathrm{O}_{2}$, NE content, sympathetic nerve fiber density and cocaine-sensitive neuronal uptake of NE were increased in these arteries. The increase in sympathetic fiber density, which averaged $13 \%$, represents a neurotrophic response. Though differences were not statistically significant, arterial NE content also appeared to be increased by chronic hypoxia. This is in line with reported effects of low oxygen tension on the expression of TH through binding of hypoxia-inducible factors to the promoter sequence of the TH gene $(18,31)$. This mechanism, though not completely established in the fetus, leads to increased NE synthesis. Increased NE levels may be accompanied by an increase in the number of adrenergic varicosities, as suggested by the increased neuronal reuptake of NE. We propose that hypoxia-induced redistribution of cardiac output from the periphery to vital organs in the embryo and fetus is ultimately maintained by stimulation of the peripheral sympathetic nerve 
development after hypoxia-induced release of adrenal NE and upregulation of tyrosine hydroxylase. The maintenance of cardiac output redistribution may also result in disproportionate growth.

Interestingly, in fetal llama, a species adapted to the chronic hypobaric hypoxemia of pregnancy at altitude, peripheral vasoconstriction in response to acute hypoxia is 4 to 5 times greater than in fetal sheep and is mediated by $\alpha$-adrenoceptors. Though the mechanism behind this enhanced $\alpha$-adrenergic response is not yet known, increased peripheral sympathetic innervation may play a role (12).

Despite biochemical and histological signs of sympathetic hyperinnervation, the adrenergic vasoconstrictor responsiveness of chicken embryo femoral arteries was not reduced after chronic hypoxia. Arterial sensitivity to exogenous NE was normalized when neuronal reuptake of NE was pharmacologically blocked with cocaine. Although we did not test this, the reduced sensitivity to sympathetic nerve stimulation may also be the consequence of enhanced neuronal reuptake of NE. In the adult, it is well established that chronic exposure to high concentrations of catecholamines results in desensitization and downregulation especially of $\beta$ adrenoceptors and their signal transduction pathways $(34,14)$. Differences in the chronic control of adrenergic function have, however, been observed between adult and developing individuals. During developmental innervation and synaptogenesis, agonist-induced upregulation of adrenoceptors rather than downregulation has been observed (43). Furthermore, the chronic regulation of innervated arterial postjunctional $\alpha_{1}$-adrenoceptors may differ from that of $\beta$ adrenoceptors (36).

Whereas perivascular sympathetic nerves have been implicated in the proliferation and differentiation of arterial smooth muscle cells (for review see Reference 8), arterial structural consequences of hypoxia-induced sympathetic hyperinnervation were limited in chicken embryo femoral artery investigated at 0.9 incubation. Media cross-sectional area and arterial lumen diameter were not modified; neither was arterial DNA content. Arterial structural consequences of increased periarterial sympathetic nerve density may require more time to develop.

Signs of hypoxia-induced sympathetic hyperinnervation were not restricted to the chicken embryo femoral artery. Also, the heart exhibited a $45 \%$ increase in NE content. In the chicken embryo, carotid artery hypoxia-induced changes were not observed, possibly because of low innervation density of this vessel (28 (chapter 2)).

Several questions remain to be addressed. Is sympathetic nerve development accelerated or increased by hypoxia? Does the effect persist during postnatal development under normoxic conditions? What are the ultimate structural and functional cardiovascular effects? As regards the underlying molecular mechanism, several candidates may be considered. Growth and differentiation of peripheral sympathetic nerves and the production of target-derived nerve growth factors can be stimulated by low oxygen tension, catecholamines (40), and glucocorticoids (11). The direct oxygen sensitivity of the immature adrenal gland (35) may link adrenal function to sympathetic nerve development through circulating catecholamines and glucocorticoids. We chose the chicken embryo to address the effects of prenatal hypoxia on sympathetic nerve development to avoid influences of fetal malnutrition and of maternal and placental hormones. In mammals, an imbalance between fetal demands and supply will of course not be restricted to oxygen. It will therefore be of interest to verify in the chicken embryo whether malnutrition, for instance, by removal of part of the ovalbumin (16), interferes with the observed hypoxia-induced hyperinnervation. Verification of the concept in mammalian situations of uteroplacental insufficiency will also be of interest.

During human pregnancy, important alterations in maternal renal and cardiovascular function develop. Blood flow changes markedly, especially in the uterine circulation. To 
accommodate an increasing fraction of the increasing cardiac output, the uterine arterial bed dilates and remodels extensively during pregnancy (30). Flow-induced vasodilation and outward arterial remodeling are endothelium-dependent processes $(21,5,24)$. Preexisting and pregnancyinduced hyperlipidemia, hypertension, diabetes, and preeclampsia are accompanied by "endothelial dysfunction" $(39,33,4,22)$, which may blunt dilation and remodeling, thereby altering the balance between maternal supply and fetal demands of oxygen and adversely affecting intrauterine fetal growth and possibly stimulating fetal peripheral cardiovascular sympathetic nerve development. In the pathogenesis of cardiovascular diseases, increased density and hyperactivity of the sympathetic nervous system play an important role. In SHR, most evidence indicates a pivotal role of early sympathetic hyperinnervation in the later development of high blood pressure $(26,15,7)$. In SHR pups, the expression of nerve growth factor is increased (9), hyperinnervation precedes the development of hypertension (26), and neonatal sympathectomy prevents hypertension (27). Also, in essentially hypertensive humans, increased spillover of $\mathrm{NE}$ into plasma and electrophysiological evidence of increased sympathetic nerve firing rates are in line with an important role of the sympathetic nervous system, but quantitative information on nerve density is lacking (10). Also, in insulin resistance, an important role of chronic sympathetic hyperactivity has been proposed $(6,32)$. High blood pressure and insulin resistance markedly increase the risk for coronary heart disease, which occurs most frequently in individuals with a low-for-age birth weight $(3,2)$. We propose that a prolonged moderate reduction of maternal oxygen supply interferes with fetal growth and stimulates peripheral cardiovascular sympathetic nerve development. The persisting elevated sympathetic nerve density leads in the long run to an increased risk for cardiovascular diseases.

In summary, we observed that in the chicken embryo, chronic moderate hypoxia not only results in disproportionate growth but also leads to increased sympathetic innervation of peripheral arteries. This sympathetic hyperinnervation may increase the risk for cardiovascular disease.

\section{Acknowledgments}

This work was supported by a grant from "Vrienden van het AZM". 


\section{References}

1. Ballew $\mathbf{C}$ and Haas JD. Hematological evidence of fetal hypoxia among newborn infants at high altitude in Bolivia. Am J Obstet Gynecol 155: 166-169, 1986.

2. Barker DJP. Fetal origins of coronary heart disease. Br Med J 311: 171-174, 1995.

3. Barker DJP, Bull AR, and Simmonds SJ. Fetal and placental size and risk of hypertension in adult life. Br Med J 301: 259-262, 1990.

4. Bouloumie A, Bauersachs J, Linz W, Scholkens BA, Wiemer G, Fleming I, and Busse R. Endothelial dysfunction coincides with an enhanced nitric oxide synthase expression and superoxide anion production. Hypertension 30: 934-941, 1997.

5. Busse $\mathbf{R}$ and Fleming L. Pulsatile stretch and shear stress: physical stimuli determining the production of endothelium-derived relaxing factors. $J$ Vase Res 35: 73-84, 1998.

6. Chang CJ, Wu JS, Lu FH, Liu IM, and Cheng JT. Sympathetic hyperactivity in Wistar rats with insulin resistance. J Auton Nerv Syst 74: 116-119, 1998.

7. Charchar FJ, Kapuscinski MK, and Harrap SB. Nerve growth factor gene locus explains elevated renal nerve growth factor mRNA in young spontaneously hypertensive rats. Hypertension 32: 705-709, 1998.

8. Daemen M.JAP and De Mey JGR. Regional heterogeneity of arterial structural changes. Hypertension 25: 464-473, 1995.

9. Falckh PH, Harkin LA, and Head R.J. Resistance vessel gene expression of nerve growh factor is elevated in young spontaneously hypertensive rats. J Hypertension 10: 913-918. 1992.

10. Folkow B. Integration of hypertension research in the era of molecular biology. G.W. Pickering memorial lecture (Dublin 1994). J Hypertension 13: 5-18, 1995.

11. Francis NJ and Landis SC. Cellular and molecular determinants of sympathetic neuron development. Anmu Rev Neurosci 22: 541-566, 1999.

12. Giussani DA, Riquelme RA, Sanhueza EM, Hanson MA, Blance CE, and Llanos AJ. Adrenergic and vasopressinergic contributions to the cardiovascular response to acute hypoxaemia in the llama fetus. J Physiol 515: 233-241, 1999.

13. Giussani DA, Spencer JAD, Moore PJ, Bennet L, and Hanson MA. Afferent and efferent components of the cardiovascular reflex responses to acute hypoxia in the term fetal sheep. $J$ Physiol 461: 431-449, 1993.

14. Hausdorff WP, Caron MG, and Lefkowitz R.J. Turning off the signal: desensitization of betaadrenergic receptor function. Faseb J 4: 2881-2889, 1990.

15. Head R.J. Hypernoradrenergic innervation: its relationship to functional and hyperplastic changes in the vasculature of the spontaneously hypertensive rat. Blood Vessels 26: 1-20, 1989.

16. Hill WL. Importance of prenatal nutrition to the development of a precocial chick. Dev Psychobiol 26: 237-249, 1993.

17. Hoet JJ and Hanson MA. Intrauterine nutrition: its importance during critical periods for cardiovascular and endocrine development. J Physiol 514.3: 617-627, 1999.

18. Holgert H, Pequignot J-M, Lagercrantz $\mathbf{H}$, and Hokfelt T. Birth-related up-regulation of mRNA encoding tyrosine hydroxylase, dopamine beta-hydroxylase, neuropeptide, tyrosine, and prepro-enkephalin in rat adrenal medulla is dependent on postnatal oxygenation. Pediatr Res 37: 701-706. 1995.

19. Jacobs R, Robinson JS, Owens JA, Falconer J, and Webster MED. The effect of prolonged hypobaric hypoxia on growth of fetal sheep. J Develop Physiol 10: 97-112, 1988.

20. Kamitomo M, Alonso JG, Okai T, Longo LD, and Gilbert RD. Effects of long-term, highaltitude hypoxemia on ovine fetal cardiac output and blood flow redistribution. $\mathrm{Am} J$ Obstet Gynecol 169: 701-707, 1993.

21. Koller A, Sun D, and Kaley G. Role of shear stress and endothelial prostaglandins in flow- and viscosity-induced dilation of arterioles in vivo. Circ Res 72: 1276-1284, 1993.

22. Kung CF and Luscher TF. Different mechanisms of endothelial dysfunctions with aging and hypertension in rat aorta. Hypertension 25: 194-200, 1995. 
23. Labarca $\mathbf{C}$ and Paigen $\mathrm{K}$. A simple, rapid and sensitive DNA assay procedure. Anal Biochem 102: 344-352, 1980.

24. Langille BL and $\mathbf{O}^{\prime}$ Donnel F. Reductions in arterial diameter produced by chronic decreases in blood flow are endothelium dependent. Science 231: 405-407, 1986.

25. Langley-Evans SC, Gardner DS, and Welham S.M. Intrauterine programming of cardiovascular disease by maternal nutritional status. Nutrition 14: 39-47, 1998.

26. Lee RMKW. Vascular changes at the prehypertensive phase in the mesenteric arteries from SHR. Blood Vessels 22: 105-126, 1985.

27. Lee RMKW, Borokowski KR, Leenen FHH, Tsoporis J, and Coughlin M. Combined effect of neonatal sympathectomy and adrenal demedullation on blood pressure and vascular changes in spontaneously hypertensive rats. Circ Res 69: 714-721, 1991.

28. Le Noble FAC, Ruijtenbeek K, Gommers S, De Mey JGR, and Blanco CE. Contractile and relaxing reactivity in carotid and femoral arteries of chicken embryos. Am J Physiol 278: H1261H1268, 2000.

29. Mulder TLM, Van Golde JC, Prinzen FW, and Blance CE. Cardiac output distribution in the chick embryo from stage 36 to 45. Cardiovase Res 34: 525-528, 1997.

30. Nienartowicz A, Link S, and Moll W. Adaptation of the uterine arcade in rats to pregnancy. $J$ Develop Physiol 12: 101-108, 1989.

31. Norris ML and Millhorn DE. Hypoxia-induced protein binding to O2-responsive sequences on the tyrosine hydroxylase gene. J Biol Chem 270: 23774-23779, 1995.

32. Phillips DIW and Barker DJP. Association between low birth weight and high resting pulse in adult life: is the sympathetic nervous system involved in programming the insulin resistance syndrome? Diabet Med 14: 673-677, 1997.

33. Poston L. Nitrovasodillators - will they be useful in lowering uterine artery resistance in preeclampsia and intra-uterine growth restriction? Ultrasound Obstet Gynecol 11: 92-93, 1998.

34. Raymond JR, Hnatowich M, Lefkowitz RJ, and Caron MG. Adrenergic receptors: Models for regulation of signal transduction processes. Hypertension 15: 119-131, 1990.

35. Slotkin TA and Seidler FJ. Adrenomedullary catecholamine release in the fetus and newbom: secretory mechanisms and their role in stress and survival. $J$ Develop Physiol 10: 1-16, 1988.

36. Stassen F, Maas R, Schiffers P, Janssen G, and De Mey J. A positive and reversible relationship between adrenergic nerves and $\alpha_{1 \mathrm{~A}}$-adrenoreceptors in rat arteries. J Pharmacol Exp Therap 284: 399-405, 1998.

37. Stassen FRM, Raat NJH, Brouwers-Ceiler DL, Fazzi GE, Smits JFM, and De Mey JGR. Angiotensin II induces media hypertrophy and hyperreactivity in mesenteric but not epigastric small arteries of the rat. J Vase Res 34: 289-297, 1997.

38. Stassen FRM, Willemsen M.JMF, Janssen GMJ, Fazzi GE, Schiffers PMH, Smits JFM, and De Mey JGR. Reduced responsiveness of rat mesenteric resistance artery smooth muscle to phenylephrine and calcium following myocardial infarction. Br J Pharmacol 120: 1505-1512, 1997.

39. Taylor PD, Oon BB, Thomas CR, Poston T, and Poston L. Prevention by insulin treatment of endothelial dysfunction but not enhanced noradrenaline-induced contractility in mesenteric resistance arteries from streptozotocin-induced diabetic rats. Br JPharmacol 111: 35-41, 1994.

40. Tuttle JB, Etheridge R, and Creedon DJ. Receptor-mediated stimulation and inhibition of nerve growth factor secretion by vascular smooth muscle cells. Exp Cell Res 208: 350-361, 1993.

41. Van Golde J, Mulder T, and Blanco CE. Changes in mean chorioallantoic artery blood flow and heart rate produced by hypoxia in the developing chick embryo. Pediatr Res 42: 293-298, 1997.

42. Weibel ER. Stereological Methods. London. Academic press limited. 1989.

43. Zeiders JL, Seidler FJ, and Slotkin TA. Agonist-induced sensitization of beta-adrenoceptor signaling in neonatal rat heart: expression and catalytic activity of adenylyl cyclase. $J$ Pharmacol Exp Therap 291: 503-510, 1999. 
44. Zhou Q-Y, Qualfe CJ, and Palmiter RD. Targeted disruption of the tyrosine hydroxylase gene reveals that catecholamines are required for mouse fetal development. Nahure 374: 640-643, 1995. 


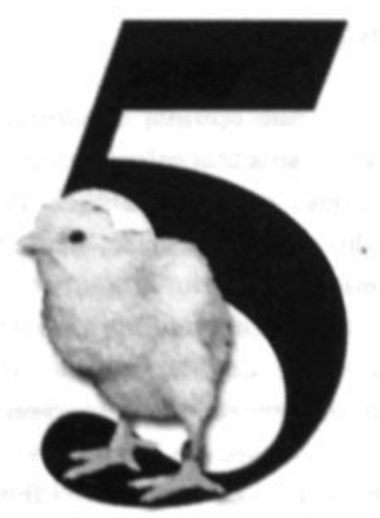

CHAPTER 5

EFFECTS OF PROTEIN MALNUTRITION ON ARTERIAL STRUCTURE AND ARTERIAL SYMPATHETIC INNERVATION OF THE CHICKEN EMBRYO

Karin Ruijtenbeek, Lilian C. G. A. Kessels, Ger M. J. Janssen, Jo G. R. De Mey, Carlos E. Blanco 


\begin{abstract}
Sub-optimal conditions during prenatal life may persistently alter fetal neurohumoral mechanisms that affect cardiovascular morbidity and mortality in the adult. We evaluated in the chicken embryo whether protein malnutrition modified features that are involved in cardiovascular disease, namely structure and sympathetic nervous innervation of peripheral arteries.

Protein malnutrition was induced by removal of $10 \%$ of the albumen content of eggs of the White Leghorn on day 0. Experiments were performed on embryonic day 19. Protein malnutrition reduced embryonic weight $(19.4 \pm 0.5 \mathrm{~g}$ vs. $22.7 \pm 0.6 \mathrm{~g})$, while relative brain weight was increased $(3.83 \pm 0.08 \%$ vs. $3.47 \pm 0.07 \%)$. Isometric force measurements showed that contractions of the isolated femoral artery to $63 \mathrm{mM} \mathrm{K}{ }^{+}$were decreased by protein malnutrition $(1.27 \pm 0.11 \mathrm{~N} / \mathrm{m}$ vs. $1.72 \pm 0.10 \mathrm{~N} / \mathrm{m})$. However, maximal contractions and sensitivity to norepinephrine (NE) and electrical stimulation of peri-arterial nerves (EFS) were not altered (NE, $\mathrm{E}_{\max }: 1.82 \pm 0.15 \mathrm{~N} / \mathrm{m}$ vs. $2.09 \pm 0.16 \mathrm{~N} / \mathrm{m}, \mathrm{pD}_{2}: 6.25 \pm 0.10$ vs. $6.27 \pm 0.08, \mathrm{EFS}, \mathrm{E}_{\max }$ : $1.10 \pm 0.17 \mathrm{~N} / \mathrm{m}$ vs. $1.39 \pm 0.09 \mathrm{~N} / \mathrm{m}$, frequency resulting in half maximal contraction: $2.19 \pm 0.22 \mathrm{~Hz}$ vs. $3.45 \pm 0.86 \mathrm{~Hz})$. Crossectional area $\left(13327 \pm 1718 \mu \mathrm{m}^{2}\right.$ vs. $\left.13013 \pm 972 \mu \mathrm{m}^{2}\right)$ and thickness $(8.66 \pm 1.06 \mu \mathrm{m}$ vs. $8.85 \pm 0.72 \mu \mathrm{m})$ of the arterial media were not changed by protein malnutrition. Blockade of neuronal reuptake of NE with cocaine increased sensitivity to NE; this effect was comparable in arteries of embryos exposed to protein malnutrition and sham controls $\left(\Delta \mathrm{pD}_{2}\right.$ : $0.43 \pm 0.08$ vs. $0.43 \pm 0.10$ ). The density of nerve fibers in the femoral artery was not modified by protein malnutrition either $\left(12.7 \pm 0.8 \times 10^{4} \mu \mathrm{m}^{2}\right.$ vs. $\left.12.6 \pm 0.3 \times 10^{4} \mu \mathrm{m}^{2}\right)$.

These data show that protein malnutrition induces embryonic growth retardation, but does not alter structure or parameters of sympathetic innervation of the femoral artery of the 19 days old chicken embryo. This indicates that effects of fetal protein malnutrition on arterial sympathetic innervation do not provide the mechanistic link between intrauterine growth retardation and cardiovascular disease in adult life.
\end{abstract}




\section{Introduction}

Adverse conditions during development may induce persistent adaptive responses that increase the risk for morbidity and mortality in the adult individual. This has been repeatedly demonstrated by epidemiological studies showing that reduced fetal growth and the resulting low birth weight may predispose to cardiovascular disease in later life $(4,2,17)$.

Changes that take place during adverse conditions in utero may involve decreases in placental activity of 11- $\beta$-hydroxysteroid dehydrogenase type II with overexposure of the fetus to glucocorticoids as a result (14, for review 28), resetting of the HPA-axis $(36,23)$, reduced nephron numbers $(29,33)$, changes in the activity of components of the renin-angiotensin system (48) and modified arterial function $(24,35)$.

However, other candidate mechanisms to explain the fetal programming of adult cardiovascular disease can be considered. Sympathetic hyperinnervation is an important feature of cardiovascular disease (review (26)). In both human (10) and animal studies, hypertensive subjects show signs of sympathetic hyperinnervation. In comparison with normotensive animals small arteries of young SHR exhibit elevated norepinephrine contents (8), increased responses to electric field stimulation and norepinephrine (7) and more dense innervation (30) at a time when blood pressure is not yet elevated. Changes in sympathetic innervation of the cardiovascular system may not be easily corrected by age. Moreover, sympathetic perivascular nerves and norepinephrine have been suggested to influence growth, proliferation and differentiation of vascular smooth muscle cells and thereby possibly vascular resistance (reviews 3, 21, 6). These adaptations may, when affected during intrauterine stress, have detrimental consequences for cardiovascular function in adult life.

Growth is limited when substrates or energy are lacking. This situation can be encountered under circumstances such as undernutrition, hypoxemia or a combination of both (placental insufficiency). Many studies have focussed on malnutrition by studying the effect of interference with maternal nutrition on cardiovascular properties of the offspring. Some epidemiological work indeed suggests that maternal undernutrition is associated with chronic heart disease (38) and risk factors for cardiovascular disease (review 39). In experimental animal studies, restriction of maternal food intake and proteins in particular (5) leads to hypertension in the offspring $(29,48,35,9,45)$.

In search of a mechanism that may link fetal growth retardation to cardiovascular diseases in adult life, we use a model in which we can investigate fetal malnutrition without placental and direct maternal influences, which is not the case in the above mentioned studies in mammalian species. Furthermore, we have previously demonstrated that another stress situation, namely chronic moderate hypoxia, not only reduces body weight, but also increases arterial sympathetic innervation in the chicken embryo (41 (chapter 4)). As lack of nutrients. like reduced oxygen availability, may interfere with growth, it is possible that it also has an effect on cardiovascular development. We therefore studied the effects of protein malnutrition on arterial structure and parameters of arterial sympathetic innervation in the chicken embryo.

\section{Methods}

\section{Experiments were performed in accordance with Dutch Law for animal experimentation.}

The total albumen content of eggs of White Leghom chickens was determined using the methods described by Hill et al. (22). Eggs $(n=18)$ were boiled and the albumen was separated 
from the yolk and weighed. A graph was constructed showing the relationship between the egg weight and total albumen weight. A new set of eggs was used for the in vitro studies and protein malnutrition was induced at day $0(n=88)$. With a sterile needle $(18 G)$ a hole was made in the eggshell (at the pointed end of the egg) and $10 \%$ of the estimated albumen content was carefully extracted from the egg to induce protein malnutrition. In another set of eggs a hole was made without albumen reduction to serve as sham controls $(n=45)$. Holes were sealed with cyanoacrylate (RS components, Corby, UK). The eggs were incubated at $38{ }^{\circ} \mathrm{C}$ and $60-70 \%$ relative air humidity. They were automatically turned every hour.

On embryonic day 19 of the 21-day incubation period embryos were removed from the egg and immediately decapitated. All embryos that were exposed to protein malnutrition and all sham controls were weighed. Organs were isolated to determine organ wet weight. Isometric force measurements were performed in segments of femoral arteries. These segments were also used for morphometric analysis. The remaining part of the femoral artery was used to determine arterial DNA content. Peri-arterial nerve density was also estimated in arteries from protein malnutrition and sham control embryos.

\section{Arterial reactivity}

Two mm segments of the right femoral artery were mounted (steel wires, diameter $\mathbf{4 0}$ $\mu \mathrm{m}$ ) in a myograph organ bath (model $610 \mathrm{M}$, Danish Myotechnology by J.P.Trading, Denmark) for isometric force measurement. Organ baths were filled with a Krebs-Ringer bicarbonate buffer, maintained at $37{ }^{\circ} \mathrm{C}$ and aerated with $95 \% \mathrm{O}_{2}$ and $5 \% \mathrm{CO}_{2}$. The arterial segments were stretched until maximal contractile responses to $63 \mathrm{mmol} / \mathrm{L}$ potassium solution $\left(\mathrm{K}^{+}\right)$were obtained ( $=$ optimal diameter). Increasing concentrations of $\mathrm{NE}\left(10^{-8}\right.$ to $10^{-5} \mathrm{~mol} / \mathrm{L}$, half $\log$ units) were added to the organ bath and concentration-response curves were constructed in the absence and presence of cocaine $(1 \mu \mathrm{mol} / \mathrm{L})$, a blocker of neuronal uptake of NE. Responses to nerve stimulation were tested using electrical field stimulation (EFS: $0.25-32 \mathrm{~Hz}$ ), which was previously shown to stimulate periarterial sympathetic nerves of the chicken embryo femoral artery and $\alpha_{1}$-adrenoceptor mediated contraction (31 (chapter 2)). At the end of the experiments, vessel segments were fixed in the organ chamber in phosphate-buffered formaldehyde $(4 \%$, $\mathrm{pH}=7.4,37^{\circ} \mathrm{C}, 30$ minutes) for subsequent morphometric analysis.

\section{Morphometry}

Lawson solution was used to stain $4 \mu \mathrm{m}$ thick cross-sections of femoral arteries. Media cross-sectional area (CSA), media thickness (Mt), radius $(r)$ and wall/lumen ratio $(\mathrm{W} / \mathrm{L})$ were then determined as previously described (44). Video images were generated by a Zeiss Axioscope (Zeiss, Germany) and standard CCD camera (Stemmer, Germany) and commercially available software (JAVA 1.21, Jandel Scientific, Corte Madera, CA, USA) was used for subsequent analyses.

\section{Staining of perivascular nerves}

Peri-arterial sympathetic nerve density was determined as described previously (41 (chapter 4$)$ ). In short, femoral artery segments were incubated, while in the organ bath, in $2 \%$ glyoxylic acid and $10 \%$ sucrose in phosphate buffer (10 minutes, room temperature). Segments were air-dried ( 90 seconds), stretched $\left(4\right.$ minutes, $\left.100{ }^{\circ} \mathrm{C}\right)$ and enclosed with entellan and a coverslip. Glyoxylic acid-induced fluorescence was visualized using fluorescent microscopy (microscope objective Fluo 10x, Nikon Diaphot, BA 470-DM 455 filter, Nikon FE2 camera). Intersections of nerve fibers with a Merz grid (distance $50 \mu \mathrm{m}$, radius $35 \mu \mathrm{m}$ ) within a selected area of the image were counted to determine nerve density. 


\section{DNA content}

Right femoral arteries were solubilized in $1 \mathrm{~N} \mathrm{KOH} \mathrm{(24} \mathrm{h,} \mathrm{room} \mathrm{temperature)} \mathrm{to}$ determine their DNA content as described previously (41 (chapter 4)). DNA levels were expressed relative to arterial segment length.

\section{Drugs and solutions}

Krebs-Ringer Bicarbonate buffer (KRB) contained (in mmol/L): $\mathrm{NaCl}, 118.5$; $\mathrm{MgSO}_{4} \cdot 7 \mathrm{H}_{2} \mathrm{O}, 1.2 ; \mathrm{KH}_{2} \mathrm{PO}_{4}, 1.2 ; \mathrm{NaHCO}_{3}, 25.0 ; \mathrm{CaCl}_{2}, 2.5 ;$ glucose, 5.5 . A K $\mathrm{K}^{+}$solution of 63 $\mathrm{mmol} / \mathrm{L}$ was prepared by replacing part of the $\mathrm{NaCl}$ by an equimolar amount of KCl. Phosphate buffered solution consisted of $0.1 \mathrm{~mol} / \mathrm{L} \mathrm{NaH}_{2} \mathrm{PO}_{4} \cdot \mathrm{H}_{2} \mathrm{O}$ and $0.1 \mathrm{~mol} / \mathrm{L} \mathrm{Na}_{2} \mathrm{HPO}_{4} \cdot 2 \mathrm{H}_{2} \mathrm{O}$. Arterenol bitartrate (norepinephrine) and cocaine hydrochloride were obtained from Sigma Chemical Co (St. Louis, MO), Lawson solution from Boom b.v. (Meppel, The Netherlands). Stock solutions of these agents were prepared in distilled water.

\section{Data analysis}

Sensitivity to $\mathrm{NE}$ (expressed as $\mathrm{pD}_{2}\left(=-\log \mathrm{EC}_{50}\right)$ ) and nerve stimulation (expressed as the frequency at which half maximal contraction was achieved) were determined for each artery by fitting individual concentration-response data to a non-linear sigmoid regression curve and interpolation (Graphpad Prism version 2.01, Graphpad software Inc, San Diego, CA). pD values of arteries of embryos exposed to protein malnutrition were compared with those of sham controls. Maximal responses $\left(\mathrm{E}_{\max }\right)$ to $\mathrm{NE}$ and EFS for each artery were expressed in terms of active wall tension (AWT, N/m). The effect of cocaine was calculated as the difference between $\mathrm{pD}_{2}$ for $\mathrm{NE}$ in the absence and presence of cocaine $\left(=\Delta \mathrm{pD}_{2}\right)$. Statistical significance of differences between findings in malnourished and sham control embryos were tested with Student t-test or Mann-Whitney U-test when normality test (Kolmogorov-Smimov) failed (Sigma Stat 2.0, Jandel Scientific). $\mathrm{P}<0.05$ was considered statistically significant. Data are presented as mean \pm SEM.

\section{Results}

Removal of $10 \%$ albumen at day 0 resulted in reduced survival ( $56 \%$ vs. $80 \%$, P $=0.03$ ) and a significant decrease of embryonic body weight at day 19 of the 21 day incubation (19.4 $\pm 0.5 \mathrm{~g}$ vs. $22.7 \pm 0.6 \mathrm{~g}, \mathrm{n}=49, \mathrm{n}=36, \mathrm{P}<0.001$, table 1 ). Relative brain weight of embryos that were exposed to protein malnutrition was larger compared to brain weights of sham controls (3.83 $\pm 0.08 \%$ vs. $3.47 \pm 0.07 \%, n=40, n=29, P=0.002$, table 1 ). Relative weights of heart and kidney were not modified $(1.00 \pm 0.03 \%$ vs. $1.00 \pm 0.03 \%, n=48, n=33, P=0.95,0.44 \pm 0.02 \%$ vs. $0.44 \pm 0.02 \%, n=45, n=32, P=0.98$, table 1$)$. Relative liver weight was increased $(2.70 \pm 0.07 \%$ vs. $2.49 \pm 0.06 \%, n=40, n=29, P=0.04$, table 1). Brain to liver ratio was comparable between the group of embryos exposed to protein malnutrition and the sham control group $(1.44 \pm 0.04$ vs. 1.41 $\pm 0.5, \mathrm{n}=40, \mathrm{n}=29, \mathrm{P}=0.59$, table 1).

Protein malnutrition did not alter optimal diameters of femoral arteries ( $461 \pm 10 \mu \mathrm{m}$ vs. $465 \pm 8 \mu \mathrm{m}, \mathrm{n}=17, \mathrm{n}=15, \mathrm{P}=0.78$ ), but decreased maximal contractions induced by $63 \mathrm{mM} \mathrm{K}$ $(1.27 \pm 0.11 \mathrm{~N} / \mathrm{m}$ vs. $1.72 \pm 0.10 \mathrm{~N} / \mathrm{m}, \mathrm{n}=17, \mathrm{n}=15, \mathrm{P}=0.006$, fig. 1). Maximal responses to exogenous norepinephrine $(1.82 \pm 0.15 \mathrm{~N} / \mathrm{m}$ vs. $2.09 \pm 0.16 \mathrm{~N} / \mathrm{m}, \mathrm{n}=11, \mathrm{n}=9, \mathrm{P}=0.24$, fig. 1$)$ and electrical stimulation of peri-arterial nerves $(1.10 \pm 0.17 \mathrm{~N} / \mathrm{m}$ vs. $1.39 \pm 0.09 \mathrm{~N} / \mathrm{m}, \mathrm{n}=8, \mathrm{n}=7$, $\mathrm{P}=0.18$, fig. 1) were not significantly reduced. 
Table 1. Effects of protein malnutrition on body and organ weights of chicken embryos.

\begin{tabular}{llllll}
\hline & sham control & & \multicolumn{2}{c}{ protein malnutrition } \\
\hline body weight $(\mathrm{g})$ & $22.7 \pm 0.6$ & $\mathrm{n}=36$ & $19.4 \pm 0.5 \quad f$ & $\mathrm{n}=49$ \\
heart (\% bodyweight) & $1.00 \pm 0.03$ & $\mathrm{n}=33$ & $1.00 \pm 0.03$ & $\mathrm{n}=48$ \\
kidney (\% bodyweight) & $0.44 \pm 0.02$ & $\mathrm{n}=32$ & $0.44 \pm 0.02$ & $\mathrm{n}=45$ \\
liver (\% bodyweight) & $2.49 \pm 0.06$ & $\mathrm{n}=29$ & $2.70 \pm 0.07 *$ & $\mathrm{n}=40$ \\
brain (\% bodyweight) & $3.47 \pm 0.07$ & $\mathrm{n}=29$ & $3.83 \pm 0.08 * *$ & $\mathrm{n}=40$ \\
brain/liver ratio & $1.41 \pm 0.05$ & $\mathrm{n}=29$ & $1.44 \pm 0.04$ & $\mathrm{n}=40$ \\
\hline
\end{tabular}

means $\pm \mathrm{SEM} ; * \mathrm{P}<0.05 * * \mathrm{P}<0.01, f \mathrm{P}<0.001$

Sensitivity to norepinephrine and electrical nerve stimulation was evaluated in arteries of embryos exposed to protein malnutrition and in sham controls, but no differences were observed $\left(\mathrm{pD}_{2} \mathrm{NE}: 6.25 \pm 0.10\right.$ vs. $6.27 \pm 0.08, \mathrm{n}=11, \mathrm{n}=9, \mathrm{P}=0.88$, fig. 2 , frequency at which half maximal contraction is observed: $2.19 \pm 0.22 \mathrm{~Hz}$ vs. $3.45 \pm 0.86 \mathrm{~Hz}, \mathrm{n}=8, \mathrm{n}=7, \mathrm{P}=0.16$ ). Both femoral arteries of malnourished embryos and of sham controls responded to treatment with the neuronal NE reuptake inhibitor, cocaine, with an increase in sensitivity to $\mathrm{NE}\left(\mathrm{pD}_{2} \mathrm{NE}\right.$ : $6.68 \pm 0.12$ vs. $6.70 \pm 0.13, n=11, n=9$, fig. 2). The effect of cocaine was comparable in the protein malnutrition and sham control group $\left(\Delta \mathrm{pD}_{2}: 0.43 \pm 0.08\right.$ vs. $\left.0.43 \pm 0.10, \mathrm{n}=11, \mathrm{n}=9, \mathrm{P}=0.98\right)$.

Medial cross-sectional area $\left(13327 \pm 1718 \mu \mathrm{m}^{2}\right.$ vs. $\left.13013 \pm 972 \mu \mathrm{m}^{2}, \mathrm{n}=12, \mathrm{n}=11, \mathrm{P}=0.88\right)$, media thickness $(8.66 \pm 1.06 \mu \mathrm{m}$ vs. $8.85 \pm 0.72 \mu \mathrm{m}, \mathrm{n}=12, \mathrm{n}=11, \mathrm{P}=0.89)$ and wall to lumen ratio $(0.037 \pm 0.004$ vs. $0.039 \pm 0.0037)$ did not differ between vessels of embryos exposed to protein malnutrition and sham control embryos. There were no differences in DNA content of the femoral arteries $(0.394 \pm 0.02$ vs. $0.369 \pm 0.02 \mu \mathrm{g} / \mathrm{mm}$ vessel length) of the two groups.

Glyoxylic acid staining revealed peri-arterial sympathetic nerve fibers. Quantification showed that peri-arterial nerve density of femoral arteries was not different between embryos exposed to protein malnutrition and sham controls $\left(12.7 \pm 0.8 \times 10^{4} \mu \mathrm{m}^{2}\right.$ vs. $\left.12.6 \pm 0.3 \times 10^{4} \mu \mathrm{m}^{2}\right)$.

\section{Discussion}

In this study we show that protein malnutrition achieved by removal of $10 \%$ of the albumen induces growth retardation, but does not alter structure or sympathetic innervation of the femoral artery of the 19 days old chicken embryo.

The eggs of chickens contain yolk and albumen. The albumen mainly contains water and amino acids, which are used by the developing embryo for whole-body protein synthesis and growth $(12,34)$. Extraction of albumen from the egg at the start of incubation reduces total embryonic weight towards the end of incubation $(22,12)$ and affects whole-body protein synthesis and growth from day 12 onwards (34). The intervention particularly affects the period of rapid growth at the end of incubation. It has been suggested that it is the lack of proteins during development rather than a caloric restriction, which is particularly effective in increasing postnatal blood pressure (5). Taking this in to account, the model we use can interfere with rapid embryonic growth and may also have an effect on cardiovascular development.

Embryos that underwent the intervention were compared with sham controls, as making a small hole in the eggshell has been shown to induce changes in embryonic metabolism, body weights and organ weights (12). As expected, body weight of the chicken embryos was reduced by protein malnutrition. Relative brain weight of the embryos exposed to protein malnutrition was significantly larger than brain weight of sham control embryos. This suggests that lack of nutrients may not equally affect organ systems and that the brain may be spared in the chicken embryo. Though relative weights of the kidney and heart were unaffected by protein 
malnutrition, relative liver weight of protein-restricted embryos was larger than of sham controls. This was not observed in 20 days old chicken embryos after $20 \%$ removal of the albumen (12), but was demonstrated in 1-day old rat pups after maternal protein restriction (35). In mammalian systems, limitation of fetal glucose supply has been suggested to result in preferential growth of organs that can use alternative substrates (19); the fetal liver can take up lactate (16).

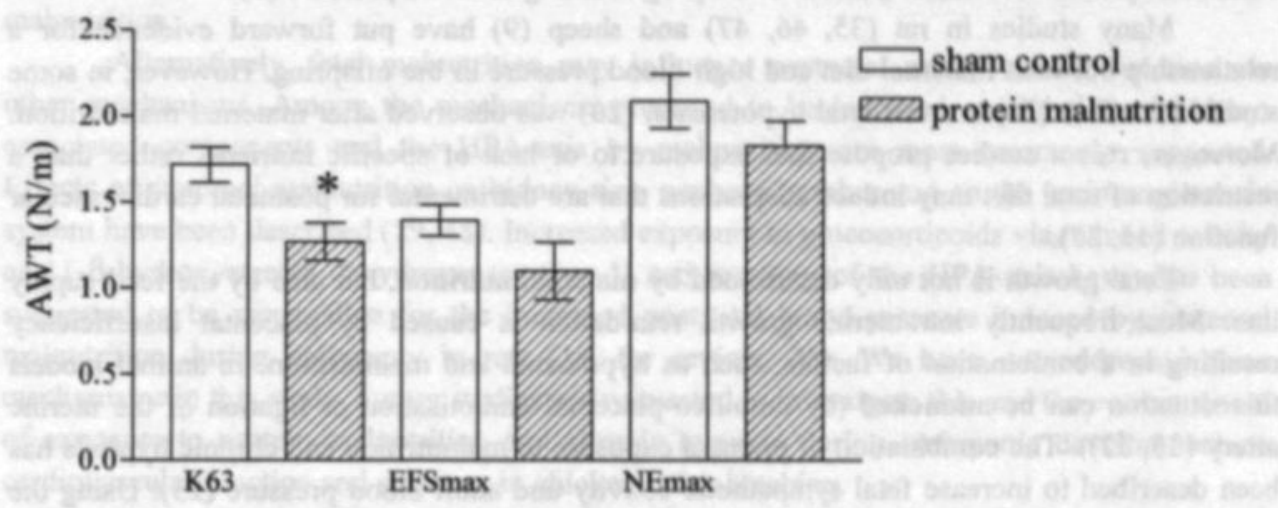

Fig. 1. Maximal responses to $63 \mathrm{mM} \mathrm{K}$, norepinephrine (NE) and electrical stimulation of peri-arterial sympathetic nerves (EFS) in sham controls (open bars) and embryos that were exposed to protein malnutrition (hatched bars). Protein malnutrition significantly reduces responses to $\mathrm{K}^{*}$. MeantSEM, * $\mathrm{P}<0.05$.

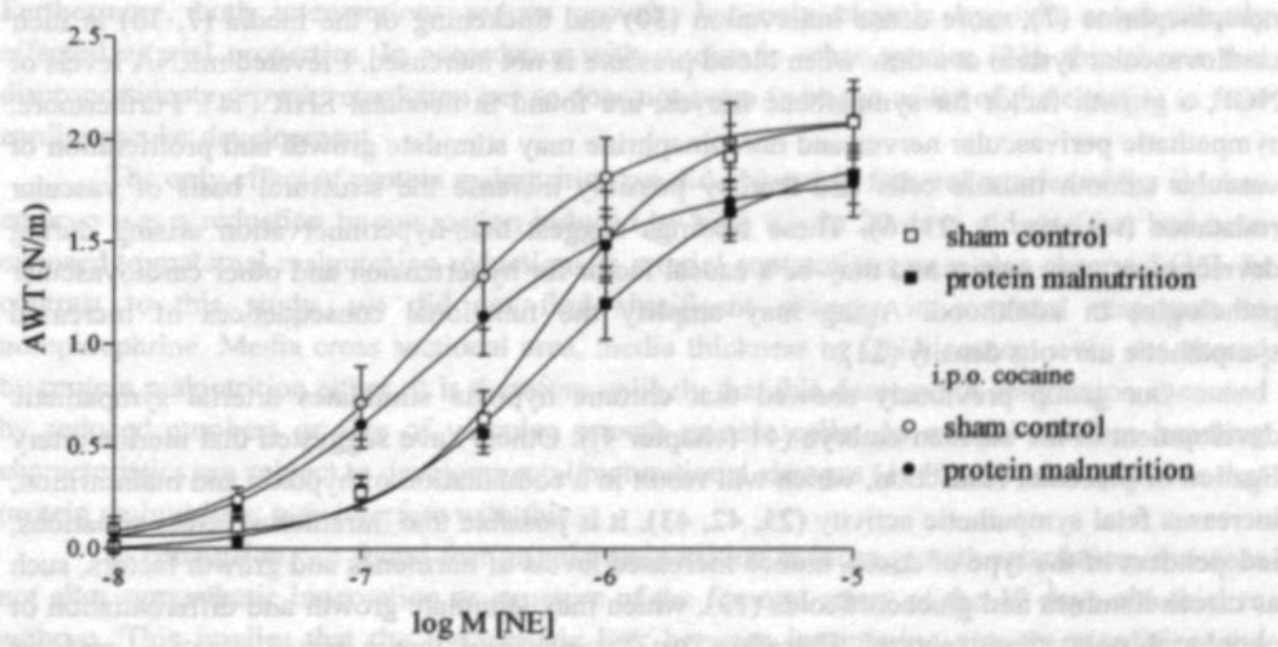

Fig. 2. Concentration-dependent responses to norepinephrine (NE) in sham controls (open symbols) and embryos that were exposed to protein malnutrition (closed symbols) in the absence (squares) and presence (circles) of the neuronal reuptake inhibitor cocaine. In absence and presence of cocaine, maximal responses and sensitivity to NE do not differ between the sham control and protein malnutrition group. 
Ever since there is substantial evidence that fetal growth retardation is associated with cardiovascular disease in adult life (17), many studies have focussed on maternal undernutrition as the cause of this fetal programming. Epidemiological studies investigating data from the Dutch famine suggest that adult risk for coronary heart disease (38) is associated with a reduced maternal intake of nutrients during pregnancy. Blood pressure in the offspring was found to be inversely related to maternal protein/carbohydrates intake, but was not influenced by reduced total caloric intake (37). Another study in human subjects also proposed a role for maternal balance of protein and carbohydrates in the programming of blood pressure (5).

Many studies in rat $(35,46,47)$ and sheep (9) have put forward evidence for a relationship between maternal diet and high blood pressure in the offspring. However, in some studies no effect (24) or even fetal hypotension (20) was observed after maternal malnutrition. Moreover, recent studies propose that exposure to or lack of specific nutrients rather than a restriction of total diet may induce adaptations that are detrimental for postnatal cardiovascular function $(15,27)$.

Fetal growth is not only determined by maternal nutrition, but also by the fetal supply line. Most frequently intrauterine growth retardation is caused by placental insufficiency resulting in a combination of factors, such as hypoxemia and malnutrition. In animal models this situation can be mimicked (by umbilico-placental embolisation or ligation of the uterine artery $(25,32)$ ). The combination of prenatal exposure to malnutrition and chronic hypoxia has been described to increase fetal sympathetic activity and adult blood pressure (23). Using the chicken embryo as an experimental model enables us to study the effects of malnutrition or hypoxia on the cardiovascular development separately.

A role for the sympathetic nervous system in the development of hypertension has been suggested. Both in human hypertensive subjects (10) and in spontaneously hypertensive rats signs of hyperinnervation of the arterial system have been demonstrated. Young SHR exhibit elevated norepinephrine contents (8), increased responses to electric field stimulation and norepinephrine (7), more dense innervation (30) and thickening of the media $(7,30)$ in their cardiovascular system at a time when blood pressure is not increased. Elevated mRNA levels of NGF, a growth factor for sympathetic nerves, are found in neonatal SHR (11). Furthermore, sympathetic perivascular nerves and norepinephrine may stimulate growth and proliferation of vascular smooth muscle cells and thereby possibly increase the structural basis of vascular resistance (reviews: $3,21,6$ ). These findings suggest that hyperinnervation arising during development may persist and may be a causal factor for hypertension and other cardiovascular pathologies in adulthood. Aging may amplify the functional consequences of increased sympathetic nervous density (21).

Our group previously showed that chronic hypoxia stimulates arterial sympathetic development in the chicken embryo (41 (chapter 4)). Others have suggested that uterine artery ligation or placental restriction, which will result in a combination of hypoxia and malnutrition, increases fetal sympathetic activity $(25,42,43)$. It is possible that intrauterine stress situations, independent of the type of stress, induce increased levels of hormones and growth factors, such as catecholamines and glucocorticoids (13), which may stimulate growth and differentiation of peripheral sympathetic nerves. Therefore, we hypothesized that a stress situation, such as protein malnutrition, might induce the same effects in the chicken embryo as we observed after chronic hypoxia. However, responses of the femoral artery to exogenous norepinephrine and electrical stimulation of peri-arterial nerves were not altered by removal of albumen. Furthermore, neuronal reuptake of norepinephrine and the density of peri-arterial sympathetic nerve fibers were not changed by this intervention either, demonstrating that protein malnutrition does not increase arterial sympathetic innervation. Arterial structural components, 
as measured by media cross sectional area and thickness and DNA content, were not significantly changed by protein malnutrition.

The lack of effect of protein malnutrition may indicate that effects on postnatal cardiovascular function induced by maternal undernutrition are the consequence of maternal metabolic/hormonal adaptations to changed diet rather than fetal nutrient deficit per se. The impact of maternal nutrition on the fetus is dependent on maternal nutrient uptake, matemal metabolism and endocrine milieu, uterine and umbilical blood flow and placental transfer and metabolism (18). Therefore maternal malnutrition can not directly be translated to fetal malnutrition.

Alternatively, fetal malnutrition may influence postnatal cardiovascular function via other mechanisms. Among the mechanisms proposed to be involved, modulation of kidneyassociated components and the HPA-axis by malnutrition are most commonly suggested. Effects of maternal malnutrition on kidney size, nephron number and on the renin-angiotensin system have been described $(29,48)$. Increased exposure to glucocorticoids via reduced activity of 11- $\beta$-hydroxysteroid dehydrogenase type II and resetting of the HPA-axis have also been suggested to be responsible for the increased postnatal blood pressure induced by maternal malnutrition during pregnancy in rats (14, for review: 28). We have not addressed these mechanisms in this study. Future studies are warranted to investigate this and the consequences of exposure to protein malnutrition and chronic hypoxia during embryonic development on cardiovascular function and structure in chickens after hatching.

Another important issue must be addressed when studying the link between fetal growth retardation and cardiovascular disease in adult life. Chronic moderate hypoxia in the chicken embryo does have effects on arterial sympathetic innervation (41 (chapter 4)) and endothelial function (40 (chapter 6)) while protein malnutrition does not (this study and 40 (chapter 6)). This may indicate that prenatal exposure to chronic hypoxia may be more detrimental to arterial structure and function with possible postnatal consequences than protein malnutrition. Furthermore, both interventions reduce growth, but only chronic hypoxia concomitantly affected arterial properties. In accordance with studies in other species (23), this shows that disproportionate growth retardation per se does not seem to be the cause of the changes in fetal cardiovascular development.

The only effect of protein malnutrition we did observe in femoral arteries of the chicken embryo was a reduction in contraction induced by high $\mathrm{K}^{+}$. In $\mathbf{2 0}$ days old rats that had been exposed to maternal malnutrition reductions in arterial contractions were also observed (35). In contrast to this study, we did not find significant changes in maximal responses to norepinephrine. Media cross sectional area, media thickness or DNA content were not altered by protein malnutrition either. It is therefore unlikely that this decrease in contraction is caused by reduced numbers or size of vascular smooth muscle cells. As arterial calcium handling characteristics are subject to developmental/maturational changes $(1,49)$, one can speculate that protein malnutrition may interfere with this.

In conclusion, we found that protein malnutrition induces growth retardation, but does not alter sympathetic innervation or structure of the femoral artery of the 19 days old chicken embryo. This implies that the mechanistic link between intrauterine growth retardation and cardiovascular disease in adult life is not provided by effects of fetal protein malnutrition on arterial sympathetic innervation.

\section{Acknowledgments}

This work was supported by a grant from "Vrienden van het AZM". 


\section{References}

1. Akopov SE, Zhang L, and Pearce WJ. Maturation alters the contractile role of calcium in basilar arteries. Pediatr Res 44: 154-160, 1998.

2. Barker DJP and Fall CHD. Fetal and infant origins of cardiovascular disease. Arch Dis Child 68: 797-799, 1993.

3. Bevan RD. Influence of adrenergic innervation on vascular growth and mature characteristics. Am Rev Respir Dis 140: 1478-1482, 1989.

4. Byrne CD and Phillips DI. Fetal origins of adult disease: epidemiology and mechanisms. J Clin Pathol 53: 822-828, 2000.

5. Campbell DM, Hall MH, Barker DJP, Cross J, Shiell AW, and Godfrey KM. Diet in pregnancy and the offspring's blood pressure 40 years later. Br JObst Gyn 103: 273-280, 1996.

6. Daemen M.AP and De Mey JGR. Regional heterogeneity of arterial structural changes. Hypertension 25: 464-473, 1995.

7. Dickhout JG and Head RJ. Structural and functional analysis of small arteries from young spontaneously hypertensive rats. Hypertension 29: 781-789, 1997.

8. Donohue S.J, Stitzel RE, and Head R.J. Time course of changes in the norepinephrine content of tissues from spontaneously hypertensive and Wistar Kyoto rats. J Pharmacol Exp Therap 245: 24-31, 1988.

9. Edwards LJ and MeMillen IC. Maternal undernutrition increases arterial blood pressure in the sheep fetus during late gestation. J Physiol 533.2: 561-570, 2001.

10. Esler M, Lambert G, and Jennings G. Increased regional sympathetic nervous activity in human hypertension: causes and consequences. J Hypertension 8: S53-S57, 1990.

11. Falckh PH, Harkin LA, and Head RJ. Resistance vessel gene expression of nerve growth factor is elevated in young spontaneously hypertensive rats. J Hypertension 10: 913-918, 1992.

12. Finkler MS, Van Orman JB, and Sotherland PR. Experimental manipulation of egg quality in chickens: influence of albumen and yolk on the size and body composition of near-term embryos in a precocial bird. J Comp Physiol 168: 17-24, 1998.

13. Francis NJ and Landis SC. Cellular and molecular determinants of sympathetic neuron development. Anmu Rev Neurosci 22: 541-566, 1999.

14. Gardner DS, Jackson AA, and Langley-Evans SC. Maintenance of maternal diet-induced hypertension in the rat is dependent on glucocorticoids. Hypertension 30: 1525-1530, 1997.

15. Ghosh P, Bitsanis D, Ghebremeskel K, Crawford MA, and Poston L. Abnormal aortic fatty acid composition and small artery function in offspring of rats fed a high fat diet in pregnancy. $J$ Physiol 533.3: 815-822, 2001.

16. Gleason CA, Rudolph CD, Bristow J, Itskovitz J, and Rudolph AM. Lactate uptake by the fetal sheep liver. J Develop Physiol 7: 177-183, 1985.

17. Godfrey KM and Barker DJP. Fetal nutrition and adult disease. Am J Clin Nutr 71: 1344S1352S, 2000.

18. Harding JE. The nutritional basis of the fetal origins of adult disease. Int J Epidemiol 30: 15-23, 2001.

19. Harding JE and Gluckman PD. Growth, metabolic, and endocrine adaptations to fetal undemutrition. Eds.: Barker DJP. in: Fetal origins of cardiovascular and lung disease. Marcel Dekker, Inc. New York - Basel. 2001. pp. 181-197.

20. Hawkins P, Steyn C, Ozaki T, Saito T, Noakes DE, and Hanson MA. Effect of maternal undernutrition in early gestation on ovine fetal blood pressure and cardiovascular reflexes. $\mathrm{Am} \mathrm{J}$ Physiol 279: R340-R348, 2000.

21. Head RJ. Hypernoradrenergic innervation: its relationship to functional and hyperplastic changes in the vasculature of the spontaneously hypertensive rat. Blood Vessels 26: 1-20, 1989.

22. Hill WL. Importance of prenatal nutrition to the development of a precocial chick. Dev Psychobiol 26: 237-249, 1993. 
23. Hoet $\mathbf{J}$ and Hanson MA. Intrauterine nutrition: its importance during critical periods for cardiovascular and endocrine development. J Phosiol 514.3: 617-627, 1999.

24. Holemans K, Gerber R, Meurrens K, De Clerck F, Poston L, and Van Assche FA. Maternal food restriction in the second half of pregnancy affects vascular function but not blood pressure of rat female offspring. Br JNutrition 81: 73-79, 1999.

25. Jansson $\mathbf{T}$ and Lambert GW. Effect of intrauterine growth restriction on blood pressure, glucose tolerance and sympathetic nervous system activity in the rat at $3-4$ months of age. $J$ Hypertension 17: 1239-1248, 1999.

26. Julius $\mathbf{S}$ and Valentini $\mathbf{M}$. Consequences of the increased autonomic nervous drive in hypertension, heart failure and diabetes. Blood Pressure 7: 5-13, 1998.

27. Langley-Evans S. Intrauterine programming of hypertension in the rat: nutrient interactions. Comp Biochem Physiol 114A: 327-333, 1996.

28. Langley-Evans SC, Gardner DS, and Welham S.M. Intrauterine programming of cardiovascular disease by matemal nutritional status. Nutrition 14:39-47, 1998.

29. Langley-Evans SC, Welham SJM, and Jackson AA. Fetal exposure to a maternal low protein diet impairs nephrogenesis and promotes hypertension in the rat. Life Sci 64: 965-974, 1999.

30. Lee RMKW. Vascular changes at the prehypertensive phase in the mesenteric arteries from SHR. Blood Vessels 22: 105-126, 1985.

31. Le Noble FAC, Ruijtenbeek K, Gommers S, De Mey JGR, and Blance CE. Contractile and relaxing reactivity in carotid and femoral arteries of chicken embryos. Am J Physiol 278: H1261H1268, 2000.

32. Louey S, Cock ML, Stevenson KM, and Harding R. Placental insufficiency and fetal growth restriction lead to postnatal hypotension and altered postnatal growth in sheep. Pediatr Res 48: 808-814, 2000.

33. Merlet-Benichou C, Gilbert T, Muffat-Joly M, Lelievre-Pegorier M, and Leroy B. Intrauterine growth retardation leads to a permanent nephron deficit in the rat. Pediatr Nephrol 8: 175-180, 1994.

34. Muramatsu T, Hiramoto K, Koshi N, Okumura J, Miyeshi S, and Mitsumete T. Importance of albumen content in whole body protein synthesis of the chick embryo during incubation. British Poultry Science 31: 101-106, 1990.

35. Ozaki T, Nishina H, Hanson MA, and Poston L. Dietary restriction in pregnant rats causes gender-related hypertension and vascular dysfunction in offspring. $J$ Physiol 530.1: 141-152, 2001.

36. Phillips DIW. Fetal growth and programming of the hypothalamic-pituitary-adrenal axis. Clin Exp Pharmacol Physiol 28: 967-970, 2001.

37. Roseboom TJ, van der Meulen JHP, van Montfrans GA, Ravelli ACJ, Osmond C, Barker DJP, and Bleker OP. Maternal nutrition during gestation and blood pressure in later life. $J$ Hypertension 19: 29-34, 2001.

38. Roseboom TJ, van der Meulen JHP, Osmond C, Barker DJP, Ravelli ACJ, SchroederTanka JM, van Montfrans GA, Michels RPJ, and Bleker OP. Coronary heart disease after prenatal exposure to the Dutch famine, 1944-45. Heart J84: 595-598, 2000.

39. Roseboom TJ, van der Meulen JHP, Ravelli ACJ, Osmond C, Barker DJP, and Bleker OP. Effects of prenatal exposure to the Dutch famine on adult disease in later life: an overview. Mol Cell Endocrinol 185: 93-98, 2001.

40. Ruijtenbeek K, Blanco CE, and De Mey JGR. Fetal programming of cardiovascular disease. Findings in the chicken embryo. J Vase Res 38 (Suppl.2): 1, 2001.

41. Ruijtenbeek K, Le Noble FAC, Janssen GMJ, Kessel CGA, Fazzi GE, Blanco CE, and De Mey JGR. Chronic hypoxia stimulates periarterial sympathetic nerve development in chicken embryo. Circulation 102: 2892-2897, 2000.

42. Shaul PW, Cha CM, and Oh W. Neonatal sympathoadrenal response to acute hypoxia: impairment after experimental intrauterine growth retardation. Pediatr Res 25: 466-467, 1989. 
43. Simonetta G, Rourke AK, Owens JA, Robinson JS, and MeMillen IC. Impact of placental restriction on the development of the sympathoadrenal system. Pediatr Res 42: 805-811, 1997.

44. Stassen FRM, Raat NJH, Brouwers-Ceiler DL, Fazzi GE, Smits JFM, and De Mey JGR. Angiotensin II induces media hypertrophy and hyperreactivity in mesenteric but not epigastric small arteries of the rat. J Vasc Res 34: 289-297, 1997.

45. Tonkiss J, Trzeinska M, Galler JR, Ruiz-Opazo N, and Herrera VLM. Prenatal malnutrition-induced changes in blood pressure, dissociation of stress and nonstress responses using radiotelemetry. Hypertension 32: 108-114, 1998.

46. Vehaskari VM, Aviles DH, and Manning J. Prenatal programming of adult hypertension in the rat. Kidney Int 59: 238-245, 2001.

47. Woodall SM, Johnston BM, Breier BH, and Gluckman PD. Chronic maternal undernutrition in the rat leads to delayed postnatal growth and elevated blood pressure of offspring. Pediatr Res 40: 438-443, 1996.

48. Woods LL, Ingelfinger JR, Nyengaard JR, and Rasch R. Maternal protein restriction suppresses the newborn renin-angiotensin sytem and programs adult hypertension in rats. Pediatr Res 49: 460-467, 2001.

49. Zurcher SD and Pearce WJ. Maturation modulates serotonin- and potassium-induced calcium45 uptake in ovine carotid and cerebral arteries. Pediatr Res 38: 493-500, 1995. 


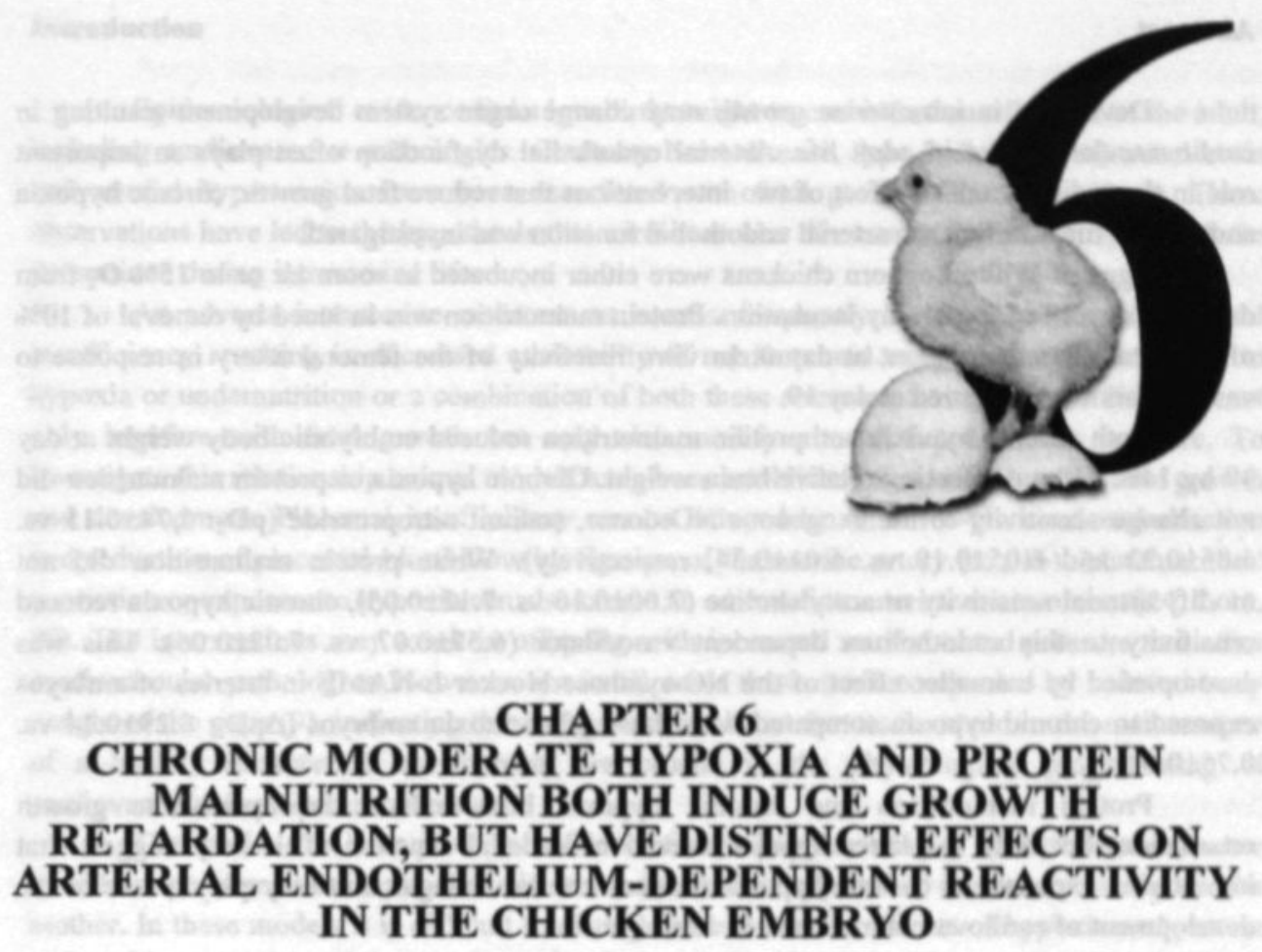

Karin Ruijtenbeek, Lilian C. G. A. Kessels, Jo G. R. De Mey, Carlos E. Blanco 


\begin{abstract}
Deviations in intrauterine growth may change organ system development resulting in cardiovascular disease in adult life. Arterial endothelial dysfunction often plays an important role in these diseases. The effect of two interventions that reduce fetal growth, chronic hypoxia and protein malnutrition, on arterial endothelial function was investigated.

Eggs of White Leghorn chickens were either incubated in room air or in $15 \% \mathrm{O}_{2}$ from day 6 till day 19 of the 21 day incubation. Protein malnutrition was induced by removal of $10 \%$ of the total albumen content at day 0 . In vitro reactivity of the femoral artery in response to vasodilators was measured at day 19.

Both chronic hypoxia and protein malnutrition reduced embryonic body weight at day 19 by $14 \%$ without affecting relative brain weight. Chronic hypoxia or protein malnutrition did not change sensitivity to the exogenous NO-donor, sodium nitroprusside $\left(\mathrm{pD}_{2}: 5.74 \pm 0.15 \mathrm{vs}\right.$. $5.85 \pm 0.23$ and $6.05 \pm 0.18$ vs. $6.01 \pm 0.34$, respectively). While protein malnutrition did not modify arterial sensitivity to acetylcholine $(7.00 \pm 0.10$ vs. $7.12 \pm 0.05)$, chronic hypoxia reduced sensitivity to this endothelium dependent vasodilator $(6.57 \pm 0.07$ vs. $7.02 \pm 0.06)$. This was accompanied by a smaller effect of the NO-synthase blocker L-NAME in arteries of embryos exposed to chronic hypoxia compared with those of normoxic embryos $\left(\Delta \mathrm{pD}_{2}: 0.29 \pm 0.14\right.$ vs. $0.75 \pm 0.04)$.

Protein malnutrition and chronic hypoxia both induce disproportionate growth retardation, but only the latter impairs arterial endothelial function. This may suggest that intrauterine exposure to chronic hypoxia induces arterial changes that may play a role in the development of cardiovascular disease in adult life.
\end{abstract}




\section{Introduction}

Epidemiological evidence links low birth weight to non-infectious diseases of the adult, including cardiovascular pathologies. Coronary heart disease, type 2 diabetes, atherosclerosis and arterial hypertension have been associated with fetal growth retardation $(1,2)$. These observations have led to the hypothesis that cardiovascular diseases in the adult may already be determined during intrauterine life.

An adverse intrauterine environment is most frequently the consequence of placental insufficiency resulting in decreased availability of nutrients and oxygen. Chronic exposure to hypoxia or undernutrition or a combination of both these stressors during prenatal life may not only interfere with fetal growth but may also modify arterial function and structure. To investigate this relationship animal models have been established that interfere with fetal growth and development. Placental insufficiency can be induced by umbilico-placental embolization and reduction of placental blood flow by ligation of the uterine artery (12, 16). Maternal food restriction or exposure to hypoxia can also create an adverse intrauterine environment $(24,7,11$. 30). The interventions may result in offspring with increased arterial blood pressure and other cardiovascular pathologies. However, not in all cases these are accompanied by reduced body weight of the pups (9), indicating that not growth itself but factors involved in the maintenance of a healthy intrauterine environment are crucial in the physiological programming of cardiovascular function and structure.

The studies that have provided evidence for the programming of cardiovascular disease have been performed in mammalians in which the fetus is exposed to intrauterine stress via the mother. In these models it is difficult to distinguish between the effects of hypoxia and protein malnutrition. As the chicken embryo develops outside the hen, this model rules out these disadvantages. In previous work we have shown that the model is suitable to study cardiovascular response mechanisms $(22,20,21)$ and that exposure to chronic moderate hypoxia changes peripheral artery function and structure at the level of the sympathetic innervation (26 (chapter 4)).

Besides sympathetic hyperinnervation (review (13)), endothelial dysfunction plays an important role in cardiovascular disease (33). In children and young adults with low birth weight endothelial function is reduced $(5,14,17)$. Endothelium-dependent relaxation involves mediators such as nitric oxide and EDHF's (33), which have also been demonstrated to participate in the response to acetylcholine in chicken embryo arteries (15 (chapter 2)). As acute and prolonged exposure to hypoxia can interfere with NO-production and release $(28,34,31)$. endothelial dysfunction resulting from chronic in utero exposure to hypoxia could be an interesting mechanism to link intrauterine stress and the programming of cardiovascular disease in the adult. On the other hand, decreased endothelial function after fetal protein malnutrition has also been described (10).

In the present study, effects of chronic hypoxia and protein malnutrition on embryonic growth and arterial endothelial relaxing function were investigated. We hypothesize that acetylcholine-induced relaxation of peripheral arteries of the chicken embryo may be modulated by a specific in ovo insult. 


\section{Methods}

\section{Interventions}

Experiments were performed in accordance with Dutch Law for animal experimentation. Fertile Lohman-selected White Leghorn eggs ('t Anker, Ochten, NL) were incubated at $38{ }^{\circ} \mathrm{C}$ and $60 \%$ relative air humidity. To induce chronic hypoxia, eggs were transferred on embryonic day 6 to an incubator (Salvis Biocenter 2001) maintained at an oxygen level of $15 \% \mathrm{O}_{2}$. Another set of eggs was transferred to a comparable incubator which was kept at $21 \% \mathrm{O}_{2}$ to serve as normoxic controls.

The albumen content of a separate set of eggs was determined using the methods described by Hill et al. (8). A new set of eggs was used for the in vitro studies and protein malnutrition was induced at day 0 . With a sterile needle (18G) a hole was made in the eggshell (at the pointed end of the egg) and $10 \%$ of the estimated albumen content (in grams) was carefully extracted from the egg to induce protein malnutrition. In another set of eggs a hole was made without albumen reduction to serve as sham controls. Holes were sealed with cyanoacrylate (RS components, Corby, UK).

On embryonic day 19 of the 21-day incubation period embryos were removed from the egg and immediately decapitated. Embryos were weighed and organs were isolated to determine organ wet weight. Isometric force measurements were performed in femoral arteries of embryos that were exposed to chronic hypoxia or to protein malnutrition and in normoxic and sham controls.

\section{Arterial reactivity}

Segments of $2 \mathrm{~mm}$ of the right femoral artery were mounted (steel wires, diameter 40 $\mu \mathrm{m}$ ) in a myograph organ bath (model $610 \mathrm{M}$, Danish Myotechnology by J.P.Trading, Denmark) for isometric force measurement. Organ baths were filled with a Krebs-Ringer bicarbonate buffer, maintained at $37{ }^{\circ} \mathrm{C}$ and aerated with $95 \% \mathrm{O}_{2}$ and $5 \% \mathrm{CO}_{2}$. The arterial segments were stretched until maximal contractile responses to $63 \mathrm{mmol} / \mathrm{L}$ potassium solution $\left(\mathrm{K}^{+}\right)$were obtained (= optimal diameter). Concentration-response curves for acetylcholine $\left(\mathrm{ACH}, 10^{-8}\right.$ to $10^{-5} \mathrm{~mol} / \mathrm{L}$, half $\log$ units) were made during contraction with $63 \mathrm{mmol} / \mathrm{L} \mathrm{K} \mathrm{K}^{+}$. Sodium nitroprusside ( $\mathrm{SNP}, 10^{-7}-10^{-4} \mathrm{~mol} / \mathrm{L}$ ) induced relaxation was studied after arterial stimulation with $10 \mu \mathrm{mol} / \mathrm{L}$ norepinephrine (NE). The effect of $\mathrm{ACH}$ was also tested in arteries of normoxic and hypoxic embryos during NE-induced contraction.

The effect of NO synthase inhibition on $\mathrm{ACH}$-induced relaxation was evaluated by constructing concentration response curves in the presence of L-NAME $\left(10^{-4} \mathrm{~mol} / \mathrm{L}\right)$. In additional experiments, the effect of L-NAME on $\mathrm{K}^{+}$-induced contraction was evaluated in side branches of the femoral artery of 3-4 weeks old chickens that had been exposed to chronic hypoxia $\left(15 \% \mathrm{O}_{2}\right)$ from embryonic day 6 to 19 and in control chickens.

\section{Drugs and solutions}

Krebs-Ringer bicarbonate buffer (KRB) contained (in mmol L $\mathrm{L}^{-1}$ ): $\mathrm{NaCl}, 118.5$; $\mathrm{MgSO}_{4} \cdot 7 \mathrm{H}_{2} \mathrm{O}, 1.2 ; \mathrm{KH}_{2} \mathrm{PO}_{4}, 1.2 ; \mathrm{NaHCO}_{3}, 25.0 ; \mathrm{CaCl}_{2}, 2.5$; glucose, 5.5. Solutions containing different concentrations of $\mathrm{K}^{+}$were prepared by replacing part of the $\mathrm{NaCl}$ by an equimolar amount of $\mathrm{KCl}$. Arterenol bitartrate (norepinephrine) and $\mathrm{N \omega}$-nitro-L-arginine methyl ester (LNAME) were obtained from Sigma Chemical Co (St. Louis, MO), acetylcholine chloride from Janssen Chimica (Beersen, Belgium) and sodium nitroprusside from Acros (Geel, Belgium). All agents were dissolved in distilled water. 


\section{Data analysis}

Body- and organ weights of all embryos exposed to protein malnutrition and of sham controls were measured at day 19. A randomly selected group of embryos, was included in the myograph studies. In previous work we describe body- and organ weights at embryonic day 19 of large numbers of hypoxic and normoxic embryos (26 (chapter 4)). A separate group of embryos was used in the myograph studies. To certify that chronic hypoxia affected growth, total embryonic weight was measured at day 19. Active wall tension (AWT) was calculated by dividing force by two times the length of the vessel segment $(\mathrm{N} / \mathrm{m})$. Responses to vasodilators were expressed as percentage change of the AWT induced by contraction. Sensitivity to ACH and $\mathrm{SNP}$ (expressed as $\mathrm{pD}_{2}\left(=-\log \mathrm{EC}_{\mathrm{s}}\right)$ ) was determined for each artery by fitting individual concentration-response data to a non-linear sigmoid regression curve and interpolation (Graphpad Prism version 2.01, Graphpad software Inc, San Diego, CA). Maximal responses $\left(\mathrm{E}_{\max }\right)$ for each artery were expressed in terms of active wall tension (AWT, N/m). The effect of $\mathrm{L}-\mathrm{NAME}$ was calculated as the difference between $\mathrm{pD}_{2}$ for $\mathrm{ACH}$ in presence and absence of $\mathrm{L}$ NAME $\left(=\Delta \mathrm{pD}_{2}\right)$.

Since the incubation procedures for the chronic hypoxia and protein malnutrition experiments were different, the intervention groups can only be compared with their own controls. Therefore, student t-tests (Sigma Stat 2.0, Jandel Scientific) were performed to compare differences in $\mathrm{pD}_{2}, \Delta \mathrm{pD}_{2}$ and $\mathrm{E}_{\max }$-values between arteries of hypoxic and normoxic embryos. Similar statistical procedures were followed to analyze differences in arterial responses of embryos exposed to protein malnutrition and sham controls. To test whether differences in $\mathrm{pD}_{2}-$ and $\mathrm{E}_{\max }-\mathrm{values}$ within one artery segment in the presence and absence of $\mathrm{L}$ NAME were statistically significant paired t-tests were performed. The non-parametric variants (Mann Whitney U-test, Signed Rank test) were used, when normality test failed (Sigma Stat 2.0, Jandel Scientific). Data are presented as mean \pm SEM of $n$ embryos and $\mathrm{P}<0.05$ was considered statistically significant.

\section{Results}

Protein malnutrition from day 0 resulted in a $14 \%$ decrease of body weight measured at day $19(19.4 \pm 0.5 \mathrm{~g}$ vs. $22.5 \pm 0.5 \mathrm{~g}, \mathrm{n}=49, \mathrm{n}=29, \mathrm{P}<0.001)$. Relative brain weights of embryos exposed to protein malnutrition were larger compared to sham controls $(3.81 \pm 0.08 \%$ vs. $3.49 \pm 0.06 \%, n=40, n=29, P<0.01$ ). Previous work of our group demonstrated that exposure of chicken embryos to chronic hypoxia from day 6 of incubation also reduced total embryonic body weight measured at day 19 by $14 \%(21.9 \pm 0.4$ vs. $25.4 \pm 0.6 \mathrm{~g}, \mathrm{n}=32, \mathrm{n}=29, \mathrm{P}<0.001)$. As observed after protein malnutrition, this was accompanied by relatively larger brain weights $(3.69 \pm 0.08 \%$ vs. $3.39 \pm 0.07 \%, n=39, n=29, P<0.01)$ ( 26 (chapter 4$)$ ). The differences in total body weights induced by the interventions were also significant when only data of embryos that were used in the myograph studies were analyzed (chronic hypoxia: $24.4 \pm 0.53$ vs. $27.5 \pm 0.58$. $\mathrm{n}=14, \mathrm{n}=9, \mathrm{P}<0.01$, protein malnutrition: $18.4 \pm 1.06$ vs. 22.9 $\pm 0.88, \mathrm{n}=17, \mathrm{n}=15, \mathrm{P}<0.01$ ).

Optimal diameters of femoral arteries of embryos exposed to chronic hypoxia ( $n=14$ vs. 9 normoxic control embryos) were not different from those of normoxic control embryos $(\mathrm{P}=1.0)$. The same was observed when artery segments of embryos exposed to protein malnutrition ( $\mathrm{n}=17$ vs. 15 sham control embryos) were compared to sham controls ( $\mathrm{P}=0.78$ ). Protein malnutrition, but not chronic hypoxia $(\mathrm{P}=0.13)$, reduced contractile responses to 63 $\mathrm{mmol} / \mathrm{L} \mathrm{K}^{+}$in comparison with sham controls $(1.27 \pm 0.11 \mathrm{~N} / \mathrm{m}$ vs. $1.72 \pm 0.10 \mathrm{~N} / \mathrm{m}, \mathrm{P}<0.01)$. 
Table 1 summarizes sensitivity and maximal responses to the endothelium-dependent agonist acetylcholine $(\mathrm{ACH})$ and the exogenous NO-donor sodium nitroprusside (SNP) in arteries of embryos exposed to chronic hypoxia or protein malnutrition and normoxic or sham control embryos. Arterial sensitivity and maximal responses to $\mathrm{ACH}$ of embryos exposed to protein malnutrition was not different from their controls $\left(\mathrm{pD}_{2}: \mathrm{P}=0.42, \mathrm{E}_{\max }: \mathrm{P}=0.33\right.$, fig. $\left.1 \mathrm{~B}\right)$. Neither was the response to sodium $\mathrm{SNP}$ changed by protein malnutrition $\left(\mathrm{pD}_{2}: \mathrm{P}=0.92, \mathrm{E}_{\max }\right.$ : $\mathrm{P}=0.59$, fig. 1D). Though maximal relaxation was unchanged $(\mathrm{P}=0.51$, fig. $1 \mathrm{~A})$, arterial segments of embryos chronically exposed to hypoxia were significantly less sensitive to $\mathrm{ACH}$ than arteries of normoxic control embryos $(\mathrm{P}<0.001$, fig. 1A). This was not accompanied by changes in sensitivity to SNP ( $P=0.71$, fig.1C). Maximal responses to SNP were slightly decreased in the hypoxia group $(\mathrm{P}=0.03$, fig. 1C). The decrease in sensitivity, but not in maximal relaxation to $\mathrm{ACH}$ was also observed when arteries of hypoxic and normoxic control embryos were contracted with norepinephrine instead of $63 \mathrm{mmol} / \mathrm{L} \mathrm{K} \mathrm{K}^{+}\left(\mathrm{pD}_{2}: 6.62 \pm 0.09\right.$ vs.7.15 $\pm 0.09, \mathrm{P}<0.001, \mathrm{E}_{\max }: 100.9 \pm 1.0 \%$ vs. $100.4 \pm 0.3 \%, \mathrm{P}=0.87$ ).

Table 1. Sensitivity (A) and maximal responses (B, \%) to ACH (in presence and absence of L-NAME) and SNP of femoral arteries of embryos exposed to chronic hypoxia or malnutrition and normoxic and sham control embryos.

A. sensitivity

\begin{tabular}{lllll}
\hline & $\begin{array}{l}\text { chronic } \\
\text { hypoxia }\end{array}$ & $\begin{array}{l}\text { normoxic } \\
\text { control }\end{array}$ & malnutrition & sham control \\
\hline ACH & $6.57 \pm 0.07 *$ & $7.02 \pm 0.05$ & $7.00 \pm 0.11$ & $7.12 \pm 0.05$ \\
ACH (i.p.o. L-NAME) & $6.31 \pm 0.13$ & $6.27 \pm 0.06 \#$ & & \\
L-NAME-effect $\left(\Delta \mathrm{pD}_{2}\right)$ & $0.29 \pm 0.14^{*}$ & $0.75 \pm 0.04$ & & \\
SNP & $5.74 \pm 0.15$ & $5.85 \pm 0.23$ & $6.04 \pm 0.18$ & $6.01 \pm 0.34$ \\
\hline
\end{tabular}

B. maximal relaxation

\begin{tabular}{|c|c|c|c|c|}
\hline & $\begin{array}{l}\text { chronic } \\
\text { hypoxia }\end{array}$ & $\begin{array}{l}\text { normoxic } \\
\text { control }\end{array}$ & malnutrition & sham control \\
\hline $\mathrm{ACH}$ & $85.3 \pm 3.2$ & $89.9 \pm 2.2$ & $92.3 \pm 1.0$ & $89.7 \pm 2.2$ \\
\hline ACH (i.p.o. L-NAME) & $41.0 \pm 5.0 \#$ & $48.6 \pm 5.3 \#$ & & \\
\hline SNP & $101.0 \pm 0.8 *$ & $104.0 \pm 1.7$ & $103.0 \pm 7.2$ & $98.7 \pm 3.9$ \\
\hline
\end{tabular}

Sensitivities to ACH and SNP in the absence and presence of (=i.p.o.) L-NAME were presented as $\mathrm{pD}_{2}$ values $\left(=-\log \mathrm{EC}_{5_{0}}\right)$ and differences between $\mathrm{pD}_{2}$-values in the absence and presence of $\mathrm{L}-\mathrm{NAME}$ as $\triangle \mathrm{pD}_{2}$. Maximal responses to $\mathrm{ACH}$ and $\mathrm{SNP}$ in the absence and presence of $\mathrm{L}-\mathrm{NAME}$ are presented as percentages of the contraction to $\mathrm{K}^{+}$(in case of $\mathrm{ACH}$ ) and to NE (in case of SNP). Mean \pm SEM. * $\mathrm{P}<0.05$ for the difference in response between arteries of embryos exposed to hypoxia and normoxic controls, \# $\mathrm{P}<0.05$ for differences in responses in the absence and presence of L-NAME.

Contractile responses to $63 \mathrm{mmol} / \mathrm{L} \mathrm{K} \mathrm{K}^{+}$of arteries of hypoxic and normoxic embryos were not changed in the presence of L-NAME (hypoxia group: $2.00 \pm 0.14 \mathrm{~N} / \mathrm{m}$ vs. $2.02 \pm 0.12$ $\mathrm{N} / \mathrm{m}, \mathrm{P}=0.66$, normoxia group: $2.29 \pm 0.22 \mathrm{~N} / \mathrm{m}$ vs. $2.36 \pm 0.20 \mathrm{~N} / \mathrm{m}, \mathrm{P}=0.42$ ). Inhibition of $\mathrm{NO}$ synthase with L-NAME significantly reduced sensitivity and maximal relaxing responses to $\mathrm{ACH}$ in arteries of normoxic embryos $\left(\mathrm{pD}_{2}: \mathrm{P}<0.01, \mathrm{E}_{\max }: \mathrm{P}<0.001\right.$, table 1, fig. 2) and maximal responses of embryos that had been exposed to hypoxia $\left(\mathrm{pD}_{2}: \mathrm{P}=0.07, \mathrm{E}_{\max }: \mathrm{P}<0.001\right.$, table 1 , fig. 2). Under these conditions arterial sensitivity to $\mathrm{ACH}$ was no longer different between hypoxic and normoxic embryos $(P=0.32$, table 1 , fig. 2$)$. Thus, the rightward shift of the concentration response curve induced by L-NAME was significantly smaller in arteries of hypoxic embryos than in arteries of their normoxic controls $\left(\Delta \mathrm{pD}_{2}: \mathrm{P}=0.01\right.$, table 1$)$, indicating 
that chronic exposure to hypoxia reduced sensitivity to $\mathrm{ACH}$ by lowering $\mathrm{ACH}$-induced NO release.

A

Acetylcholine: hypoxia vs. normoxia

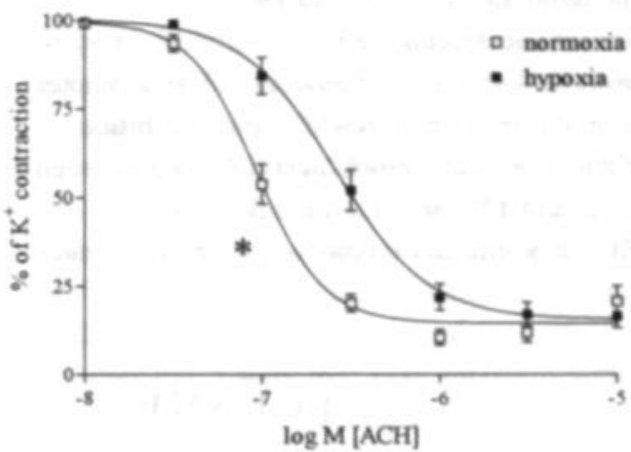

C

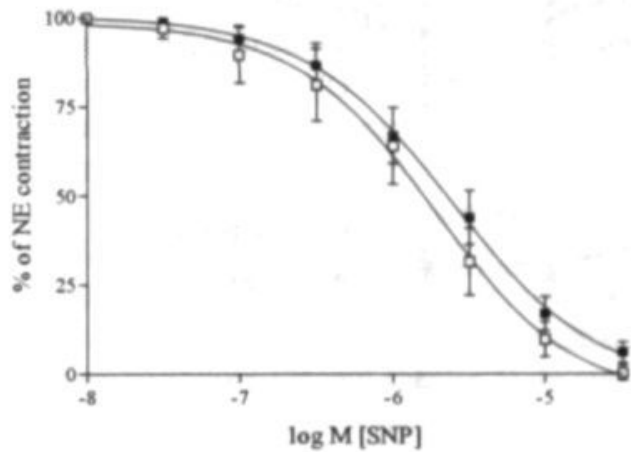

B

Acetylcholine: malnutrition vs. control

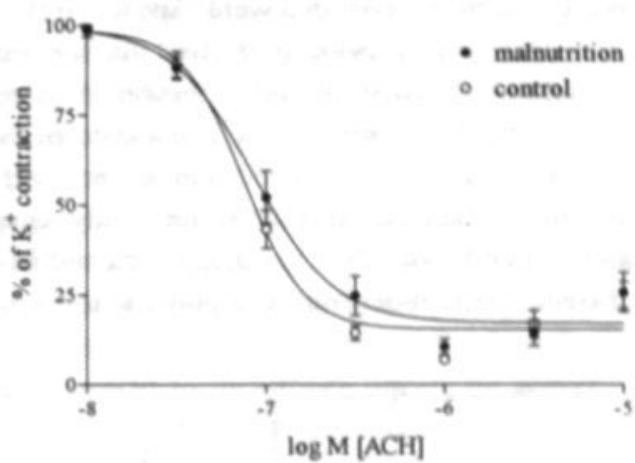

DNP: malnutrition vs. control

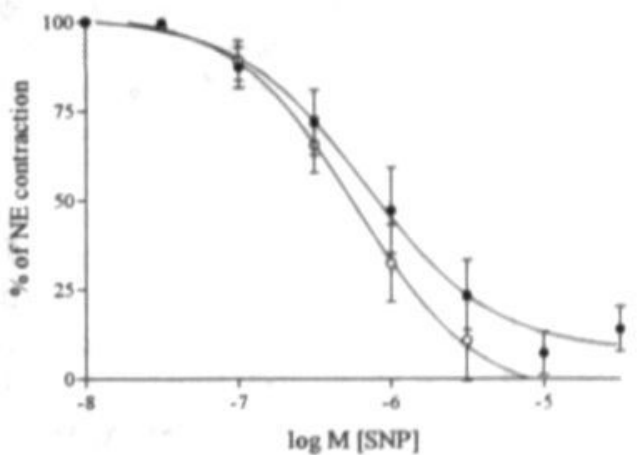

Fig. 1. Acetylcholine ( $\mathrm{ACH}$ - and sodium nitroprusside (SNP)- induced relaxation in femoral arteries contracted with $63 \mathrm{mmol} / \mathrm{L} \mathrm{K}^{+}$of embryos exposed to chronic hypoxia or protein malnutrition and normoxic and sham control embryos.

Sensitivity to ACH was decreased in artery segments of hypoxic (A. filled symbols) compared to normoxic embryos (A, open symbols), whereas responses to SNP (C) were unchanged after chronic hypoxia. Arterial responses to ACH (B) and SNP (D) were not significantly different between embryos exposed to protein malnutrition (filled symbols) and sham control embryos (open symbols). Means \pm SEM. * $\mathrm{P}<0.05$ (for the entire concentration-response curve).

In side branches of the femoral artery of 3-4 weeks old control chickens, L-NAME induced an increase of contraction stimulated with $63 \mathrm{mM} \mathrm{K}^{+}$of $0.68 \pm 0.20 \mathrm{~N} / \mathrm{m}\left(\mathrm{K}^{+}\right.$-induced contraction in absence of L-NAME: $2.26 \pm 0.25 \mathrm{~N} / \mathrm{m}, \mathrm{n}=14)$. No significant effect $(-0.16 \pm 0.33$ $\mathrm{N} / \mathrm{m}$ ) of L-NAME on $\mathrm{K}^{*}$-contraction was observed in chickens that had been exposed to chronic hypoxia during development, suggesting that chronic hypoxia before hatching affects basal NO release after hatching. 


\section{Discussion}

The present study demonstrates that exposure to chronic hypoxia and protein malnutrition both induce disproportionate growth retardation of the chicken embryo. However, only chronic hypoxia had consequences for arterial function. Endothelium-dependent relaxation was reduced in embryos that were exposed to chronic hypoxia from day 6 to 19 .

Our group previously showed that the response to acetylcholine in the femoral artery of the chicken embryo at the end of incubation is entirely endothelium-dependent ( 15 and chapter 2). Precontraction with high $\mathrm{K}^{+}$, blockade of NO-synthase with L-NAME and inhibition of cyclo-oxygenase with indomethacin are not sufficient to entirely block acetylcholine-induced relaxation in the chicken embryo (this study, chapter 2 and 15 ) and adult chicken $(6,18)$. This indicates that besides NO, prostaglandins and EDHF, an additional unknown factor contributes to the endothelium-dependent response in this species.

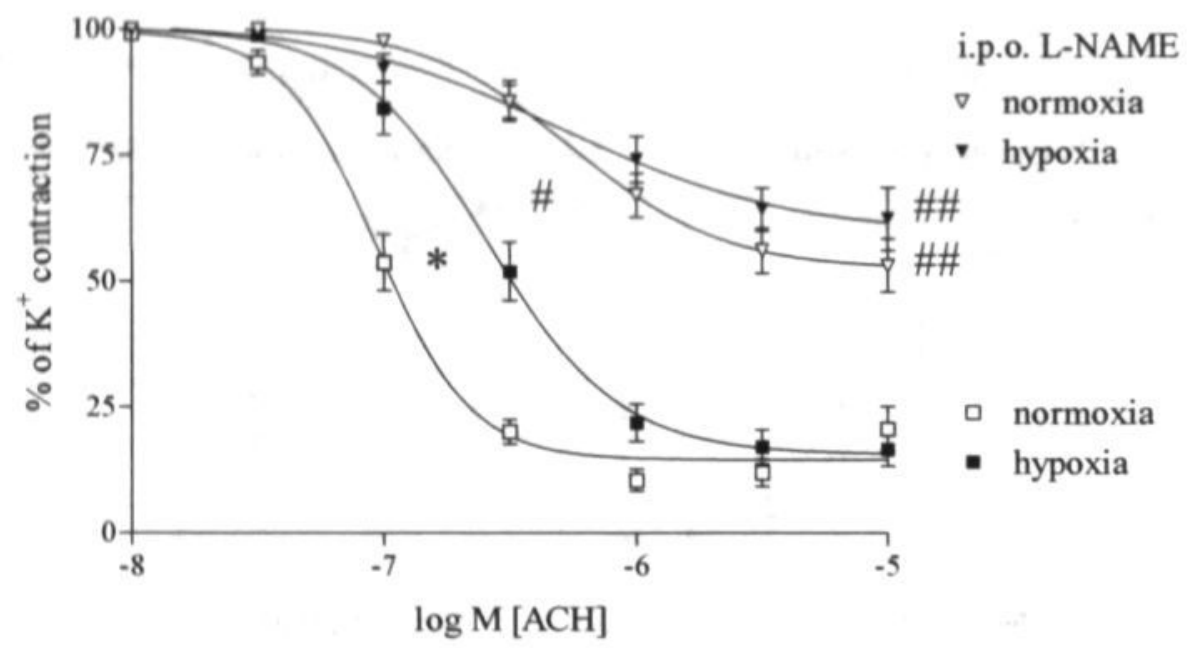

Fig. 2. Acetylcholine (ACH)-induced relaxation in the presence and absence of L-NAME in femoral arteries of embryos exposed to chronic hypoxia and normoxic embryos.

NO-synthase blockade by L-NAME decreases maximal responses to $\mathrm{ACH}$ in arteries of chronic hypoxic embryos (filled squares in absences of L-NAME, filled triangles in presence of L-NAME) and sensitivity and maximal responses in arteries of normoxic embryos (open squares in absence of L-NAME, open triangles in presence of $\mathrm{L}-\mathrm{NAME}$ ). Means $\pm \mathrm{SEM}, * \mathrm{P}<0.05$ for the difference in sensitivity between arteries of embryos exposed to hypoxia and arteries of normoxic controls in the absence of L-NAME. \# $\mathrm{P}<0.05$ for the difference in sensitivity in the absence and presence of L-NAME in normoxic controls. \#\# $\mathrm{P}<0.05$ for the difference in maximal relaxation in absence and presence L-NAME in both arteries of the hypoxic embryos and arteries of normoxic controls. The rightward shift $\left(\Delta \mathrm{pD}_{2}\right.$, see table 1) of the curves. that is induced by L-NAME is significantly smaller after chronic hypoxia.

The effect of chronic hypoxia on $\mathrm{ACH}$-induced relaxation seems to involve only the NOS-dependent component of the response, as during incubation with L-NAME responses to $\mathrm{ACH}$ in arteries of chronic hypoxic embryos were comparable to those in arterial segments of normoxic control embryos. Sensitivity to SNP, an exogenous NO donor, was not modified by chronic hypoxia, indicating that the capacity of the smooth muscle cells to relax in response to NO was not changed. Though the small change in maximal relaxing response to SNP was statistically significant, this is probably physiologically of little importance. 
During acute fetal hypoxemia in vivo, blood flow in peripheral vascular beds is decreased $(4,20)$. This reduces shear stress, which in turn may result in a decrease in arterial eNOS expression (32). Furthermore, inhibitory effects of hypoxia on endothelium-derived NO production during acute and long-term exposure in isolated fetal pulmonary (28) and adult systemic arteries $(34,31)$ have been demonstrated. Moreover, acute hypoxia completely inhibits acetylcholine-induced relaxation in femoral arteries of the chicken embryo (abstract (25) and chapter 3 ). This indicates that hypoxemia might modify both the presence and effects of NO. However, to elucidate the mechanisms involved in the effects of chronic hypoxia on endothelial function, future studies are necessary. These can investigate a range of endothelium-dependent vasodilators, NO synthase expression and NO production.

A relationship between intrauterine growth retardation and impaired endothelial function has been described in humans. Flow-mediated dilatation of the brachial artery $(5,14)$ and acetylcholine-induced dilatation (17) are reduced in healthy children and young adults that had low birth weights compared with normal birth weight subjects. Animal studies have focused on prenatal insults that may interfere with fetal growth to investigate effects on endothelial arterial function. Endothelial function was evaluated in offspring (100-120 days old) of foodrestricted rats. Only when total food intake was reduced by $50 \%$ in the second half of gestation. reductions in endothelium-dependent relaxation were observed (10); a reduction of the matemal food intake by $30 \%$ did not alter endothelial reactivity (24). In guinea pigs, effects of exposure of the mother to chronic hypoxia on endothelial function were observed in the offspring. While the contribution of NO to the acetylcholine-induced relaxing response and eNOS mRNA levels in fetal hearts were increased (29), chronic hypoxia reduced maximal responses to acetylcholine in fetal carotid arteries (30).

We used two different models to induce growth retardation in the chicken embryo. We (26 and chapter 4$)$ and others $(19,35)$ previously showed that long-term exposure to moderate hypoxia reduces total embryonic body weight. In these experiments we also demonstrated increased hematocrit levels, indicating that the embryos were indeed exposed to hypoxemia in these conditions ( 26 and chapter 4 ). In our model reduced total body weight was accompanied by a sparing effect on brain weight. Protein malnutrition was induced by removal of $10 \%$ of the albumen. The eggs of chickens contain yolk, which consists of water, fat and proteins and primarily determines the degree of development of the chick at hatching. The other component of the egg. albumen, mainly $(-95 \%)$ contains water and amino acids, which are used by the developing embryo for whole-body protein synthesis and growth $(8,23)$. As previously shown $(23,3)$, extraction of albumen from the egg was found to reduce total embryonic weight towards the end of incubation. Like after exposure to chronic hypoxia, relative brain weight was spared. Comparisons between the two models should be made with caution since incubation procedures were different and making a small hole in the eggshell (as performed in the protein malnutrition studies) has been shown to induce changes in embryonic metabolism, body and organ weights (3). However, both interventions induced growth retardation of comparable severity, but had different effects on the arterial reactivity.

Two critical points may be raised here. First, the period of exposure to the insult may be different between the two models. In the model of chronic moderate hypoxia, the embryo is constantly exposed to low oxygen levels from day 6 to 19. However, the effects of albumen removal may occur primarily during the second half of incubation (8). This may be of importance considering that insults may affect developing organ systems like the cardiovascular system at critical time points. Second, while chronic hypoxia reduced relative body weights of all organs apart from the brain (26 and chapter 4 ), protein malnutrition did not significantly decrease relative heart, liver and kidney weights (data not shown, chapter 5), suggesting that the 
reduction in total body weight is accounted for by other tissues, like skeletal muscle or the skeleton (3). The authors like to stress that, though there may be differences in exposure period and the exact features of the reduction in embryonic growth, disproportionate growth retardation per se does not seem to be the cause of the changes in arterial functional properties. We clearly showed that the disproportionate reduction in growth caused by chronic hypoxia is accompanied by changes in acetylcholine-induced relaxation while the reduction in in ovo growth induced by protein malnutrition is not.

Though evidence is limited others have reported effects of maternal food-restriction on endothelial function (10). Important in this respect is that maternal undernutrition in mammalians may modify maternal hormone balances and metabolism, which may indirectly influence fetal vascular function. Furthermore, the effects of maternal food-restriction were demonstrated in adult offspring, whereas we evaluated endothelial function at the end of incubation time ( 0.9 gestation). Therefore, changes in endothelium-dependent relaxation as a result of chronic hypoxia in the chicken embryo may point to a more early and causal role of impaired endothelial function in the fetal programming of cardiovascular disease, while indirect effects of protein malnutrition may become evident postnatally. Future studies in post-hatch chickens will address these points.

There is now substantial evidence from epidemiological studies in humans and from animal studies associating an adverse intrauterine environment with cardiovascular diseases in adult life (1, 2). Endothelial dysfunction plays an important role in diseases such as artherosclerosis, heart failure and hypertension (33). Changes in endothelial function may be causally involved in the development of these diseases. The role of endothelial NO as mediator may be considerable, as it may affect both smooth muscle tone and smooth muscle cell proliferation $(27,36)$. We show that prolonged exposure to chronic moderate hypoxia does, and protein malnutrition does not, reduce endothelium-dependent relaxation as a result of decreased NO release in peripheral arteries of the chicken embryo. Furthermore, our findings in 3-4 weeks old chickens indicate that effects on the NO system induced by chronic hypoxia during development, are also present after hatching. These results warrant further investigation in chickens of various ages.

We suggest that, in addition to the previously demonstrated effect of embryonic hypoxemia on sympathetic nervous development (26 and chapter 4 ), changes in endothelial function, especially the NO-dependent component, induced by chronic exposure to hypoxia during fetal life may contribute to the development of cardiovascular disease in later stages of life.

\section{Acknowledgments}

This work was supported by a grant from "Vrienden van het AZM". 


\section{References}

1. Barker DJP and Fall CHD. Fetal and infant origins of cardiovascular disease. Arch Dis Child 68: 797-799, 1993.

2. Byrne CD and Phillips DI. Fetal origins of adult disease: epidemiology and mechanisms. J Clin Pathol 53: 822-828, 2000.

3. Finkler MS, Van Orman JB, and Sotherland PR. Experimental manipulation of egg quality in chickens: influence of albumen and yolk on the size and body composition of near-term embryos in a precocial bird. J Comp Physiol 168: 17-24, 1998.

4. Giussani DA, Spencer JAD, Moore PJ, Bennet L, and Hanson MA. Afferent and efferent components of the cardiovascular reflex responses to acute hypoxia in the term fetal sheep. $J$ Physiol 461: 431-449, 1993.

5. Goodfellow J, Bellamy MF, Gorman ST, Brownlee M, Ramsey MW, Lewis M.J, Davies DP, and Henderson AH. Endothelial function is impaired in fit young adults of low birth weight. Candiovase Res 40: 600-606, 1998.

6. Hasegawa $\mathbf{K}$, Nishimura $\mathbf{H}$, and $\mathbf{K h o s l a ~} \mathbf{M}$. Angiotensin II-induced endothelium-dependent relaxation of fow aorta. Am J Physiol 264: R903-R911, 1993.

7. Hawkins P, Steyn C, Oraki T, Saito T, Noakes DE, and Hanson MA. Effect of maternal undernutrition in early gestation on ovine fetal blood pressure and cardiovascular reflexes. Am J Physiol 279: R340-R348, 2000.

8. Hill WL. Importance of prenatal nutrition to the development of a precocial chick. Dev Psychobiol 26: 237-249, 1993.

9. Hoet $\mathbf{J J}$ and Hanson MA. Intrauterine nutrition: its importance during critical periods for cardiovascular and endocrine development. J Physiol 514.3: 617-627, 1999.

10. Holemans K, Gerber R, Meurrens K, De Clerck F, Poston L, and Van Assche FA. Maternal food restriction in the second half of pregnancy affects vascular function but not blood pressure of rat female offspring. Br J Nutrition 81: 73-79, 1999.

11. Jacobs R, Robinson JS, Owens JA, Falconer J, and Webster MED. The effect of prolonged hypobaric hypoxia on growth of fetal sheep. J Develop Physiol 10: 97-112, 1988.

12. Jansson $\mathbf{T}$ and Lambert GW. Effect of intrauterine growth restriction on blood pressure, glucose tolerance and sympathetic nervous system activity in the rat at 3-4 months of age. $J$ Hypertension 17: 1239-1248, 1999.

13. Julius $\mathbf{S}$ and Valentini $\mathbf{M}$. Consequences of the increased autonomic nervous drive in hypertension, heart failure and diabetes. Blood Pressure 7: 5-13, 1998.

14. Leeson CPM, Whincup PH, Cook DG, Donald AE, Papacosta O, Lucas FRCP, and Deanfield JE. Flow-mediated dilation in 9- to 11-year-old children. The influence of intrauterine and childhood factors. Circulation 96: 2233-2238, 1997.

15. Le Noble FAC, Ruijtenbeek K, Gommers S, De Mey JGR, and Blance CE. Contractile and relaxing reactivity in carotid and femoral arteries of chicken embryos. Am J Physiol 278: H1261H1268, 2000.

16. Louey S, Cock ML, Stevenson KM, and Harding R. Placental insufficiency and fetal growth restriction lead to postnatal hypotension and altered postnatal growth in sheep. Pediatr Res 48: 808-814, 2000.

17. Martin $\mathbf{H}, \mathbf{H u} \mathbf{J}$, Gennser $\mathbf{G}$, and Norman $\mathbf{M}$. Impaired endothelial function and increased carotid stiffness in 9-year-old children with low birth weight. Circulation 102: 2739-2744, 2000.

18. Martinez-Lemus LA, Hester RK, Becker E, Jeffrey JS, and Odom TW. Pulmonary artery endothelium-dependent vasodilation is impaired in a chicken model of pulmonary hypertension. Am J Physiol 277: R190-R197, 1999.

19. MeCutcheon IE, Metcalfe J, Metzenberg AB, and Ettinger T. Organ growth in hyperoxic and hypoxic chick embryos. Resp Physiol 50: 153-163, 1982. 
20. Mulder ALM, Van Golde JC, Prinzen FW, and Blanco CE. Cardiac output distribution in response to hypoxia in the chick embryo in the second half of the incubation time. J Physiol 508 (part1): 281-287, 1998.

21. Mulder ALM, Van Golde JMCG, Van Goor AAC, Giussani DA, and Blanco CE. Developmental changes in plasma catecholamine concentrations during normoxia and acute hypoxia in the chick embryo. J Physiol 527.3: 593-599, 2000.

22. Mulder TLM, Van Golde JC, Prinzen FW, and Blanco CE. Cardiac output distribution in the chick embryo from stage 36 to 45. Cardiovase Res 34: 525-528, 1997.

23. Muramatsu T, Hiramoto K, Koshi N, Okumura J, Miyoshi S, and Mitsumoto T. Importance of albumen content in whole body protein synthesis of the chick embryo during incubation. British Poultry Science 31: 101-106, 1990.

24. Ozakd T, Nishina H, Hanson MA, and Poston L. Dietary restriction in pregnant rats causes gender-related hypertension and vascular dysfunction in offspring. J Physiol 530.1: 141-152, 2001.

25. Ruijtenbeek K, Blance C, and De Mey J. Acute hypoxia attenuates acetylcholine-induced dilatation in peripheral arteries of the chicken embryo. J Submicrosc Cytol Pathol 32: 343 (A016), 2000.

26. Ruijtenbeek K, Le Noble FAC, Janssen GM.J, Kessel CGA, Fazi GE, Blance CE, and De Mey JGR. Chronic hypoxia stimulates periarterial sympathetic nerve development in chicken embryo. Circulation 102: 2892-2897, 2000.

27. Scott-Burden T, Resink TJ, Hahn AWA, and Bühler FR. Vasoactive peptides and growth factors in the pathophysiology of hypertension. J Cardiovasc Pharmacol 20: S55-S64, 1992.

28. Shaul PW, Farrar MA, and Magness RR. Pulmonary endothelial nitric oxide production is developmentally regulated in the fetus and newborn. Am J Physiol 265: H1056-1063, 1993.

29. Thompson LP, Aguan K, Pinkas G, and Weiner CP. Chronic hypoxia increases the NO contribution of acetylcholine vasodilation of the guinea pig heart. Am J Physiol 279: R1813R1820, 2000.

30. Thompson LP and Weiner CP. Effects of acute and chronic hypoxia on nitric oxide mediated relaxation of fetal guinea pig arteries. Am JObstet Gynecol 181: 105-111, 1999.

31. Toporsian M, Govindaraju K, Nagi M, Eidelman D, Thibault G, and Ward ME. Downregulation of endothelial nitric oxide synthase in rat aorta after prolonged hypoxia in vivo. Circ Res 86: 671-675, 2000.

32. Tuttle J, Nachreiner RD, Bhuller AS, Condict KW, Connors BA, Dalsing MC, and Unthank JL. Shear level influences resistance artery remodelling: wall dimensions, cell density, and eNOS expression. Am JPhysiol 281: H1380-H1389, 2001.

33. Vanhoutte PM, Perrault LP, and Vilaine JP. Endothelial dysfunction and vascular disease. Eds.: Rubanyi GM and Dzau VJ. in: The endothelium in clinical practice. Source and target of novel strategies. Marcel Dekker, Inc. New York, Basel, Hong Kong. 1997. pp. 265-289.

34. Wadsworth RM. Vasoconstrictor and vasodilator effects of hypoxia. TIPS 15: 47-52, 1994.

35. Xu L and Mortola JP. Effects of hypoxia and hyperoxia on the lung of the chick embryo. Can J Plysiol Pharmacol 67: 515-519, 1989.

36. Yu S-M, Hung L-M, and Lin C-C. cGMP-elevating agents suppress proliferation of vascular smooth muscle cells by inhibiting the activation of epidermal growth factor signalling pathway. Cinculation 95: 1269-1277, 1997. 


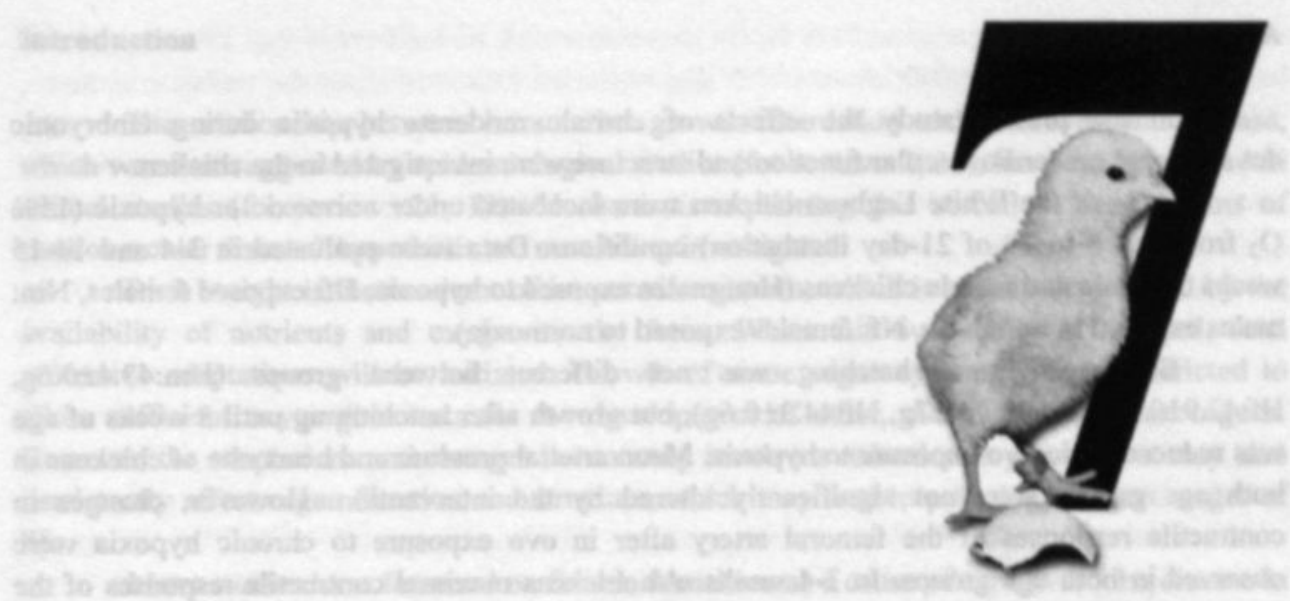

CHAPTER 7

CHRONIC MODERATE HYPOXIA DURING IN OVO DEVELOPMENT ALTERS ARTERIAL PROPERTIES IN CHICKENS

Karin Ruijtenbeek, Lilian C. G. A. Kessels, Ben J. A. Janssen, Nicole J. J. E. Bitsch, Gregorio E. Fazi, Ger M. J. Janssen, Jo G. R. De Mey, Carlos E. Blanco 


\section{Abstract}

In the present study the effects of chronic moderate hypoxia during embryonic development on cardiovascular function and structure were investigated in the chicken.

Eggs of the White Leghom chicken were incubated under normoxic or hypoxic (15\% $\mathrm{O}_{2}$ from day 6 to 19 of 21-day incubation) conditions. Data were evaluated in 3-4 and 14-15 weeks old male and female chickens (Hm: males exposed to hypoxia, Hf: exposed females, $\mathrm{Nm}$ : males exposed to normoxia, Nf: females exposed to normoxia).

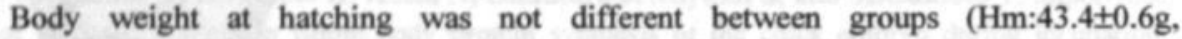
Hf: $42.9 \pm 0.7 \mathrm{~g}, \mathrm{Nm}: 43.7 \pm 0.7 \mathrm{~g}, \mathrm{Nf}: 44.3 \pm 0.6 \mathrm{~g}$ ), but growth after hatching up until 3 weeks of age was reduced by in ovo exposure to hypoxia. Mean arterial pressure and heart rate of chickens in both age groups were not significantly altered by the intervention. However, changes in contractile responses of the femoral artery after in ovo exposure to chronic hypoxia were observed in both age groups. In 3-4 weeks old chickens maximal contractile responses of the femoral artery to norepinephrine (Hm:11.39 $\pm 0.43 \mathrm{~N} / \mathrm{m}, \quad \mathrm{Hf}: 11.90 \pm 0.40 \mathrm{~N} / \mathrm{m}$, $\mathrm{Nm}: 10.19 \pm 0.70 \mathrm{~N} / \mathrm{m}, \quad \mathrm{Nf}: 10.21 \pm 0.34 \mathrm{~N} / \mathrm{m}), \quad$ phenylephrine $\quad(\mathrm{Hm}: 9.87 \pm 0.79 \mathrm{~N} / \mathrm{m}$, Hf:9.70 $\pm 0.78 \mathrm{~N} / \mathrm{m}, \mathrm{Nm}: 7.27 \pm 0.56 \mathrm{~N} / \mathrm{m}, \mathrm{Nf}: 6.09 \pm 0.74 \mathrm{~N} / \mathrm{m}$ ) and serotonin (Hm:8.43 $\pm 0.62 \mathrm{~N} / \mathrm{m}$, Hf:8.19 $\pm 0.42 \mathrm{~N} / \mathrm{m}, \mathrm{Nm}: 7.51 \pm 0.84 \mathrm{~N} / \mathrm{m}, \mathrm{Nf}: 6.80 \pm 0.55 \mathrm{~N} / \mathrm{m}$ ) were significantly increased. Femoral arteries of 14-15 weeks old chickens were more sensitive to electrical (frequency of half maximal contraction. Hm: $1.62+0.33 \mathrm{~Hz}$. Hf: $1.92 \pm 0.88 \mathrm{~Hz}$. Nm: $2.49 \pm 0.49 \mathrm{~Hz}$ Nf: $2.83 \pm 0.31 \mathrm{~Hz}$ ) and pharmacological stimulation of peri-arterial sympathetic nerves (contraction to tyramine: $\mathrm{Hm}: 5.27 \pm 0.85 \mathrm{~N} / \mathrm{m}$, Hf: $4.10 \pm 0.9 \mathrm{~N} / \mathrm{m}, \mathrm{Nm}: 2.26 \pm 0.67 \mathrm{~N} / \mathrm{m}, \mathrm{Nf}: 3.65 \pm 0.51 \mathrm{~N} / \mathrm{m}, \mathrm{P}=0.07$ ) after the in ovo intervention. Arterial structural parameters (morphometry, DNA content, density of sympathetic nerve fibers) were not altered by in ovo hypoxia in either age group. In side branches of the femoral artery, the increase in contraction to high $\mathrm{K}^{+}$induced by NO synthase blockade with L-NAME was reduced after in ovo hypoxia in $3-4$ weeks $(\mathrm{H}:-0.16 \pm 0.33$, $\mathrm{N}: 0.68 \pm 0.20$ ) and 14-15 weeks old chickens (Hm:0.35 $\pm 0.91 \mathrm{~N} / \mathrm{m}, \mathrm{Hf}: 1.29 \pm 0.36 \mathrm{~N} / \mathrm{m}, \mathrm{Nm}$ : $2.88 \pm 0.19 \mathrm{~N} / \mathrm{m}, \mathrm{Nf}: 2.79 \pm 0.58 \mathrm{~N} / \mathrm{m}$ ). In $14-15$ weeks old chickens this was accompanied by a decreased effect of $\mathrm{L}-\mathrm{NAME}$ to $\mathrm{ACH}$-induced relaxation $\left(\Delta \mathrm{pD}_{2}, \mathrm{H}: 0.32 \pm 0.11, \mathrm{~N}: 0.62 \pm 0.05\right)$.

The present study shows that exposure to chronic moderate hypoxia during in ovo development affects contractile and relaxing arterial responses of 3-4 and 14-15 weeks old chickens. Although hypoxia did not lead to changes in blood pressure at these ages the observed effects on arterial smooth muscle, sympathetic and endothelial function may be involved in the development of cardiovascular disease at later stages of life. 


\section{Introduction}

The relationship between intrauterine growth retardation and cardiovascular disease, which was first suggested by epidemiological studies (for review: 2,35 ), has been confirmed in animal studies (for review: 21, 13). Mechanisms explaining this so-called "fetal origins of cardiovascular disease" hypothesis are now being investigated.

Birth weight is the resultant of intrauterine growth, which is mainly determined by the availability of nutrients and oxygen to the fetus. When this availability is reduced, fetal protective adaptations will be initiated. Growth of some organ systems will be restricted to allow sufficient oxygen/nutrients for the development of other, more important/vital organs. However, the adaptations and changes do not only involve a reduction in growth, but may also persistently affect organ function and structure, which may lead to pathology at later stages of life.

Many studies have focussed on fetal malnutrition as a cause of cardiovascular disease in later life. However, the most common cause of intrauterine growth retardation is placental insufficiency, which is a combination of both malnutrition and chronic hypoxia. Fetal hypoxemia induces adaptive responses of the cardiovascular system.

Redistribution of the cardiac output during acute fetal hypoxemia involves peripheral vasoconstriction induced by high levels of circulating catecholamines released by the adrenal medulla and by activation of sympathetic nerves $(55,11,44)$. Exposure to hypoxia for several days has been demonstrated to result in increased levels of key enzymes for catecholamine production (23). High plasma catecholamine levels (58) and maintenance of the redistribution of the cardiac output (29) have been observed during chronic hypoxia in the fetus.

Hypoxia may also exert effects on the arterial endothelium. In in vitro systems acute as well as long-term changes in oxygen tension alter endothelial properties of fetal pulmonary (54), fetal carotid (61) and cerebral arteries (37). The changes in blood flow occurring during fetal hypoxemia may alter arterial shear stress, which in turn can modulate the expression and activity of endothelial enzymes, such as NO synthase (62).

In previous work we have demonstrated in the chicken embryo that chronic exposure to moderate hypoxia, which leads to growth retardation, increases sympathetic innervation (53, chapter 4) and reduces endothelial function (52, chapter 6) at embryonic day 19. Increased sympathetic innervation and reduced NO production have been proposed to stimulate vascular smooth muscle cell proliferation $(6,66)$. Moreover, both sympathetic hyperinnervation and endothelial dysfunction, which have been linked to intrauterine growth retardation $(49,39,12$, 33), have been associated with hypertension and other cardiovascular diseases in the adult (for review: 27,63 ). Therefore, we now investigate whether in ovo exposure to chronic moderate hypoxia also affects arterial properties in chickens 3-4 and 14-15 weeks after hatching and has consequences for blood pressure and its autonomic control.

\section{Methods}

Experiments were performed according to the institutional Guidelines and Dutch Law, and were approved by the institutional animal ethics committee.

Eggs of White Leghom chickens ('t Anker, Ochten, NL) were incubated at $38{ }^{\circ} \mathrm{C}$ and $60-70 \%$ relative air humidity. Chronic hypoxia was induced as previously described (53, chapter 4). From embryonic day 6 to 19 of the 21-day incubation period eggs were kept in an incubator (Salvis Biocenter 2001) that maintained oxygen levels at $15 \%$ (in ovo hypoxia). 
Control eggs were incubated at $21 \% \mathrm{O}_{2}$ (in ovo normoxia). At embryonic day 19 all eggs were transferred to an incubator in air in which they were not turned to allow the embryos to hatch. Within 24 hours after hatching. chickens were weighed and transferred to a cage in which temperature was maintained sufficiently high. The chickens were housed at the central Animal Facilities of Maastricht University and were allowed normal chicken chow (Kenner opfokkorrel, Agri Retail b.v., Arnhem, NL; $18 \%$ protein, $1 \% \mathrm{Ca}^{2+}$ ) and drinking water ad libitum. Total bodyweight was measured at $1,2,3,5,7,8,9,10$ and14-15 weeks after hatching.

\section{Measurement of heart rate (HR) and mean arterial pressure (MAP)}

Surgical procedures were performed in chickens at the age of $21 \pm 0.2$ days $(n=44)$ and at 14-15 weeks $(\mathrm{n}=32)$. Chickens were anaesthetized with $30 \mathrm{mg} / \mathrm{kg}$ ketamine and $10 \mathrm{mg} / \mathrm{kg}$ xylazine i.m. Local anesthesia was applied with xylocaine when needed. A catheter (PE10 for 3 weeks old and PE50 for 14-15 weeks old chickens), filled with heparin $(50 \mathrm{U} / \mathrm{ml}) /$ saline-solution was implanted in the left femoral artery and advanced retrogradely so that its tip was $1-2 \mathrm{~cm}$ in the abdominal aorta. Similarly, in the 14-15 weeks old chickens, a venous catheter was inserted into the femoral vein. Catheters were guided under the skin and exteriorized at the base of the neck. The chickens were allowed a recovery period of 3 days before blood pressure was measured. Mean arterial pressure and heart rate were monitored via a CP-01 low volume displacement pressure transducer (Century technology Co, Inglewood, CA, USA) in conjunction with an on-line monitoring computer program (Hemodynamic Data Acquisition Systems, Instrumental Services, Maastricht University) for 30 minutes to obtain stable measurements. During the measurements lights were turned down to keep the chickens quiet. In 3-4 weeks old chickens, only basal HR and MAP measurements were performed. In the 14-15 weeks old chickens the contribution of the autonomic nervous system to the control of blood pressure was investigated by intravenous injections of the following agents. Atropine ( $1 \mathrm{mg} / \mathrm{kg})$, metopropolol $(2.5 \mathrm{mg} / \mathrm{kg})$ and hexamethonium $(25 \mathrm{mg} / \mathrm{kg})$ were injected at 15 minutes intervals (to allow stabilization of responses) to determine vagal $(\triangle H R)$, cardiac sympathetic $(\triangle H R)$ and arterial sympathetic ( $\mathrm{MAP}$ ) nervous tone, respectively. 24 Hours after the HR and MAP measurements, blood samples were taken (via the arterial catheter) from these animals. HPLC techniques based on previously described methods were used to determine plasma norepinephrine (24) and plasma corticosterone concentrations (which is the main glucocorticoid in chickens $(4))(41,19)$.

24-48 Hours after blood pressure measurements 3-4 and 14-15 weeks old chickens were sacrificed by decapitation. Body weight and wet weights of the heart, right kidney, liver, brain, right lung and right adrenal were determined. Arteries were then isolated for isometric force measurements, determination of DNA content, morphometry and analysis of peri-arterial nerve density.

\section{Arterial reactivity}

Two $\mathrm{mm}$ arterial segments of femoral arteries and side branches leading to the $\mathrm{m}$. quadriceps femoris of 3-4 weeks old chickens were mounted (steel wires, diameter $40 \mu \mathrm{m}$ ) in a wire myograph organ bath (model $610 \mathrm{M}$, Danish Myotechnology, Denmark) filled with a Krebs-Ringer bicarbonate buffer, maintained at $37{ }^{\circ} \mathrm{C}$ and aerated with $95 \% \mathrm{O}_{2}$ and $5 \% \mathrm{CO}_{2}$. Two mm segments of the femoral artery of 14-15 weeks old chickens were mounted in Allhin organ chambers (Grass FT07 force-displacement transducer) as described previously (65). Wire myography was used to measure arterial side branches.

The arterial segments were stretched until maximal contractile responses to high potassium solution (35-63 mmol/L $\mathrm{K}^{+}$) were obtained. Increasing concentrations of vasoactive 
substances $\left(10^{-9}\right.$ to $10^{-3} \mathrm{~mol} / \mathrm{L}$, half $\log$ units) were added to the organ bath and concentrationresponse curves were constructed. Contraction stimulated with the adrenergic agent norepineprine (NE) was measured in the presence and absence of cocaine $(1 \mu \mathrm{mol} / \mathrm{L})$, a blocker of the neuronal uptake of NE. Responses to nerve stimulation were tested using electrical field stimulation (EFS: $0.25-32 \mathrm{~Hz}$ ), which was previously shown to stimulate peri-arterial nerves of the chicken embryo femoral artery, leading to adrenoceptor-mediated contraction (34, chapter 2). Contractile responses to $\alpha_{1}$-adrenoceptor stimulation were evaluated with phenylephrine (PHE) and non-adrenergic contraction with serotonin (5HT). In femoral arteries of 14-15 weeks old chickens, responses to tyramine $\left(10^{-5} \mathrm{~mol} / \mathrm{L}\right)$, which stimulates NE release from the sympathetic nerves, were also measured. Arterial relaxing responses were investigated with acetylcholine ( $\mathrm{ACH}, \mathrm{K}^{+}$precontraction), an endothelium-dependent vasodilator (34, chapter 2), in the presence and absence of L-NAME, an inhibitor of NO synthase, and with sodium nitroprusside (SNP, NE precontraction), an exogenous NO donor. At the end of the experiments, vessel segments were fixed in the organ chamber in phosphate-buffered formaldehyde $\left(4 \%, \mathrm{pH}=7.4,37^{\circ} \mathrm{C}, 30\right.$ minutes $)$ for subsequent morphometric analysis.

\section{Arterial structure}

Morphometry. Lawson solution was used to stain $4 \mu \mathrm{m}$ thick cross-sections of femoral arteries. Arterial media cross-sectional area (CSA) and lumen radius were determined as previously described (57). Video images were generated by a Zeiss Axioscope (Zeiss, Germany) and standard CCD camera (Stemmer, Germany) and commercially available software (JAVA 1.21, Jandel Scientific, Corte Madera, CA. USA) was used for subsequent analyses.

DNA content. Right femoral artery segments and hearts were solubilized in $1 \mathrm{~N} \mathrm{KOH}$ (24 h, room temperature) to determine their DNA content (30). DNA levels were expressed relative to arterial segment length and heart wet weight.

Staining of perivascular nerves. Peri-arterial sympathetic nerve density was determined as described previously (53, chapter 4 ). In short, femoral artery segments were incubated, while in the organ bath, in $2 \%$ glyoxylic acid and $10 \%$ sucrose in phosphate buffer ( 10 minutes, room temperature). Segments were air-dried $\left(90\right.$ seconds), stretched $\left(4\right.$ minutes, $\left.100^{\circ} \mathrm{C}\right)$ and enclosed with entellan and a coverslip. Glyoxylic acid-induced fluorescence was visualized using fluorescent microscopy (microscope objective Fluo 10x, Nikon Diaphot, BA 470-DM 455 filter, Nikon FE2 camera). Intersections of nerve fibers with a Merz grid (distance $50 \mu \mathrm{m}$, radius 35 $\mu \mathrm{m})$ within a selected area of the image were counted to determine nerve fiber density.

\section{Drugs and solutions}

Heparin was obtained from Leo Pharmaceuticals (Weesp, the Netherlands) and ketamine and xylazine from Eurovet (Bladel, the Netherlands). Atropine methyl nitrate, metoprolol tartrate and hexamethonium bromide from Sigma (St. Louis, MO, USA). KrebsRinger Bicarbonate buffer (KRB) contained (in mmol/L): $\mathrm{NaCl}, 118.5 ; \mathrm{MgSO}-7 \mathrm{H} 2 \mathrm{O}, 1.2$; KH2PO4, 1.2; $\mathrm{NaHCO}_{2}, 25.0 ; \mathrm{CaCl}_{2}$, 2.5; glucose, 5.5. High $\mathrm{K}^{+}$solutions were prepared by replacing part of the $\mathrm{NaCl}$ by an equimolar amount of $\mathrm{KCl}$. Phosphate buffered solution consisted of $0.1 \mathrm{~mol} / \mathrm{L} \mathrm{NaH} 2 \mathrm{PO} 4 \cdot \mathrm{H} 2 \mathrm{O}$ and $0.1 \mathrm{~mol} / \mathrm{L} \mathrm{Na2HPO4} 2 \mathrm{H} 2 \mathrm{O}$. Arterenol bitartrate (norepinephrine), L-phenylephrine, 5-hydroxytryptamine creatinine sulphate (serotonin), cocaine hydrochloride and $\mathrm{N} \omega$-nitro-L-arginine methyl ester (L-NAME) were obtained from Sigma Chemical Co (St. Louis, MO). Lawson solution from Boom b.v. (Meppel. The Netherlands), acetylcholine from Janssen Chimica (Beerse, Belgium), sodium nitroprusside from Acros (Geel. Belgium) and tyramine chloride from Merck (Darmstadt, Germany). All agents were dissolved in distilled water. 


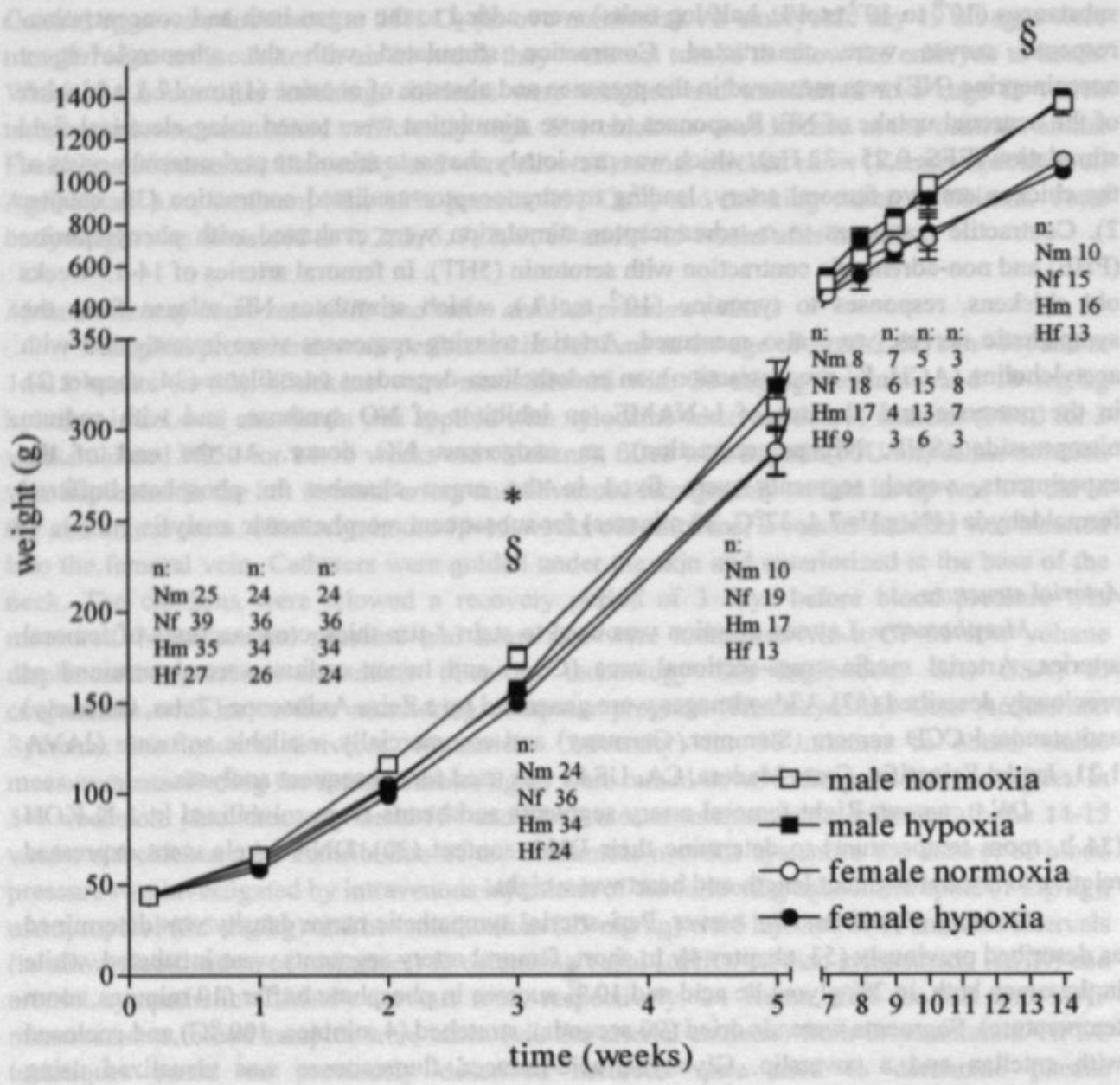

Fig. 1. Body weight of male (squares) and female (circles) chickens exposed to in ovo normoxia (open symbols) and hypoxia (closed symbols) from 1 day after hatching until 14 weeks (weights of 15 weeks old chickens were incorporated in weights at 14 weeks as they were not significantly different). Weight at 1 day after hatching was not significantly different between groups. Up until 3 weeks of age, growth was negatively affected by exposure to chronic hypoxia during development. This effect disappeared after 3 weeks. Gender differences were apparent over the entire period. * $\mathrm{P}<0.05$ for differences between chickens exposed to in ovo hypoxia and normoxia. $\S \mathrm{P}<0.05$ for differences between males and females. 


\section{Data analysis}

Differences in relative numbers of chicken embryos, alive at embryonic day 19, that hatched and differences in incubation time before hatching were compared by means of Chisquare test. Gender differences were not included in the analysis of these data. Further analysis evaluated effects of in ovo hypoxia and gender and data were presented for the four groups of chickens; male chickens that had been exposed to in ovo hypoxia ( $\mathrm{Hm})$, male chickens that developed in normoxic conditions $(\mathrm{Nm})$, female chickens that had been exposed to in ovo hypoxia (Hf) and female chickens that developed in normoxic conditions (Nf).

Growth of the chickens exposed to chronic hypoxia during development and of control chickens was evaluated by repeated measurements test. Organ weights were expressed as percentage of total body weight.

Basal hemodynamic parameters were estimated by averaging MAP and HR over a steady state $\sim 10$ minutes period. $\triangle \mathrm{HR}$ and $\triangle \mathrm{MAP}$ values were calculated to determine effects of blockade of vagal, cardiac sympathetic and arterial sympathetic tone. Sensitivity to vasoactive substances (expressed as $\mathrm{pD}_{2}\left(=-\log \mathrm{EC}_{5_{0}}\right)$ ) and nerve stimulation were determined for each artery by fitting individual concentration-response data to a non-linear sigmoid regression curve and interpolation (Graphpad Prism version 2.01, Graphpad software Inc, San Diego, CA).

Maximal responses $\left(\mathrm{E}_{\max }\right)$ to NE, EFS, PHE and 5HT for each artery were expressed in terms of active wall tension (AWT, N/m), as were contractile responses to high $\mathrm{K}^{+}$solutions and $10 \mu \mathrm{mol} / \mathrm{L}$ tyramine. The effect of cocaine was calculated as the difference between $\mathrm{pD}_{2}$ for $\mathrm{NE}$ in the presence and absence of cocaine $\left(=\Delta p D_{2}\right)$ Similarly, $\Delta p D_{2}$ and $\Delta E_{\max }$ values were calculated to determine the effect of L-NAME on sensitivity and maximal responses to ACH. Basal NO production was indicated by the increase in $\mathrm{K}^{+}$-induced contraction by L-NAME. Relaxing responses to $\mathrm{ACH}$ and SNP were expressed as percentage of $\mathrm{K}^{+}$- and NE-induced contraction, respectively.

Differences between findings in male and female chickens that had been exposed to chronic hypoxia or normoxia during development were tested with two-way ANOVA with the intervention (in ovo hypoxia/normoxia) and gender as fixed factors. T-test (for intervention) was used in case the number of data was small. When normality test (Kolmogorov-Smimov) failed, $\log$ transformation was performed on the data or Mann-Whitney U test was used to confirm intervention or gender differences observed with two-way ANOVA. To test effects of drug infusion on absolute values in heart rate (HR) and mean arterial pressure (MAP) in 14-15 weeks old chickens paired t-tests (all chickens included) were used. Data were statistically analyzed with SPSS 10.0 (SPSS inc., Chicago, Illinois, USA). Data are presented as mean \pm SEM. $\mathrm{P}<0.05$ was considered statistically significant.

\section{Results}

\section{Body and organ weights}

Exposure to chronic moderate hypoxia from day 6 to 19 of the 21-day incubation did not lead to reduced body weight at 1 day after hatching (Hm: $43.4 \pm 0.6 \mathrm{~g}, \mathrm{n}=35$, Hf: $42.9 \pm 0.7 \mathrm{~g}$. $\mathrm{n}=27$ vs. Nm: $43.7 \pm 0.7 \mathrm{~g}, \mathrm{n}=25, \mathrm{Nf}: 44.3 \pm 0.6 \mathrm{~g}, \mathrm{n}=39$ ). The relative number of chicken embryos (alive at embryonic day 19) that hatched and the duration of incubation was not significantly affected by in ovo hypoxia $(66 \pm 6 \%, n=78$ vs. $80 \pm 5 \%, n=70$ and $21.4 \pm 0.1$ days, $n=78$ vs. $21.3 \pm 0.1$ days, $n=70$ ). Repeated measurements analysis of body weights from hatching up until 3 weeks of age showed that growth of chickens was negatively affected by in ovo hypoxia $(\mathrm{P}<0.05)$ and it was influenced by gender $(\mathrm{P}<0.05)$, without any interaction between gender and 
intervention (fig. 1). When data up until 14-15 weeks were included in the analysis, differences between chickens exposed to in ovo normoxia and hypoxia were not significant, but the gender dependency was maintained $(\mathrm{P}<0.05)$ (fig. 1).

Table 1.A. demonstrates that total body weights of 3-4 weeks old male and female chickens were reduced by in ovo hypoxia. Apart from adrenal weight, which was significantly increased by in ovo hypoxia, relative organ weights did not differ between groups. Though effects on relative adrenal weight seemed to be more pronounced in females, testing for interaction did not show statistical significance. At 14-15 weeks of age relative heart weight was significantly increased in chickens that had been exposed to in ovo hypoxia. Relative kidney weight was also increased by the intervention, but interaction between gender and intervention hampers interpretation. Irrespective of exposure to in ovo hypoxia or normoxia, relative weights of the heart and adrenal were significantly larger in males than in females, while relative brain weight was smaller (table 1.B.).

Table 1.A. body- and organ weights of 3-4 weeks old male and female chickens exposed to in ovo hypoxia or normoxia.

\begin{tabular}{|c|c|c|c|c|}
\hline \multicolumn{5}{|c|}{ body- and organ weight } \\
\hline$c^{4}$ & \multicolumn{2}{|c|}{ in ovo normoxia } & \multicolumn{2}{|c|}{ in ovo hypoxia } \\
\hline & male $(\mathrm{n}=7-12)$ & female $(n=9-12)$ & male $(\mathrm{n}=7-12)$ & female $(n=10-11)$ \\
\hline body weight $(B W, g)$ \# & $195 \pm 11$ & $188 \pm 9$ & $182 \pm 10$ & $*$ \\
\hline heart & $0.92 \pm 0.02$ & 1 & .08 & \\
\hline ght $(\%$ of BW) & & 0.6 & 03 & \\
\hline ( $(\%$ of $B W)$ & $3.22 \pm 0.14$ & $3.20 \pm$ & $3.18 \pm 0.13$ & 3. \\
\hline brain & $0.99 \pm 0.06$ & 0.95 & 0.06 & 05 \\
\hline lung weight (\% of BW) & $0.42 \pm 0.03$ & $0.45 \pm 0.03$ & $0.41 \pm 0.03$ & $0.39 \pm 0.02$ \\
\hline adrenal weight ( $\%$ of $\mathrm{BW}$ & $1.09 \pm 0.07\left(\times 10^{-2}\right)$ & $0.98 \pm 0.06\left(\times 10^{-2}\right)$ & $1.11 \pm 0.06\left(\times 10^{-2}\right)$ & $1.30 \pm 0.12\left(\times 10^{-2}\right)^{*}$ \\
\hline brain/liver ratio & $0.31 \pm 0.01$ & $0.30 \pm 0.02$ & $0.30 \pm 0.02$ & $0.31 \pm 0.02$ \\
\hline
\end{tabular}

Table 1.B. body- and organ weights of 14-15 weeks old male and female chickens exposed to in ovo hypoxia or normoxia.

\begin{tabular}{lcccc}
\hline & \multicolumn{4}{c}{ body- and organ weight } \\
\hline & \multicolumn{3}{c}{ in ovo normoxia } & \multicolumn{2}{c}{ in ovo hypoxia } \\
\cline { 2 - 5 } body weight $(\mathrm{BW}, \mathrm{g}) \#$ & male $(\mathrm{n}=10)$ & female $(\mathrm{n}=13)$ & male $(\mathrm{n}=14)$ & female $(\mathrm{n}=13)$ \\
\cline { 2 - 5 } heart weight $(\%$ of $\mathrm{BW})$ & $1326 \pm 61$ & $1031 \pm 37$ & $1301 \pm 64$ & $933 \pm 35 \S$ \\
kidney weight $(\%$ of $\mathrm{BW})$ & $0.63 \pm 0.05$ & $0.59 \pm 0.03$ & $0.75 \pm 0.03$ & $0.64 \pm 0.04 * \S$ \\
liver weight $(\%$ of $\mathrm{BW})$ & $2.20 \pm 0.11$ & $0.43 \pm 0.01$ & $0.44 \pm 0.01$ & $0.43 \pm 0.01 * \S f$ \\
brain weight $(\%$ of $\mathrm{BW})$ & $0.25 \pm 0.01$ & $0.32 \pm 0.15$ & $2.27 \pm 0.07$ & $2.31 \pm 0.01$ \\
lung weight $(\%$ of $\mathrm{BW})$ & $0.38 \pm 0.03$ & $0.37 \pm 0.02$ & $0.23 \pm 0.01$ & $0.30 \pm 0.01 \S$ \\
adrenal weight $(\%$ of $\mathrm{BW})$ & $0.81 \pm 0.03\left(\times 10^{-2}\right)$ & $0.73 \pm 0.04\left(\mathrm{x} 10^{-2}\right)$ & $0.78 \pm 0.02\left(\mathrm{x} 10^{-2}\right)$ & $0.32 \pm 0.02$ \\
brain/liver ratio & $0.12 \pm 0.01$ & $0.13 \pm 0.01$ & $0.10 \pm 0.01$ & $0.13 \pm 0.01$ \\
\hline
\end{tabular}

Mean \pm SEM, results of 2-way ANOVA analysis are depicted as follows: * denotes differences between chickens exposed to in ovo hypoxia and normoxia. $\S$ denotes differences between males and females. $f$ denotes interaction between the intervention and gender.

\# Body weights (BW) were determined right before chickens were sacrificed. Only body weights of chickens that were also used to determine organ weight were included. 

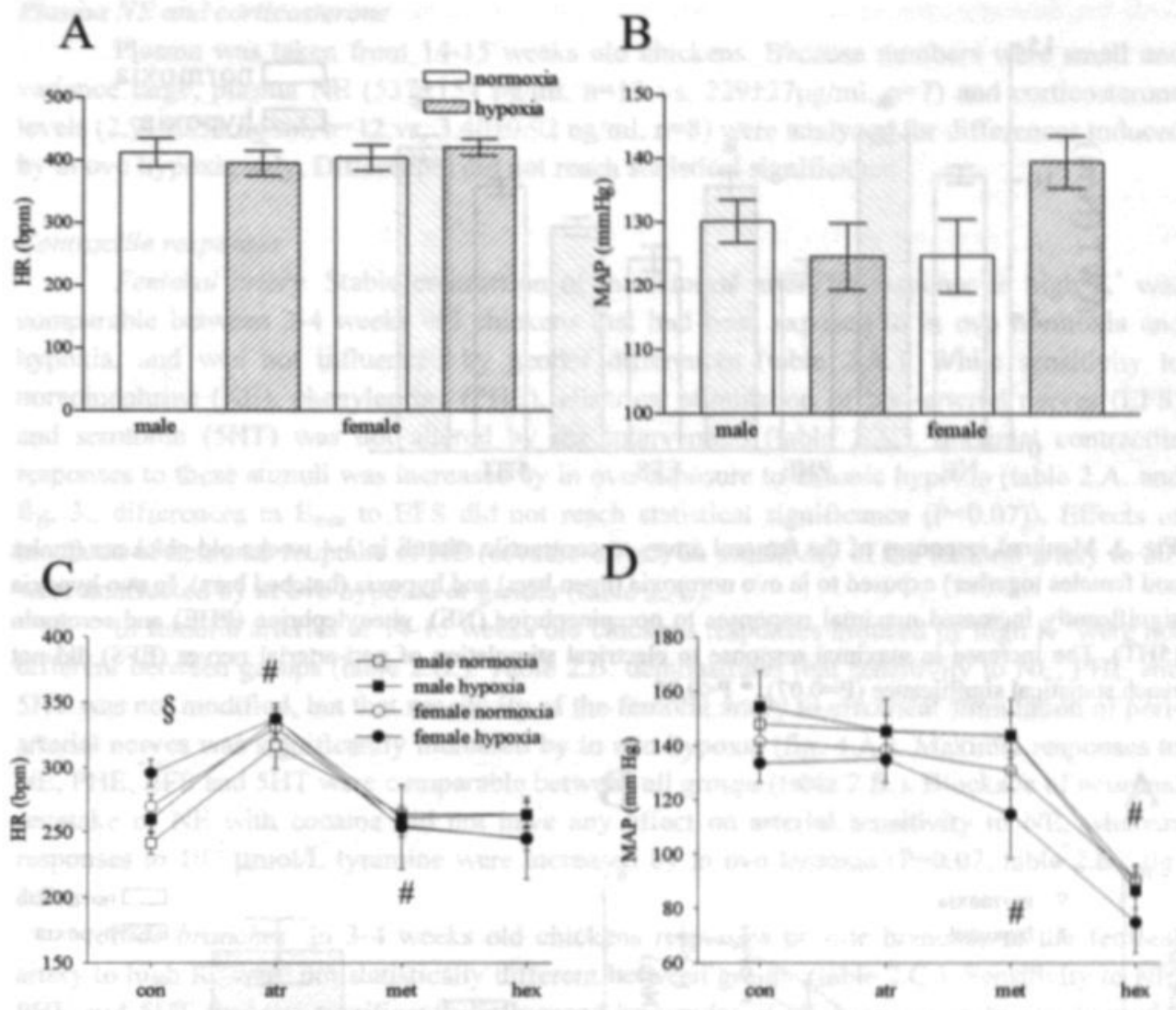

\section{D}

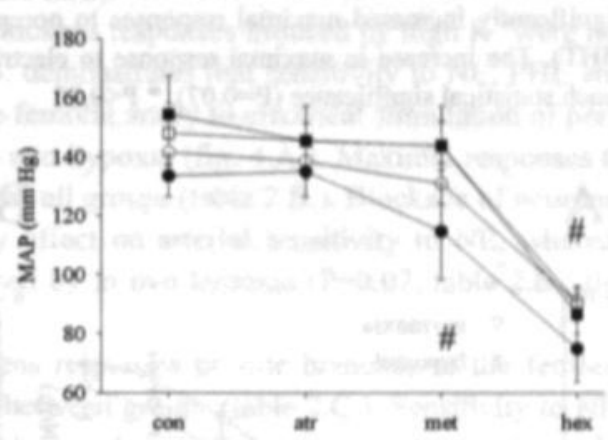

Fig. 2. Heart rate (HR, A) and mean arterial pressure (MAP, B) in 3-4 weeks old male and female chickens exposed to in ovo normoxia (open bars) and hypoxia (hatched bars). No statistically significant differences between groups were observed. Heart rate (C) and mean arterial pressure (D) in 14-15 weeks old male (squares) and female (circles) chickens exposed to in ovo normoxia (open symbols) and hypoxia (closed symbols) were not different. Infusion of atropine (atr) increased HR ( condition (con) in all groups to the same extent. Metoprolol (met) then decreased HR again (" P<0.05) without any differences between the four groups and hexamethonium (hex) did not influence HR. MAP was slightly but significantly reduced by infusion of metoprolol $(\# \mathrm{P}<0.05)$ and hexamethonium further decreased MAP $(\# \mathrm{P}=0.05)$. Differences in decreases in MAP were comparable between groups. \$. $\mathrm{P}<0.05$ for differences between males and females.

\section{Heart rate (HR) and mean arterial pressure (MAP)}

Basal HR of 3-4 weeks old chickens was not affected by in ovo exposure to hypoxia and was not different between males and females (fig. 2.A.). Analysis of variance did not reveal statistically significant gender- or intervention-induced differences in MAP (fig. 2.B.), but a significant interaction between gender and intervention was observed.

In ovo chronic hypoxia did not alter HR (fig. 2.C.) or MAP (fig. 2.D.) of 14-15 weeks old chickens. While gender differences did not influence MAP, HR of hens was significantly higher than HR of roosters. Effects of atropine (increase in HR as an indicator of vagal tone), metoprolol (decrease in HR; cardiac sympathetic tone) and hexamethonium (decrease in MAP; arterial sympathetic tone) did not significantly differ between animals exposed to normoxia and hypoxia during embryonic development (fig. 2.C. and 2.D.). 


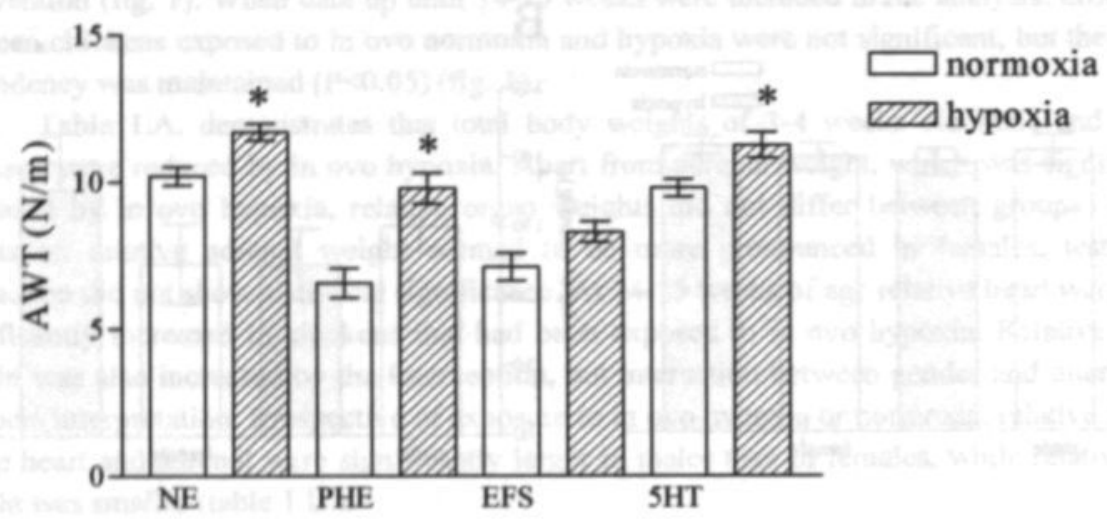

Fig. 3. Maximal responses of the femoral artery to contractile stimuli in 3-4 weeks old chickens (males and females together) exposed to in ovo normoxia (open bars) and hypoxia (hatched bars). In ovo hypoxia significantly increased maximal responses to norepinephrine (NE), phenylephrine (PHE) and serotonin (5HT). The increase in maximal response to electrical stimulation of peri-arterial nerves (EFS) did not reach statistical significance $(\mathrm{P}=0.07) * * 0.05$

A

B

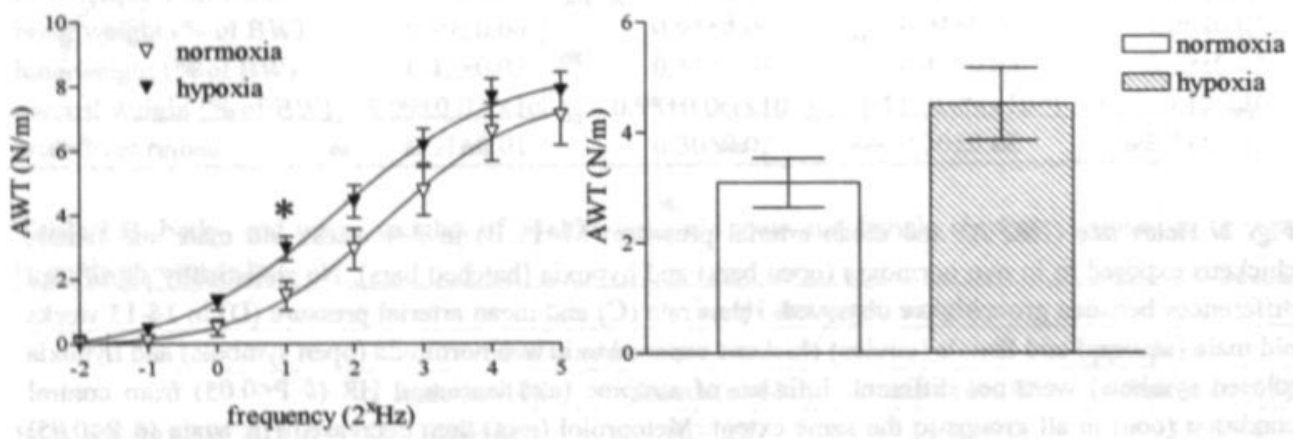

Fig. 4.A. Responses to electrical stimulation of peri-arterial nerves of the femoral artery of 14-15 weeks old chickens that had been exposed to normoxia (open symbols) or hypoxia (closed symbols) during development (males and females together). Arteries of chickens exposed to in ovo hypoxia start contracting at a lower stimulation frequency. ${ }^{*} \mathrm{P}<0.05$

Fig. 4.B. Responses to tyramine in the femoral artery of 14-15 weeks old chickens that had been exposed to normoxia (open bar) or hypoxia (hatched bar) during development (males and females together). Arteries of chickens exposed to in ovo hypoxia show increased contraction, but differences were not statistically significant $(\mathrm{P}=0.07)$. 


\section{Plasma NE and corticosterone}

Plasma was taken from 14-15 weeks old chickens. Because numbers were small and variance large, plasma NE $(537 \pm 154 \mathrm{pg} / \mathrm{ml}, \mathrm{n}=12$ vs. $229 \pm 27 \mathrm{pg} / \mathrm{ml}, \mathrm{n}=7)$ and corticosterone levels $(2.91 \pm 0.51 \mathrm{ng} / \mathrm{ml}, \mathrm{n}=12$ vs. $3.40 \pm 0.92 \mathrm{ng} / \mathrm{ml}, \mathrm{n}=8)$ were analyzed for differences induced by in ovo hypoxia only. Differences did not reach statistical significance.

\section{Contractile responses}

Femoral artery. Stable contraction of the femoral artery in response to high $\mathrm{K}^{+}$was comparable between 3-4 weeks old chickens that had been exposed to in ovo normoxia and hypoxia, and was not influenced by gender differences (table 2.A.). While sensitivity to norepinephrine (NE), phenyleprine (PHE), electrical stimulation of peri-arterial nerves (EFS) and serotonin (5HT) was not altered by the intervention (table 2.A.), maximal contractile responses to these stimuli was increased by in ovo exposure to chronic hypoxia (table 2.A. and fig. 3., differences in $E_{\max }$ to EFS did not reach statistical significance ( $\left.P=0.07\right)$ ). Effects of blockade of neuronal reuptake of NE (cocaine-effect) on sensitivity of the femoral artery to NE were unaffected by in ovo hypoxia or gender (table 2.A.).

In femoral arteries of 14-15 weeks old chickens responses induced by high $\mathrm{K}^{+}$were not different between groups (table 2.B.). Table 2.B. demonstrates that sensitivity to NE, PHE and 5HT was not modified, but that sensitivity of the femoral artery to electrical stimulation of periarterial nerves was significantly increased by in ovo hypoxia (fig. 4.A.). Maximal responses to NE, PHE, EFS and 5HT were comparable between all groups (table 2.B.). Blockade of neuronal reuptake of NE with cocaine did not have any effect on arterial sensitivity to NE, whereas responses to $10^{-5} \mu \mathrm{mol} / \mathrm{L}$ tyramine were increased by in ovo hypoxia ( $\mathrm{P}=0.07$, table $2 . \mathrm{B}$., fig. 4.B.).

Side branches. In 3-4 weeks old chickens responses of side branches of the femoral artery to high $\mathrm{K}^{+}$were not statistically different between groups (table 2.C.). Sensitivity to NE, PHE and 5HT was not significantly influenced by gender or by exposure to in ovo hypoxia. Changes in maximal responses to these contractile stimuli were not statistically significant either (table 2.C.). Sensitivity of side branches to EFS was not determined, but maximal responses were comparable between groups (table 2.C.). Neuronal NE reuptake blockade increased sensitivity to NE, but the effect was not modulated by in ovo hypoxia or gender (table 2.C.).

Side branches of the femoral artery of male and female 14-15 weeks old chickens that had been exposed to normoxia or hypoxia during development showed no differences in contraction induced by high $\mathrm{K}^{+}$(table 2.D.). Sensitivity to NE, EFS and $5 \mathrm{HT}$ was not affected by in ovo hypoxia or by gender, but arteries of chickens that had been exposed to hypoxia were more sensitive to PHE (because of small numbers gender differences were not taken into account in the analysis of PHE response). Maximal responses to the contractile stimuli were comparable between chickens exposed to normoxia and hypoxia (table 2.D.). Maximal responses to EFS were significantly larger in males than in females (table 2.D.). The increase in $\mathrm{NE}$ sensitivity induced by inhibition of the neuronal reuptake with cocaine was comparable between groups. 
Table 2.A. Sensitivity and maximal contractile responses of the femoral artery in 3-4 weeks old chickens exposed to in ovo hypoxia or normoxia.

\begin{tabular}{|c|c|c|c|c|}
\hline & \multicolumn{4}{|c|}{ sensitivity $\left(\mathrm{pD}_{2}\right) * *$} \\
\hline & \multicolumn{2}{|c|}{ in ovo normoxia } & \multicolumn{2}{|c|}{ in ovo hypoxia } \\
\hline & male $(n=4-9)$ & female $(n=6-12)$ & male $(n=5-8)$ & female $(\mathrm{n}=5-10)$ \\
\hline NE & $5.87 \pm 0.13$ & $5.74 \pm 0.08$ & $5.59 \pm 0.10$ & $5.71 \pm 0.10$ \\
\hline PHE & $4.75 \pm 0.12$ & $5.13 \pm 0.17$ & $4.99 \pm 0.03$ & $5.06 \pm 0.01$ \\
\hline EFS & $2.03 \pm 0.83$ & $2.57 \pm 0.26$ & $2.84 \pm 0.14$ & $3.20 \pm 0.30$ \\
\hline 5HT & $6.09 \pm 0.07$ & $6.05 \pm 0.08$ & $6.14 \pm 0.05$ & $6.20 \pm 0.11$ \\
\hline \multirow[t]{2}{*}{ cocaine $\left(\Delta \mathrm{pD}_{2}\right)$} & $0.35 \pm 0.18$ & $0.24 \pm 0.11$ & $0.33 \pm 0.20$ & $0.16 \pm 0.08$ \\
\hline & \multicolumn{4}{|c|}{ maximal contraction $\left(\mathrm{E}_{\max }: \mathrm{N} / \mathrm{m}\right)$} \\
\hline $63 \mathrm{mM} \mathrm{K}^{+}$ & $3.81 \pm 0.58$ & $3.54 \pm 0.34$ & $3.62 \pm 0.56$ & $4.13 \pm 0.38$ \\
\hline NE & $10.19 \pm 0.70$ & $10.21 \pm 0.34$ & $11.39 \pm 0.43$ & $11.90 \pm 0.40^{*}$ \\
\hline PHE & $7.27 \pm 0.56$ & $6.09 \pm 0.74$ & $9.87 \pm 0.79$ & $9.70 \pm 0.78$ * \\
\hline EFS & $7.51 \pm 0.84$ & $6.80 \pm 0.55$ & $8.43 \pm 0.62$ & $8.19 \pm 0.42$ \\
\hline $5 \mathrm{HT}$ & $9.75 \pm 0.51$ & $9.82 \pm 0.35$ & $10.70 \pm 0.89$ & $11.66 \pm 0.38 *$ \\
\hline
\end{tabular}

Table 2.B. Sensitivity and maximal contractile responses of the femoral artery in 14-15 weeks old chickens exposed to in ovo hypoxia or normoxia.

\begin{tabular}{|c|c|c|c|c|}
\hline \multicolumn{5}{|c|}{ sensitivity $\left(\mathrm{pD}_{2}\right)^{* *}$} \\
\hline & \multicolumn{2}{|c|}{ in ovo normoxia } & \multicolumn{2}{|c|}{ in ovo hypoxia } \\
\hline & male $(n=4-6)$ & female $(n=6-10)$ & male $(n=5-9)$ & female $(n=9-12)$ \\
\hline NE & $7.52 \pm 0.21$ & $7.34 \pm 0.17$ & $7.61 \pm 0.25$ & $7.55 \pm 0.28$ \\
\hline PHE & $5.56 \pm 0.13$ & $5.96 \pm 0.05$ & $5.72 \pm 0.18$ & $5.81 \pm 0.15$ \\
\hline EFS & $2.49 \pm 0.49$ & $2.83 \pm 0.31$ & $1.62 \pm 0.33$ & $1.92 \pm 0.18 *$ \\
\hline \multirow[t]{2}{*}{$5 \mathrm{HT}$} & $6.71 \pm 0.11$ & $7.01 \pm 0.14$ & $6.90 \pm 0.14$ & $7.00 \pm 0.14$ \\
\hline & \multicolumn{4}{|c|}{ maximal contraction $\left(\mathrm{E}_{\max }: \mathrm{N} / \mathrm{m}\right)$} \\
\hline $63 \mathrm{mM} \mathrm{K}^{+}$ & $3.95 \pm 0.17$ & $3.52 \pm 0.70$ & $2.94 \pm 0.45$ & $3.87 \pm 0.66$ \\
\hline NE & $13.48 \pm 1.07$ & $13.19 \pm 0.95$ & $12.97 \pm 0.79$ & $12.54 \pm 1.20$ \\
\hline PHE & $10.26 \pm 2.02$ & $11.81 \pm 1.00$ & $12.59 \pm 0.84$ & $10.45 \pm 1.03$ \\
\hline EFS & $7.82 \pm 0.77$ & $6.99 \pm 1.49$ & $9.27 \pm 0.81$ & $7.42 \pm 0.74$ \\
\hline $5 \mathrm{HT}$ & $12.13 \pm 1.38$ & $12.95 \pm 0.89$ & $12.71 \pm 0.78$ & $11.31 \pm 1.06$ \\
\hline Tyr $(10 \mu \mathrm{M})$ & $2.26 \pm 0.67$ & $3.65 \pm 0.51$ & $5.27 \pm 0.85$ & $4.10 \pm 0.9$ \\
\hline
\end{tabular}


Table 2.C. Sensitivity and maximal contractile responses of the side branches of the femoral artery in $3-4$ weeks old chickens exposed to in ovo hypoxia or normoxia.

\begin{tabular}{|c|c|c|c|c|}
\hline & \multicolumn{4}{|c|}{ sensitivity $\left(\mathrm{pD}_{2}\right) *$} \\
\hline & \multicolumn{2}{|c|}{ in ovo normoxia } & \multicolumn{2}{|c|}{ in ovo hypoxia } \\
\hline & male $(n=4)$ & female $(\mathrm{n}=11)$ & male $(n=6)$ & female $(n=8)$ \\
\hline & & & & \\
\hline NE & $5.57 \pm 0.18$ & $5.57 \pm 0.06$ & $5.56 \pm 0.11$ & $5.49 \pm 0.08$ \\
\hline PHE & $4.71 \pm 0.40$ & $4.87 \pm 0.26$ & $5.04 \pm 0.11$ & $4.89 \pm 0.22$ \\
\hline 5HT & $6.09 \pm 0.10$ & $6.13 \pm 0.06$ & $6.06 \pm 0.08$ & $5.71 \pm 0.21$ \\
\hline \multirow[t]{2}{*}{ cocaine $\left(\Delta \mathrm{pD}_{2}\right)$} & $0.27 \pm 0.09$ & $0.22 \pm 0.07$ & $0.26 \pm 0.09$ & $0.23 \pm 0.06$ \\
\hline & & maximal contr & $n\left(E_{\max }: N / m\right)$ & \\
\hline $63 \mathrm{mM} \mathrm{K}^{+}$ & $2.06 \pm 0.46$ & $2.48 \pm 0.30$ & $1.73 \pm 0.11$ & $2.93 \pm 0.56$ \\
\hline NE & $4.31 \pm 0.29$ & $4.45 \pm 0.19$ & $3.65 \pm 0.49$ & $4.56 \pm 0.25$ \\
\hline PHE & $2.12 \pm 0.58$ & $2.42 \pm 0.33$ & $3.12 \pm 0.75$ & $3.14 \pm 0.40$ \\
\hline EFS & $0.83 \pm 0.27$ & $0.93 \pm 0.15$ & $0.58 \pm 0.18$ & $1.05 \pm 0.17$ \\
\hline 5HT & $4.56 \pm 0.27$ & $4.99 \pm 0.32$ & $4.30 \pm 0.45$ & $4.63 \pm 0.28$ \\
\hline
\end{tabular}

Table 2.D. Sensitivity and maximal contractile responses of the side branches of the femoral artery in 1415 weeks old chickens exposed to in ovo hypoxia or normoxia.

\begin{tabular}{|c|c|c|c|c|}
\hline & \multicolumn{4}{|c|}{ sensitivity $\left(\mathrm{pD}_{2}\right) *$} \\
\hline & \multicolumn{2}{|c|}{ in ovo normoxia } & \multicolumn{2}{|c|}{ in ovo hypoxia } \\
\hline & male $(n=5)$ & female $(n=10)$ & male $(n=8)$ & female $(n-12)$ \\
\hline NE & $5.44 \pm 0.11$ & $5.40 \pm 0.11$ & $5.30 \pm 012$ & $5.53 \pm 0.08$ \\
\hline PHE & \multicolumn{2}{|c|}{$5.02 \pm 0.07(\mathrm{n}=8)$} & \multicolumn{2}{|c|}{$5.20 \pm 0.05(\mathrm{n}=9)^{*}$} \\
\hline EFS & $3.15 \pm 0.16$ & $3.56 \pm 0.50$ & $3.44 \pm 0.25$ & $3.23 \pm 0.35$ \\
\hline 5HT & $5.93 \pm 0.28$ & $6.19 \pm 0.13$ & $5.90 \pm 0.12$ & $6.23 \pm 0.13$ \\
\hline \multirow[t]{2}{*}{ cocaine $\left(\Delta \mathrm{pD}_{2}\right)$} & $0.43 \pm 0.06$ & $0.61 \pm 0.10$ & $0.48 \pm 0.07$ & $0.46 \pm 0.12$ \\
\hline & \multicolumn{4}{|c|}{ maximal contraction $\left(\mathrm{E}_{\max }: \mathrm{N} / \mathrm{m}\right)$} \\
\hline $63 \mathrm{mM} \mathrm{K}^{+}$ & $3.34 \pm 0.56$ & $4.16 \pm 0.62$ & $4.43 \pm 0.86$ & $3.48 \pm 0.64$ \\
\hline NE & $8.37 \pm 0.63$ & $8.30 \pm 0.55$ & $7.91 \pm 1.04$ & $7.40 \pm 0.63$ \\
\hline PHE & \multicolumn{2}{|c|}{$5.66 \pm 0.77$} & \multicolumn{2}{|c|}{$5.70 \pm 0.91$} \\
\hline EFS & $3.44 \pm 0.64$ & $2.14 \pm 0.51$ & $3.60 \pm 0.67$ & $1.40 \pm 0.298$ \\
\hline $5 \mathrm{HT}$ & $8.53 \pm 0.88$ & $8.00 \pm 0.52$ & $7.94 \pm 1.00$ & $6.96 \pm 0.48$ \\
\hline
\end{tabular}

Mean \pm SEM, results of 2-way ANOVA analysis are depicted as follows: * denotes differences between chickens exposed to in ovo hypoxia and normoxia. $\$$ denotes differences between males and females. $f$ denotes interaction between the intervention and gender.

NE=norepinephrine, PHE=phenylephrine, EFS= Electrical Field Stimulation of peri-arterial nerves, $5 \mathrm{HT}=$ serotonin, , tyr-tyramine ** for EFS, sensitivity was expressed as the frequency (in $\mathrm{Hz}$ ) at which half maximal contraction was achieved. Of tyramine and $\mathrm{K}^{+}$only one concentration was used. "cocaine $\left(\Delta \mathrm{pD}_{2}\right)^{\prime \prime}$ represents the difference in $\mathrm{pD}_{2}$ values for $\mathrm{NE}$ in the presence and absence of cocaine. 
Table 3.A. Sensitivity and maximal relaxing responses of the femoral artery in 3-4 weeks old chickens exposed to in ovo hypoxia or normoxia.

\begin{tabular}{|c|c|c|c|c|c|}
\hline & \multicolumn{5}{|c|}{ sensitivity $\left(\mathrm{pD}_{2}\right)$} \\
\hline & & \multicolumn{2}{|c|}{ in ovo normoxia } & \multicolumn{2}{|c|}{ in ovo hypoxia } \\
\hline & $18=$ & male $(\mathrm{n}=7)$ & female $(n=12)$ & male $(n=8)$ & female $(n=9)$ \\
\hline $\mathrm{ACH}$ & & $6.56 \pm 0.20$ & $6.25 \pm 0.14$ & $6.09 \pm 0.16$ & $6.40 \pm 0.08 \mathrm{f}$ \\
\hline SNP & & $5.28 \pm 0.15$ & $5.23 \pm 0.09$ & $5.18 \pm 0.14$ & $5.28 \pm 0.12$ \\
\hline & & & & & \\
\hline \multicolumn{2}{|c|}{$\triangle \mathrm{L}$-NAME,ACH } & \multicolumn{2}{|c|}{$0.50 \pm 0.09(\mathrm{n}=10)$} & \multicolumn{2}{|c|}{$0.53 \pm 0.19(\mathrm{n}=10)$} \\
\hline & & \multicolumn{4}{|c|}{ maximal relaxation $\left(\mathrm{E}_{\max }: \%\right) *$} \\
\hline $\mathrm{ACH}$ & 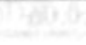 & $54.64 \pm 6.32$ & $48.69 \pm 7.52$ & $40.51 \pm 9.34$ & $57.33 \pm 7.54$ \\
\hline SNP & & $78.43 \pm 5.27$ & $77.73 \pm 2.46$ & $76.20 \pm 4.48$ & $77.39 \pm 2.43$ \\
\hline$\Delta \mathrm{L}-\mathrm{N} /$ & $\mathrm{K}^{+}$ & \multicolumn{2}{|c|}{$3.65 \pm 0.36(n=10)$} & \multicolumn{2}{|c|}{$4.14 \pm 0.31(n=10)$} \\
\hline$\Delta \mathrm{L}-\mathrm{N} /$ & $\mathrm{ACH}$ & \multicolumn{2}{|c|}{$20.68 \pm 6.69$} & \multicolumn{2}{|c|}{$25.39 \pm 5.94$} \\
\hline
\end{tabular}

Table 3.B. Sensitivity and maximal relaxing responses of the femoral artery in 14-15 weeks old chickens exposed to in ovo hypoxia or normoxia.

\begin{tabular}{|c|c|c|c|c|}
\hline & \multicolumn{4}{|c|}{ sensitivity $\left(\mathrm{pD}_{2}\right)$} \\
\hline & \multicolumn{2}{|c|}{ in ovo normoxia } & \multicolumn{2}{|c|}{ in ovo hypoxia } \\
\hline is & male $(\mathrm{n}-6)$ & female $(n=8)$ & male $(n=9)$ & female $(n=12)$ \\
\hline \multirow{3}{*}{$\begin{array}{l}\text { ACH } \\
\text { SNP }\end{array}$} & \multicolumn{2}{|c|}{$6.57 \pm 0.16(n=10)$} & \multicolumn{2}{|c|}{$6.37 \pm 0.17(\mathrm{n}=15)$} \\
\hline & $4.98 \pm 0.06$ & $5.16 \pm 0.16$ & $5.02 \pm 0.10$ & $5.08 \pm 0.06$ \\
\hline & \multicolumn{4}{|c|}{ maximal relaxation $\left(\mathrm{E}_{\max }: \%\right) * *$} \\
\hline $\mathrm{ACH} \#$ & \multicolumn{2}{|c|}{$45.58 \pm 6.96$} & \multicolumn{2}{|c|}{$38.85 \pm 6.05$} \\
\hline SNP & $62.06 \pm 3.47$ & $67.44 \pm 4.11$ & $59.90 \pm 3.84$ & $70.82+3.65$ \\
\hline$\triangle \mathrm{L}-\mathrm{NAME}, \mathrm{K}^{+}$ & \multicolumn{2}{|c|}{$3.26 \pm 0.51(\mathrm{n}=8)$} & \multicolumn{2}{|c|}{$3.75 \pm 0.50(\mathrm{n}=13)$} \\
\hline
\end{tabular}

\section{Relaxing responses}

Femoral artery. Statistical analysis of arterial sensitivity of the femoral artery of 3-4 weeks old chickens to acetylcholine $(\mathrm{ACH})$, an endothelium-dependent vasodilator, showed significant interaction between the intervention and gender, which may suggest that in ovo hypoxia had different effects on male and female arteries (table 3.A.). Arterial sensitivity to sodium nitroprusside (SNP), an exogenous NO-donor, was comparable in all groups. Maximal responses to these vasodilators were not influenced by in ovo hypoxia or by differences in gender (table 3.A.). Blockade of NO-synthase with L-NAME increased contraction to 63 $\mathrm{mmol} / \mathrm{L} \mathrm{K} \mathrm{K}^{+}$and reduced arterial sensitivity and maximal responses to $\mathrm{ACH}$, but effects were comparable in arteries of chickens exposed to in ovo normoxia and hypoxia (table 3.A.).

Of the femoral arteries of 14-15 weeks old chickens almost $30 \%$ did not respond to $\mathrm{ACH}$ and in $15 \%$ of the responding arteries a concentration-response relation was difficult to determine. No response and responses without clear concentration-dependency were observed more often in males than in females. In responding arteries no effects of exposure to in ovo hypoxia were observed (table 3.B.). Sensitivity and maximal relaxation to SNP were not affected by in ovo hypoxia or by gender differences (table 3.B.). Effects of L-NAME on ACHinduced relaxation were not evaluated, but L-NAME did increase contraction in response to 63 $\mathrm{mmol} / \mathrm{L} \mathrm{K} \mathrm{K}^{+}$without any differences between femoral arteries of chickens exposed to normoxia or hypoxia (table 3.B.).

Side branches. From table 3.C. it can be observed that no differences in sensitivity or maximal responses to either ACH or SNP between 3-4 weeks old male and female chickens 
Table 3.C. Sensitivity and maximal relaxing responses of the side branch of the femoral artery in 3-4 weeks old chickens exposed to in ovo hypoxia or normoxia.

\begin{tabular}{|c|c|c|c|c|}
\hline & \multicolumn{4}{|c|}{ sensitivity $\left(\mathrm{pD}_{2}\right)$} \\
\hline & \multicolumn{2}{|c|}{ in ovo normoxia } & \multicolumn{2}{|c|}{ in ovo hypoxia } \\
\hline & male $(n=4)$ & female $(n=6-10)$ & male $(n=4-6)$ & female $(n-6-10)$ \\
\hline $\mathbf{A C H}$ & $6.93 \pm 0.12$ & $6.95 \pm 0.08$ & $6.82 \pm 0.18$ & $6.90 \pm 0.13$ \\
\hline SNP & $5.39 \pm 0.09$ & $5.46 \pm 0.18$ & $5.49 \pm 0.25$ & $5.79 \pm 0.40$ \\
\hline \multirow[t]{2}{*}{$\triangle \mathrm{L}$-NAME,ACH } & \multicolumn{2}{|c|}{$0.72 \pm 0.10(\mathrm{n}=9)$} & \multicolumn{2}{|c|}{$0.68 \pm 0.28(\mathrm{n}=-6)$} \\
\hline & \multicolumn{4}{|c|}{ maximal relaxation $\left(\mathrm{E}_{\max }: \%\right) *$} \\
\hline ACH & $86.34 \pm 1.69$ & $80.08 \pm 3.92$ & $81.08 \pm 5.72$ & $78.57 \pm 4.65$ \\
\hline SNP & $84.70 \pm 2.95$ & $85.20 \pm 1.81$ & $78.67 \pm 7.36$ & $77.47 \pm 5.71$ \\
\hline$\triangle \mathrm{L}-\mathrm{NAME}, \mathrm{K}^{+}$ & \multicolumn{2}{|c|}{$0.68 \pm 0.20(n=10)$} & \multicolumn{2}{|c|}{$-0.16 \pm 0.33(n=10) *$} \\
\hline$\triangle \mathrm{L}$-NAME_ACH & \multicolumn{2}{|c|}{$46.09 \pm 3.55$} & \multicolumn{2}{|c|}{$41.35 \pm 5.10$} \\
\hline
\end{tabular}

Table 3.D. Sensitivity and maximal relaxing responses of the side branch of the femoral artery in 14-15 weeks old chickens exposed to in ovo hypoxia or normoxia.

\begin{tabular}{|c|c|c|c|c|}
\hline \multicolumn{5}{|c|}{ sensitivity $\left(\mathrm{pD}_{2}\right)$} \\
\hline & \multicolumn{2}{|c|}{ in ovo normoxia } & \multicolumn{2}{|c|}{ in ovo hypoxia } \\
\hline & male $(\mathrm{n}=5)$ & female $(n=10)$ & male $(n=7)$ & female $(\mathrm{n}=12)$ \\
\hline $\mathrm{ACH}$ & $6.74 \pm 0.08$ & $6.99 \pm 0.13$ & $6.66 \pm 0.10$ & $.10 \$$ \\
\hline SNP & $5.04 \pm 0.25$ & $5.41 \pm 0.16$ & $5.36 \pm 0.27$ & $5.28 \pm 0.16$ \\
\hline \multirow[t]{2}{*}{$\triangle \mathrm{L}$-NAME,ACH } & \multicolumn{2}{|c|}{$0.62 \pm 0.05(\mathrm{n}=10)$} & \multicolumn{2}{|c|}{$0.32 \pm 0.11(\mathrm{n}=11)^{*}$} \\
\hline & \multicolumn{4}{|c|}{ maximal relaxation $\left(\mathrm{E}_{\max }: \%\right) * *$} \\
\hline ACH & $58.99 \pm 5.27$ & $68.76 \pm 4.25$ & $62.14 \pm 6.24$ & $74.15 \pm 2.90 \S$ \\
\hline SNP & $78.27 \pm 10.42$ & $94.81 \pm 1.58$ & $73.61 \pm 4.65$ & $94.06 \pm 1.07 \S$ \\
\hline$\triangle \mathrm{L}$-NAME, $\mathbf{K}^{+}$ & $2.88 \pm 0.19$ & $2.79 \pm 0.58$ & $0.35 \pm 0.91$ & $1.29 \pm 0.36^{\circ}$ \\
\hline$\triangle \mathrm{L}$-NAME,ACH & \multicolumn{2}{|c|}{$22.21 \pm 4.15$} & \multicolumn{2}{|c|}{$22.68 \pm 1.89$} \\
\hline
\end{tabular}

Mean \pm SEM, results of 2-way ANOVA analysis are depicted as follows: * denotes differences between chickens exposed to in ovo hypoxia and normoxia. $\$$ denotes differences between males and females. $f$ denotes interaction between the intervention and gender.

$\mathrm{ACH}=$ acetylcholine, SNP=sodium nitropnusside, ** the effect of L-NAME on $\mathbf{K}^{*}$-contraction is expressed in $\mathrm{N} / \mathrm{m}$ in stead of $\%$.

\# values of responding arteries only

exposed to in ovo normoxia or hypoxia were observed. However, the effect of L-NAME on $\mathrm{K}^{+}$induced contraction was smaller (or even absent) in chickens exposed to in ovo hypoxia compared to control chickens. Sensitivity and maximal responses to $\mathrm{ACH}$ were reduced to the same extent in all groups (table 3.C.).

Sensitivity of side branches to SNP was comparable in all groups at the age of 14-15 weeks, but maximal responses to both SNP and $\mathrm{ACH}$ were significantly smaller in males than in females (table 3.D.). In ovo hypoxia did not affect these responses. Side branches of the femoral artery of male chickens were also less sensitive to $\mathrm{ACH}$ than those of females, but sensitivity was not affected by in ovo hypoxia. However, the effect of L-NAME on $\mathrm{K}^{*}$-induced contraction and on sensitivity to ACH was significantly smaller after in ovo hypoxia (fig 5.A. and 5.B., table 3.D.). 


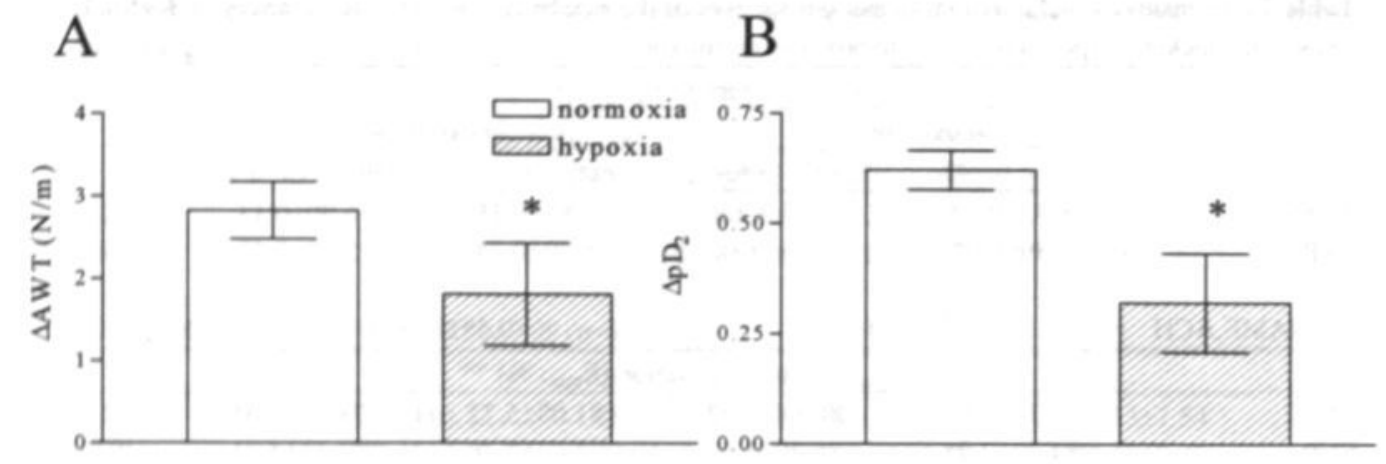

\section{B}

Fig. 5.A. Effect of L-NAME on contraction induced by $\mathrm{K}^{+}(\triangle \mathrm{AWT})$ in side branches of the femoral artery of 14-15 weeks old chickens (males and females together) that were exposed to in ovo normoxia (open bars) and hypoxia (hatched bars). In ovo hypoxia reduced the effect of L-NAME. * P $<0.05$

Fig. 5.B. Effect of $L-N A M E$ on sensitivity to acetylcholine $\left(\Delta \mathrm{pD}_{2}\right)$ in side branches of the femoral artery of 14-15 weeks old chickens (males and females together) that were exposed to in ovo normoxia (open bars) and hypoxia (hatched bars). In ovo hypoxia reduced the effect of L-NAME. ${ }^{*} P<0.05$.

\section{Structural parameters}

Table 4.A. shows that in ovo hypoxia did not change media cross sectional area (CSA) of femoral arteries and side branches of 3-4 and 14-15 weeks old male and female chickens. While media CSA was comparable in males and females at 3-4 weeks of age, 14-15 week old roosters had significantly larger media CSA than hens. Arterial lumen radius was not modulated by the intervention or by gender (table 4.B.).

Differences in DNA content of male and female femoral arteries were apparent at 3-4 weeks of age, but did not reach statistical significance in 14-15 weeks old chickens (table 4.C.). In ovo hypoxia did not affect DNA content of the femoral artery. DNA contents of the heart of 3-4 and 14-15 weeks old chickens were comparable in all four groups (table 4.C.).

As numbers were small, only effects of in ovo exposure to hypoxia (regardless of gender) on peri-arterial nerve density were statistically analyzed, but no differences were observed in femoral arteries and side branches of 3-4 weeks old chickens nor in side branches of 14-15 weeks old chickens (table 4.D.).

\section{Discussion}

The present study shows that exposure to moderate chronic hypoxia during in ovo development resulted in distinct alterations of arterial smooth muscle function, responses to perivascular sympathetic nerve stimulation and endothelial function in chickens after hatching. At this stage in life this was not accompanied by elevations in blood pressure.

In previous studies, we showed that exposure to chronic moderate hypoxia from day 6 to day 19 reduces embryonic growth and leads to sympathetic hyperinnervation (53, chapter 4 ) and endothelial dysfunction (52, chapter 6) of the femoral artery at embryonic day 19. 
Table 4.A. Media cross sectional area of femoral arteries and side branches of 3-4 and 14-15 weeks old chickens exposed to in ovo hypoxia or normoxia

\begin{tabular}{|c|c|c|c|c|}
\hline & \multicolumn{4}{|c|}{ media cross sectional area $\left(\times 10^{3} \mu \mathrm{m}^{2}\right)$} \\
\hline & \multicolumn{2}{|c|}{ in ovo normoxia } & \multicolumn{2}{|c|}{ in ovo hypoxia } \\
\hline & male & female & male & female \\
\hline FA $3-4$ w & $95.47 \pm 7.17(\mathrm{n}=9)$ & $86.78 \pm 4.94(\mathrm{n}=12)$ & $97.24 \pm 8.80(\mathrm{n}=8)$ & $94.81 \pm 5.00(n=10)$ \\
\hline SB $3-4 \mathrm{w}$ & $16.80+2.43(n=4)$ & $17.47 \pm 1.73(\mathrm{n}=10)$ & $16.33 \pm 1.65(\mathrm{n}-4)$ & $18.12 \pm 1.20(\mathrm{n}=8)$ \\
\hline FA $14-15 w$ & $305.20 \pm 22.71(n=6)$ & $228.02 \pm 16.02(\mathrm{n}=9)$ & $314.57 \pm 23.41(\mathrm{n}=9)$ & $217.15 \pm 12.69(\mathrm{n}=12) \S$ \\
\hline SB14-15 w & $74.51 \pm 8.53(\mathrm{n}=5)$ & $46.34 \pm 1.63(\mathrm{n}=10)$ & $63.63 \pm 6.40(\mathrm{n}=8)$ & $49.72 \pm 4.64(\mathrm{n}=12) \&$ \\
\hline
\end{tabular}

Table 4.B. Lumen radius of femoral arteries and side branches of 3-4 and 14-15 weeks old chickens exposed to in ovo hypoxia or normoxia

\begin{tabular}{|c|c|c|c|c|}
\hline & \multicolumn{4}{|c|}{ radius $(\mu \mathrm{m})$} \\
\hline & \multicolumn{2}{|c|}{ in ovo normoxia } & \multicolumn{2}{|c|}{ in ovo hypoxia } \\
\hline & male & female & male & female \\
\hline FA $3-4$ w & $320 \pm 5.66(\mathrm{n}=9)$ & $314 \pm 6.78(\mathrm{n}=12)$ & $314 \pm 6.80(n=8)$ & $317 \pm 6.24(\mathrm{n}=10)$ \\
\hline SB 3-4 w & $143 \pm 5.76(n=4)$ & $158 \pm 5.75(n=10)$ & $145 \pm 7.05(n=4)$ & $146 \pm 4.17(n-8)$ \\
\hline FA $14-15 w$ & $611 \pm 35.01(n=6)$ & $585 \pm 29.98(n=9)$ & $566 \pm 29.88(n=9)$ & $593 \pm 30.56(n-12)$ \\
\hline SB14-15 w & $274 \pm 13.39(\mathrm{n}=5)$ & $264 \pm 6.61(\mathrm{n}=10)$ & $259 \pm 4.74(n=8)$ & $260 \pm 9.45(\mathrm{n}=12)$ \\
\hline
\end{tabular}

Table 4.C. DNA content of femoral arteries and hearts of 3-4 and 14-15 weeks old chickens exposed to u ovo aypoxia or normoxia

\begin{tabular}{|c|c|c|c|c|}
\hline & \multicolumn{4}{|c|}{ DNA content ( $\mu \mathrm{g} / \mathrm{mm}$ arterial length, $\mu \mathrm{g} / \mathrm{mg}$ wet weight) } \\
\hline & \multicolumn{2}{|c|}{ in ovo normoxia } & \multicolumn{2}{|c|}{ in ovo hypoxia } \\
\hline & male & female & male & female \\
\hline FA $3-4$ w & $0.89 \pm 0.05(n=7)$ & $0.76 \pm 0.03(n=9)$ & $0.81 \pm 0.05(n=9)$ & $0.74 \pm 0.04(n-8) \&$ \\
\hline heart 3-4 w & $2.20 \pm 0.16(n=8)$ & $2.09 \pm 0.11(\mathrm{n}=10)$ & $2.24 \pm 0.09(\mathrm{n}=10)$ & $2.19 \pm 0.13(\mathrm{n}-9)$ \\
\hline FA $14-15 w$ & $1.16 \pm 0.14(\mathrm{n}=7)$ & $1.03 \pm 0.07(n=5)$ & $1.19 \pm 0.10(n=5)$ & $1.06 \pm 0.12(n-6)$ \\
\hline heart 14-15 w & $2.12 \pm 0.12(\mathrm{n}=7)$ & $2.14 \pm 0.07(\mathrm{n}=5)$ & $2.14 \pm 0.10(\mathrm{n}=5)$ & $2.10 \pm 0.13(\mathrm{n}=6)$ \\
\hline
\end{tabular}

Table 4.D. Peri-arteial sympathetic nerve density of arteries of 3-4 and 14-15 weeks old chickens exposed to in ovo hypoxia or normoxia

\begin{tabular}{lcc}
\hline & \multicolumn{2}{c}{ peri-arterial nerve sympathetic density $\left(\mathrm{cnts} / 10^{4} \mu \mathrm{m}^{2}\right)$} \\
\hline & in ovo normoxia & in ovo hypoxia \\
FA 3-4 w & $14.20 \pm 0.39(\mathrm{n}=12)$ & $14.08 \pm 0.58(\mathrm{n}=10)$ \\
SB 3-4 w & $13.38 \pm 0.62(\mathrm{n}=10)$ & $14.77 \pm 0.40(\mathrm{n}=8)$ \\
SB14-15 w & $13.70 \pm 0.58(\mathrm{n}=8)$ & $13.80 \pm 0.49(\mathrm{n}=5)$ \\
\hline
\end{tabular}

Mean $\pm \mathrm{SEM}, \mathrm{FA}=$ femoral artery, $\mathrm{SB}=$ side branch, w=week, results of 2-way ANOVA analysis are depicted as follows: * denotes differences between chickens exposed to in ovo hypoxia and normoxia. \$ denotes differences between males and females. $f$ denotes interaction between the intervention and gender. 
Sympathetic hyperinnervation precedes media thickening, hypercontractility and the rise in blood pressure in spontaneously hypertensive rats $(32,18)$. Reduced NO production may also modulate vascular smooth muscle cell proliferation (66) and contractility. Therefore, we hypothesized that, following exposure to in ovo chronic hypoxia, persisting arterial sympathetic hyperinnervation and endothelial dysfunction may lead to increased arterial media thickness and contractility consequently resulting in hypertension.

\section{Effects on growth}

Neither the percentage of chickens that hatched nor the incubation period until hatching were affected by in ovo exposure to hypoxia. While we (53) and others (43) have previously shown that chronic hypoxia reduces growth of the chicken embryo, this was not reflected by differences in body weight at 1 day after hatching. From day 19 of incubation onwards embryos were replaced in normoxia. During this period body weight was almost duplicated and weight differences between chickens exposed to in ovo normoxia and hypoxia disappeared. The presence of cardiovascular effects after in ovo hypoxia without changes in weight at hatching. confirms studies that suggest that cardiovascular consequences of prenatal insults do not necessarily go together with reduced birth weight (21). However, growth after hatching was reduced until 3 weeks after hatching in chickens that had been exposed to in ovo chronic hypoxia. Similar perinatal growth patterns have been observed in rats that develop hypertension in later life (SHR, 36) and in chickens exposed to in ovo chronic hypoxia by partial covering of the eggshell (3). After 3 weeks of age the chickens in the intervention group caught up with controls. Some studies propose that particularly postnatal catch up growth is critical in the development of cardiovascular disease in later stages of life (14). We did not determine food intake of the chickens. It is, however, noteworthy that fetal malnutrition has been described to affect neonatal appetite and to increase the risk for obesity (64).

In addition to total body weight, specific organs seemed to be affected by in ovo exposure to chronic hypoxia. In 3-4 weeks old chickens, increased relative adrenal weight was observed. Increases in fetal adrenal weight and upregulation of adrenal enzymes after chronic hypoxia and placental restriction $(23,25)$ have been described. Our results suggest that these effects persist to some stage in postnatal life. In older chickens (14-15 weeks) no differences in relative adrenal weight were demonstrated, but relative weight of the heart and kidneys was increased by in ovo chronic hypoxia. The characteristics of the larger hearts and kidneys of these animals were not further examined. However, the enlarged heart may suggest cardiac hypertrophy, which is an independent risk factor for cardiovascular disease (10). Effects of adverse intrauterine conditions on the renal structure and function resulting in hypertension in later life have been proposed $(31,7)$.

\section{Heart rate (HR) and blood pressure (MAP)}

Chickens, like other avian species, have higher blood pressures than mammals and are prone to develop hypertension, especially males $(28,46,56)$. The basal MAP and HR levels, which we observed were in agreement with earlier data $(28,46)$. The changes in these parameters after pharmacological blockade of vagal and sympathetic nervous input were comparable to those observed in mammalian species, as was previously proposed $(59,45,28)$. Alterations in MAP and HR following blockade did not differ between chickens that had been exposed to in ovo normoxia and hypoxia. Basal blood pressure and heart rate were not modulated either. However, the intervention did induce changes in arterial properties. 


\section{Effects on arterial contractile reactivity}

In ovo chronic hypoxia increased maximal responses of the femoral artery of 3-4 weeks old chickens to adrenergic (NE, PHE) and non-adrenergic stimulation (5HT), suggesting that contractile capacity was affected in an aspecific way. The increases in maximal contraction can probably not be explained by increases in the number or size of the vascular smooth muscle cells, which is indicated by comparable DNA contents and media cross sectional areas in arteries of chickens exposed to in ovo chronic hypoxia and control chickens. Furthermore, responses to $63 \mathrm{mmol} / \mathrm{L} \mathrm{K}^{+}$were not significantly altered by the intervention, suggesting that particularly pharmaco-mechanical coupling was affected. The observed change in contractile capacity may then be sought in alterations in second messengers or calcium handling (51). It is interesting to note that, besides maturation (50), rapid growth patterns (47) have been associated with increases in arterial contractility in chickens.

While maximal contraction was not altered in 14-15 weeks old chickens, sensitivity to electrical stimulation of peri-arterial nerves was increased by in ovo chronic hypoxia. Application of tyramine, which releases norepinephrine from the perivascular nerves (60), also resulted in increased contraction. At this stage, this was not accompanied by changes in arterial media cross-sectional area, DNA content or responsiveness to exogenous norepinephrine. These data indicate that the sympathetic nerve endings of femoral arteries of chickens that had been exposed to in ovo hypoxia contained more norepinephrine and/or that this was released at lower levels of stimulation than in arteries of control chickens. Resting circulating levels of NE in avian species are thought to be mainly derived from the vascular sympathetic nerve endings rather than from the adrenal (56). The large decrease in HR during $\beta$-blockade and in MAP during ganglion-blockade in addition to high levels of plasma catecholamines we observed may indicate that resting sympathetic and adrenal activity in chickens is high, as was suggested before $(28,56)$. However, in ovo hypoxia did not significantly affect any of these parameters. Therefore, our findings in the femoral artery probably do not indicate increased sympathetic nervous activity, but an alteration in the function of the peri-arterial sympathetic nerve endings.

\section{Effects on endothelial function}

In the present study we demonstrate that effects of in ovo chronic hypoxia on endothelial NO were apparent in side branches of the femoral artery of chickens 3-4 weeks and, even more pronounced, 14-15 weeks after hatching. Although we have not investigated this in side branches of the femoral artery of chickens after hatching, responses to acetylcholine in the femoral artery are entirely endothelium-dependent in the chicken embryo (34). Endotheliumdependency of acetylcholine-induced relaxation was also demonstrated in adult chicken aorta and pulmonary arteries $(16,40)$. Decreased arterial endothelial function as a result of chronic hypoxemia has been described in the mammalian fetus $(37,61)$ and in rats that were exposed to maternal food restriction during the second half of gestation (22). To our knowledge this parameter of vascular dysfunction has not been studied postnatally in systemic arteries of animals that were exposed to a long term hypoxemic insult in utero.

It should be noted that, in contrast to the side branches, relaxation to $\mathrm{ACH}$ in the main femoral artery of these chickens was poor. This has also been described in studies that investigated these responses in adult chickens (42).

Many questions remain with regards to region-selectivity of effects, the lack of persistence of alterations observed in embryos and consequences for hemodynamic parameters, and the mechanism behind the arterial changes induced by in ovo exposure to chronic hypoxia. 
In chicken embryos, we previously demonstrated increases in arterial sympathetic nerve density and neuronal NE reuptake (53, chapter 4 ). While responses to stimulation of the perarterial nerve endings were increased in 14-15 weeks old chickens that had been exposed to in ovo hypoxia, no apparent signs of alterations in sympathetic nerve density or neuronal NE uptake were demonstrated in chickens after hatching. The sympathetic nerves have generally been regarded as robust structures, which, once fully developed, are not subject to many changes. In the chicken the development of the sympathetic nervous system largely occurs before hatching (20). We therefore expected the changes in nerve density, induced by chronic hypoxia as observed in the embryo (53, chapter 4 ), to persist after hatching. This lack of persistence may indicate that in the period from embryonic day 19 until hatching or thereafter (when chicken embryos and chickens were kept in normoxic conditions and body weight substantially increased) neuronal development can still be modulated. Indeed, in sympathetic ganglia of the chicken, increases in tyrosine hydroxylase activity occur up until two days after hatching (8). The course of developmental changes in arterial nerve fiber density remains to be established. Dynamic processes of proliferation and apoptosis of neurons under the influence of target-derived growth factors and gene-products, that promote or inhibit neuronal survival (9), ultimately determine the number of peri-arterial nerve fibers.

In the present study, effects of in ovo chronic hypoxia on maximal contractile properties were mainly observed in the femoral artery, whereas effects on (endothelial) NO were apparent in the side branches of this artery. Regional selectivity of effects of chronic hypoxia has been demonstrated in adult and fetal arteries $(1,37)$. As lumen diameter of the side branch of the femoral artery of 14-15 weeks old chickens was in the same range of femoral artery lumen diameter at embryonic day 19, the effects of hypoxia on the endothelial function of side branches could also be related to vessel size.

Changes in arterial properties were not accompanied by alterations in heart rate or blood pressure. As both in humans and in animal models hypertension is most commonly observed in middle age, the 14-15 weeks old chickens, which are only just becoming sexually mature, may have been too young to show distinct differences in blood pressure. The techniques and interventions we used only give information about hemodynamic control and the contribution of (para)sympathetic activity under basal conditions. Others have found that prenatal hypoxemia results in altered fetal and postnatal sympathetic activity in stress situations $(38,26)$. As we observed increased release of NE during stimulation of the arterial sympathetic nerve endings, differences in hemodynamic responses may become apparent when the sympathetic nervous system is highly activated, for instance by exposure to acute hypoxia or (psychosocial) stress.

Hypoxia may also be a risk factor for other cardiovascular disease than hypertension. In chickens, the incidence of atherosclerosis is high $(15,5)$ and vascular plaques are frequently observed prior to sexual maturation (50). Changes in endothelial function, like we observed in the side branches of femoral arteries after in ovo hypoxia, are observed in atherosclerosis (63) and have been associated with the presence of atherosclerotic lesions in chickens $(17,50)$.

Future research is implied to allow us to elucidate the mechanisms behind the vascular effects induced by in ovo exposure to hypoxia. The diversity of effects after hatching and differences in sites of action provoke speculations on resetting of cardiovascular control systems rather than the induction of persistent changes in structure by chronic moderate hypoxia during development. Although we did not observe changes in corticosterone levels, others have proposed that resetting of HPA-axis plays an important role in the association between adverse intrauterine conditions and hypertension (48).

In conclusion, we have shown that in ovo exposure to chronic hypoxia alters function of the arterial sympathetic nerve endings and endothelium in chickens after hatching. These type of 
alterations have also been demonstrated in cardiovascular disease (for review: 27, 63) and have been suggested to link IUGR to cardiovascular disease in human adults $(49,39,12,33)$. Therefore, we suggest that the effects of prenatal hypoxia on arterial properties have to be taken into account when cardiovascular outcome is considered.

\section{Acknowledgments}

The authors would like to express their gratitude to prof. H. Nishimura and Dr. D. Zhang (Dept. Physiology, University of Tennessee, Memphis, USA) for their advice and help with regards to blood pressure measurements in the chickens. J. Bost and Dr. R. Hermans (Dept. Pharmacology and toxicology, Maastricht University, The Netherlands) kindly performed measurements of plasma catecholamines and corticosterone. The authors thank J. Debets for technical assistance. The help from Dr. Nieman (KEMTA, University Hospital Maastricht) with the statistical analysis is gratefully acknowledged.

This work was supported by a grant from "Vrienden van het AZM". 


\section{References}

1. Buchholz $\mathbf{J}$ and Duckles SP. Chronic hypoxia alters prejunctional $\alpha_{2}$-receptor function in vascular adrenergic nerves of adult and fetal sheep. Am J Physiol 281: R926-R934, 2001.

2. Byrne CD and Phillips DL. Fetal origins of adult disease: epidemiology and mechanisms. J Clin Pathol 53: 822-828, 2000.

3. Camm EJ, Gibbs ME, and Harding R. Restriction of prenatal gas exchange impairs memory consolidation in the chick. Developmental Brain Research 132: 141-150, 2001.

4. Carsia RV and Harvey S. Adrenals. Eds.: Whittow GC. in: Sturkie's Avian Physiology. Academic Press. San Diego. 2000. pp. 489-538.

5. Clarkson TB. Animal models of atherosclerosis. Eds.: Brandly CA and Cornelius CE. in: Advances in veterinary science and comparative medicine. Academic Press. New York, London. 1972. pp. 151-174.

6. Daemen MJAP and De Mey JGR. Regional heterogeneity of arterial structural changes. Hypertension 25: 464-473, 1995.

7. Dodic M, Baird R, Hantzis V, Koukoulas I, Moritz K, Peers A, and Wintour EM. Organs/systems potentially involved in one model of programmed hypertension in sheep. Clin Exp Pharmacol Physiol 28: 952-956, 2001.

8. Fairman K, Giacobini E, and Chiapinelli V. Developmental variations of tyrosine hydroxylase and acetylcholinesterase in embryonic and post-hatching chicken sympathetic ganglia. Brain Res 102: 301-312, 1976.

9. Francis NJ and Landis SC. Cellular and molecular determinants of sympathetic neuron development. Anmu Rev Neurosci 22: 541-566, 1999.

10. Gheorghiade $\mathbf{M}$ and Bonow RO. Chronic heart failure in the United States. A manifestation of coronary heart disease. Circulation 97: 282-289, 1998.

11. Giussani DA, Spencer JAD, Moore PJ, Bennet L, and Hanson MA. Afferent and efferent components of the cardiovascular reflex responses to acute hypoxia in the term fetal sheep. $J$ Physiol 461: 431-449, 1993.

12. Goodfellow J, Bellamy MF, Gorman ST, Brownlee M, Ramsey MW, Lewis MJ, Davies DP, and Henderson AH. Endothelial function is impaired in fit young adults of low birth weight. Cardiovasc Res 40: 600-606, 1998.

13. Green LR. Programming of endocrine mechanisms of the cardiovascular control and growth. $J$ Soc Gynecol Invest 8: 57-68, 2001.

14. Gunnell D, Smith GD, MeConnachie A, Greenwood R, Upton M, and Frankel S. Separating in-utero and postnatal influences on later disease. Lancet 354: 1526-1527, 1999.

15. Gupta PP and Grewal GS. Spontaneous aortic atherosclerosis in chicken. Indian J Med Res 71: $410-415,1980$.

16. Hasegawa $\mathbf{K}$ and Nishimura $\mathbf{H}$. Humoral factor mediates acetylcholine-induced endotheliumdependent relaxation of the chicken aorta. Gen Comp Endocrinol 84: 164-169, 1991.

17. Hasegawa $\mathbf{K}$, Nishimura $\mathbf{H}$, and Khosla $\mathbf{M}$. Angiotensin II-induced endothelium-dependent relaxation of fowl aorta. Am J Physiol 264: R903-R911. 1993.

18. Head R.J. Hypernoradrenergic innervation: its relationship to functional and hyperplastic changes in the vasculature of the spontaneously hypertensive rat. Blood Vessels 26: 1-20, 1989.

19. Hermans JJR, Van Essen H, Sruijker-Boudier HAJ, Johnson RM, Theeuwes F, and Smits JFM. Pharmacokinetic advatange of intrapericardially applied substances in the rat. J Pharmacol Exp Therap 301: 672-678, 2002.

20. Higgins D and Pappano AJ. Development of transmitter secretory mechanisms by adrenergic neurons in the embryonic chick heart ventricle. Devel Biol 87: 148-162, 1981.

21. Hoet $\mathbf{J}$ and Hanson MA. Intrauterine nutrition: its importance during critical periods for cardiovascular and endocrine development. J Physiol 514.3: 617-627, 1999. 

food restriction in the second half of pregnancy affects vascular function but not blood pressure of rat female offspring. Br J Nutrition 81: 73-79, 1999.

23. Holgert H, Pequignot JM, Lagererantz $\mathbf{H}$, and Hokfelt T. Birth-related up-regulation of mRNA encoding tyrosine hydroxylase, dopamine beta-hydroxylase, neuropeptide tyrosine, and prepro-enkephalin in rat adrenal medulla is dependent on postnatal oxygenation. Pediatr Res 37: 701-706, 1995.

24. Heorn van der FAJ, Boomsma F, Man in 't Veld AJ, and Schalekamp MADH. Determination of catecholamines in human plasma by high-performance liquid chromatography: comparison between a new method with fluoresence detection and an established method with electrochemical detection. J Chrom 487: 17-28, 1989.

25. Jacobs R, Robinson JS, Owens JA, Falconer J, and Webster MED. The effect of prolonged hypobaric hypoxia on growth of fetal sheep. J Develop Physiol 10: 97-112, 1988.

26. Jansson $\mathbf{T}$ and Lambert $\mathbf{G W}$. Effect of intrauterine growth restriction on blood pressure, glucose tolerance and sympathetic nervous system activity in the rat at 3-4 months of age. $J$ Hyperiension 17: 1239-1248, 1999.

27. Julius $\mathbf{S}$ and Valentini $\mathbf{M}$. Consequences of the increased autonomic nervous drive in hypertension, heart failure and diabetes. Blood Pressure 7: 5-13, 1998.

28. Kamimura K, Nishimura $\mathbf{H}$, and Bailey JR. Blockade of $\beta$-adrenoceptor in control of blood pressure in fowl. Am J Physiol 269: R914-922, 1995.

29. Kamitome M, Alonse JG, Okai T, Longe LD, and Gilbert RD. Effects of long-term, highaltitude hypoxemia on ovine fetal cardiac output and blood flow redistribution. Am J Obstet Gynecol 169: 701-707, 1993.

30. Labarca $\mathbf{C}$ and Paigen K. A simple, rapid and sensitive DNA assay procedure. Anal Biochem 102: 344-352, 1980.

31. Langley-Evans SC, Welham SJM, and Jackson AA. Fetal exposure to a maternal low protein diet impairs nephrogenesis and promotes hypertension in the rat. Life Sci 64: 965-974, 1999.

32. Lee RMKW. Vascular changes at the prehypertensive phase in the mesenteric arteries from SHR. Blood Vessels 22: 105-126, 1985.

33. Leeson CPM, Whincup PH, Cook DG, Donald AE, Papacosta O, Lucas FRCP, and Deanfield JE. Flow-mediated dilation in 9- to 11-year-old children. The influence of intrauterine and childhood factors. Circulation 96: 2233-2238, 1997.

34. Le Noble FAC, Ruijtenbeek K, Gommers S, De Mey JGR, and Blance CE. Contractile and relaxing reactivity in carotid and femoral arteries of chicken embryos. Am J Physiol 278: H1261H1268, 2000.

35. Leon DA and Koupilova L. Birth weight, blood pressure, and hypertension: epidemiological studies. Eds.: Barker DJP. in: Fetal origins of cardiovascular and lung disease. Marcel Dekker. Inc. New York. 2001. pp. 23-48.

36. Lewis RM, Batchelor DC, Bassett NS, Johnston BM, Napier J, and Skinner S.JM. Perinatal growth disturbance in the spontaneously hypertensive rat. Pediatr Res 42: 758-764. 1997.

37. Longo LD, Hull AD, Long DM, and Pearce WJ. Cerebrovascular adaptations to high altitude hypoxaemia in fetal and adult sheep. Am J Physiol 264: R65-R72, 1993.

38. Longo LD and Pearce WJ. High altitude, hypoxic-induced modulation of noradrenergicmediated responses in fetal and adult cerebral arteries. Comp Biochem Physiol 119A: 683-694. 1998.

39. Martin $\mathbf{H}, \mathbf{H u} \mathbf{J}$, Gennser $\mathbf{G}$, and Norman $\mathbf{M}$. Impaired endothelial function and increased carotid stiffness in 9-year-old children with low birth weight. Circulation 102: 2739-2744, 2000.

40. Martinez-Lemus LA, Hester RK, Becker E, Jeffrey JS, and Odom TW. Pulmonary artery endothelium-dependent vasodilation is impaired in a chicken model of pulmonary hypertension. Am J Physiol 277: R190-R197, 1999.

41. Mason SR, Ward LC, and Reilly PEB. Fluorimetric detection of serum corticosterone using high -performance liquid chromatography. J Chrom 581: 267-271, 1992. 
42. MeCain WC, Flaherty DM, Correll L, Jortner B, and Ehrich M. Catecholamine concentrations and contractile responses of isolated vessels from hens treated with cyclic phenyl saligenin phosphate or paraoxon in the presence or absence of verapamil. $J$ Toxicol Environ Health 48: 397-411, 1996.

43. MeCutcheon IE, Metcalfe J, Metzenberg AB, and Ettinger T. Organ growth in hyperoxic and hypoxic chick embryos. Resp Physiol 50: 153-163, 1982.

44. Mulder ALM, Miedema A, de Mey JGR, Giussani DA, and Blanco CE. Sympathetic control of the cardiovascular response to acute hypoxemia in the chick embryo. Am J Physiol 282: R1156-R1163, 2002.

45. Nakamura Y, Nishimura $\mathbf{H}$, and Khosla MC. Vasodepressor action of angiotensin in conscious chickens. Am J Physiol 243: H456-462, 1982.

46. Nishimura $\mathbf{H}$, Nakamura $\mathbf{Y}$, Taylor AA, and Madey MA. Renin-angiotensin and adrenergic mechanisms in control of blood pressure in fowl. Hypertension 3: 141-I49, 1981.

47. Peacock AJ, Pickett C, Morris K, and Reeves JT. The relationship between rapid growth and pulmonary hemodynamics in the fast-growing broiler chicken. Am Rev Respir Dis 139: 1524$1530,1989$.

48. Phillips DIW. Fetal growth and programming of the hypothalamic-pituitary-adrenal axis. Clin Exp Pharmacol Physiol 28: 967-970, 2001.

49. Phillips DI and Barker DJP. Association between low birth weight and high resting pulse in adult life: is the sympathetic nervous system involved in programming the insulin resistance syndrome? Diabet Med 14: 673-677, 1997.

50. Qin Z-L and Nishimura $\mathbf{H}$. $\mathrm{Ca}^{2+}$ signaling in fow aortic smooth muscle increases during maturation but is impaired in neointimal plaques. J Exp Biol 201: 1695-1705, 1998.

51. Ruffolo RR, Nichols AJ, Stadel JM, and Hieble JP. Structure and function of alphaadrenoceptors. Pharmacol Rev 43: 475-505, 1991.

52. Ruijtenbeek K, Blanco CE, and De Mey JGR. Fetal programming of cardiovascular disease. Findings in the chicken embryo. J Vase Res 38 (Suppl.2): 1, 2001.

53. Ruijtenbeek K, le Noble FAC, Janssen GMJ, Kessel CGA, Fazzi GE, Blanco CE, and De Mey JGR. Chronic hypoxia stimulates periarterial sympathetic nerve development in chicken embryo. Circulation 102: 2892-2897, 2000.

54. Shaul PW, Farrar MA, and Zellers T. Oxygen modulates endothelium-derived relaxing factor production in fetal pulmonary arteries. Am J Physiol 262: H355-364, 1992.

55. Slotkin TA and Seidler FJ. Adrenomedullary catecholamine release in the fetus and newborn: secretory mechanisms and their role in stress and survival. J Develop Physiol 10: 1-16, 1988.

56. Smith FM, West NH, and Jones DR. The cardiovascular system. Eds.: Whittow GC. in: Sturkie's Avian Physiology. Academic press. San Diego. 2000. pp. 141-231.

57. Stassen FRM, Raat NJH, Brouwers-Ceiler DL, Fazzi GE, Smits JFM, and De Mey JGR. Angiotensin II induces media hypertrophy and hyperreactivity in mesenteric but not epigastric small arteries of the rat. $J$ Vase Res 34: 289-297, 1997.

58. Stein PE, White SE, Homan J, Fraher L, MeGarrigle HHG, Hanson MA, and Bocking AD. Fetal endocrine responses to prolonged reduced uterine blood flow are altered following bilateral sectioning of the carotid sinus and vagus nerves. J Endocrinol 157: 149-155, 1998.

59. Szeto PM, Grant EA, Lioy F, and Parkes CO. Inhibition by atropine, phenoxybenzamine and propanolol of autonomic nervous system. Poultry Science 56: 1201-1205, 1977.

60. Takauchi Y, Yamazaki T, and Akiyama T. Tyramine-induced endogenous noradrenaline efflux from in situ cardiac sympathetic nerve ending in cats. Acta Physiol Scand 168: 287-293, 2000.

61. Thompson L.P and Weiner CP. Effects of acute and chronic hypoxia on nitric oxide mediated relaxation of fetal guinea pig arteries. Am JObstet Gynecol 181: 105-111, 1999.

62. Tuttle J1, Nachreiner RD, Bhuller AS, Condict KW, Connors BA, Dalsing MC, and Unthank JL. Shear level influences resistance artery remodelling: wall dimensions, cell density, and eNOS expression. Am J Physiol 281: H1380-H1389, 2001. 
63. Vanhoutte PM, Perrault LP, and Vilaine JP. Endothelial dysfunction and vascular disease. Eds.: Rubanyi GM and Dzau VJ. in: The endothelium in clinical practice. Source and target of novel strategies. Marcel Dekker,Inc. New York, Basel, Hong Kong. 1997. pp. 265-289.

64. Vickers MH, Breier BH, Cutfield WS, Hofman PL, and Gluckman PD. Fetal origins of hyperphagia, obesity and hypertension and postnatal amplification by hypercaloric nutrition. $\mathrm{Am}$ JPhysiol 279: E83-E87, 2000.

65. Villamer E, Perez-Vizcaine F, Ruiz T, Leza JC, Moro M, and Tamarge J. Group B streptococcus and E.coli LPS-induced NO-dependent hyporesponsiveness to noradrenaline in isolated intrapulmonary arteries of neonatal piglets. $\mathrm{Br} J$ Pharmacol 115: 261-266, 1995.

66. Yu S-M, Hung L-M, and Lin C-C. cGMP-elevating agents suppress proliferation of vascular smooth muscle cells by inhibiting the activation of epidermal growth factor signalling pathway. Circulation 95: 1269-1277, 1997. 


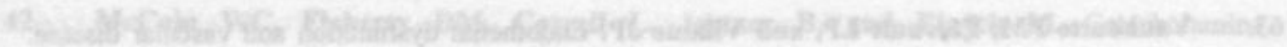

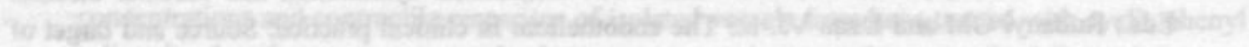

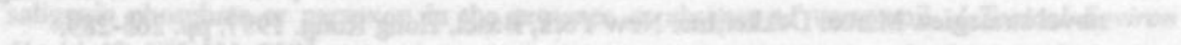

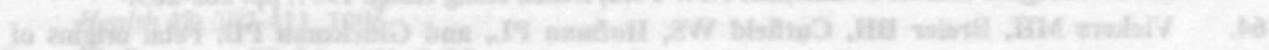

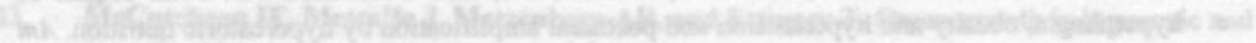

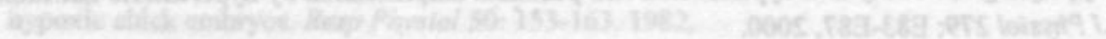

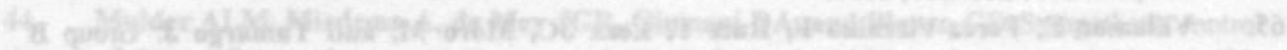

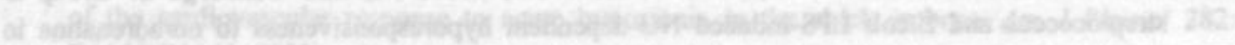

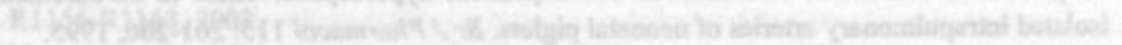

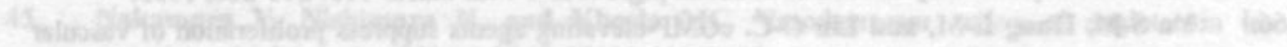

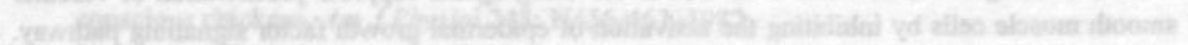

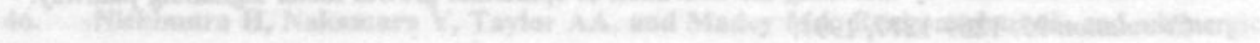

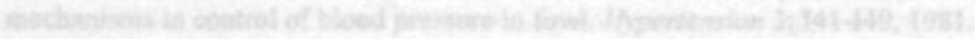

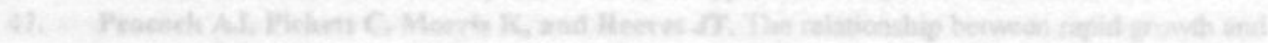

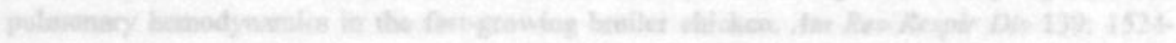
1500. 1969.

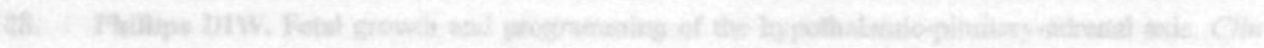

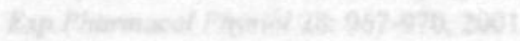

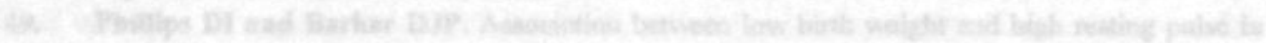

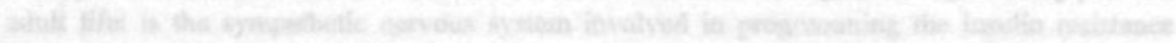

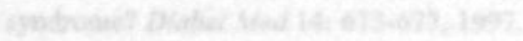

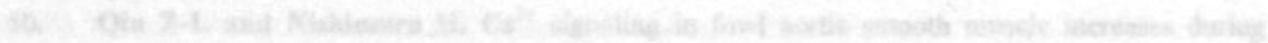

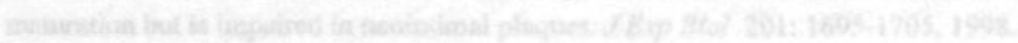

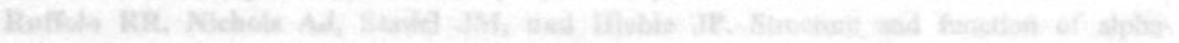

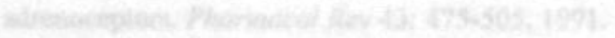

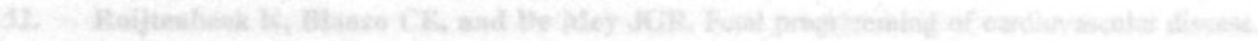

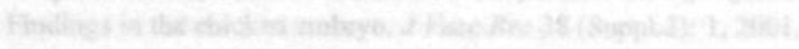

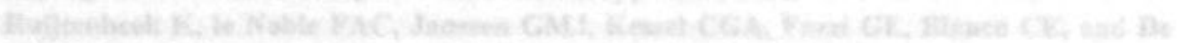

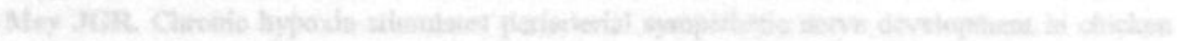

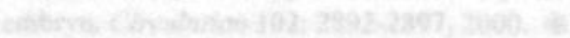

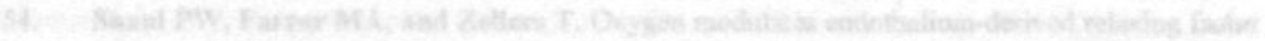

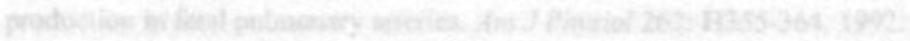

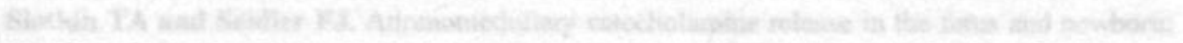

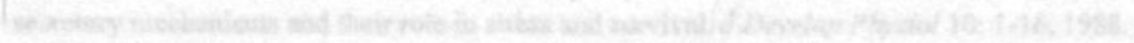

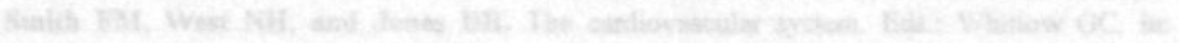

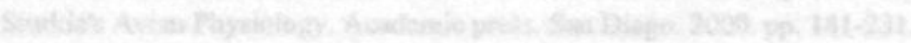

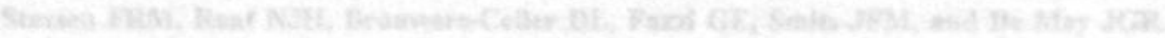

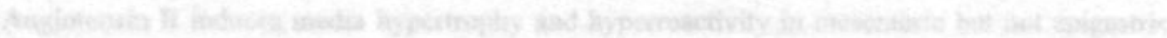

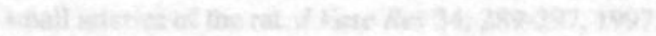

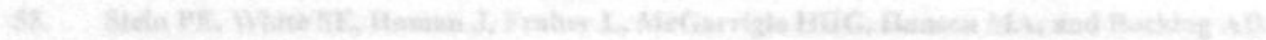

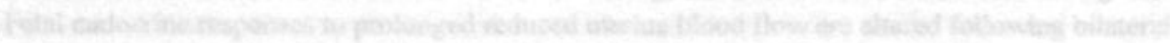

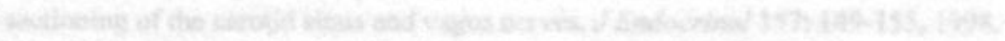

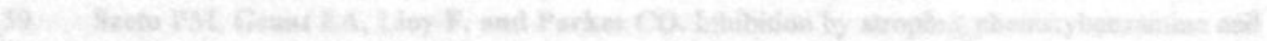

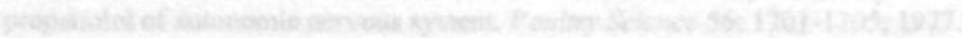

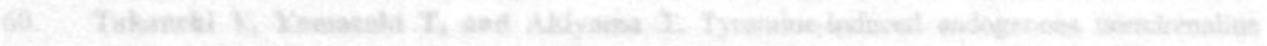

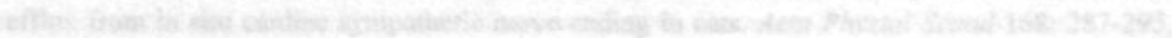
3

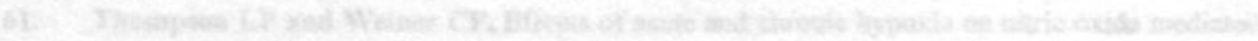

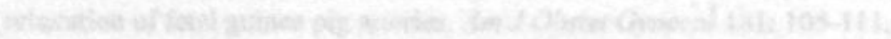

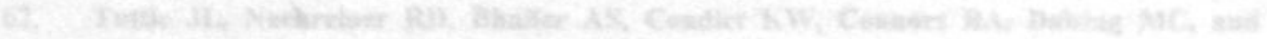

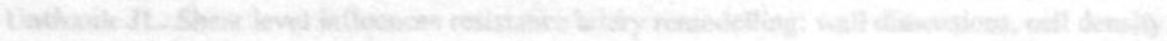

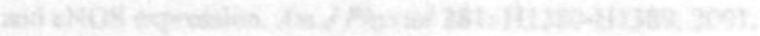




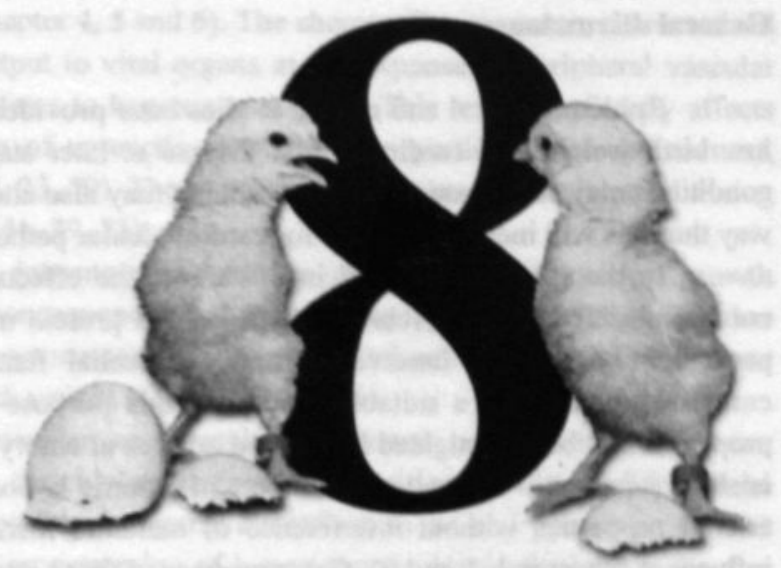

CHAPTER 8

GENERAL DISCUSSION 


\section{General discussion}

Epidemiological and animal studies have provided evidence for a relationship between low birth weight and cardiovascular disease at later stages in life (3). Adverse intrauterine conditions may compromise fetal growth, but may also alter developing organ systems in such a way that this will increase the risk for cardiovascular pathology in later life.

In the studies presented in this thesis the effects of intrauterine conditions that may compromise fetal growth (chronic hypoxia and protein malnutrition) on arterial properties, in particular sympathetic innervation and endothelial function, were evaluated. The chicken embryo proved to be a suitable model for this purpose as chapter 2 and 3 show that these properties can be investigated in isolated arteries at embryonic day 19. Furthermore, this model enables separate investigation of effects of chronic hypoxia and protein malnutrition on fetal arterial properties without interference of maternal metabolic, endocrine and cardiovascular influences (chapter 4,5 and 6). Consequences of these interventions for later stages of life were studied in chickens after hatching (chapter 7).

\section{Growth retardation and vascular changes}

In the chicken embryo, protein malnutrition and chronic moderate hypoxia both interfered with growth resulting in reduced total body weights at embryonic day 19. Interestingly, only exposure to chronic hypoxia was accompanied by alterations in arterial properties (chapter 4,5 and 6).

Both reductions in fetal nutrients and of oxygen availability have been demonstrated to result in intrauterine growth retardation in various animal species and humans $(69,26,35,63)$. However, there may be some fundamental differences in the way chronic hypoxia and malnutrition restrict growth and in the fetal responses they induce. Normal fetal growth and development require adequate provision and utilization of nutrients. The nutrients, most importantly glucose, lactate and amino acids, are used for the accretion of tissues and as fuel reserves (fat and glycogen). In addition, a large part of the nutrient pool is oxidized to provide energy to the growing tissues. During undernutrition, fetal oxygen consumption and thus the nutrient requirements for oxidative metabolism do not change. To maintain the balance between nutrient supply and demand, fetal growth rate is reduced (19,63, 55). During hypoxic conditions cellular energy metabolism is disturbed $(46,63)$. Energy derived from oxidation under these conditions is mainly used to maintain vital functions in the fetus at the expense of growth. Thus, while malnutrition results in a limitation of building materials, hypoxia interferes with the energy required for the building process.

Not only metabolic responses to fetal malnutrition and chronic hypoxia are different. but endocrine adaptations may vary as well. Insulin, which stimulates glucose utilization and uptake, and IGF-I may be more affected by malnutrition resulting in a lowering of fetal plasma levels $(14,63,31)$ than by hypoxemia $(50,81)$. Thyroid hormones (involved in oxidative processes) may also be differently modulated by reduced oxygen than by reduced nutrient availability $(14,63,55)$. In addition, many paracrine factors (such as VEGF), enzymes (tyrosine hydroxylase, eNOS), genes and transcription factors (bcl-2, CREB, HIF-1) are known to be modulated by oxygen availability (as will be discussed), whereas others are particularly affected by specific nutrients (13).

However, together with differences in metabolic, endocrine, paracrine, enzymatic and genetic control, the specific cardiovascular response induced by hypoxemia may explain why chronic hypoxia did and malnutrition did not induce changes in arterial properties of the chicken 
embryo as described in this thesis (chapter 4,5 and 6). The chemoreflex response, characterized by a redistribution of the cardiac output to vital organs at the expense of peripheral vascular beds, is an instant adaptation of the fetus to hypoxia to survive. This response directly affects arteries by altering the concentration of vasoactive hormones (in particular catecholamines). sympathetic input and blood flow $(24,23,59)$. These arterial changes may be maintained during prolonged fetal exposure to hypoxia $(41,79,75)$.

Thus, the type of adverse intrauterine condition rather than intrauterine growth retardation per se may determine consequences for the developing fetus. Studies in other experimental animal models have demonstrated effects of prenatal adverse conditions without concomitant reductions in fetal or birth weight $(15,32,35)$.

Fetal programming of hypertension as a result of maternal undernutrition has been described in many animal studies. In the chicken embryo, malnutrition did not modify arterial properties (chapter 5 and 6). It is possible that early alterations in arterial properties are not involved in the malnutrition-induced programming of hypertension. Alternatively, the changes may become apparent in early postnatal life as described by others (64) or the timing of the insult (protein malnutrition affects the chicken embryo from day 12 of incubation (60)) explains the absence of apparent changes, as has been proposed before (35). Alternatively, intrauterine exposure to malnutrition may program hypertension via other mechanisms than early changes in arterial properties. For instance, there is now substantial evidence that structural and functional changes of the fetal and adult kidney are associated with the fetal programming of hypertension $(45,53,4)$.

When considering maternal malnutrition as an explanation of the link between IUGR and hypertension or cardiovascular disease in later life, a few aspects might have to be taken into account. The impact of maternal nutrition on the fetus is dependent on maternal nutrient uptake, maternal metabolism and endocrine milieu, uterine and umbilical blood flow and placental transfer and metabolism (30). Therefore maternal malnutrition can not directly be translated to fetal malnutrition. Moreover, while maternal undernutrition can reduce fetal growth in many animal species, it does not seem to have large effects in human fetuses (30). Impaired placental function, a combination of both fetal undernutrition and chronic hypoxia, is a much more common cause of human intrauterine growth retardation $(44,69,70,73)$. The findings that maternal undernutrition may reduce vasodilatation of the uterine artery (39). uterine blood flow (9) and placental function and size $(9,14,25)$, which may result in concomitant fetal hypoxemia, also emphasize the important contribution of chronic hypoxia to adverse intrauterine conditions. Considering this and the results in this thesis (chapter 4,5 and 6), which show alteration of arterial properties by chronic hypoxia, the role of prenatal chronic hypoxia in the fetal programming of cardiovascular disease deserves considerable attention.

\section{Effects of prenatal chronic hypoxia on fetal arterial sympathetic innervation and endothelial function}

The chemoreflex is a very important cardiovascular response to promote fetal survival during an acute decrease in oxygen availability. Both in chicken embryos and mammalian species catecholamines are released from the adrenal medulla and, at the end of gestation, from the peri-arterial sympathetic nerves $(23,24,57,59)$ during acute hypoxia. The peripheral vasoconstriction that contributes to redistribution of the cardiac output during acute hypoxemia is largely mediated by these catecholamines, that interact with arterial $\alpha$-adrenoceptors $(24,23$. 58 ). In this thesis, it was demonstrated that exposure of chicken embryo isolated arteries to an acute decrease in oxygen tension at the end of incubation directly affects arterial function. 
While norepinephrine-induced contraction was partly reduced by acute hypoxia, endothelial dependent relaxation was entirely abolished (chapter 3 ). The ultimate result of these responses, namely contraction, indicates that these direct effects of acute hypoxia may contribute to the increase in peripheral vascular resistance during in vivo fetal hypoxemia.

The arterial endothelium and sympathetic innervation may not only play a role in the adaptational response to acute hypoxemia, but may also be modulated during more prolonged exposure to hypoxia. Genes encoding enzymes catalyzing the synthesis of catecholamines, such as tyrosine hydroxylase and dopamine $\beta$-hydroxylase, contain hypoxia-response elements (HIF$1 \alpha(61,54)$, CREB $(5,43,38))$. Upregulation of tyrosine hydroxylase has been reported after several days of hypoxia (36). Similarly, it has been demonstrated that prolonged episodes of reduced oxygen availability decreases levels of eNOS mRNA $(52,49,17)$.

During even more prolonged fetal exposure to hypoxia circulating catecholamine levels also seem to be elevated $(79,75)$. These have been proposed to contribute to the maintenance of the redistribution of the cardiac output, also observed during acute episodes of fetal hypoxemia (41) and indicate that the fetal sympathetic nervous system may also be affected during chronic hypoxia. In this thesis, data were presented demonstrating that fetal exposure to chronic hypoxia increased presynaptic reuptake of norepinephrine in the femoral artery (chapter 4) of chicken embryos at the end of the incubation period. This is consistent with studies in fetal sheep that were exposed to chronic hypoxia via the mother $(6,48)$. The data (chapter 4$)$ suggest that increased arterial neuronal reuptake of norepinephrine after chronic hypoxia may be due to an increase in the density of sympathetic peri-arterial nerve endings. It was suggested before (48) that chronic moderate hypoxia may accelerate or stimulate the maturation of the arterial sympathetic innervation. Although we and others did not observe an augmentation of sympathetically mediated arterial contraction (6 and chapter 4$)$ nor increased post-synaptic $\alpha$ adrenergic contraction (chapter 4 and 85,48 ) after chronic hypoxia, this may result in altered function at later stages of development.

Functional consequences of chronic moderate hypoxia on the endothelium have been observed. This thesis shows that arterial endothelium-dependent relaxation to acetylcholine was substantially altered by chronic hypoxia in chicken embryos (chapter 6). Although acetylcholine may induce the release of multiple factors from the endothelium in the chicken embryo (chapter 2 and 87), the endothelial NO system in particular seemed to be affected by prolonged exposure to hypoxia. Impaired endothelium dependent relaxation and reduced stimulated NO-release has also been shown in chronic hypoxemic mammalian fetuses (82).

Increased arterial sympathetic innervation and decreased endothelium-dependent relaxation would contribute to peripheral vasoconstriction and thus to the redistribution of the cardiac output during chronic hypoxia to maintain blood flow to vital organs. However, to conclude whether the observed changes participate in long-term fetal cardiovascular adaptations, information on blood flow and pressure in the femoral artery of the chicken embryo during chronic hypoxia is required.

Factors that may be modulated by hypoxia and effects that were described in this thesis are depicted in fig. 1. Potential mechanisms and interactions are discussed below.

\section{Mechanisms}

Hypoxia not only interferes with arterial properties during acute exposure, but this thesis demonstrates that arterial sympathetic innervation and endothelial functions are also affected during chronic hypoxia (chapter 4 and 6 ). The mechanisms behind the increase in arterial sympathetic nerve fiber density and endothelial NO dysfunction can be speculated on. 
In addition to direct effects of hypoxia on enzyme systems, interactions and mediators may be involved. For instance, mechanical stimuli, which may be altered during adaptation to chronic hypoxia, may interfere with eNOS activity and expression. Reduced shear stress, as a result of decreased blood flow, decreases eNOS activity and expression (83, 49, 88). Elevated hydrostatic pressure has been reported to exert similar effects (49). Furthermore, in response to hypoxia mitochondria release reactive oxygen species, that, in addition to functioning as second messengers to modulate transcription factor activity (8), may decrease NO availability and NOS activity (65).

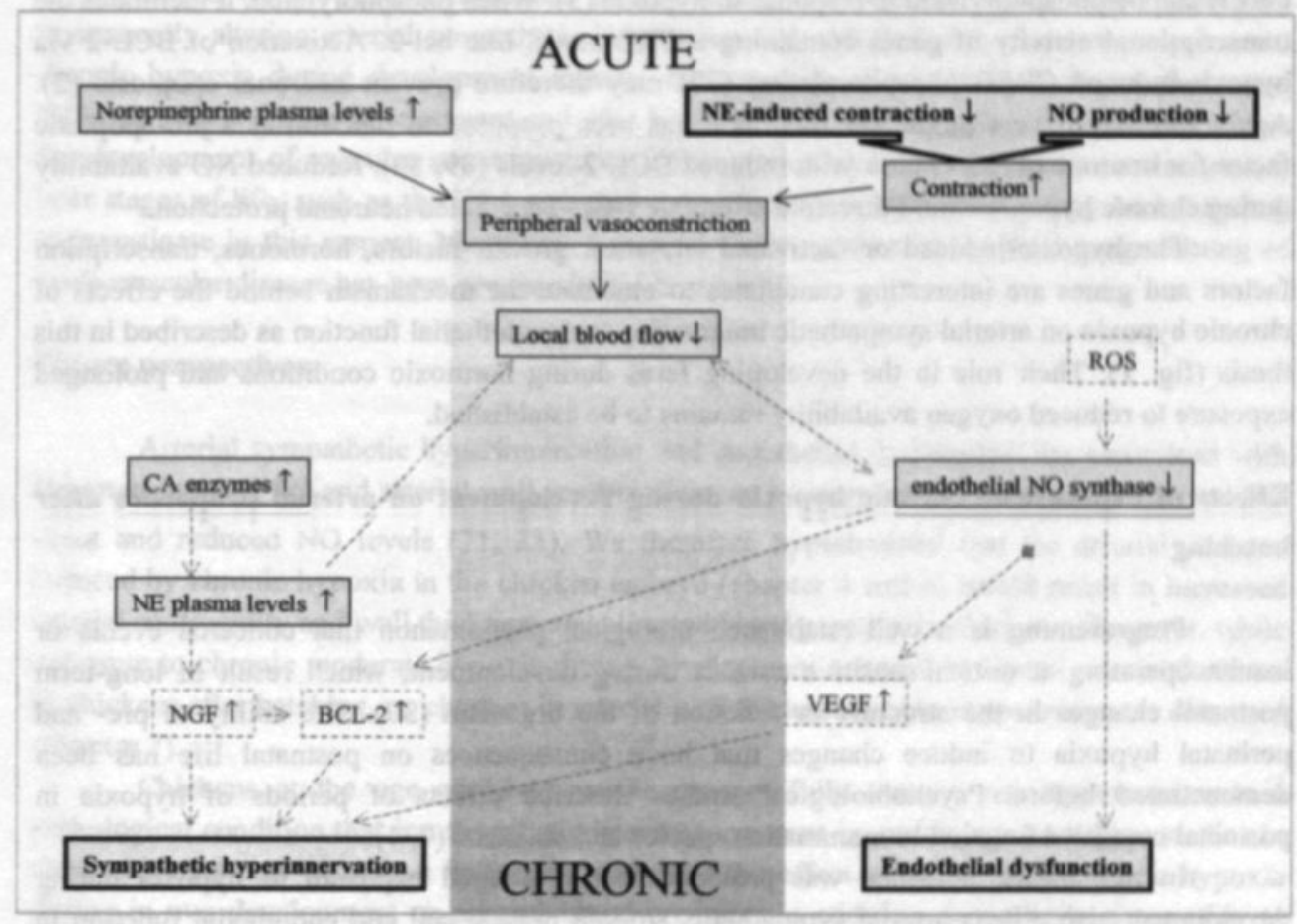

Fig. 1. Effects of hypoxia on arterial contractile, sympathetic and endothelial properties in the embryo during acute, prolonged and chronic exposure and possible interactions between effects. Dashed lines indicate interactions and speculated mechanisms. Bold items indicate findings that were presented in this thesis. $\mathrm{CA}=$ catecholamines, $\mathrm{NE}=$ norepinephrine, $\mathrm{ROS}=$ Reactive oxygen species.

Increased norepinephrine levels or $\alpha$-adrenergic stimulation, which also occur during chronic hypoxemia, can stimulate NGF production leading to increased outgrowth and survival of sympathetic nerve fibers $(84,21,11)$. In addition to circulating hormones and mechanical stimuli, paracrine factors may be activated by hypoxia. An important growth factor, which is upregulated in response to low oxygen levels, is vascular endothelial growth factor (VEGF, 74). Transcription of the VEGF gene can be activated by hypoxia-inducible factor (HIF-1, 18). VEGF has been reported to stimulate axonal outgrowth through interaction with the receptors present on neurons in sympathetic ganglia $(77,78)$. Deletion of the hypoxia-responsive element in the VEGF promotor causes degeneration of motor neurons (62). Taken together, these data suggest that activation of VEGF could be an interesting candidate mechanism to explain hypoxia-induced increases in nerve density. Moreover, as NO has been reported to inhibit HIF-1 $(76,37)$ and to suppress hypoxic induction of VEGF mRNA and protein production in vascular 
smooth muscle cells (47), reductions in NO availability during chronic hypoxia may even augment the effects of VEGF. Stimulatory effects of VEGF on eNOS, in turn may counteract this effect (90).

While stimulatory processes are important in the development of innervation, physiological breakdown of neurons due to cell death also takes place $(28,56,20,21)$. Ultimate nerve density is determined by the balance between factors promoting and factors inhibiting apoptosis. An important inhibitor of neuronal apoptosis is BCL-2, of which the gene expression can be modulated by interaction with cAMP responsive element binding protein (CREB) (2). CREB can be phosphorylated in response to hypoxia (5). When phosphorylated, it facilitates the transcriptional activity of genes containing a CRE motif, like bcl-2. Activation of BCL-2 via hypoxia-induced CREB phosphorylation (22) may therefore prevent neuronal apoptosis (2). Again NO may have a modulator role, as it has been proposed to function as a pro-apoptotic factor for neurons in association with reduced BCL-2 levels $(89,80)$. Reduced NO availability during chronic hypoxia would therefore stimulate BCL-2 mediated neuronal protection.

The hypoxia-induced or -activated enzymes, growth factors, hormones, transcription factors and genes are interesting candidates to elucidate the mechanism behind the effects of chronic hypoxia on arterial sympathetic innervation and endothelial function as described in this thesis (fig. 1). Their role in the developing fetus during normoxic conditions and prolonged exposure to reduced oxygen availability remains to be established.

\section{Effects of exposure to chronic hypoxia during development on arterial properties after hatching}

Programming is a well-established biological phenomenon that concerns events or insults operating at critical/sensitive periods during development, which result in long-term postnatal changes in the structure or function of the organism (30). The ability of pre- and perinatal hypoxia to induce changes that have consequences on postnatal life has been demonstrated before. Psychobiological studies describe effects of periods of hypoxia in postnatal cognitive function in mammalian species and chickens $(7,1)$.

In this thesis, evidence was provided that prolonged exposure to hypoxia during development also affects arterial sympathetic, smooth muscle cell and endothelial function in the chicken after hatching (chapter 7). Interestingly, these changes were not the result of the persistence of the arterial alterations observed at embryonic day 19.

While in the chicken embryo increased nerve density in the femoral artery was observed, sympathetic function was modulated without signs of altered numbers of peri-arterial nerve fibers or neuronal norepinephrine reuptake in chickens 14-15 weeks after hatching. From day 19 of incubation embryos were replaced in normoxia. In the period until just after hatching weight almost doubles and becomes comparable to weight of hatchlings that had not been exposed to chronic hypoxia. The absence of notable structural differences in sympathetic innervation in older animals could indicate that this period of substantial growth from embryonic day 19 until hatching or thereafter allows substantial modulation of the number of sympathetic peri-arterial nerve fibers in the chicken embryo or chick. While neurons in sympathetic ganglia of the chicken embryo undergo progressive maturation up until two days after hatching as indicated by increases in enzymatic activity (16), the course of developmental changes in arterial nerve fiber density is largely unknown. However, in the CNS, hypoxia has not only been suggested to protect from neuronal cell death, but hypoxia-induced delayed apoptotic cell death in selective populations of cells, including neurons $(89,29)$, has also been described. Provided that such a process plays a role in arteries of the developing chicken 
embryo during chronic hypoxia, removal of the hypoxic stimulus would result in postponed neuronal cell death and possibly a decrease in nerve density.

Although signs of endothelial dysfunction were present before and after hatching (chapter 6 and 7), changed endothelial function after chronic hypoxia during development was only observed in side branches and not in the main femoral artery, like in the embryo. This may indicate that effects depend on the size and/or location of the artery. Vascular heterogeneity of the actions of vasoactive substances and mechanical stimuli on the endothelium and vascular reactivity has been frequently described $(12,68,83,10,34)$.

Based on the results presented in this thesis, it could be argued that rather than permanently altering arterial sympathetic innervation and endothelial dysfunction, exposure to chronic hypoxia during development induces the resetting of regulatory systems, that exert different effects during development and after birth. Systems that may play an important role in the development of vascular structure during development and can modulate vascular tone at later stages of life, such as the HPA-axis and the renin-angiotensin-system, may be interesting to investigate in this respect. Moreover, a role for these systems in the fetal programming of cardiovascular disease has been proposed $(66,26,51,72)$.

\section{Future perspectives}

Arterial sympathetic hyperinnervation and endothelial dysfunction are associated with hypertension $(40,86)$ and arterial wall proliferation can be augmented by increased sympathetic input and reduced NO levels $(71,33)$. We therefore hypothesized that the arterial changes induced by chronic hypoxia in the chicken embryo (chapter 4 and 6) would result in increased arterial contractility and wall thickness and elevated blood pressure in chickens. However, while exposure to chronic moderate hypoxia during development resulted in altered arterial function in chickens after hatching, no changes in arterial wall thickness or blood pressure were observed (chapter 7).

Chickens at the age of 14-15 weeks are not fully mature yet. Hypertension is a pathological condition that in man mostly becomes apparent in middle age; therefore studies in older chickens may provide a better impression of the effect of exposure to chronic hypoxia during in ovo development on arterial blood pressure. In addition, it would be interesting to determine blood pressure in stress/stimulated conditions. Basal autonomic nervous control of blood pressure and heart rate (evaluated by infusion of cholinergic and adrenergic inhibitors and by ganglion blockade) in 14-15 weeks old chickens was not altered by in ovo exposure to hypoxia (chapter 7). However, the increased arterial sympathetic release of norepinephrine during electrical activation in isolated arteries of these chickens may very well result in increased arterial constriction and blood pressure during stimulation of the sympathetic nervous system. Methods that can be applied to achieve this include exposing the chicken to an episode of acute hypoxia provoking a chemoreflex or by subjecting them to metabolic (cold) or psychological stress factors. Alternatively, pharmacological tools can be used to induce a baroreflex response.

Although hypertension is a major risk factor for many cardiovascular diseases (42), signs of cardiovascular pathology may be present without being accompanied by elevated blood pressure. Atherosclerotic plaques can be observed in the chicken prior to sexual maturation (27, 67). It might therefore be interesting to investigate whether vascular lesions accompany the observed changes in endothelial relaxing function. 
Together with attempts to unravel the mechanisms behind the hypoxia-induced effects, these experiments may elucidate whether the consequences of prenatal chronic hypoxia on arterial properties play a role in the development of cardiovascular disease in later life.

If so, low birth weight and other anthropometric estimates may not be adequate measures to define individuals at risk. As suggested, the specific adverse intrauterine conditions rather than growth retardation per se may determine effects in the developing fetus. Since chronic hypoxia and malnutrition may exert different effects with consequences for particular organ systems, only a range of specific markers would provide information on affected fetal systems. 


\section{References}

1. Balduini W, De Angelis V, Mazzoni E, and Cimino M. Long-lasting behavioral alterations following a hypoxic/ischemic brain injury in neonatal rats. Brain Res 859: 318-325, 2000.

2. Banasiak KJ, Cronin T, and Haddad GG. Bel-2 prolongs neuronal survival during hypoxiainduced apoptosis. Moll Brain Res 72: 214-225, 1999.

3. Barker DJP. Fetal origins of cardiovascular and lung disease. New York, Basel. Marcel Dekker Inc. 2001.

4. Bauer R, Walter B, and Zwiener $\mathbf{U}$. Effect of severe normocapnic hypoxia on renal function in growth restricted newbom piglets. Am J Physiol 279: R.1010-R1016, 2000.

5. Beitner-Johnson D and Millhorn DE. Hypoxia induces phosphorylation of the cyclic AMP response element-binding protein by a novel signaling mechanism. $J$ Biol Chem 273: 1983419838, 1998.

6. Buchholz $\mathbf{J}$ and Duckles $\mathbf{S P}$. Chronic hypoxia alters prejunctional $\alpha 2$-receptor function in vascular adrenergic nerves of adult and fetal sheep. Am J Phisiol 281: R926-R934, 2001.

7. Camm EJ, Gibbs ME, and Harding R. Restriction of prenatal gas exchange impairs memory consolidation in the chick. Develop Brain Res 132: 141-150, 2001.

8. Chandel NS, MeClintock S, Feliciano CE, Wood TM, Melendez JA, Redriguez AM, and Schumacker PT. Reactive oxygen species generated at mitochondrial complex III stabilize hypoxia-inducible factor-la during hypoxia. J Biol Chem 275: 25130-25138, 2000.

9. Chandler KD, Leury BJ, Bird AR, and Bell AL. Effects of undernutrition and exercise during late pregnancy on uterine, fetal and uteroplacental metabolism in the ewe. Br J Nutrition 53: 625-635, 1985.

10. Chen L, MeNeill JR, Wilson TW, and Gopalakrishnan V. Heterogeneity in vascular smooth muscle responsiveness to angiotensin II. Role of endothelin. Hyperiension 26: 83-88, 1995.

11. Creedon D and Tuttle JB. Nerve growth factor synthesis in vascular smooth muscle. Hypertension 18: 730-741, 1991.

12. Daemen MJAP and De Mey JGR. Regional heterogeneity of arterial structural changes. Hypertension 25: 464-473, 1995.

13. Dauncey MJ. Nutrition-hormone receptor-gene interactions: implications for development and disease. Proc Nutr Soc 60: 63-72, 2001.

14. Dwyer CM, Madgwick A.J, Crook AR, and Stickland NC. The effect of maternal undernutrition on the growth and development of the guinea pig placenta. J Develop Physiol 18: 295-302, 1992.

15. Edwards LJ and MeMillen IC. Maternal undernutrition increases arterial blood pressure in the sheep fetus during late gestation. J Physiol 533.2: 561-570, 2001.

16. Fairman K, Giacobini E, and Chiapinelli V. Developmental variations of tyrosine hydroylase and acetylcholinesterase in embryonic and post-hatching chicken sympathetic ganglia. Brain Res 102: 301-312, 1976.

17. Faller DV. Endothelial cell responses to hypoxic stress. Clin Exp Pharmacol Physiol 26: 74-84, 1999.

18. Forsythe JA, Jiang B, Iyer NV, Agani F, Leung SW, Koos RD, and Semenza GL. Activation of vascular endothelial growth factor gene transcription by hypoxia-inducible factor 1. Mol Cell Biol 16: 4604-4613, 1996.

19. Fowden AL. Nutrient requirements for normal fetal growth and metabolism. Eds: Hanson MA, Spencer JAD, and Rodeck CH. in: Fetus and neonate. Physiology and clinical applications. Cambridge University Press. Cambridge. 1995. pp. 31-56.

20. Francis N, Farinas I, Brennan C, Rivas-Plata K, Backus C, Reichardt L, and Landis S. NT3, like NGF, is required for survival of sympathetic neurons, but not their precursors. Devel Biol 210: 411-427, 1999.

21. Francis NJ and Landis SC. Cellular and molecular determinants of sympathetic neuron development. Annu Rev Neurosci 22: 541-566, 1999. 
22. Freeland K, Boxer LM, and Latchman DS. The cyclic AMP response element in the Bcl-2 promoter confers inducibility by hypoxia in neuronal cells. Moll Brain Res 92: 98-106, 2001.

23. Giussani DA, Riquelme RA, Moraga FA, MeGarrigle HGH, Gaete CR, Sanhueza EM, Hanson MA, and Llanes AJ. Chemoreflex and endocrine components of the cardiovascular responses to acute hypoxaemia in the llama fetus. Am J Physiol 271: R73-R83, 1996.

24. Giussani DA, Spencer JAD, Moore PJ, Bennet L, and Hanson MA. Afferent and efferent components of the cardiovascular reflex responses to acute hypoxia in the term fetal sheep. $J$ Physiol 461: 431-449, 1993.

25. Godfrey KM and Barker DJP. Maternal nutrition in relation to fetal and placental growth. Eur JObstet Gynecol Reprod Biol 61: 15-22, 1995.

26. Green LR. Programming of endocrine mechanisms of the cardiovascular control and growth. $J$ Soc Gynecol Invest 8: 57-68, 2001.

27. Gupta PP and Grewal GS. Spontaneous aortic atherosclerosis in chicken. Indian J Med Res 71: 410-415, 1980.

28. Hallbook F, Ayer-Lelievre C, Ebendal T, and Persson H. Expression of nerve growth factor receptor mRNA during early development of the chicken embryo: emphasis on cranial ganglia. Development 108: 693-704, 1990.

29. Halterman MW, Miller CC, and Federoff J. Hypoxia-inducible factor-1a mediates hypoxiainduced delayed neuronal death that involves p53.J Neurosc 19: 6818-6824, 1999.

30. Harding JE. The nutritional basis of the fetal origins of adult disease. Int J Epidemiol 30: 15-23, 2001.

31. Harding JE and Gluckman PD. Growth, metabolic, and endocrine adaptations to fetal undemutrition. Eds.: Barker DJP. in: Fetal origins of cardiovascular and lung disease. Marcel Dekker, Inc. New York - Basel. 2001. pp. 181-197.

32. Hawkins P, Steyn C, Ozaki T, Saito T, Noakes DE, and Hanson MA. Effect of maternal undernutrition in early gestation on ovine fetal blood pressure and cardiovascular reflexes. Am J Physiol 279: R340-R348, 2000.

33. Head RJ. Hypernoradrenergic innervation: its relationship to functional and hyperplastic changes in the vasculature of the spontaneously hypertensive rat. Blood Vessels 26: 1-20, 1989.

34. Himmel HM, Whorton AR, and Strauss HC. Intracellular calcium, currents, and stimulusresponse coupling in endothelial cells. Hypertension 21: 112-127, 1993.

35. Hoet $\mathbf{J J}$ and Hanson MA. Intrauterine nutrition: its importance during critical periods for cardiovascular and endocrine development. J Physiol 514.3: 617-627, 1999.

36. Holgert $\mathbf{H}$, Pequignot JM, Lagercrantz $\mathbf{H}$, and Hokfelt T. Birth-related up-regulation of mRNA encoding tyrosine hydroxylase, dopamine beta-hydroxylase, neuropeptide tyrosine, and prepro-enkephalin in rat adrenal medulla is dependent on postnatal oxygenation. Pediatr Res 37: 701-706, 1995.

37. Huang LE, Willmore WG, Gu J, Goldberg MA, and Bunn HF. Inhibition of hypoxiainducible factor 1 activation by carbon monoxide and nitric oxide. $J$ Biol Chem 13: 9038-9044. 1999.

38. Ishiguro H, Kim K, Joh T, and Kim K. Neuron-specific expression of the human dopamine beta-hydroxylase gene requires both the cAMP-response element and silencer region. $J$ Biol Chem 268: 17987-17994, 1993.

39. Itoh S, Brawley L, Wheeler T, Anthony FW, Poston L, and Hanson MA. Vasodilation to vascular endothelial growth factor in the uterine artery of the pregnant rat is blunted by low dietary protein intake. Pediatr Res 51: 485-491, 2002.

40. Julius $\mathbf{S}$ and Valentini $\mathbf{M}$. Consequences of the increased autonomic nervous drive in hypertension, heart failure and diabetes. Blood Pressure 7: 5-13, 1998.

41. Kamitome M, Alonse JG, Okai T, Longe LD, and Gilbert RD. Effects of long-term, highaltitude hypoxemia on ovine fetal cardiac output and blood flow redistribution. Am J Obstet Gynecol 169: 701-707, 1993. 
42. Kannel WB. Elevated systolic blood pressure as a cardiovascular risk factor. Am J Candiol 85: 251-255, 2000.

43. Kim K, Lee MK, Carroll J, and Joh TH. Both the basal and inducible transcription of the tyrosine hydroxylase gene are dependent upon a cAMP response element. $J$ Biol Chem 268: 15689-15695, 1993.

44. Kliegman RM. Intrauterine growth retardation. Eds.: Fanaroff AA and Martin RJ. in: Neonatalperinatal medicine. Diseases of the fetus and infant. Mosby-Yearbook inc. St. Louis. 1997. pp. 203-240.

45. Langley-Evans SC, Welham SJM, and Jackson AA. Fetal exposure to a maternal low protein diet impairs nephrogenesis and promotes hypertension in the rat. Life Sci 64: 965-974, 1999.

46. Lister G. Oxygen transport and consumption. Eds.: Gluckman PD and Heymann MA. in: Pediatrics \& perinatology. The scientific basis. Amold. London. 1996. pp. 778-790.

47. Liu Y, Christou H, Morita T, Laughner E, Semenza GL, and Keurembanas S. Carbon monoxide and nitric oxide suppress the hypoxic induction of vascular endothelial growth factor gene via the 5 ' enhancer. J Biol Chem 24: 15257-15262, 1998.

48. Longo LD and Pearce WJ. High altitude, hypoxic-induced modulation of noradrenergicmediated responses in fetal and adult cerebral arteries. Comp Biochem Plysiol 119A: 683-694, 1998.

49. Malek AM, Izumo S, and Alper SL. Modulation by pathophysiological stimuli of the shear stress-induced up-regulation of the endothelial nitric oxide synthase expression in endothelial cells. Neurosurgery 45: 334-345, 1999.

50. MeLellan KC, Hooper SB, Bocking AD, Delhanty PJD, Phillips ID, Hill DJ, and Han VKM. Prolonged hypoxia induced by the reduction of matemal uterine blood flow alters insulinlike growth factor-binding protein-1 (IGFBP-1) and IGFBP-2 gene expression in the ovine fetus. Endocrinology 131: 1619-1628, 1992.

51. MeMillen I, Adams MB, Ross JT, Coulter CL, Simonetta G, Owens JA, Robinson JS, and Edwards LJ. Fetal growth restriction: adaptations and consequences. Reproduction 122: 195204, 2001.

52. MeQuillan LP, Leung GK, Marsden PA, Kostyk SK, and Kourembanas S. Hypoxia inhibits expression of eNOS via transcriptional and posttranscriptional mechanisms. Am J Physiol 36: H1921-H1927, 1994.

53. Merlet-Benichou C, Gilbert T, Muffat-Joly M, Lelievre-Pegerier M, and Leroy B. Intrauterine growth retardation leads to a permanent nephron deficit in the rat. Pediatr Nephrol 8: 175-180, 1994.

54. Millhorn DE, Raymond R, Conforti L, Zha W, Beitner-Johnson D, Filiske T, Genther M, Kobayashi S, and Peng M. Regulation of gene expression for tyrosine hydroxylase in oxygen sensitive cells by hypoxia. Kidney Int 51: 527-535, 1997.

55. Milner RDG and Gluckman PD. The regulation of growth. Eds.: Harding R and Bocking AD. in: Fetal growth and development. University Press. Cambridge. 2001. pp. 284-289.

56. Monk CS, Webb SJ, and Nelson CA. Prenatal neurobiological development: molecular mechanisms and anatomical change. Dev Neuropsychol 19: 211-236, 2001.

57. Mulder ALM, Van Golde JMCG, Van Goor AAC, Giussani DA, and Blance CE. Developmental changes in plasma catecholamine concentrations during normoxia and acute hypoxia in the chick embryo. J Physiol 527.3: 593-599, 2000.

58. Mulder ALM, van Goor CA, Giussani DA, and Blance CE. $\alpha$-Adrenergic contribution to the cardiovascular response to acute hypoxia in the chick embryo. Am J Physiol 281: R2004-R2010, 2001.

59. Mulder ALM, Miedema A, de Mey JGR, Giussani DA, and Blance CE. Sympathetic control of the cardiovascular response to acute hypoxemia in the chick embryo. Am J Physiol 282: R1156-R1163, 2002. 
60. Muramatsu T, Hiramoto K, Koshi N, Okumura J, Miyoshi S, and Mitsumoto T. Importance of albumen content in whole body protein synthesis of the chick embryo during incubation. $\mathrm{Br}$ Poultry Science 31: 101-106, 1990.

61. Norris $\mathrm{ML}$ and Millhorn DE. Hypoxia-induced protein binding to $\mathrm{O} 2$-responsive sequences on the tyrosine hydroxylase gene. J Biol Chem 270 (40): 23774-23779, 1995.

62. Oosthuyse B, Moons L, Storkebaum E, Beck H, Nuyens D, Brusselmans K, Van Dorpe J, Hellings P, Gorselink M, Heymans S, Theilmeier G, Dewerchin M, Laudenbach V, Vermylen P, Raat H, Acker T, Vleminckx V, Van Den Bosch L, Cashman N, Fujisawa H, Drost MR, Sciot R, Bruyninckx F, Hicklin DJ, Ince C, Gressens P, Lupu F, Plate K, Robberecht W, Herbert J, Collen D, and Carmeliet P. Deletion of the hypoxia-response element in the vascular endothelial growth factor promotor causes motor neuron degeneration. Nature Gen 28: 131-138, 2001.

63. Owens PC and Robinson JS. Experimental restriction of fetal growth. Eds.: Hanson MA, Spencer JAD, and Rodeck CH. in: Fetus and Neonate. Physiology and clinical applications. Cambridge University Press. Cambridge. 1995. pp. 139-176.

64. Ozaki T, Nishina H, Hanson MA, and Poston L. Dietary restriction in pregnant rats causes gender-related hypertension and vascular dysfunction in offspring. $J$ Physiol 530.1: 141-152, 2001,

65. Peterson TE, Poppa V, Ueba H, Wu A, Yan C, and Berk B. Opposing effects of reactive oxygen species and cholesterol on endothelial cell caveolae. Circ Res 1999: 29-37, 1999.

66. Phillips DIW. Fetal growth and programming of the hypothalamic-pituitary-adrenal axis. Clin Exp Pharmacol Physiol 28: 967-970, 2001.

67. Qin Z-L and Nishimura $\mathbf{H}$. $\mathrm{Ca}^{2+}$ signaling in fowl aortic smooth muscle increases during maturation but is impaired in neointimal plaques. J Exp Biol 201: 1695-1705, 1998.

68. Robinson BF. Differences in response to dilator agents in blood vessels of different types: physiological bases for selectivity. J Hypertension 7: S147-S151, 1989.

69. Robinson JS and Owens JA. Pathophysiology of intrauterine growth failure. Eds.: Gluckman PD and Heymann MA. in: Pediatrics \& perinatology, the scientific basis. Arnold, Hodder Headline group. London. 1996. pp. 290-297.

70. Salafia CM. Placental pathology of fetal growth restriction. Obstet Gynecol 40: 740-749, 1997.

71. Scott-Burden T, Resink TJ, Hahn AWA, and Bühler FR. Vasoactive peptides and growth factors in the pathophysiology of hypertension. J Cardiovasc Pharmacol 20: S55-S64, 1992.

72. Seckl JR, Cleasby M, and Nyirenda MJ. Glucocorticoids, 11 beta-hydroxysteroid dehydrogenase, and fetal programming. Kidney Int 57: 1412-1417, 2000.

73. Seeds JW. Impaired fetal growth: definition and clinical diagnosis. J Am Coll Obstet Gynecol 64: 303-310, 1984.

74. Shweiki D, Itin A, Soffer D, and Keshet E. Vascular endothelial growth factor induced by hypoxia may mediate hypoxia-initiated angiogenesis. Nature 359: 843-845, 1992.

75. Simonetta G, Rourke AK, Owens JA, Robinson JS, and McMillen IC. Impact of placental restriction on the development of the sympathoadrenal system. Pediatr Res 42: 805-811, 1997.

76. Sogawa K, Numayama-Tsuruta K, Ema M, Abe M, Abe H, and Fuji-Kuriyama Y. Inhibition of hypoxia-inducible factor 1 activity by nitric oxide donors in hypoxia. Proc Natl Acad Sci USA 95: 7368-7373, 1998.

77. Sondell M, Lundborg G, and Kanje M. Vascular endothelial growth factor has neurotrophic activity and stimulates axonal outgrowth, enhancing cell survival and Schwann cell proliferation in the peripheral nervous system. J Neurose 19: 5731-5740, 1999.

78. Sondell $\mathbf{M}$, Sundler $\mathbf{F}$, and Kanje $\mathbf{M}$. Vascular endothelial growth factor is a neurotrophic factor which stimulates axonal outgrowth through the flk-1 receptor. Eur $J$ Neuroscience 12: 4243-4254, 2000.

79. Stein PE, White SE, Homan J, Fraher L, MeGarrigle HHG, Hanson MA, and Bocking AD. Fetal endocrine responses to prolonged reduced uterine blood flow are altered following bilateral sectioning of the carotid sinus and vagus nerves. J Endocrinol 157: 149-155, 1998. 
80. Tamatani M, Ogawa S, Youichirou N, and Tohyama M. Involvement of bel-2 family and caspase-3 like protease in NO-mediated neuronal apoptosis. Journal of Neurochemistry 71: 1588-1596, 1998.

81. Tapanainen PJ, Bang P, Wilson K, Unterman TG, Vreman HJ, and Rosenfeld RG. Maternal hypoxia as a model for intrauterine growth retardation: effects on insulin-like growth factors and their binding proteins. Pediatr Res 36: 152-158, 1994.

82. Thompson LP and Weiner CP. Effects of acute and chronic hypoxia on nitric oxide mediated relaxation of fetal guinea pig arteries. Am J Obstet Gynecol 181: 105-111, 1999.

83. Topper JN and Gimbrone Jr MA. Blood flow and vascular gene expression: fluid shear stress as a modulator of endothelial phenotype. Mol Med Today 5: 40-46, 1999.

84. Tuttle JB, Etheridge R, and Creedon DJ. Receptor-mediated stimulation and inhibition of nerve growth factor secretion by vascular smooth muscle cells. Exp Cell Res 208: 350-361, 1993.

85. Ueno $\mathbf{N}$, Zhao $\mathbf{Y}, \mathbf{Z}$ hang $\mathbf{L}$, and Longe LD. High altitude-induced changes in $\alpha 1$-adrenergic receptors and Ins(1,4,5)P3 responses in cerebral arteries. Am J Physiol 41: R669-R674, 1997.

86. Vanhoutte PM, Perrault LP, and Vilaine JP. Endothelial dysfunction and vascular disease. Eds.: Rubanyi GM and Dzau VJ. in: The endothelium in clinical practice. Source and target of novel strategies. Marcel Dekker,Inc. New York, Basel, Hong Kong. 1997. pp. 265-289.

87. Villamor E, Ruijtenbeek K, Pulgar V, De Mey JGR, and Blance CE. Vascular reactivity in intrapulmonary arteries of chicken embryos during transition to ex vivo life. Am J Physiol 282: R917-R927, 2002.

88. Xiao Z, Zhang Z, and Diamond SL. Shear stress induction of the endothelial nitric oxide synthase gene is calcium-dependent but not calcium-activated. $J$ Cell Physiol 171: 205-211. 1997.

89. Yun JK, McCormick TS, Judware R, and Lapetina EG. Cellular adaptive responses to low oxygen tension: apoptosis and resistance. Neurochem Res 22: 517-521, 1997.

90. Van der Zee R, Murohara T, Luo Z, Zollmann F, Passeri J, Lekutat C, and Isner JM. Vascular endothelial growth factor/vascular permeability factor augments nitric oxide release from quiescent rabbit and human vascular endothelium. Circulation 95: 1030-1037, 1997. 


\section{SUMMARY}

The work presented in this thesis addresses aspects of the "fetal origins of cardiovascular disease" hypothesis. It has been proposed that adverse conditions during intrauterine life, which result in growth retardation, increase the risk for hypertension and other cardiovascular diseases in adult life. Disturbance of the fetal supply line (as occurs e.g. during placental insufficiency) leads to reduced availability of nutrients and/or oxygen for fetal growth. In addition to growth retardation, malnutrition and chronic hypoxia may alter the development of organ systems.

Since arterial sympathetic hyperinnervation and endothelial dysfunction are important features of cardiovascular disease in the adult, the studies described in the present thesis were aimed to investigate the specific effects of malnutrition and chronic hypoxia on these arterial properties. For this purpose experiments were performed in the chicken (embryo).

First, the suitability of the chicken embryo as an experimental model to study reactivity and histology of isolated arteries was evaluated. The data presented in chapter 2 demonstrate that peri-arterial sympathetic nerve fibers of the femoral artery could be visualized and that neurogenic $\alpha$-adrenergic contraction could be measured at embryonic day 19 (of the 21-day incubation period). Endothelium-dependent relaxation was observed at even earlier stages of development (day 15). Differences that were observed between the carotid and femoral arteries with respect to these parameters of sympathetic innervation and endothelial function may reflect differences in their contribution to cardiac output redistribution during acute fetal hypoxemia.

In chapter 3 the direct effect of an acute insult, namely acute hypoxia, on the reactivity of the femoral artery at embryonic day 19 was investigated. Acute hypoxia partly reduced $\alpha$ adrenergic contraction and completely abolished endothelium-dependent relaxation. The net effect, locally increased contraction, may participate in the peripheral vasoconstriction that is observed during acute hypoxemia in vivo.

In the following chapters consequences of chronic exposure to hypoxia and to protein malnutrition during in ovo development for arterial properties were studied. In chapter 4 and 5 it was demonstrated that both chronic moderate hypoxia and protein malnutrition reduced embryonic body weight while relative brain weight was spared. Chronic moderate hypoxia increased sympathetic nerve fiber density and neuronal reuptake of NE in the femoral artery of day 19 chicken embryos (chapter 4). However, growth retardation induced by protein malnutrition was not accompanied by these signs of arterial sympathetic hyperinnervation (chapter 5). Furthermore, the data presented in chapter 6 show that chronic hypoxia, but not protein malnutrition, resulted in reduced arterial endothelium-dependent relaxation in the chicken embryo.

Experiments in 3 and 14 weeks old chickens were performed to evaluate consequences of exposure to chronic hypoxia during in ovo development on arterial properties and hemodynamic control after hatching. The data presented in chapter 7 demonstrate that blood pressure and arterial structure (e.g. media thickness) were not altered by in ovo chronic hypoxia. However, smooth muscle contractile properties of the femoral artery were altered in 3 weeks old chickens. In 14 weeks old chickens, contraction induced by stimulation of the peri-arterial nerve endings was augmented in the main femoral artery and endothelium-dependent NO production was reduced in side branches of the femoral artery after in ovo chronic hypoxia. 
The data presented in this thesis show that in ovo chronic hypoxia alters arterial properties, in particular sympathetic innervation and endothelial function, both before and after hatching. This suggests that the effects of prenatal chronic hypoxia on arterial properties may provide a mechanistic link between adverse intrauterine conditions resulting in growth retardation and cardiovascular disease in adult life. 


\section{SAMENVATTING}

Dit proefschrift beschrijft studies die gericht zijn op de stelling dat hart- en vaatziekten mogelijk hun oorsprong vinden in de periode vóór de geboorte. Eerder onderzoek heeft aangetoond dat mensen met een laag geboortegewicht meer kans hebben op een hoge bloeddruk (hypertensie) en andere hart- en vaatziekten op volwassen leeftijd dan mensen die zwaar of normaal van gewicht waren bij de geboorte.

Als de baarmoeder slecht functioneert, gaan er minder voedingstoffen en zuurstof via het bloed van de moeder naar de vrucht. De groei van de ongeboren baby zal dan achterblijven. De vraag is nu of deze ongewenste omstandigheden tegelijkertijd vaateigenschappen van de ontwikkelende foetus zodanig veranderen dat dit later in het leven problemen op zou kunnen gaan leveren.

De wand van bloedvaten bestaat uit verschillende weefsellagen. In de middelste laag liggen de gladde spiercellen, die door samen te trekken of te ontspannen de diameter van het vat kunnen verkleinen of juist vergroten. De zogenaamde endotheelcellen in de binnenste laag en de uiteinden van zenuwvezels in de buitenste laag kunnen werkzame stoffen afgeven. Deze kunnen op hun beurt op de gladde spiercellaag inwerken en de doorsnede van het vat veranderen. Bij mensen en dieren met hypertensie is vaak het aantal en de activiteit van de vezels van het sympathische zenuwstelsel rondom de bloedvaten toegenomen (sympathische hyperinnervatie) en de functie van de binnenste laag van de vaten veranderd (endotheliale dysfunctie). De toegenomen vaatvernauwing en afgenomen vaatverwijding (met als resultaat een kleinere vaatdiameter) die in deze situatie optreden kunnen ertoe leiden dat de druk van het bloed op de vaatwand toeneemt. Een hoge bloeddruk is een belangrijke risicofactor voor een groot aantal andere hart- en vaatziekten.

De studies in dit proefschrift onderzochten of een gebrek aan zuurstof (hypoxie) of een tekort aan voedingsstoffen (malnutritie) niet alleen leiden tot foetale groeivertraging maar ook tot een verandering van vaateigenschappen. Met name de sympatische zenuwvezels en het functioneren van de endotheelcellen werd bestudeerd. Om dit te onderzoeken werd gebruik gemaakt van het kippenembryo en de kip als dierexperimenteel model.

Het kippenembryo ontwikkelt zich in het ei en is dus niet op directe wijze verbonden met de hen. Het is dus mogelijk de uitwerking van een zuurstof- en/of voedingstekort te bestuderen zonder dat, zoals bij zoogdieren, veranderingen die bij de moeder tijdens de zwangerschap optreden hierop van invloed zijn. Bovendien kunnen in het kippenembryo, in tegenstelling tot in zoogdieren, de effecten van hypoxie en malnutritie relatief eenvoudig onafhankelijk van elkaar bestudeerd worden. De totale ontwikkeling van het kippenembryo in het ei neemt slechts 21 dagen in beslag.

Het tweede hoofdstuk van dit proefschrift laat zien dat het mogelijk is om vaatverwijding en -vernauwing in kleine vrijgeprepareerde arteriën (aanvoerende bloedvaten) uit een pootje van een kippenembryo op 19 dagen van de ontwikkeling te meten. De zenuwvezels rondom de vaten konden zichtbaar gemaakt worden met een kleuringstechniek en het stimuleren van deze vezels met electrische pulsen liet het vat samentrekken (contractie). De endotheelcellen in de binnenste laag van de vaatwand (het endotheel), reageerden zelfs op vroegere tijdstippen van de ontwikkeling (vanaf 15 dagen) al op stoffen die ontspanning (relaxatie) van het vat in gang zetten.

Hoofdstuk 3 beschrijft experimenten waarin de vrijgemaakte arteriën van 19 dagen oude kippenembryo's blootgesteld werden aan een kortdurend zuurstoftekort (acute hypoxie). Deze 
ingreep veroorzaakte een vermindering van de contractie en een afgenomen relaxatie via het endotheel. De netto-uitkomst van deze reacties, namelijk contractie op lokaal niveau, zou een bijdrage kunnen leveren aan de vaatvernauwing van diverse vaatbedden die optreedt tijdens acute hypoxie in de foetus.

De gevolgen van een langdurig zuurstoftekort (chronische hypoxie) en van een aanhoudend voedingstekort aan eiwitten (eiwit malnutritie) voor de eigenschappen van ontwikkelende vaten staan beschreven in de volgende hoofdstukken. Zowel eiwit malnutritie als chronische hypoxie leidden tot een afname van het lichaamsgewicht van de embryo's. De experimenten van hoofdstuk 4 en 5 toonden echter aan dat het aantal sympathische zenuwvezels rondom de arteriëen van het kippenembryo toenam (sympathische hyperinnervatie) als gevolg van chronische hypoxie, maar niet in geval van eiwit malnutritie. In hoofdstuk 6 staat beschreven dat ook de endotheel afhankelijke relaxatie van de bloedvaten door chronische hypoxie verminderd werd (endothelial dysfunctie). Malnutritie had geen effect op de functie van het endotheel.

De resultaten van de genoemde hoofdstukken deden vermoeden dat met name chronische hypoxie (meer dan eiwit malnutritie) een belangrijke uitwerking heeft op de vaateigenschappen. Daarom werden experimenten gedaan waarbij de gevolgen van blootstelling aan chronische hypoxie tijdens de periode in het ei op de lange termijn werden bestudeerd. Vaateigenschappen en bloeddruk van uitgekomen kuikens ( 3 weken oud) en 14 weken oude kippen werden daartoe gemeten. Zoals hoofdstuk 7 aantoont, veranderde chronische hypoxie de bloeddruk van de kuikens en kippen niet. Maar de vaten van 14 weken oude kippen die tijdens de ontwikkeling in het ei waren blootgesteld aan een langdurig zuurstoftekort trokken harder samen wanneer de (sympathische) zenuwvezels werden gestimuleerd dan vaten van kippen die een normale ontwikkeling in het ei hadden doorgemaakt. Ook functioneerde het endotheel van de vaten van de blootgestelde kippen minder goed.

De studies in dit proefschrift laten zien dat chronische blootstelling aan hypoxie tijdens de ontwikkeling in het ei vaateigenschappen van kippenembryo's en ook van kippen na het uitkomen verandert. Hoewel de veranderingen van de sympathische zenuwvezels en het endotheel nog niet tegelijkertijd leiden tot een verhoging van de bloeddruk, zouden ze voorbodes van hart- en vaatziekten op latere leeftijd kunnen zijn. Dit geeft aan dat een langdurig tekort aan zuurstof vóór de geboorte niet alleen uit kan monden in een laag geboortegewicht, maar ook de kans op hart- en vaatziekten bij de volwassen mens zou kunnen vergroten. 


\section{CURRICULUM VITAE}

Karin Ruijtenbeek was born July 25th 1974. After passing the VWO- $\beta$ exam at the Titus Brandsma Lyceum in Oss, she studied Biomedical Health Science at the Catholic University of Nijmegen. As a trainee, she performed a patient oriented research project on Chronic Obstructive Pulmonary Disease and oxidative stress supervised by Drs. P. Wielders and Prof. R. Dekhuijzen in the department of Lung Diseases of the of the Academic Hospital Nijmegen, St. Radboud. In the department of Pharmacology \& Toxicology of the university of Nijmegen she studied the effects of a sulphonylureum derivative on resistance arteries under supervision of Prof. F. Russel and Prof. P. Smits. She further specialized in vascular pharmacology in the department of Pharmacology \& Therapeutics of St. Mary's hospital (Imperial College) in London. Here, she evaluated the vascular effects of a diuretic agent and was supervised by Prof. A. Hughes. After graduation, she started a PhD project in the department of Pediatrics in cooperation with the department of Pharmacology \& Toxicology at the University Maastricht and University Hospital Maastricht in 1998 (research institutes GROW and CARIM). Under the supervision of Prof. C. Blanco and Prof. J. De Mey the studies presented in this thesis were performed.

Karin Ruijtenbeek werd geboren op 25 juli 1974. Zij haalde haar VWO- $\beta$ examen aan het Titus Brandsma Lyceum in Oss en ging daarna Biomedische Gezondheidswetenschappen studeren aan de Katholieke Universiteit Nijmegen. Als stagiaire voerde zij een patiënt gebonden onderzoek naar Chronisch Obstructief Pulmonair Lijden en oxidatieve stress uit onder begeleiding van drs. P. Wielders en Prof. R. Dekhuijzen op de afdeling Longziekten van het Academisch Ziekenhuis Nijmegen, St. Radboud. Op de afdeling Farmacologie van de universiteit van Nijmegen deed zij een stage begeleid door Prof. F. Russel en Prof. P. Smits, waarin zij effecten van een sulfonylureum derivaat op weerstandvaten bestudeerde. Een verdere specialisatie in de vasculaire farmacologie vond plaats op de afdeling Pharmacology \& Therapeutics van het St. Mary's hospital (Imperial College) in Londen. Hier onderzocht zij. onder supervisie van Prof. A. Hughes, de vasculaire effecten van een diureticum. Na het afstuderen begon zij in 1998 als AIO bij de vakgroep Kindergeneeskunde in samenwerking met de afdeling Farmacologie \& Toxicologie aan een promotieonderzoek op de Universiteit van Maastricht en het Academisch Ziekenhuis Maastricht (onderzoeksinstituten GROW en CARIM). Onder begeleiding van Prof. C. Blanco en Prof. J. De Mey werden de studies, die in dit proefschrift beschreven staan, uitgevoerd. 


\section{LIST OF PUBLICATIONS}

Le Noble FAC, Ruijtenbeek K, Gommers S, De Mey JGR, Blanco CE. Contractile and relaxing reactivity in carotid and femoral arteries of chicken embryos. Am J Physiol 278:H1261H1268, 2000).

Ruijtenbeek K, le Noble FAC, Janssen GMJ, Kessels CGA, Fazzi GE, Blanco CE, De Mey JGR. Chronic hypoxia stimulates periarterial sympathetic nerve development in chicken embryo. Circulation 102:2892-2897, 2000).

Ruijtenbeek K, De Mey JGR, Blanco CE. Foetale programmering: consequenties op volwassen leeftijd. Nederlands Tijdschrift voor Kindergeneeskunde 69: 78-81, 2001 (review).

Villamor E, Ruijtenbeek K, Pulgar V, De Mey JGR, Blanco CE. Vascular reactivity in intrapulmonary arteries of chicken embryos during transition to ex ovo life. Am J Physiol 282: R917-R927, 2002.

Ruijtenbeek K, Kessels CGA, Villamor E, Blanco CE, De Mey JGR. Direct effects of acute hypoxia on peripheral arteries of the chicken embryo. Am J Physiol 283: R331-R338, 2002

Ruijtenbeek, K, De Mey JGR, Blanco CE. The chicken embryo in developmental physiology of the cardiovascular system: a traditional model with new possibilities. Am $J$ Physiol 283:R549-R551, 2002 (Letter to the Editor).

Ruijtenbeek K, Kessels CGA, De Mey JGR, Blanco CE. Chronic moderate hypoxia and protein malnutrition both induce growth retardation, but have distinct effects on arterial endothelium-dependent reactivity in the chicken embryo (submitted).

Ruijtenbeek K, Kessels CGA, Janssen GMJ, de Mey JGR, Blanco CE. Effects of protein malnutrition on arterial structure and arterial sympathetic innervation of the chicken embryo (submitted).

Ruijtenbeek K, Kessels CGA, Janssen BJA, Bitsch NJJE, Fazzi GE, Janssen GMJ, de Mey JGR, Blanco CE. Chronic moderate hypoxia during in ovo development alters arterial properties of chickens (submitted). 


\section{DANKWOORD}

Dagge bedaankt zet, da witte! (Brabants; dat je bedankt wordt, dat weet je!)

Ik hoop het. Ik hoop dat iedereen op een eerder moment van de hele promotieperiode al eens gemerkt heeft dat ik ieders inzet voor mijn project en mijn persoon waardeerde. Toch wil ik, nu mijn boekje klaar is (!), ook de namen noemen van "iedereen".

Carlos, het is af en "se me quitó un peso del corazón". Dat deze promotie een zaak van het hart geworden is, komt zeker ook door jou. Je wist me te motiveren en waarderen. Als er wat was, kreeg ik "kom naar mij" te horen. En je loste het op; steeds kon en kan ik bij je terecht. Het was heel fijn te opereren (figuurlijk, maar ook letterlijk!) met een persoon met een groot hart. Voor het onderzoek en voor zijn mensen! Bedankt! Bij het hart horen de vaten. Jo, voor jouw onuitputtelijke kennis, originaliteit en enthousiasme, heb ik veel bewondering. Als ik na een goed "oppep" gesprek weer naar het lab of mijn kamer ging, dacht ik wel eens: "Hoe doet ie dat toch?" Ik weet het nog steeds niet, maar ben je er dankbaar voor. Carlos, Jo, Karin en "de kip" waren een goed team! Dank ook aan de "Vrienden van het AZM" voor het vertrouwen in dit team.

Hoewel niet officieel zo genoemd; er waren meerdere begeleiders/mentoren. Ferdi, je stond aan het begin van dit alles (en zo ook in het boekje) en daarvoor wil ik je hier aan het eind bedanken. Jos Wesselman, ik heb ooit het woord "vertrouwens-post-doc" laten vallen en daar blijf ik bij. Voor jou is een probleem nooit te klein om er tijd voor vrij te maken. Ik heb veel aan je gehad als extra begeleider, luisterend oor èn stress bestrijder. Bovendien ben je ook nog een een hele gezellige kamergenoot. Ook Eduardo wil ik bedanken voor een stukje begeleiding. Voor al je hulp en nooit aflatende interesse. Wat een energie heb jij toch! Ben, bedankt voor je hulp met het laatste hoofdstuk!

Analisten maken het lab. Maar Lilian, jij bent meer dan een geweldig goede analiste. Dit is ook jouw boekje. De goede en de mindere tijden; we hebben ze doorstaan. Met structuur (?) en vooral veel lachen gingen we steeds weer als een trein (een TGV!). Bedankt voor alles! Honderd procent inzet kwam ook van de kant van Ger. Wat werden we er soms moedeloos van, hè? Maar altijd stond je weer klaar en was het fijn samenwerken. Fazzi, $(\mathbf{H H H}=\mathrm{His}$ Histological Highness) niet alleen in het lab kon ik bij je terecht. Ook bij computerproblemen (inclusief opleuken van het boekje), voor een hoop humor en sterke (doch waargebeurde) verhalen ben jij de aangewezen persoon. Jet, je zat niet bij ons op het lab, maar menig monster van ons is (via Paul; bedankt!) door je handen gegaan. Bedankt voor al die metingen. Sjaak, voor die ondankbare klus die je nogal eens klaarde ben ik je zeer dankbaar.

De mensen van Anatomie en van de Centrale Proefdier Voorziening wil ik bij deze bedanken voor de zorg voor de eieren en de kippen (Harry, bedankt!). Daarnaast ook dank aan iedereen die ooit voor me "gedraaid" heeft. I would like to thank Prof. Hiroko Nishimura, her husband and the people of her lab for teaching me all about "those strange birds" and making my stay in Memphis pleasant.

Bovenstaande mensen zorgden er in vrij directe zin voor dat het onderzoek liep. Bovendien zorgden zij ervoor dat ik het naar mijn zin had. Maar er waren er meer!

Dank aan alle mensen van onze vakgroep Kindergeneeskunde, die zich voor mij en mijn onderzoek interesseerden. Wilma en Marije, jullie zaten in hetzelfde schuitje en waren dus altijd in voor een goed en waardevol gesprek over het AIO-schap. En Wilma, we hebben toch menig congres gevuld met science, niet-science en een beetje science? Twan, bedankt voor je hulp! Tamara en Marleen, bedankt voor al het geregel door de jaren heen. En over geregel gesproken...Natascha, bedankt dat ik kan promoveren! 
Iedereen van Jo\&Co natuurlijk hartelijk bedankt voor de fijne tijd! Marijke: samen begonnen, samen met fetal programming bezig en dus samen naar congres! Vlieland, de pub, heelings, dronken dwergen, we maakten het mee! Met jou valt een gesprek nooit stil! Kristof, het was kort, maar wel heel gezellig met jou op de kamer (dat kan, alles kan, Tarkan!). Jolanda, het was leuk er op het eind nog een "kippig" persoon bij te hebben.

Ook de anderen van Farmacologie \& Toxicologie wil ik bedanken voor de leuke jaren! In de plaatsvervangende koffiekamer bij Sjaak, Peter, Nicole en Agnieskza was altijd plek voor mij. Rob Hermans, Helma en Liesje en andere AIO's waren steeds geïnteresseerd en de meiden van Tox altijd in voor geklets (hè, Mariken?) of gekick (hè, Chantal?). En Els en Mia niet te vergeten. Jullie waken over de vakgroep en iedereen hoort erbij!

Sommige collega's worden je beste vrienden.

Nicole, voor jou is helpen een tweede natuur en vriendschap vanzelfsprekend. Je hebt teveel voor me gedaan om je simpel te bedanken. Toch kan het hier alleen met eenvoudige woorden: maatje, bedankt! Wendy, in mijn gedachten noem ik je meestal $100 \%$-Wendy, omdat je de dingen nooit half doet. Zo is ook je vriendschap volledig; op het werk en daarbuiten, bij lachen en bij huilen. Ook hier zegt "bedankt" niet genoeg...Meiden, jullie zijn kanjers!

De achterban zorgt ervoor dat je relativeert en door kunt zetten.

Vrienden van Nijmegen en Oss, bedankt! Familie (Ruijtenbeek, van Hoom en Vink), bedankt voor jullie interesse, maar ook voor het feit dat jullie er gewoon altijd zijn. Rob en Marjolein: het is zo fijn, als mensen je snappen! We weten dat ons pap nu zou zeggen "zie je wel, dat je het kunt, Ket!" Mam, jij was er altijd om dat te bevestigen en me daaraan te herinneren. Bedankt! Ewoud, jij was een mentor, een analist (eieren wegen/draaien/overzetten, kuikens uithalen, kippen flushen), een vormgever (nice job, die lay-out) en bovenal een groot gelover (in mijn onderzoek en mij). Nu gaan we verder. Ook weer samen. Come what may... 

Prenatal growth retardation is associated with cardiovascular disease in the adult. Advene intrauterine conditions, as occur during chronic hypoxia or malnutrition, can reduce fetal growth. In addition, they may alter arterial properties and thereby increase the risk to cardiovascular disorders. The studies presented in this thesis demonstrate that exposure to chronic hypoxia, but not malnutrition, during in ovo development modifies arterial properties of chicken embryos. In ovo chronic hypoxia also changes the properties of arteries of chickens after hatching. The observed changes in periarterial sympathetic innervation and the endothelium may predispose to cardiovascular diseases at later stages of life. 